\title{
AXIAL AND SHEAR BEHAVIOR OF PROFILED STEEL SHEET DRY BOARD (PSSDB) COMPOSITE WALLING SYSTEM
}

\author{
By \\ Asmah Jahan \\ Bachelor of Science in Civil Engineering \\ Abu Dhabi University, Abu Dhabi, United Arab Emirates, 2015
}

\author{
A thesis \\ presented to Ryerson University \\ in partial fulfillment of the requirements for the \\ degree of Master of Applied Science in the program of Civil Engineering
}

Toronto, Ontario, Canada, 2018

(C) Asmah Jahan, 2018 


\section{AUTHOR'S DECLARATION}

I hereby declare that I am the sole author of this thesis. This is a true copy of the thesis, including any required final revisions, as accepted by my examiners.

I authorize Ryerson University to lend this thesis to other institutions or individuals for the purpose of scholarly research.

I further authorize Ryerson University to reproduce this thesis by photocopying or by other means, in total or in part, at the request of other institutions or individuals for the purpose of scholarly research.

I understand that my thesis may be made electronically available to the public. 


\title{
AXIAL AND SHEAR BEHAVIOR OF PROFILED STEEL SHEET DRY BOARD (PSSDB) COMPOSITE WALLING SYSTEM
}

\author{
Asmah Jahan \\ Master of Applied Science, 2018 \\ Civil Engineering \\ Ryerson University, Toronto, Ontario, Canada
}

\begin{abstract}
This research describes the structural behavior of profiled steel sheet dry board (PSSDB) composite wall panels under shear and axial loading based on experimental, theoretical and finite element (FE) analyses. The proposed PSSDB walling system consists of an individual profiled steel sheet (PSS) assembled with a single or double plywood dry board (DB) with or without concrete in-fill. The influences of various parameters such as presence or absence of concrete-infill/opening and boundary frame as well as DB-PSS/DB-PSS-DB/PSSDB-frame connections/fasteners and panel geometric/material properties on load-deformation response, ultimate load capacity and failure modes are investigated. Experimental results of PSSDB wall panels were used to validate the performance of FE and theoretical models for predicting the shear and axial strength capacity. The FE analysis coupled with experimental and theoretical analyses provides a better understanding of the structural performance of PSSDB walls and hence, helps to develop design guidelines for their use as structural units in buildings.
\end{abstract}




\section{ACKNOWLEDGEMENTS}

I would like to express my utmost gratitude to my supervisor Dr. Khandaker M. Anwar Hossain for his guidance throughout the completion of this degree. His extensive knowledge in the area has enabled me to gain valuable insights in the course of this research work. His constant encouragement and enthusiasm has inspired me to undertake this research. I am very grateful for his time, patience and unconditional support that motivated me to assert my maximum potential into this research.

Sincere gratitude is extended to the research team members at Ryerson especially L. Mol and M. S. Anwar for conducting experimental tests and providing me with the data for further analysis. I'd also like to thank my colleagues and friends for their help and motivation throughout my studies at Ryerson University.

Lastly, I am forever indebted to my parents who have built a solid foundation for me to grow and achieve my dreams. I'd like to thank them as well as my brothers for their unconditional love, encouragement and unfailing support throughout my years of study and through the process of researching and writing this thesis. This accomplishment would not have been possible without them. 


\section{TABLE OF CONTENTS}

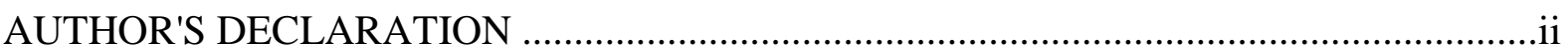

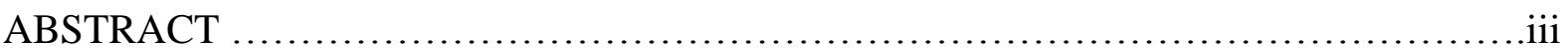

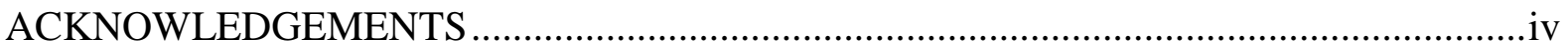

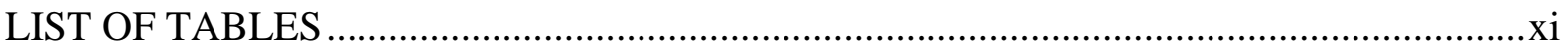

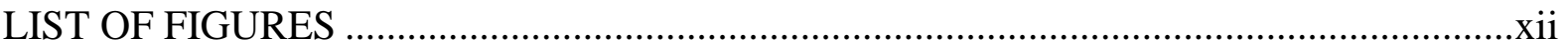

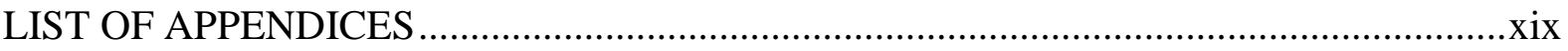

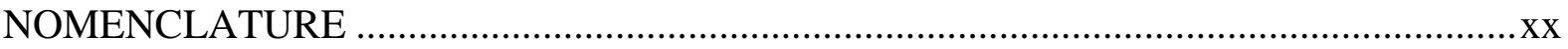

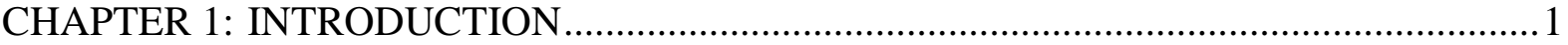

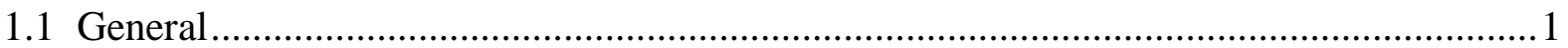

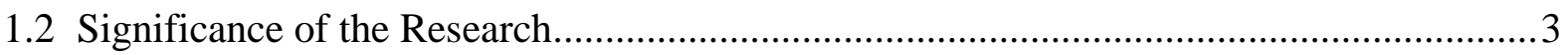

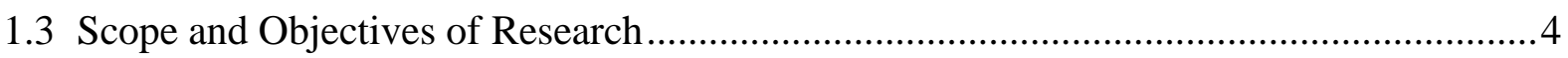

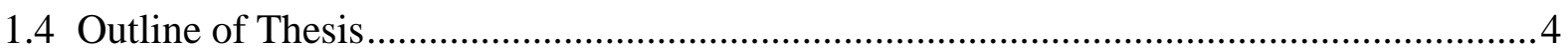

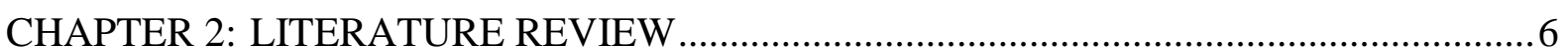

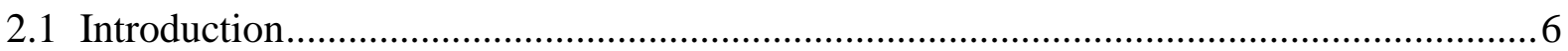

2.2 Profiled Steel Sheet Dry Board Composite (PSSDB) System.......................................6

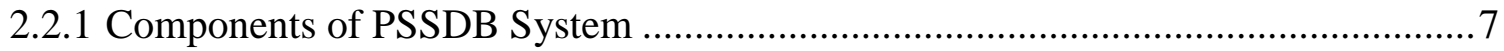

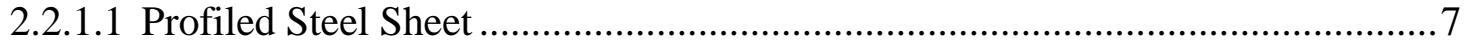

2.2.1.2 Dry Board (DB) - Properties and Modelling ............................................... 8

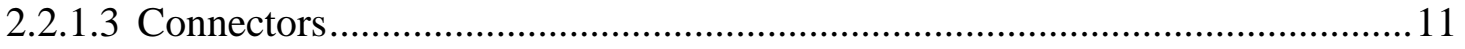

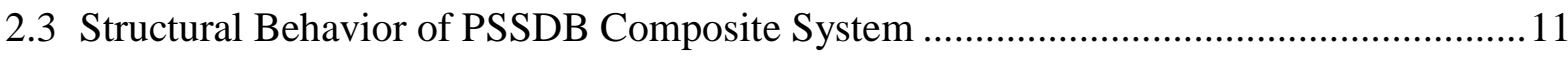

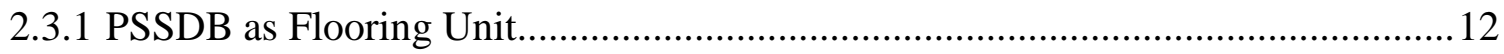

2.3.2 PSSDB as Folded Plate Roof Member................................................................ 16

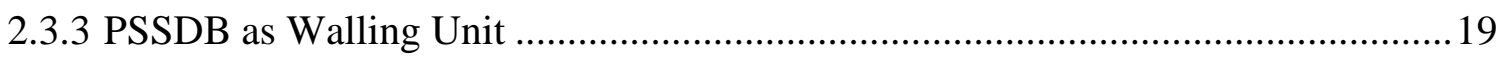

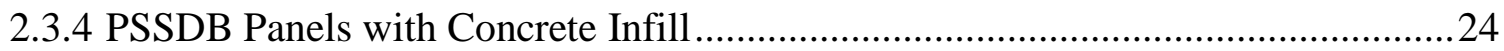

2.4 Practical Application and Advantages of using PSSDB System .....................................30

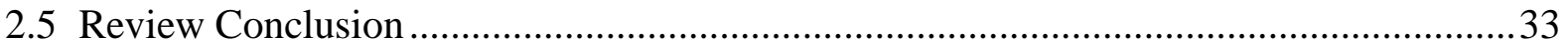


CHAPTER 3: EXPERIMENTAL, ANALYTICAL AND FINITE ELEMENT MODELING

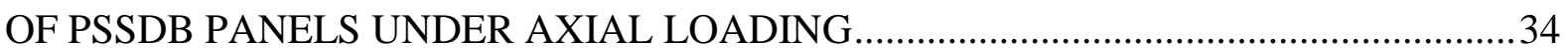

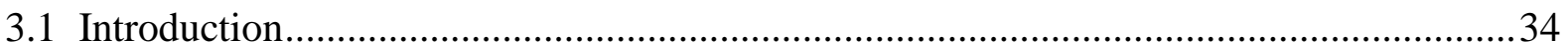

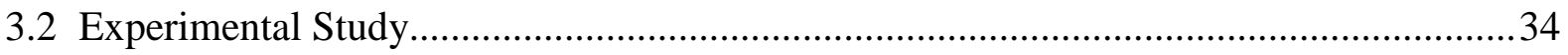

3.2.1 PSSDB Specimen Design, Material Properties, Axial Load Test Set-up,

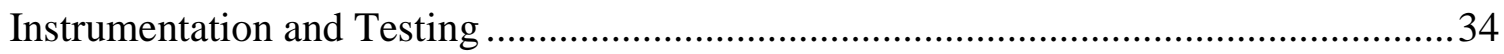

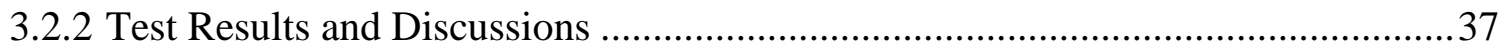

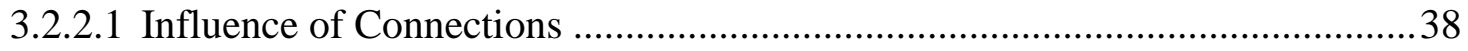

3.2.2.2 Effect of Height to Width Ratio (h/w) of Walls Having Same Rows (3 or 5) of Connections

3.2.2.3 Filled Composite Panels with Varying Heights and Constant Rows of Spacers

3.2.2.4 Unperforated Filled and Unfilled Composite Panels .....................................41

3.2.2.5 Perforated Filled and Unfilled Composite Panels ..........................................42

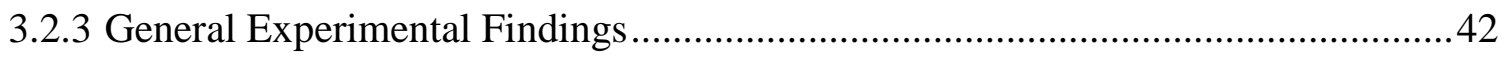

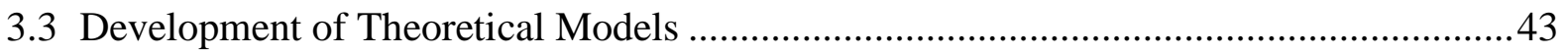

3.3.1 Axial Load Capacity of PSSDB walls with and without concrete infill ................43

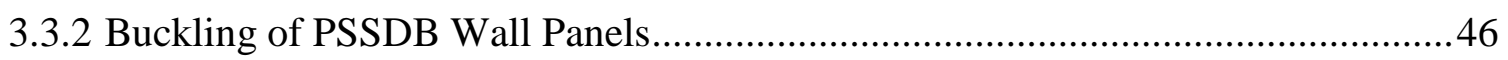

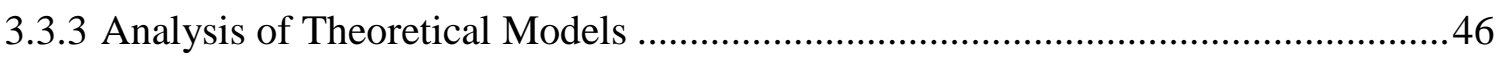

3.3.4 Summary of Theoretical Findings ................................................................ 48

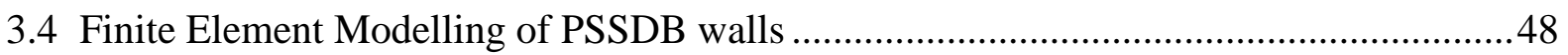

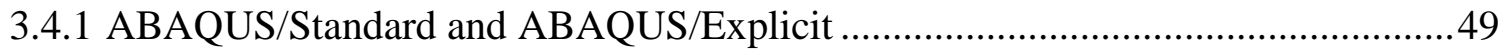

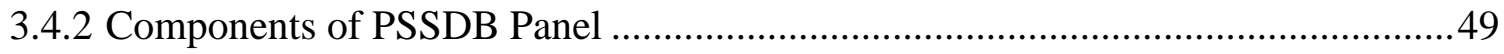

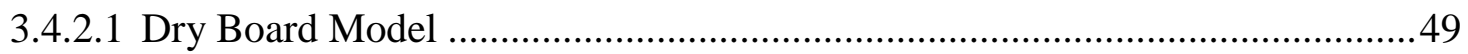

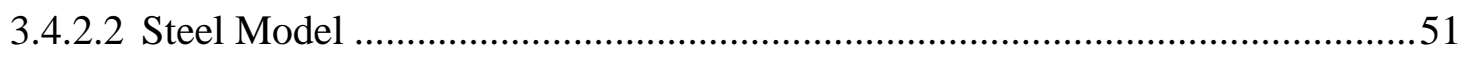

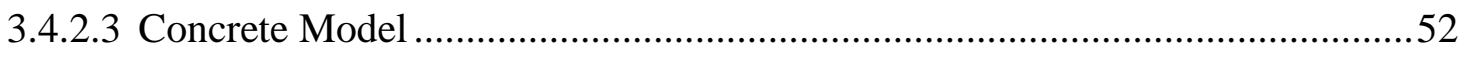

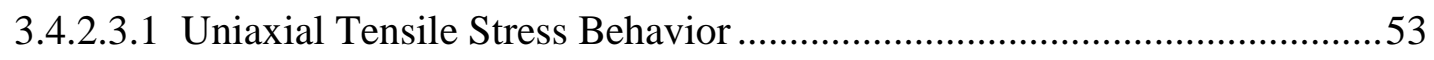

3.4.2.3.2 Uniaxial Compressive Stress Behavior ................................................54 
3.4.2.3.3 Stress-Strain Relationship in Concrete .55

3.4.2.3.4 Tensile Damage and Compressive Damage .............................................56

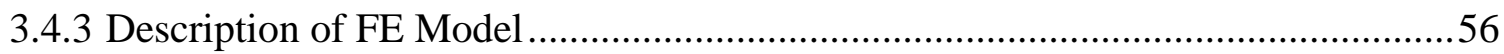

3.4.3.1 Parts, Element Assignment, Mesh............................................................ 57

3.4.4 Assembly of Parts, Step and Contact/Interactions ..............................................59

3.4.5 Boundary Condition and Displacement Control Analysis ...................................61

3.4.6 Finite Element Results: Axial Load-Deformation Response ................................62

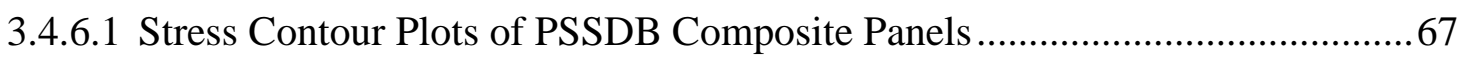

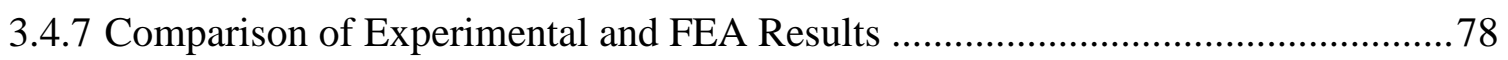

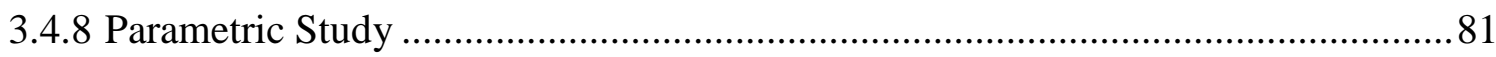

3.4.8.1 Effect of Varying the Geometric Properties of the Board and PSS .................81

3.4.8.2 Effect of Varying the Material Properties of PSS and Concrete Core ............. 82

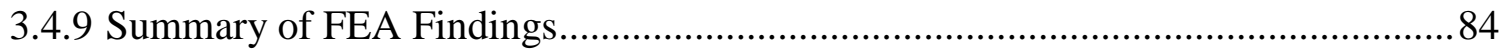

CHAPTER 4: EXPERIMENTAL, ANALYTICAL AND FINITE ELEMENT MODELING

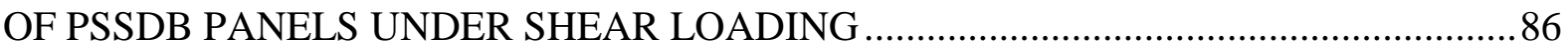

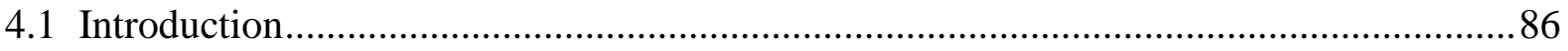

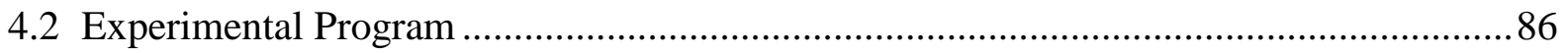

4.2.1 PSSDB Specimen Design, Material Properties and Shear Load Test set-up,

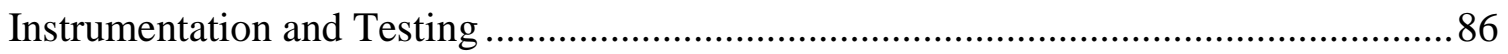

4.2.2 Test Observation: Failure Mode and Shear Load-Deformation Response..............93

4.2.2.1 Effect of panel-frame connectors/fasteners in individual and composite PSSDB

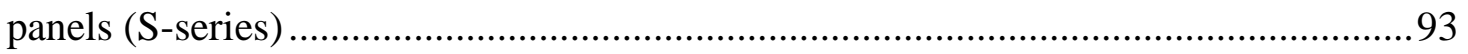

4.2.2.2 Non-Pierced and Pierced Composite Panel with Both Vertical and Horizontal

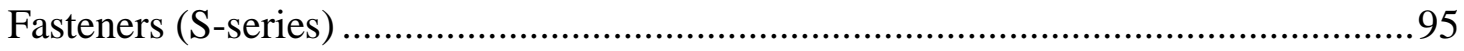

4.2.2.3 Non-Pierced and Pierced Profiled Steel Sheet with Vertical Fasteners Only (S-

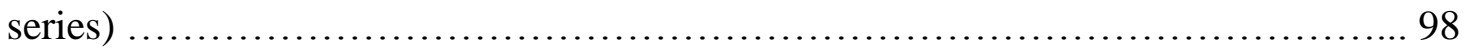

4.2.2.4 Non-Pierced vs. Pierced Dry Boards with Vertical Fasteners Only (S-series) 99 4.2.2.5 Summary of Experimental Findings for S-Series 100 
4.2.2.6 Structural Performance of Non-pierced and Pierced PSSDB Walls (A1-series) 101

4.2.2.7 Structural Performance of Non-Pierced and Pierced B1-series 102

4.2.2.8 Summary of Experimental Findings for A1 and B1-Series 103

4.3 Development of Analytical Model for Shear resistance of Composite PSSDB Panels.. 104

4.3.1 Buckling Shear Strength of Profiled Steel Sheet 104

4.3.1.1 Local Shear Buckling and Global Shear Buckling Mode of Failure 106

4.3.2 Shear Capacity of the Profiled Steel Sheet Bounded by Frame with Fasteners .... 107

4.3.3 Shear Strength of Profiled Concrete Core .......................................................... 108

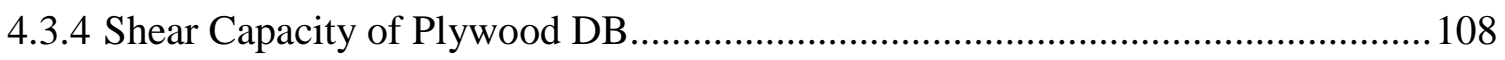

4.3.5 Ultimate Shear Strength of Panel with Rectangular Opening ............................... 111

4.3.6 Shear Resistance of the PSSDB Composite Wall Panels and its Components ......112

4.3.6.1 S-Series

4.3.6.1.1 Shear Resistance of Non-Pierced and Pierced DB Panel Considering Different Mode of Failure 113

4.3.6.1.2 Shear Resistance of Non-Pierced and Pierced PSS Panel Considering Different Mode of Failure 113

4.3.6.1.3 Shear Resistance of Non-Pierced and Pierced PSSDB Panel Considering Different Mode of Failure 114

4.3.6.2 A1-B1 Series PSSDB Wall Panels 115

4.3.6.2.1 Shear Resistance of Non-Pierced Panels without concrete infill ( $V_{A 1-n p}, V_{B 1-}$ nр)

4.3.6.2.2 Shear Resistance of Non-Pierced Panels with concrete infill ( $\mathrm{V}_{\mathrm{A1} \text {-npc}}, \mathrm{V}_{\mathrm{B} 1-}$ npc)

4.3.6.2.3 Shear Resistance of Pierced Panels With $\left(\mathrm{V}_{\mathrm{A} 1-\mathrm{p}}, \mathrm{V}_{\mathrm{B} 1-\mathrm{p}}\right)$ and Without $\left(\mathrm{V}_{\mathrm{A1}-}\right.$ pc, V $\mathrm{B1-pc}$ ) Concrete Infill 117

4.3.7 Performance Validation of Analytical Models 118

4.3.7.1 Wall Panels bounded by a rigid frame (S-series) 118 
4.4 Finite Element Modeling Of PSSDB Walls under Shear Loading (A1-B1 Series)........ 120

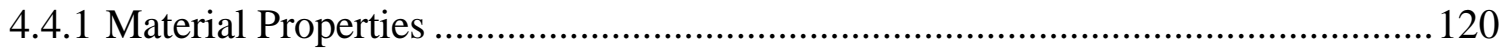

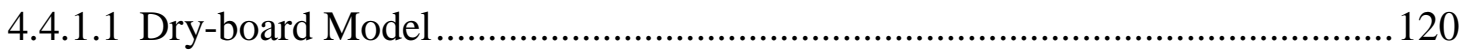

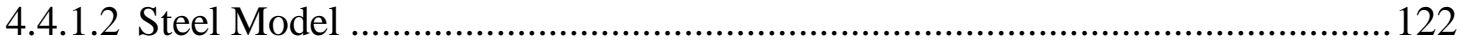

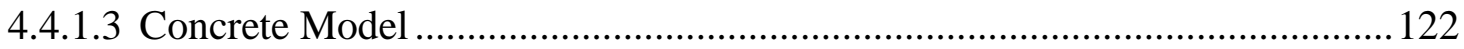

4.4.2 Description of the Developed FE Model....................................................... 123

4.4.2.1 Parts, Meshing and Element Assignment................................................. 123

4.4.2.2 Assembly of Parts, Step and Contact/Interactions ....................................... 124

4.4.2.3 Boundary Condition and Displacement Control Analysis ............................ 126

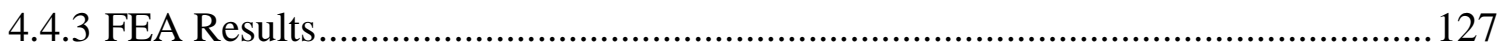

4.4.3.1 Shear Load-Deformation Response of A1 and B1 Panels ............................ 127

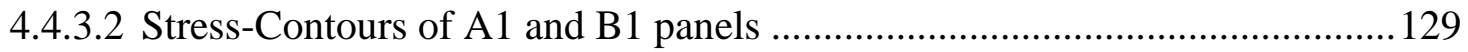

4.4.4 Comparison of FEA and Experimental Results .............................................. 135

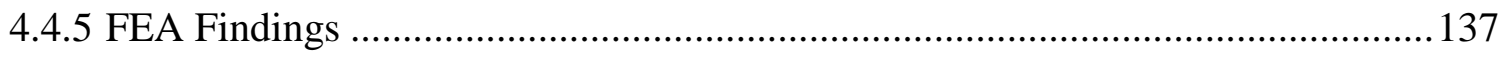

CHAPTER 5: CONCLUSIONS AND RECOMMENDATION ......................................... 138

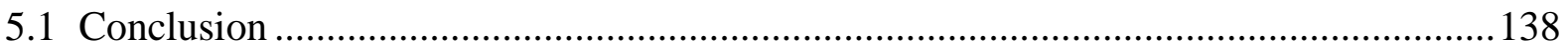

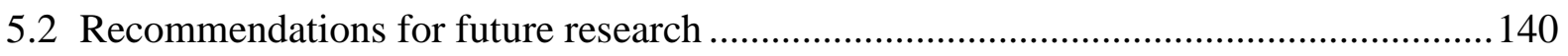

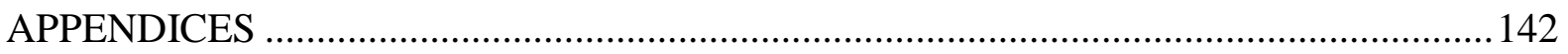

Appendix A: Detailed Theoretical Axial Load Capacity Calculations ................................. 142

A.1 Axial Load Capacities of Double Skinned PSSDB Panels With and Without Concrete

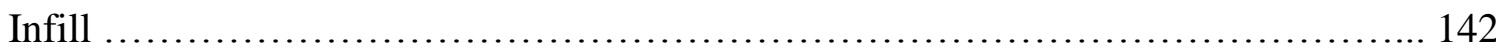

A.2 Axial buckling load Capacities of double skinned PSSDB panels with and without

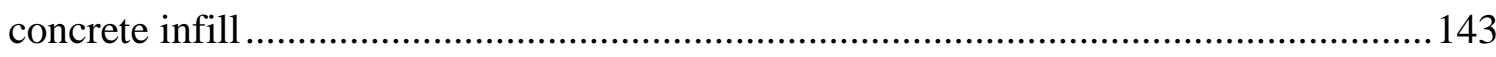

Appendix B: Detailed Theoretical Shear Resistance Calculations ....................................... 146

B.1 Shear Resistance of Non-Pierced Panels ............................................................... 146

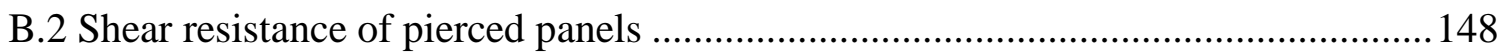

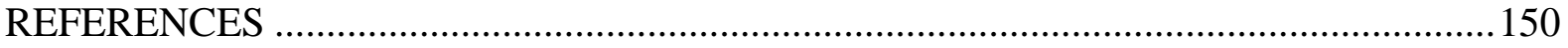


GLOSSARY 


\section{LIST OF TABLES}

Table 2.1 Axial load capacity of PSSDB panels with and without in-fill .............................27

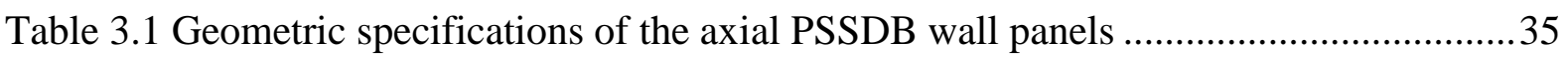

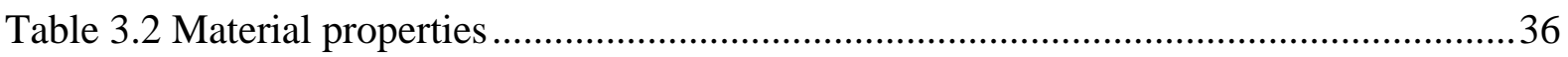

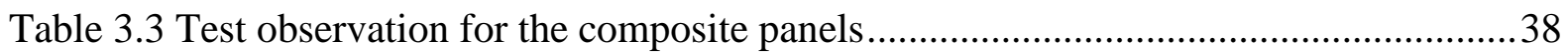

Table 3.4 Comparison of theoretical with experimental results ............................................48

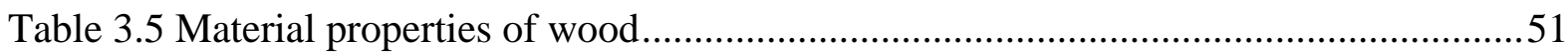

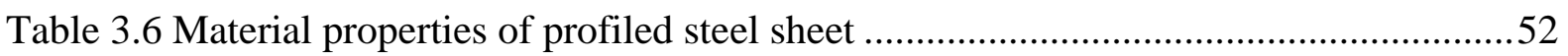

Table 3.7 Material properties for the concrete model .........................................................53

Table 3.8 Description of stress/displacements elements (Rafiei, 2011) ................................57

Table 3.9 Summary of the maximum positive compressive principal stress values in the PSSDB

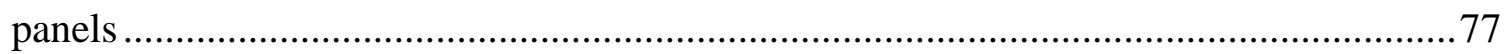

Table 3.10 Summary of the maximum negative stress values in the PSSDB composite panels .78

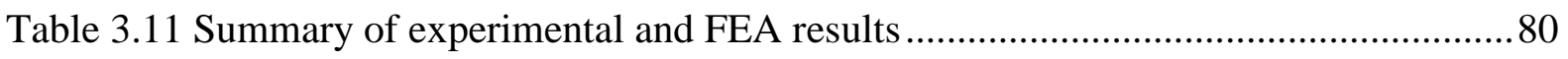

Table 3.12 Summary of results from parametric studies ................................................... 84

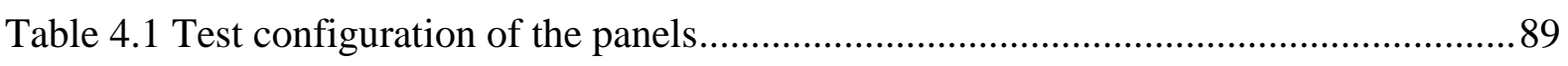

Table 4.2 Material properties of PSSDB panels .............................................................. 90

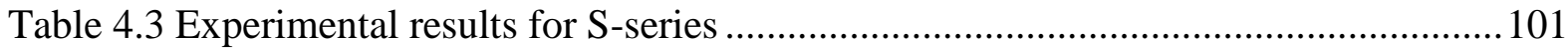

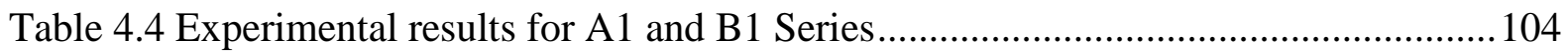

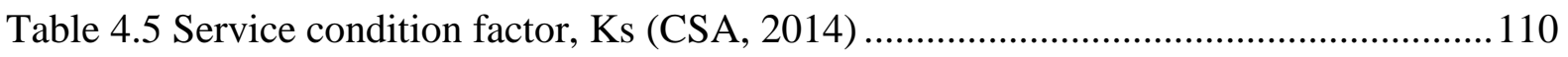

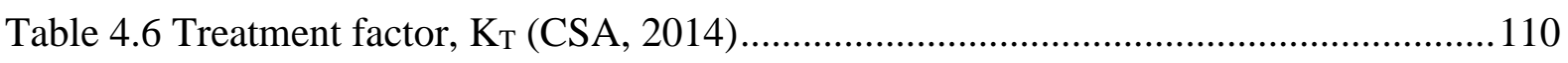

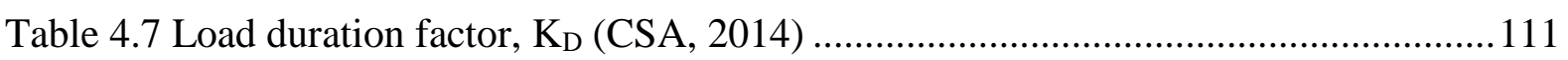

Table 4.8 Comparison of analytical and experimental shear load capacities of wall panels

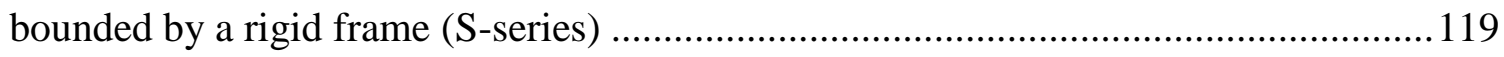

Table 4.9 Comparison between analytical and experimental shear load capacities of PSSDB

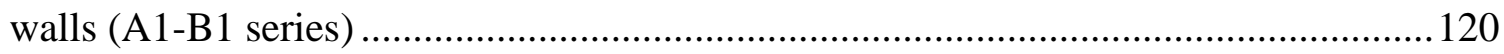

Table 4.10 Dry board material properties …................................................................ 122

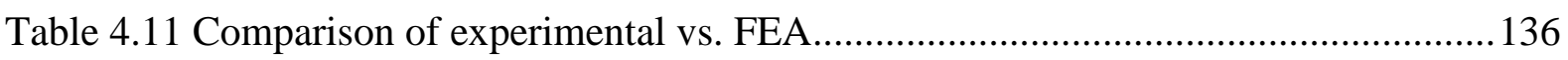




\section{LIST OF FIGURES}

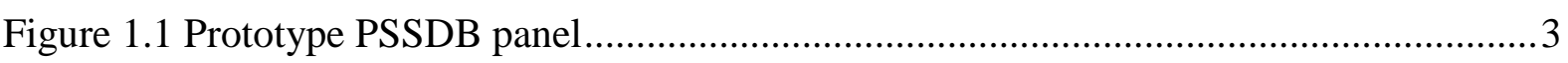

Figure 2.1 Roof application (a) P-3615 \& P-3606 (b) P-2436 \& P-2404 (CANAM, 2017) .....7

Figure 2.2 Floor application (a) P-3615 \& P-3606 Composite (b) P-3623 Composite (c) P-2432

Composite (d) P-3012 Form Deck (CANAM, 2017) .......................................................... 7

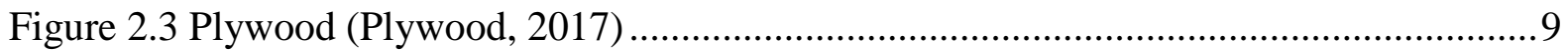

Figure 2.4 Typical stress-strain curves for wood loaded in compression in longitudinal (L), radial $(\mathrm{R})$ and tangential $(\mathrm{T})$ directions and for tension in the longitudinal direction

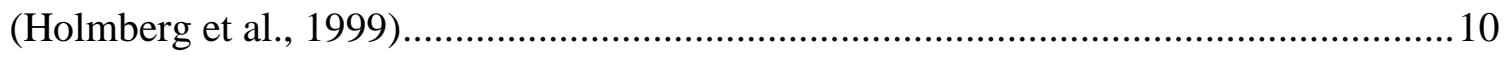

Figure 2.5 Fasteners and threaded products (Fastening House Inc, 2017) ............................ 11

Figure 2.6 Structural components (left) and finite element model (right) of BCCFP panel

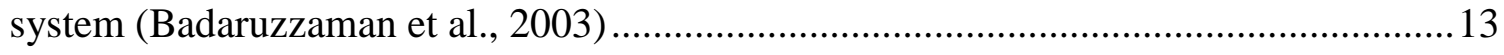

Figure 2.7 Flexural load-deflection response of BCCFP with (a) varying board thickness (b) connectors at different spacing (c) different types of boards (Badaruzzaman et al., 2003)

Figure 2.8 Loading arrangement of the panel (left) and typical failure of the specimen under loading (right) (Ahmed et al., 2002) .15

Figure 2.9 Full scale folded plate roof structure model tested by Wan Badaruzzaman (1994) 16

Figure 2.10 Complete model of PSSDB folded roof plate tested in the laboratory by Ahmed et al. (2000). .16

Figure 2.11 Load conditions on model structures (Ahmed et al., 2000) ................................17

Figure 2.12 A typical test set-up (Awang and Badaruzzaman, 2010) ................................... 18

Figure 2.13 Buckling of lower flange of the profiled steel sheet (Awang and Badaruzzaman,

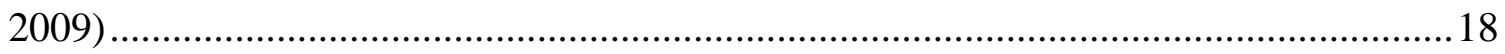

Figure 2.14 Plan and elevation view of the PSSDB roof in the school module (Awang and Badaruzzaman, 2011)

Figure 2.15 Schematic diagram of a composite walling system (Hossain and Wright, 2004) 20 Figure 2.16 Mode of failure of PSS and dry board of the double sheathed composite PSSDB Wall Panel System (Majid \& Badaruzzaman, 2013). .22

Figure 2.17 Failure at the corner of opening during experiment (Hamzah \& Badaruzzaman, 2009) .23 
Figure 2.18 Deflection vs. screw spacing for the models (Hamzah and Wan Badaruzzaman 2002)

Figure 2.19 Experimental test set-up (left) and FEM loading system (right) (Seraji et al., 2014)

Figure 2.20 Load-deflection response for the control sample (CS) vs. (a) different normal concrete panels and (b) geopolymer concrete panels (Jaffar et al., 2016).......................26

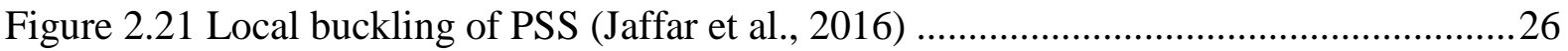

Figure 2.22 Experimental Model and FEM displaying horizontal slip of PSSDB infill (Jaffar et al., 2016) .26

Figure 2.23 Cross-section of the tested PSSDB panel (Badaruzzaman et al., 2004). .27

Figure 2.24 Typical sample failure mode of the concrete infilled PSSDB wall panel (Badaruzzaman et al., 2004) .28

Figure 2.25 Load-deflection response and failure mode of PSSDB panel without concrete infill (Shakeel, 2012) .29

Figure 2.26 Load-deflection response and failure mode of PSSDB panel with ECC infill (Shakeel, 2012)

Figure 2.27 Effect of (a) h/w ratio and (b) s/h ratio on axial load (Shakeel, 2012; Hossain and

Shakeel 2012) .29

Figure 2.28 Interaction factor for PSSDB wall panels (Shakeel, 2012) 30

Figure 2.29 View of the BCCFP floor at the Hyatt Hotel during construction (left) and tiles placed on the BCCFP floor at the Hyatt Hotel (right) (Badaruzzaman et al., 2003)........31

Figure 2.30 A view of the new three-storey distance learning center, UKM (Badaruzzaman et al., 2003) .31

Figure 2.31 A solar house at UKM (left) and a private house in Bangi, Malaysia (right) (Badaruzzaman et al., 2003)..... .32

Figure 2.32 PSSDB roof panels (Awang \& Badaruzzaman, 2010). 32

Figure 3.1 Schematic drawing showing details and dimensions of PSSDB sandwiched wall panels (dimensions in $\mathrm{mm}$ ) .35

Figure 3.2: Geometry of profiled steel sheet .36

Figure 3.3 MTS test set-up for PSSDB wall panel subjected to axial loading..... .37

Figure 3.4 Load-deformation responses of PSSDB panels with 3 and 5 rows of connections 39 Figure 3.5 (a) Effect of height-to-width (h/w) ratio on axial load and (b) load-deformation response with varying $\mathrm{h} / \mathrm{w}$ and 5 rows of spacers 40 
Figure 3.6 Load-deformation response of composite wall with altering $\mathrm{h} / \mathrm{w}$ ratio and constant rows of fasteners

Figure 3.7 Load-deformation response of perforated filled and unfilled composite panels .... 41

Figure 3.8 Load-deformation response of filled and unfilled composite with an opening......42

Figure 3.9 Typical effective width model for plate under uniform compression (Bedair, 2000)

Figure 3.10 Crushable foam model with isotropic hardening: yield surface and flow potential in the p-q stress plane (Abaqus Analysis User's Guide, 2014). .50

Figure 3.11 Constitutive model of profiled steel sheet .52

Figure 3.12 Response of concrete to uniaxial loading in tension (Abaqus 6.12 Analysis User's Manual, 2012) .54

Figure 3.13 (a) Response of concrete to uniaxial loading in compression (Abaqus 6.12 Analysis User's Manual, 2012)...... .55

Figure 3.14 Integration points for linear elements (Rafiei, 2011) ….................................57

Figure 3.15 Profiled steel sheet- linear quadrilateral shell element (S4R) ............................58

Figure 3.16 Dry board - linear hexahedral solid element (C3D8R) .....................................58

Figure 3.17 (a) Profiled concrete core -linear hexahedral solid element (C3D8R) .................59

Figure 3.18 Assembled PSSDB composite panel with discrete fasteners aligned ..................60

Figure 3.19 Pierced unfilled (left) and filled (right) PSSDB panel ......................................60

Figure 3.20 Location of reference point and constraining y-direction using kinematic coupling

Figure 3.21 Axial load-deformation response comparing PSSDB panels with varying h/w ratio and rows of fasteners

Figure 3.22 Displacements (mm) and deformed shape of the PSSDB panels at the end point of FEA run for (a) A1 (b) A2.

Figure 3.23 Displacements (mm) and deformed shape of the PSSDB panels at the end point of the FEA run for (a) A3 (b) A4. .64

Figure 3.24 Axial load-deformation response comparing filled composite (A5, A6 and A8) PDDSB panels with varying heights and 3 rows of spacers

Figure 3.25 Displacements (mm) and deformed shape of filled PSSDB panels at the end point of FE run with varying heights and 3 rows of spacers (a) A5 (b) A6

Figure 3.25 (c) Displacements (mm) and deformed shape of filled PSSDB panels (A8) at the end point of FE run. .66 
Figure 3.26 Axial load-deformation response comparing filled and unfilled pierced PSSDB panels

Figure 3.27 Displacements (mm) and failure mode of pierced (a) filled (A7) and (b) unfilled (A9) PSSDB panels at the end point of FE run

Figure 3.28 Maximum compressive principal stress, S22 (MPa) at (a) 50\% of ultimate load, (b) ultimate load, and (c) end point of FE run for A1 (without in-fill)

Figure 3.29 Maximum compressive principal stress, S22 (MPa) at (a) 50\% of ultimate load, (b) ultimate load, and (c) end point of FE run for A2 (without in-fill)

Figure 3.30 Maximum compressive principal stress, S22 (MPa) at (a) 50\% of ultimate load, (b) ultimate load, and (c) end point of FE run for A3 (without in-fill) .... .70

Figure 3.31 Maximum compressive principal stress, S22 (MPa) at (a) 50\% of ultimate load, (b) ultimate load, and (c) end point of FE run for A4 (without infill)

Figure 3.32 Maximum compressive principal stress, S22 (MPa) at (a) 50\% of ultimate load, (b) ultimate load, and (c) end point of FE run for A5 (with infill).

Figure 3.33 Maximum compressive principal stress, S22 (MPa) at (a) 50\% of ultimate load, (b) ultimate load, and (c) end point of FE run for A6 (with infill).....

Figure 3.34 Maximum compressive principal stress, S22 (MPa) at (a) 50\% of ultimate load, (b) ultimate load, and (c) end point of FE run for A7 (with infill)..... .74

Figure 3.35 Maximum compressive principal stress, S22 (MPa) at (a) 50\% of ultimate load, (b) ultimate load, and (c) end point of FE run for A8 (with infill). .75

Figure 3.36 Maximum compressive principal stress, S22 (MPa) at (a) 50\% of ultimate load, (b) ultimate load, and (c) end point of FE run for A9 (without infill) .76

Figure 3.37 (a) Comparison of experimental and FEA axial load deformation response of PSSDB panels .79

Figure 3.37 (b) Comparison of experimental and FEA axial load deformation response of PSSDB panels . 80

Figure 3.38 Axial load-deformation response of PSSDB panels with varying thickness of the DB. 81

Figure 3.39 Axial load-deformation response of PSSDB panels with varying thickness of the PSS.

Figure 3.40 Axial load-deformation response of varying the yield strength (Fy) of PSS .83

Figure 3.41 Axial Load-deformation response of varying compressive strength of concrete infill .83

Figure 4.1 Schematic drawing and cross-section of the S-series .87 
Figure 4.2 (a) Cross-section of A1-series (b) cross-section of B1-series (c) schematic diagram of the pierced and non-pierced PSSDB shear wall panels (A1 and B1 Series) .88

Figure 4.3 (a) Schematic drawing of the experimental set-up for the S-series panels bounded by rigid frames 91

Figure 4.3 (b) Experimental set-up for the S-series panels bounded by rigid frames 91

Figure 4.4 (a) Schematic drawing of the experimental set-up for A1-B1 series wall panels subjected to horizontal shear loading 92

Figure 4.4 (b) Experimental set-up for A1-B1 series wall panels subjected to horizontal shear loading 92

Figure 4.5 Load-deformation response of (a) DB with both vertical and horizontal fasteners (S1-DB) and vertical fasteners only (S3-DB) (b) PSS with both vertical and horizontal fasteners (S2-PSS) and vertical fasteners only (S5-PSS)

Figure 4.6 Failure pattern of DB panel with both vertical and horizontal fasteners (S1-DB) (left) and with vertical fasteners only (S3-DB) (right)

Figure 4.7 Failure pattern of PSS with both vertical and horizontal fasteners (S2-PSS) (left)

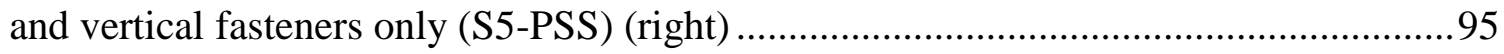

Figure 4.8 Failure pattern of the PSSDB panel (S4-PSSDB) …….................................... 95

Figure 4.9 Load-deformation response of non-pierced (S6-PSSDB) and pierced (S9p-PSSDB) composite wall with both vertical and horizontal fasteners .96

Figure 4.10 Schematic drawing displaying failure mode of non-pierced composite panel (S6PSSDB).

Figure 4.11 Schematic drawing displaying failure mode of pierced composite panel (S9pPSSDB).

Figure 4.12 Load-deformation response of non-pierced (S7-PSS) and pierced steel sheet panel (S10p-PSS) with vertical fasteners only .98

Figure 4.13 Failure patterns of (a) non-pierced (S7-PSS) and (b) pierced steel sheet (S10p-PSS) with vertical fasteners

Figure 4.14 Load-deformation responses of non-pierced and pierced DB panels with vertical fasteners

Figure 4.15 Failure patterns of (a) non-pierced (S8-DB) and (b) pierced (S11p-DB) panels with vertical fasteners only.

Figure 4.16 Load-deformation response of (a) non-pierced and (b) pierced PSSDB panels with and without concrete infill (A1-series) 
Figure 4.17 Load-deformation response of (a) non-pierced and (b) pierced DB-PSS-DB panels

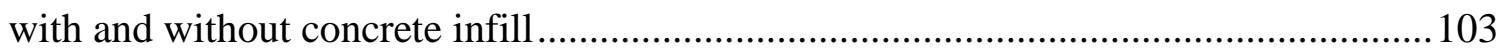

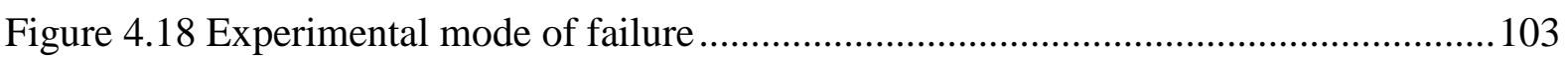

Figure 4.19 Panel bounded by pin ended rigid frame and cross-section of profiled steel sheet 106

Figure 4.20 (a) Local shear buckling mode and (b) global shear buckling mode (Yi et. al., 2008)

Figure 4.21 Definition of stress components and material directions (Sandhas et al., 2012)121

Figure 4.22 Profiled steel sheet - linear quadrilateral shell element (S4R)

Figure 4.23 Profiled concrete core - linear hexahedral solid element (C3D8R) ................... 124

Figure 4.24 Dry board - quadrilateral continuum shell element (SC8R). 124

Figure 4.25 Non-pierced and pierced PSS-DB (A1-np and A1-p) and DB-PSS-DB (B1-np and B1-p) composite panels 125

Figure 4.26 Location of reference point and constraining X-direction using kinematic coupling 126

Figure 4.27 Load-deformation response of non-pierced PSS-DB (A1-np) and DB-PSS-DB (B1-np) composite panels 127

Figure 4.28 Deformed shape of the non-pierced pierced (a) A1-np and (b) B1-np PSSDB panels 127

Figure 4.29 Load-deformation response of pierced PSS-DB (A1-p) and DB-PSS-DB (B1-p) composite panels. 128

Figure 4.30 Deformed shape of the pierced (a) PSSDB (A1-p) and (b) DB-PSS-DB (B1-p) composite panels 128

Figure 4.31(a) Load-deformation response comparing B1 panels with and without concrete infill (b) deformed shape of the non-pierced DB-PSS-DB composite panels with concrete infill

Figure 4.32 The Von-Mises stress (MPa) distribution in the non-pierced PSS-DB (A1-np) composite panel at the peak load 130

Figure 4.33 The Von-Mises stress (MPa) distribution in the DB-PSS-DB (B1-np) panel at the peak load. 130

Figure 4.34 Maximum in-plane principal stress (MPa) in the non-pierced PSS-DB (A1-np) panel at the peak load 131

Figure 4.35 Maximum in-plane principal stress (MPa) in the DB-PSS-DB (B1-np) panel at the peak load. 131 
Figure 4.36 Minimum in-plane principal stress (MPa) in the non-pierced PSS-DB (A1-np) panel at the peak load

Figure 4.37 Minimum in-plane principal stress (MPa) in the DB-PSS-DB (B1-np) panel at the peak load. 132

Figure 4.38 Von-Mises stress (MPa) distribution in the pierced PSS-DB (A1-p) composite panel at the peak load

Figure 4.39 The Von-Mises stress (MPa) distribution in the pierced DB-PSS-DB (B1-p) composite panel at the peak load

Figure 4.40 Maximum in-plane principal stress (MPa) in the pierced PSS-DB (A1-p) composite panel at the peak load

Figure 4.41 Maximum In-Plane Principal stress (MPa) in the pierced DB-PSS-DB (B1-p) composite panel at the peak load 134

Figure 4.42 Minimum In-Plane Principal stress (MPa) in the pierced PSS-DB (A1-p) composite panel at the peak load 134

Figure 4.43 Minimum in-plane principal stress (MPa) in the pierced DB-PSS-DB (B1-p) composite panel at the peak load 135

Figure 4.44 The (a) Von-Mises stress (MPa) distribution (b) maximum and (c) minimum inplane principal stress $(\mathrm{MPa})$ of $\mathrm{B} 1-\mathrm{npc}$ composite panel with concrete infill at the peak load 135

Figure 4.45 Comparison of experimental vs. FEA load-deformation response 136 


\section{LIST OF APPENDICES}

Appendix A: Detailed Theoretical Axial Load Capacity Calculations ................................. 142

A.1 Axial Load Capacities of Double Skinned PSSDB Panels With and Without Concrete

Infill

A.2 Axial buckling load Capacities of double skinned PSSDB panels with and without concrete infill.... 143

Appendix B: Detailed Theoretical Shear Resistance Calculations 146

B.1 Shear Resistance of Non-Pierced Panels 146

B.2 Shear resistance of pierced panels 148 


\section{NOMENCLATURE}

As $\quad$ Cross-sectional area of profiled steel sheeting

$\mathrm{A}_{\mathrm{b}} \quad$ Cross-sectional area of dry board

$\mathrm{A}_{\mathrm{cc}} \quad$ Cross-sectional area of concrete core

$\mathrm{k} \quad$ Interaction factor

$\mathrm{k} \quad$ Reduction factor

k' Partial interaction factor

${ }_{\mathrm{E}} \mathrm{E}_{\mathrm{db}} \quad$ Elastic Modulus of board

$\mathrm{E}_{\mathrm{cc}} \quad$ Elastic Modulus of concrete core

$\mathrm{H} \quad$ Wall height

$\sigma_{1}, \sigma_{2} \quad$ Principal normal stresses

$\tau_{\max } \quad$ Maximum shear stress

w Maximum fold width

L Local shear buckling coefficient

$\mathrm{V}_{\mathrm{g}} \quad$ Governing shear resistance

$\mathrm{V}_{\mathrm{f}, \mathrm{DB}(\mathrm{v})} \quad$ Shear resistance of $\mathrm{DB}$ considering failure at the vertically aligned panel-frame fasteners

$\mathrm{V}_{\mathrm{f}, \mathrm{DB}(\mathrm{h})} \quad$ Shear resistance of $\mathrm{DB}$ considering failure at the horizontally aligned panelframe fasteners

$\mathrm{V}_{\mathrm{f}, \mathrm{PSS}(\mathrm{v})} \quad$ Shear resistance of PSS considering failure at the vertically aligned panel-frame fasteners

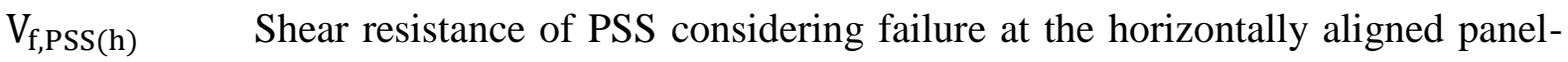
frame fasteners

$\mathrm{V}_{\mathrm{DB}} \quad$ Shear resistance of non-pierced DB panel

$\mathrm{V}_{\mathrm{DB}(\mathrm{p})} \quad$ Shear resistance of pierced DB panel

$\mathrm{F}_{\mathrm{sb}, \mathrm{DB}}, \mathrm{F}_{\mathrm{sc}, \mathrm{DB}} \quad$ Strength of bolted DB connection

$\mathrm{F}_{\mathrm{sb}, \mathrm{PSS}}, \mathrm{F}_{\mathrm{sc}, \mathrm{PSS}}$ Strength of bolted PSS connection

VPSS Shear resistance of non-pierced PSS panel

VPSS(p) Shear resistance of pierced PSS panel

VPSSDB Shear resistance of non-pierced PSSDB panel

VPSSDB(p) Shear resistance of pierced PSSDB panel

$\gamma \quad$ Shear resistance contribution factor

n Modular ratio 


\begin{tabular}{|c|c|}
\hline $\mathrm{V}_{\mathrm{A} 1-\mathrm{npc}}$ & Shear resistance of non-pierced PSSDB panel with concrete infill \\
\hline$V_{\text {B1-npc }}$ & Shear resistance of non-pierced DB-PSS-DB panel with concrete infill \\
\hline$\mu$ & Modification factor \\
\hline$\lambda$ & Adjustment factor \\
\hline $\mathrm{V}_{\mathrm{PSS}+\mathrm{C}}$ & Shear resistance of the profiled steel-concrete composite panels \\
\hline $\mathrm{D}_{\mathrm{x}}$ & Bending stiffness per unit length about $\mathrm{x}$-axis \\
\hline $\mathrm{D}_{\mathrm{y}}$ & Bending stiffness per unit length about $y$-axis \\
\hline$\beta$ & Buckling coefficient \\
\hline$\frac{(a+b)}{(a+c)}$ & Length reduction Factor \\
\hline $\mathrm{f}_{\mathrm{c}}^{\prime}$ & Cylinder compressive strength of concrete \\
\hline${\mathrm{f}_{\mathrm{t}}^{\prime}}^{\prime}$ & Splitting tensile strength of concrete \\
\hline$t_{e q}$ & Equivalent thickness of concrete panel \\
\hline $\mathrm{dp}$ & Depth of structural panel in plane of bending \\
\hline $\mathrm{P}_{\mathrm{u}}$ & Axial load capacity of wall without concrete core \\
\hline $\mathrm{P}_{\mathrm{uc}}$ & Axial load capacity of wall with concrete core \\
\hline EPSS & Modulus of elasticity of PSS, \\
\hline $\mathrm{P}_{\mathrm{cr}}$ & Buckling load capacity \\
\hline $\mathrm{K}$ & Effective length factor \\
\hline $\mathrm{I}_{\mathrm{c}}$ & $\begin{array}{l}\text { Second moment of area of the equivalent transformed steel section of the } \\
\text { PSSDB walls with or without concrete core }\end{array}$ \\
\hline$\sigma_{y}$ & Yield strength of PSS \\
\hline$v$ & Poisson's ratio of the material \\
\hline $\mathrm{t}$ & Thickness of the plate. \\
\hline $\mathrm{k}$ & Interaction parameter, \\
\hline $\mathrm{h}$ & Wall height \\
\hline s & Connector spacing \\
\hline w & Width of the panel \\
\hline $\mathrm{H}$ & Width of profiled steel sheet \\
\hline $\mathrm{L}$ & Length parallel to the line of corrugation and \\
\hline$\beta$ & Buckling Coefficient Factor \\
\hline $\mathrm{P}_{\mathrm{u}}$ & Theoretical crushing load \\
\hline$p_{a}, p_{b}$ & Spacing between the fasteners \\
\hline$F_{s b}$ & Ultimate strength of one sheet-beam fastener \\
\hline
\end{tabular}


$F_{S C} \quad$ Ultimate strength of one sheet-column fastener

Shear Strength due to sheet-beam or sheet-column fasteners

$V_{s}$

Shear strength of the profiled steel sheet

$V_{c}$

Shear strength of the profiled concrete core

$V_{p}$

Shear resistance governed by sheathing-to framing connection strength resistance or shear resistance governed by sheathing panel buckling

$N_{u} \quad$ Lateral strength resistance of sheathing-to-framing connection along panel edges per fastener

Fastener spacing along panel edges

$\mathrm{D}$

Adjustment factor for diaphragm and shear wall construction

$n_{S}$

Number of shear planes in sheathing-to-framing connections

$J_{S}$

Fastener spacing factor

$\mathrm{S}$

Fastener spacing along panel edges

$J_{u s}$

Strength adjustment factor for unblocked shear walls

$J_{h d}$

Hold-down effect factor for shear wall segment

$L_{S}$

Length of shear wall segment parallel to direction of factored load

a

Larger dimension of panel

b

Smaller dimension of panel

$B_{a, 0}$

Axial stiffness of panel $0^{\circ}$ orientation

$B_{a, 90}$

Axial stiffness of panel $90^{\circ}$ orientation

$B_{v}$

Shear-through-thickness rigidity

$\mathrm{t}$

Panel thickness

$v_{p}$

Specified strength capacity in shear-through thickness

$K_{D}$

Load duration factor

$K_{S}$

Service condition factor

$K_{T}$

Treatment Factor

$v_{p b}$

Panel buckling strength of the most critical structural panel within the segment

$K_{p b}$

Panel buckling factor

$F_{\text {su(op })}$

Ultimate strength capacity of CSSW with opening

$F_{s u}$

Ultimate strength of a CSSW without opening

$d_{o p}$

Diameter of the opening

$D$

Diameter of the panel

1

Length of the rectangular opening 


\begin{tabular}{|c|c|}
\hline $\mathrm{h}$ & Height of the rectangular opening \\
\hline$\beta$ & Shear resistance contribution factor \\
\hline$\varphi$ & Factor recommended by ACI 318-83 depending on H/L \\
\hline$t_{e q c}$ & Width of the equivalent concrete rectangular block \\
\hline$V_{\exp }$ & Experimental Shear Capacity \\
\hline $\mathrm{t}_{\mathrm{b}}$ & thickness of board \\
\hline $\mathrm{t}_{\mathrm{s}}$ & thickness of steel \\
\hline$f_{c}^{\prime}$ & Ultimate compressive strength of concrete \\
\hline $\mathrm{n}$ & Curve-fitting factor, \\
\hline$E_{c}$ & Initial tangent modulus, \\
\hline$E_{c}^{\prime}$ & Tangent modulus of concrete at $f_{c}^{\prime}$, \\
\hline$\varepsilon_{0}$ & Strain when $f_{c}$ reaches $f_{c}^{\prime}$, \\
\hline$K$ & Factor to control the slope of the stress-strain curve \\
\hline$\sigma_{c 0}$ & Initial yield point \\
\hline$\sigma_{c u}$ & Ultimate stress \\
\hline$\sigma_{t 0}$ & Failure stress \\
\hline$\sigma_{\text {nom }}$ & Nominal stress, \\
\hline$\varepsilon_{\text {nom }}$ & Nominal strain \\
\hline$\sigma_{\text {true }}$ & True stress \\
\hline$\varepsilon_{l n}^{p l}$ & Plastic strain \\
\hline$q$ & Mises stress \\
\hline $\mathrm{S}$ & Deviatoric stress \\
\hline$p$ & Pressure stress \\
\hline B & Size of the (vertical) q-axis of the yield ellipse \\
\hline$\alpha$ & Shape factor of the yield ellipse \\
\hline$p_{c}$ & Yield stress in hydrostatic compression \\
\hline$\sigma_{c}$ & Absolute value of the yield stress in uniaxial compression \\
\hline $\mathrm{F}$ & Yield surface \\
\hline $\mathrm{L}$ & Longitudinal (1-1) \\
\hline $\mathrm{R}$ & Radial (2-2) \\
\hline $\mathrm{T}$ & Tangential (3-3) \\
\hline $\mathrm{G}_{12}$ & Shear modulus in the radial direction \\
\hline $\mathrm{G}_{13}$ & Shear Modulus in the tangential direction \\
\hline
\end{tabular}




$\begin{array}{ll}\mathrm{G}_{23} & \text { Rolling Shear Modulus } \\ \mathrm{E}_{1} & \text { Modulus of Elasticity in the longitudinal direction that corresponds to the } \\ & \text { direction parallel-to-grain (main grain direction) } \\ \mathrm{E}_{2} & \text { Modulus of Elasticity in the radial direction that corresponds to the direction } \\ & \text { perpendicular-to-grain } \\ \mathrm{E}_{3} & \text { Modulus of Elasticity in the tangential direction that corresponds to the } \\ F_{f t} & \text { direction perpendicular-to-grain } \\ F_{f c} & \text { Fiber Tension } \\ F_{m t} & \text { Fiber Compression } \\ F_{m c} & \text { Matrix Tension } \\ \mathrm{f}_{\mathrm{t}, 0} & \text { Matrix Compression } \\ \mathrm{f}_{\mathrm{c}, 0} & \text { Longitudinal Tensile Strength } \\ \mathrm{f}_{\mathrm{t}, 90} & \text { Longitudinal Compressive Strength } \\ \mathrm{f}_{\mathrm{c}, 90} & \text { Transverse Tensile Strength } \\ \mathrm{f}_{\mathrm{v}, 0} & \text { Transverse Compressive Strength } \\ \mathrm{f}_{\mathrm{v}, 90} & \text { Longitudinal Shear Strength } \\ \mathrm{G}_{\mathrm{ft}, 0} & \text { Transverse Shear Strength } \\ \mathrm{G}_{\mathrm{fc}, 0} & \text { Longitudinal Tensile Fracture Energy } \\ \mathrm{G}_{\mathrm{ft}, 90} & \text { Longitudinal Compressive Fracture Energy } \\ \mathrm{G}_{\mathrm{fc}, 90} & \text { Transverse Tensile Fracture Energy } \\ \eta & \text { Viscosity Parameter } \\ & \text { Coefficient that determines the contribution of the shear stress to the Compressive Fracture Energy } \\ & \end{array}$




\section{CHAPTER 1: INTRODUCTION}

\subsection{General}

The fast and ongoing evolution of science and technology in the construction industry has led to the development of various innovative construction materials and methods to substitute the traditional concepts of construction. New perceptions of construction technology such as the steel building systems, composite systems, modular systems (lightweight panels, hollow blocks) and other Industrialized Building Systems (IBS) are now becoming more acceptable (Awang and Badaruzzaman, 2009). IBS has widely been used in low and high rise residential and commercial structures. One form of IBS that is commonly used in building and civil engineering construction is prefabricated wall panel structure. This structure has been used in a bulk quantity of construction process at the construction site. Profiled Steel Sheet Dry Board (PSSDB) system is one such innovative load bearing panel system in the IBS category.

Few researches have been conducted on the use of new materials and enhancing the composite construction as wall panels. Wright and Evans (1986) first introduced the PSSDB system as a substitute to existing timber joist floor. Apart from flooring systems, this structural system was exploited by researchers at Universiti Kebangsaan Malaysia (UKM) to extend its application as walling and roofing systems along with the IBS concept. It has several advantages over the traditional forms of constructions. Besides being relatively lightweight the construction procedure is simple as it does not require temporary formwork or propping. It can be erected by unskilled labor and is easily transportable and cost effective. Some of the previous publications on the PSSDB as floor, wall and roof and IBS systems are reported (Ahmed, 1999; Ahmed and Wan Badaruzzaman, 2005; Ahmed et al., 2000; Akhand, 2001; Awang, 2008; Awang and Wan Badaruzzaman, 2009; Wan Badaruzzaman et al., 2003a, 2003b). The structural performance and strength of the PSSDB composite panel system depends greatly on the properties of each components (PSS and DB) forming the PSSDB system and the degree of interaction between them. Depending on the connector modulus and spacing, the degree of interaction (full or partial interaction) is achieved. The combination of the profiled steel sheet (PSS) and dry board (DB) also creates complete and incomplete interactions between them. Each PSSDB component in the composite system has its own role. PSS is found to be the most crucial component of the PSSDB system as optimizing the cross-section of the PSS enhances the optimization of the PSSDB system. It also serves as tensile reinforcement and permanent formwork. Although dry boards are mainly 
used as partitions in buildings and as other non-load bearing building elements, it is used in loadbearing applications if its structural potential and abilities are properly used. The DB component provides a flat surface and improves the strength and stiffness of the profiled steel sheet/system. Furthermore, the connection between the components (profiled steel sheet and plywood DB) forming the composite action plays an important role in predicting the overall behavior and strength. Fasteners present in the panel play a vital role in transferring horizontal shear loads from the steel sheet to the plywood and to form a composite action.

Earlier, researchers have concentrated on investigating the structural behavior of the system as floor panels; however, further studies have demonstrated it has adequacy to be used as wall and roof panels. Other researchers investigated the effect of the infill material (rockwool, sand and concrete) for structural purposes (stiffness and bending strength) and non-structural purposes (fireresistance and sound proofing) (Al-Shaikhli et al., 2017).

PSSDB system is introduced as an efficient composite construction technique on load bearing wall panel that is feasible. In the construction industry, load bearing wall panels are capable of transferring loads to the foundation thus making the structure efficient and economic. In addition to being lightweight, the composite panel has the ability to satisfy basic requirements such as load carrying capacity, stiffness and durability in creating load-bearing structures (Wan Badaruzzaman et al., 2004).

This research investigates the structural behavior and the ultimate load carrying capacity of pierced and non-pierced composite wall under axial and shear loading. Further investigation was done to study the effect of introducing concrete infill in the trough of the corrugated steel sheet to form a rigid wall panel. The proposed PSSDB system is a lightweight composite system comprising of profiled steel sheet and dry board sheathed at both sides and attached with a series of screws for the component to act as a single structure. Figure 1.1 shows a prototype of the PSSDB panel used for this study. 


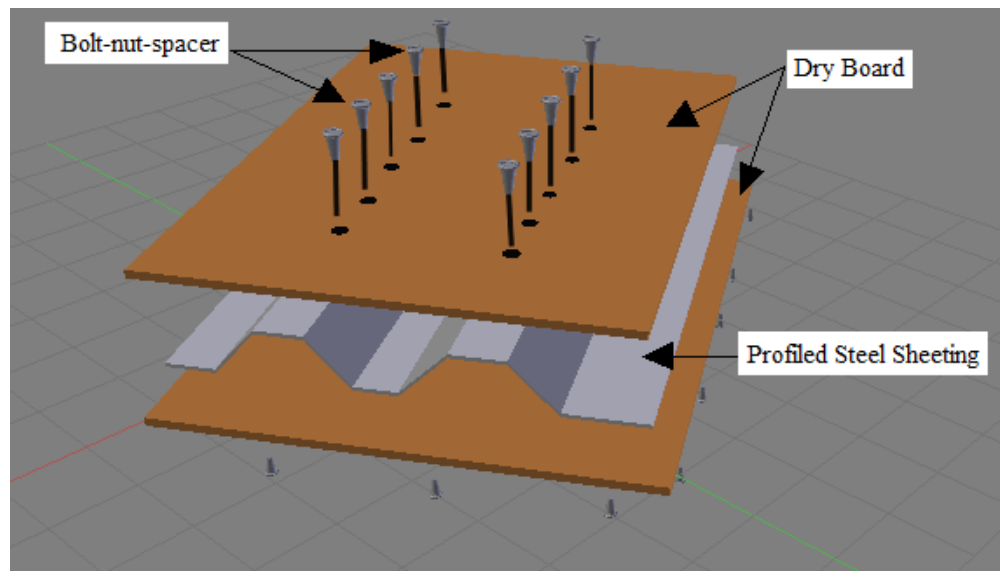

Figure 1.1 Prototype PSSDB panel

\subsection{Significance of the Research}

Extensive research has been conducted on the innovative PSSDB composite panel to replace the traditional techniques of construction that have been practiced for several decades. Earlier publications reported work on using PSSDB as a structural load bearing system to be used for different structural purposes. Despite the exploitation of the various aspects of this system, more computational modelling is required to understand the feasibility of using a combination of different types of wooden board, profiled steel sheet, connectors and concrete infill. To date, no research studies have been conducted to assess the structural behavior of PSSDB wall panels subjected to shear loading. This research presents the FE modeling of non-pierced or pierced PSSDB system using profiled steel sheeting sandwiched with DB panels (with or without concrete in-fill) coupled with experimental and analytical investigations based on the shear/axial strength, stiffness, load-deformation response, interaction between the PSS-DB-infill concrete and possible failure modes. The structural response of a composite PSSDB panel is predominantly non-linear. The current study involves a realistic structural analysis to predict the ultimate load capacity and load-deformation behavior that cater the nonlinearities of the component materials (PSS, DB and concrete). DB and steel sheet thickness, single/double skin DB panel, pierced and non-pierced panels, with and without concrete infill and material properties of each PSSDB components are the variables considered in the analyses. The results of this research will contribute significantly to understand the structural behavior of such walling system as shear or core wall in buildings in addition to axial load bearing wall and will prove its feasibility to be used in the practical construction applications. 


\subsection{Scope and Objectives of Research}

The main objective this research is to investigate the structural performance of PSSDB composite wall panels under axial and shear loading based on experimental, analytical and finite element (FE) analyses. The main objective of this research is achieved through fulfilling the following sub-objectives as follows:

- Analyze experimental data of PSSDB wall panels conducted by the research team at Ryerson under axial and shear loading conditions to obtain a comprehensive understanding of the structural behavior of the systems. Ten rectangular PSSDB wall panels of having varying width/height ratio, PSS-DB connections, with/without concrete in-fill or perforations were tested to failure under axial loading. Nineteen shear panels (11 panels connected to a pin-ended boundary frame in $S$ series and 8 cantilever panels without boundary frame in A-B series) having various configurations such as DB or PSS only, PSSDB or SB-PSS-DB combinations, with or without central hole, with or without concrete in-fill, varying height-width ratio and varying frame-panel connection or PSS-DB connections were tested. The performance of these wall panels is analyzed based on loaddeformation response, strength and failure modes.

- Perform non-linear finite element analysis using ABAQUS software to assess the axial and shear behavior of PSSDB composite system subjected to axial and shear loading. Validate the accuracy of the finite element models using experimental and analytical results. Conduct extensive parametric studies using FE models to highlight the factors that influence the load-bearing capacity of the PSSDB walls under axial loading.

- Develop analytical models or design equations that are able to predict the axial and shear strength non-pierced/pierced PSSDB wall panels and their components (PSS, DB and concrete) with and without concrete infill based on existing models and design equations. Validate the performance of developed equations based on experimental results.

\subsection{Outline of Thesis}

This thesis comprises of five chapters and are briefly outlined as follows:

Chapter 1 provides a brief introduction on the efficiency of using profiled steel sheet dry board (PSSDB) composite system as a load-bearing wall panel. The main objective of conducting this research and its significance are also emphasized. 
Chapter 2 presents an extensive literature review on researches conducted by scholars on using profiled steel sheet dry board composite system. The exploitation of PSSDB panels as walls folded plate roof structures and floors were discussed. Furthermore, the structural behavior of the structural elements subjected to axial and shear loading was also described along with practical construction applications.

Chapter 3 provides an overview of the experimental study conducted by Ryerson research group on PSSDB specimens under axial loading. Moreover, analytical models and finite element models (FEMs) are developed to predict the behavior of axially loaded non-pierced and pierced PSSDB panels with and without concrete infill. A detailed step-by-step description of performing the nonlinear finite element analysis using ABAQUS/STANDARD is presented. Sensitivity analysis is also conducted to determine the influence of different parameters. The performance of FE models and analytical equations are judged based on experimental results.

Chapter $\mathbf{4}$ presents an overview of the experimental study conducted by Ryerson research group on PSSDB wall panels subjected to vertical (cantilever mode without boundary frame) and horizontal (with pin-ended boundary frame) shear loading. Analytical and finite element models are developed to predict the shear strength capacity of single board and double board non-pierced and pierced PSSDB composite panels with and without concrete infill. The load bearing capacity of each individual components in the composite shear panel is also investigated. The theoretical and FEA results are then validated through experimental results followed by parametric FE modeling to study influence of various parameters.

Chapter 5 summarizes the main conclusions from each chapter of this thesis and proposes recommendations for future research on composite PSSDB structural walling system. 


\section{CHAPTER 2: LITERATURE REVIEW}

\subsection{Introduction}

New concepts, such as those comprising of steel structural systems, composite steel-concrete systems, and lightweight panels made of various materials, hollow blocks and other similar Industrialized Building System (IBS) are becoming more suitable to the construction technology (Awang and Badaruzzaman, 2009). IBS has gained its recognition in the construction industry to improve the efficiency of construction processes, consequently allowing higher productivity and quality and reducing construction time and costs (Rahmadi et al., 2002). In the quest to develop new construction materials and techniques, researchers have found profiled steel sheet dry board (PSSDB) as a type of the IBS category that forms the load bearing structure. This chapter presents some of the studies conducted by various researchers on the structural performance of PSSDB composite panels as floors, wall units and folded plate roof structures. It highlights the components of the composite system used for different structural purposes. Practical applications and several advantages of the system have also been highlighted.

\subsection{Profiled Steel Sheet Dry Board Composite (PSSDB) System}

PSSDB composite panel system is a lightweight composite structure which comprises of a profiled steel sheet and dry board and assembled together with a series of screws. It was originally developed by Wright and Evans (1986), using PSSDB system as flooring units in residential and low-rise buildings as a replacement for existing timber joist floors. Subsequently, research has advanced to determine the performance of PSSDB composite system as walling and roofing units in buildings. Some earlier studies on the behavior of PSSDB floor, wall and roof systems were reported by Ahmed (1996, 1999), Ahmed and Wan Badaruzzaman (2003, 2005), Ahmed et al., (1999a, 1999b, 2000), Akhand (2001), Benayoune and Wan Badaruzzaman (2000), Shodiq (2004), Wan Badaruzzaman (1994), Wan Badaruzzaman et al., (1996), Wan Badaruzzaman et al., (2003), Wan Badaruzzaman and Wright (1998), Wright et al., (1989), and Wright (1988). These studies included the structural as well as the non-structural performance of the system (Awang \& Badaruzzaman, 2010). Researchers have found out that when PSSDB composite system is used as flooring units, it carries out-of-plane bending and shear, and when used as walling units, it is able to carry in plane shear and deformation. Lastly, when used as folded plate roof units, it carries both in-plane and out of plane bending and shear (Badaruzzaman et al., 1996). 


\subsubsection{Components of PSSDB System}

\subsubsection{Profiled Steel Sheet}

Different types of steel sheets have been examined in various tests and sorted into different sets, based on its shape and depth. The performance of the PSSDB system is significantly influenced by the change in shape and depth of the steel sheet. The stiffness of the sheet increases along with the depth of the profile (Awang \& Badaruzzaman, 2010). Figure 2.1 and Figure 2.2 display profiled steel sheets (presented by its commercial names), produced by CANAM group in Canada for roof and deck applications (CANAM, 2017).
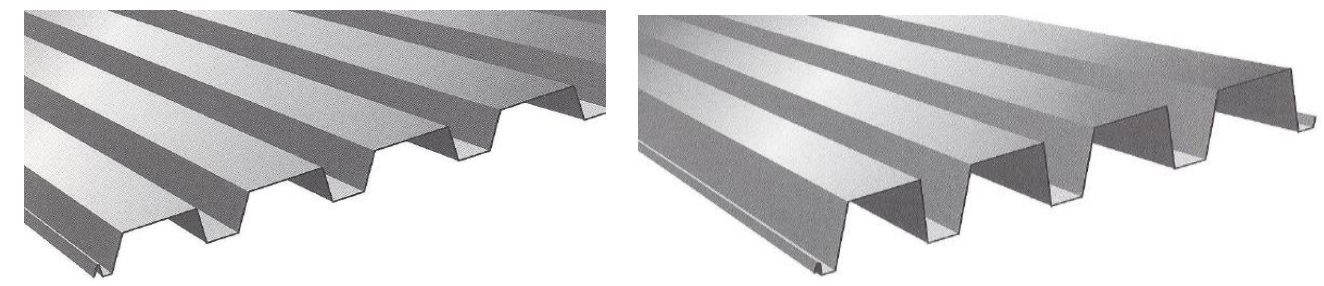

Figure 2.1 Roof application (a) P-3615 \& P-3606 (b) P-2436 \& P-2404 (CANAM, 2017)

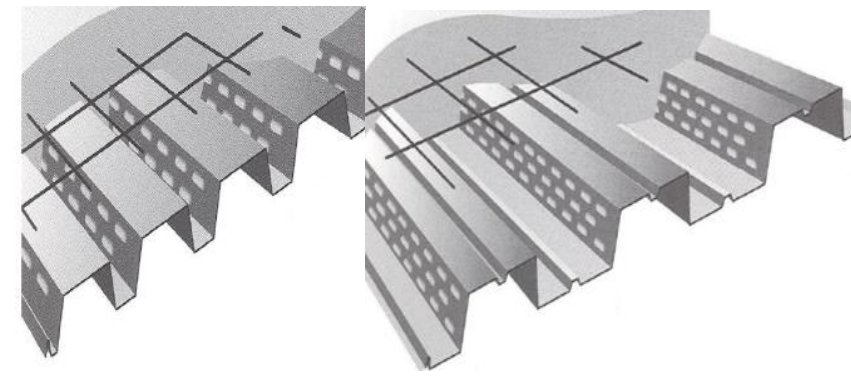

(a) (b)

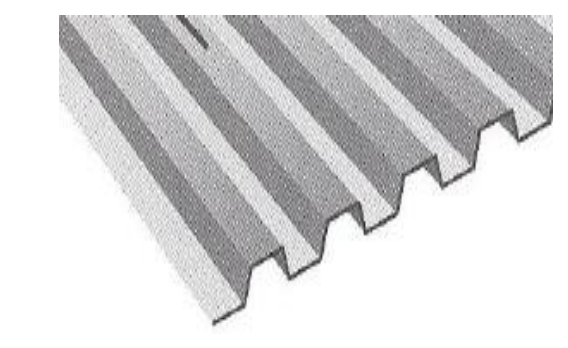

(d)

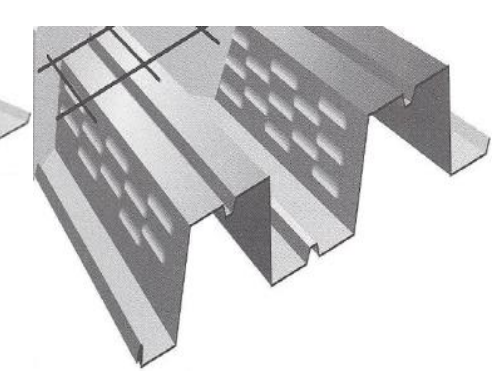

(c)

Figure 2.2 Floor application (a) P-3615 \& P-3606 Composite (b) P-3623 Composite (c) P-2432 Composite (d) P-3012 Form Deck (CANAM, 2017) 
Profiled steel sheet made from cold-formed flat steel "coil" is coated with zinc/aluminum alloy, also known as zincalume based on the Australian Standard AS 1397:1993. Zincalume is a corrosion resistant, alloy coated steel produced by continuous hot dip process. The zincalume coating serves optimum composition of aluminum and zinc for corrosion resistance and galvanic protection. The yield strength of the profiled steel sheet range between $350 \mathrm{MPa}$ to $550 \mathrm{MPa}$. The stiffness characteristic is low, despite the high strength of steel sheet. For wall and roof applications, the thickness of the sheeting is reasonably thin, ranging between $0.4 \mathrm{~mm}-0.6 \mathrm{~mm}$ (Awang \& Badaruzzaman, 2010). For commercial and industrial construction, profiled steel sheet is designed as a strong attractive roofing material. It associates strength with lightness rigidity and economy. Moreover, it can be aligned easily and the process of fixing with hexagon headed screws, is simple and quick (Nagar, 2017).

\subsubsection{Dry Board (DB) - Properties and Modelling}

Dry board is a crucial element in the PSSDB wall panel system that provides a flat surface to carry the load. It enhances the strength and stiffness of the PSSDB system. The board is connected to the profiled steel sheeting via fasteners. The interaction between the board and the steel sheet forms a composite section creating either full or partial interaction behavior. Different types of boards such as plywood, chipboard, cement bonded mineral board and hardboard are widely available that can be suitable for various application. Under compressive loading and elastic deflection of the PSSDB system, it contributes in postponing local buckling of the thin profiled steel sheet, in addition to sustaining minimal loading (Awang \& Badaruzzaman, 2010).

Plywood (Figure 2.3) is constructed by gluing together thin layers of plies of wood veneers with the grain direction rotated at right angles in each successive layers. A plywood panel is made of three layers comprising of two faces and a core. The layers of plies are placed in odd numbers to balance on either side of a center core so that the grains on the exterior layers will eventually run in the same direction (Plywood, 2017). Plywood has several advantages that contribute to the load bearing capacity of the PSSDB wall. Plywood has high impact resistance, high thermal and sound insulation, chemical and fire resistance, and high strength to weight ratio. It is cost-effective and durable material to be used in structural applications. 


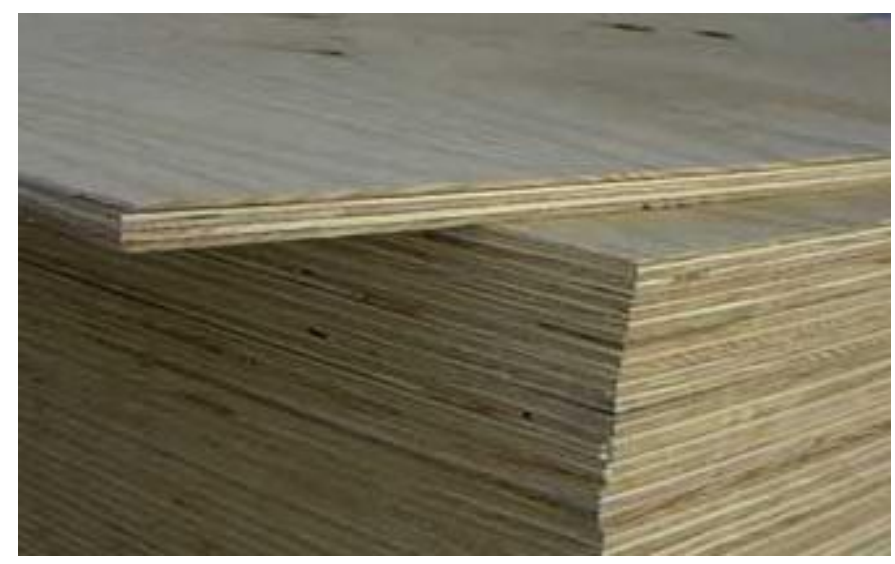

Figure 2.3 Plywood (Plywood, 2017)

Plywood is said to be a layered cross-ply unidirectional fiber reinforced composite. Nonlinear behavior of wood and timber joints are difficult to model using finite element programs as they do not provide a standard model to input wood specifications. Besides its uniformity, concerns pertaining to material specifications initiate numerical problems due to its highly anisotropic nature with different strengths in tension and shear displaying brittle behavior and ductile behavior in compression. Both brittle and ductile failure modes occur simultaneously. The existing approaches are mainly based on specific approaches for various problem definitions. Schmid (2002), and Ballerini \& Rizzi (2005) modelled the brittle failure mode using fracture mechanics approaches within a continuum framework while other researchers (Wittel et al. 2005, Reichert 2009, Nagy 2010) adopted the discrete lattice models. On the contrary, classical flow theory of plasticity in combination with the Hill criterion (Dias et al. (2010)), the Hoffman criterion (Xu et al. (2009)) or even the Tsai-Wu criterion (Bouchaïr et al. (1995) and Dorn (2012)) is commonly used to define the ductile mode of failure (Sandhaas and van de Kuilen, 2013).

Holmberg et al. (1999) investigated the non-linear mechanical behaviour and analysis of wood and fibre materials. The study investigated the mechanical behavior of wood (loaded perpendicular to grain) from a micro level to macro level. Wood exhibits highly non-linear stressstrain behavior similar to other cellular solids, as shown in Figure 2.4. The mechanical properties for both the cellular structure and wood were classified and modeled using the irregular cell shape, the anisotropic layered structure of the cell walls and the periodic variations in density. Two approaches used in this study are continuum model and crushable foam model to define the material properties of wood subjected to compression. Using a homogenization procedure and the finite element method, the continuum properties were derived where the stiffness and shrinkage 
properties were determined. Therefore, the developed constitutive properties at different structural levels can be used in numerical simulations of the behavior of wood in different industrially related areas (Holmberg et al., 1999).

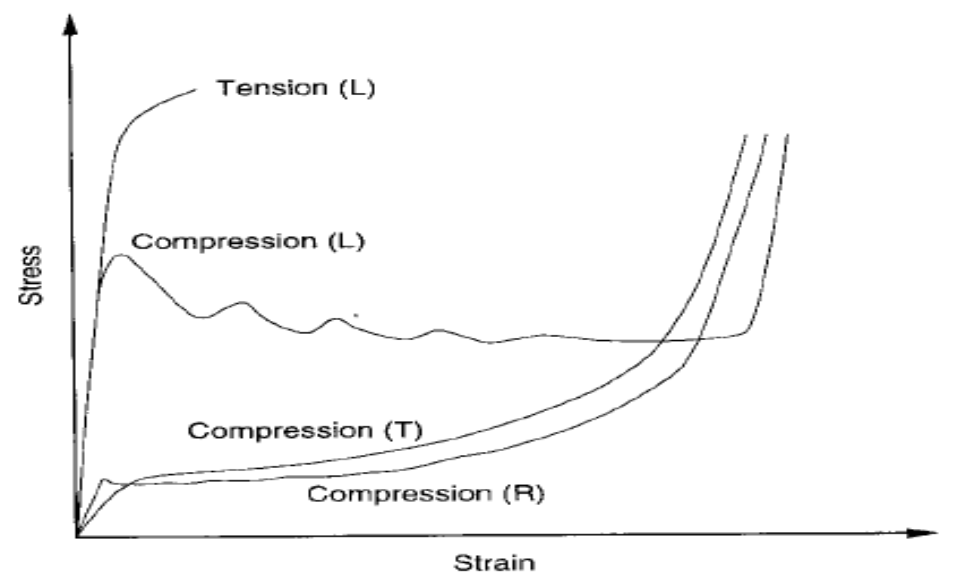

Figure 2.4 Typical stress-strain curves for wood loaded in compression in longitudinal (L), radial (R) and tangential (T) directions and for tension in the longitudinal direction (Holmberg et al., 1999)

A wide range of constitutive models to model the behaviour of timber that can be categorized to 1D, 2D and 3D have been developed over the last three decades. Among available orthotropic failure criteria implemented in the commercial software is the Hashin damage model that uses seven input parameters. It also has the potential to be used as for the non-linear behaviour of timber structures. The damage model assesses the interaction between stress components to evaluate various failure modes (Khorsandnia, 2013).

Ivanov et al. (2008) conducted experimental tests (Compaction tension (CT)) and finite element analysis to investigate the behavior of plywood elements in tension. The characteristic of the damages was initiated during the CT tests performed in different directions of plywood fibre orientation. The plywood CT elements were modelled using continuum shell elements and cohesive finite elements with damage evolution using Hashin criterion as the material constitutive law. The failure criterion is readily available in ABAQUS thus different strength values can be set in tension and compression along longitudinal and radial directions with different values of fracture energy. FEM results successfully validate the experimental behavior of plywood specimens and allow thorough analysis of the different types of damage development and interaction. It was concluded that the FEM of plywood is practical for its lay-up optimization and 
capable of developing large-scale simulations of computational models of plywood (Ivanov et al., 2008).

\subsubsection{Connectors}

The connection between the profiled steel sheet and dry board plays a vital role in the PSSDB system. Connectors are used to connect the dry board to the steel sheeting to form a composite unit. The screwed connection between the component layers is quick and easy yet, efficient and positive. Screws in the system transfer horizontal shear force between the board and the profiled steel sheeting. The degree of composite action, whether full or partial interaction, is determined based on the performance of the connections (type of screw and spacing) thus determining the stiffness of the structural composite unit. The capacity of a screw connection is calculated as the amount of shear force transferred per unit length of shear displacement by its shear modulus. Push out test determine the shear modulus and total shear capacity of the screw connections (Wan Badaruzzaman et al., 2003). Figure 2.5 shows the different types of fasteners and threaded products available to use as connectors in the composite panels.

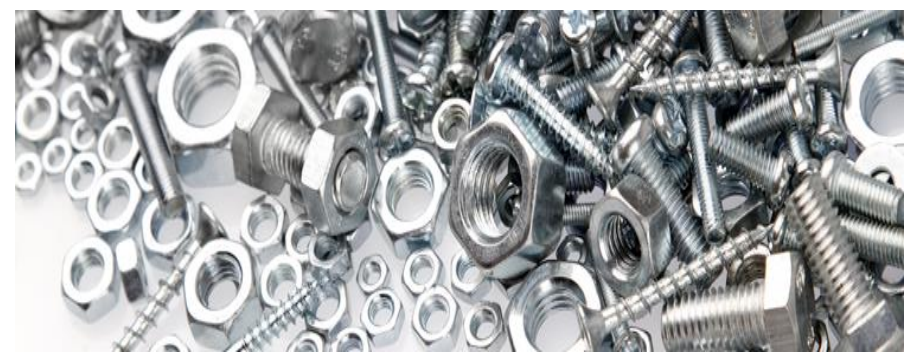

Figure 2.5 Fasteners and threaded products (Fastening House Inc, 2017)

\subsection{Structural Behavior of PSSDB Composite System}

Various researches have been conducted to understand the structural aspect of PSSDB panel when used as a replacement to the conventional flooring, walling and roofing system in building constructions. The lightweight of the panel makes it easy to be transported and assembled together by incompetent workers. The research works conducted by various scholars prove potential of PSSDB panels to be used for conventional flooring, walling and roofing system in building frameworks. It gives slender sections for mezzanine and domestic floors as flooring units while it gives exceptional axial, bending and racking resistance. The PSSDB system is efficient in resisting both combined in and out of plane actions, as folded plate roofs (Badaruzzaman, Ahmed, \& Rashid, 1996). Moreover, load bearing walls have proven to be structurally efficient and 
economical in transferring loads to the foundation and used in many major building projects. Each PSSDB component in the composite system has its own role where the profiled steel sheeting serves as tensile reinforcement and permanent formwork, while the dry-board provides a flat surface and improves the system stiffness, and the connectors ensures the composite action between the board and the steel sheeting.

\subsubsection{PSSDB as Flooring Unit}

Wright et al. (1989) first initiated the idea of dry-board floor system using profiled steel sheet. The proposed PSSDB flooring system was a replacement of timber joist flooring for small-scale domestic building. Research has been done to exploit the possible applications of the PSSDB system as a flooring unit. A total of nine tests were conducted using simply supported floors with different spans for three different types of profiled steel sheet (PMF60/0.9mm, PMF60/1.2mm and PMF100) along with two types of dry-boards (18mm-ply board and 18mm-chipboard) and fasteners (nails and self-drill self-tap screws) (Wright et al., 1989).

The PSSDB concept was further studied by Badaruzzaman and Wright (1994) and had successfully developed and marketed a structural composite system known as Bondek II (profiled steel sheeting manufactured by BHP Steel Building Products, Malaysia) Cemboard (dry board manufactured by Hume Cemboard Berhad, Malaysia) Composite Floor Panel (BCCFP) at University Kebansagan Malaysia (UKM) as shown in Figure 2.6. Besides investigating the structural performance of the BCCFP floors, other factors such as construction procedures and costing, fire resistance tests, waterproofing tests, vibration, thermal resistance, insulation and noise transmission behavior etc. were also investigated. Amongst the publications describing these aspects of the new BCCFP system are Ahmed (1996), Ahmed et al. (1996), Basri et al. (1998), Wan Badaruzzaman and Wright (1998), Ahmed (1999), Ahmed et al. (2000), Osman et al. (2000), Ismail et al.(2000), Wan Badaruzzaman et al. (2001), and Wan Badaruzzaman et al. (2002). Thus, these studies have led to the practical application of the composite BCCFP system in real buildings. Moreover, introducing a certain combination of under soffit, infill and topping materials makes the design more suitable for various fire rating requirements (Badaruzzaman et al. 2001). 

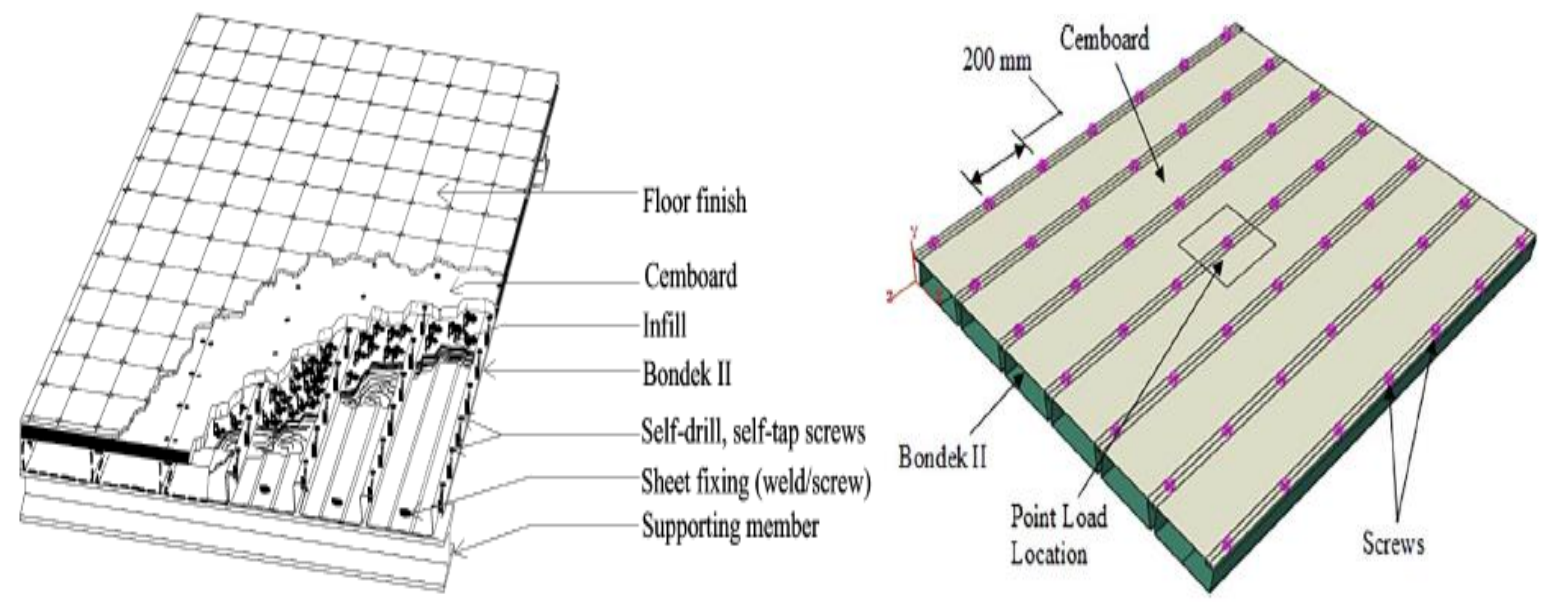

Figure 2.6 Structural components (left) and finite element model (right) of BCCFP panel system (Badaruzzaman et al., 2003)

The application of using different types of dry-boards with varying thickness as a structural component in a lightweight BCCFP system was investigated and reported that dry-boards play a dual role. Firstly, it provides a flat floor surface covering the corrugated profiled steel sheeting. Secondly, it plays a vital role in enhancing the stiffness and strength of the composite system. Moreover, the effect of varying screw spacing in the composite flooring panel was also studied, as shown in Figure 2.7. The test results show that the application of dry boards increases the flexural stiffness of the composite panel from $12.8 \%$ to $26.3 \%$ in comparison to the steel sheeting alone for the various tested samples. The addition of a dry board to the steel sheeting increased its moment capacity by $12.2 \%$ from $8.2 \mathrm{kNm} / \mathrm{m}$ with the steel sheet alone to $12.2 \mathrm{kNm} / \mathrm{m}$ of the typical BCCFP system (Badaruzzaman et al., 2003). 


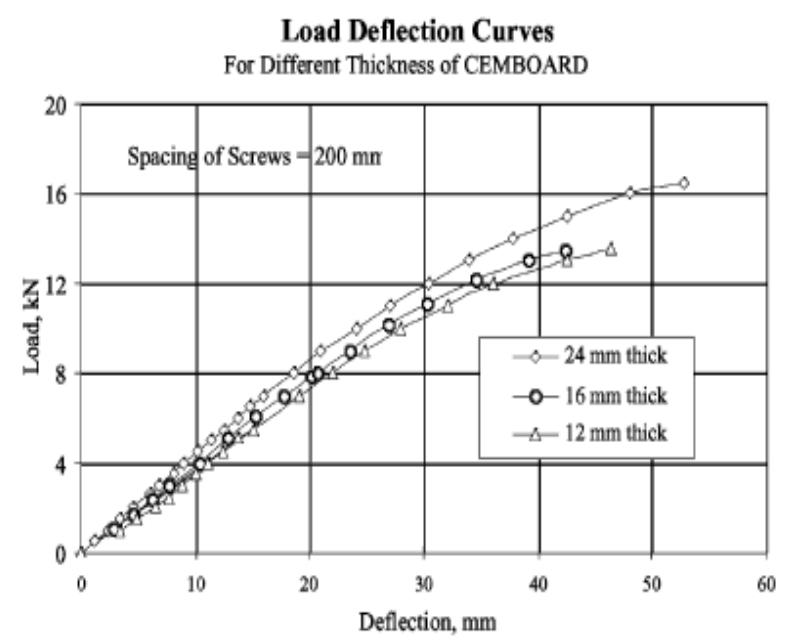

(a)

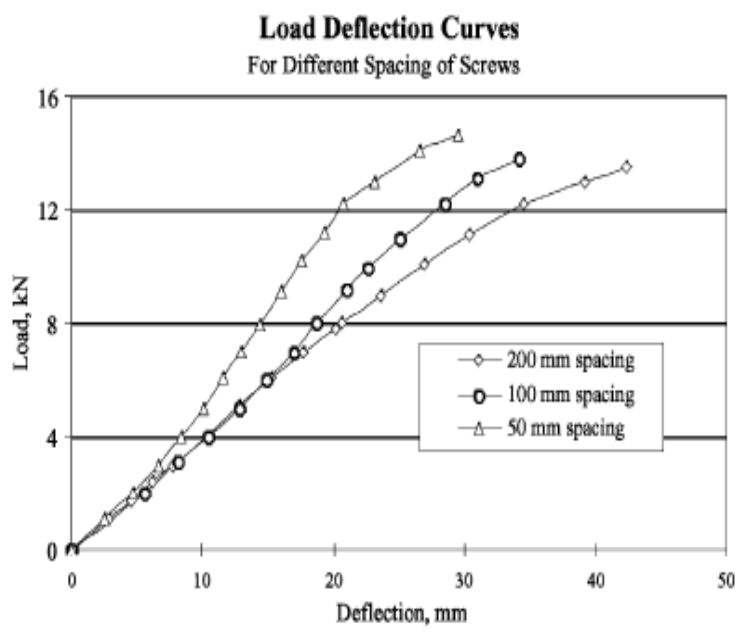

(b)

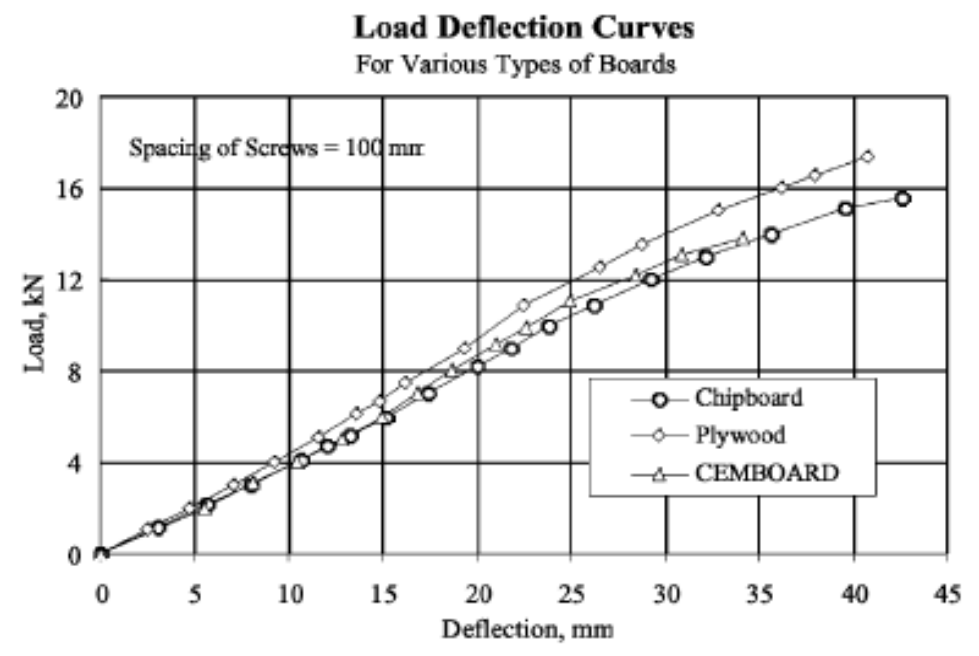

(c)

Figure 2.7 Flexural load-deflection response of BCCFP with (a) varying board thickness (b) connectors at different spacing (c) different types of boards (Badaruzzaman et al., 2003)

Ahmed et al. (2002) described the structural performance of two-way PSSDB panels. Experimental study as well as finite element modelling were performed to assess the two-way floor panels subjected to out-of-plane loading. Figure 2.8 shows the loading arrangement of the panel and a typical failed sample under loading. 


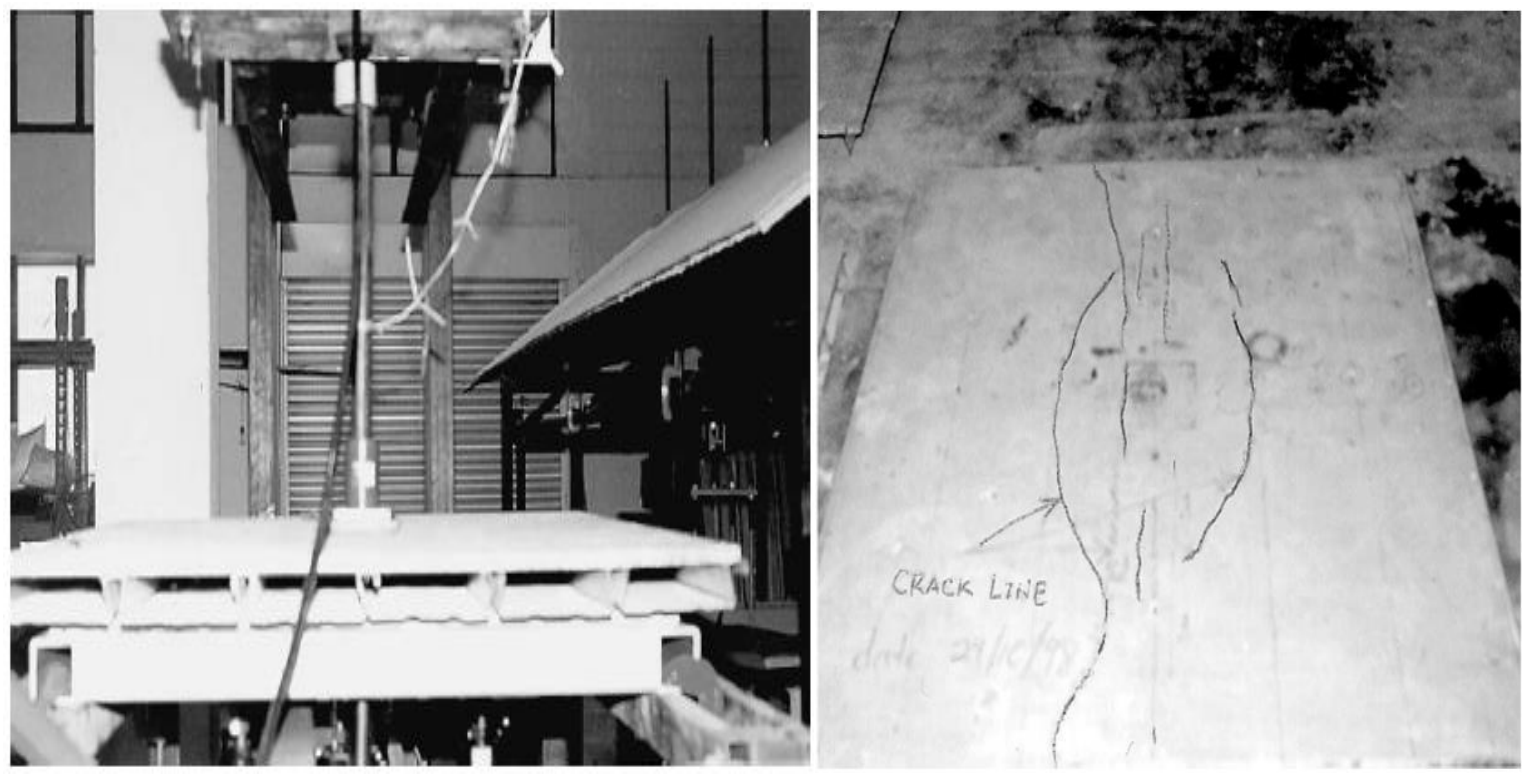

Figure 2.8 Loading arrangement of the panel (left) and typical failure of the specimen under loading (right) (Ahmed et al., 2002)

Analytical models have also been proposed to further verify the results obtained via finite element modelling Ahmed et al. (2002). The system consisting of profiled steel sheeting and dry-board connected by self-drilling, self-tapping screws were modelled as isotropic and orthotropic models using LUSAS FE software. In finite element analysis, the idealization of profiled steel sheet as an equivalent orthotropic plate of uniform thickness, was said to be capable of predicting its structural response. Moreover, dry board was modelled as an isotropic plate element and the connectors were modelled using "dummy" plate. Connectors play an important role in predicting the structural behavior of PSSDB panels or folded plate structures where the profiled steel sheet and board are assembled together. Providing "dummy" plates take into account the slips occurring between the two adjacent individual panels. Results obtained prove isotropic models to be more accurate when compared to the theoretical and experimental results. On the contrary, the orthotropic model displayed greater discrepancy of more than $30 \%$, indicating the need of further improvement. The equivalent orthotropic approach was found to be feasible for practical design purposes than the isotropic model as it is less tedious, requires less computer memory and computational time and is more conservative in predicting deflection values of two-way PSSDB panel. However, the implementation of this approach was found to be impractical for panels having very high rib spacing compared to the plate boundary dimension (Ahmed et al., 2002). 


\subsubsection{PSSDB as Folded Plate Roof Member}

Folded plate constructions are surface structures assembled by joining individual plane surfaces or plates to form a composite surface. This construction type has been widely used in the construction of long span roof systems due to its economy and interesting architectural appearance (Ahmed et al., 2000). Research work to study the behavior of structures formed by assembling a number of PSSDB panels into a folded plate configuration was first studied by Wan Badaruzzaman (1994). Innovative application of using a full-scale composite roof panel system was tested to replace the traditional form of roof construction. The PSSDB roofing system eradicates the roof trusses in buildings compared to the traditional roofing systems and materials. The system carries both the in-plane and out-of-plane bending and shear that results in a strong and efficient structure with several advantages over traditional forms (Ahmed et al., 2000). Figure 2.9 and Figure 2.10 show a PSSDB folded roof models tested.

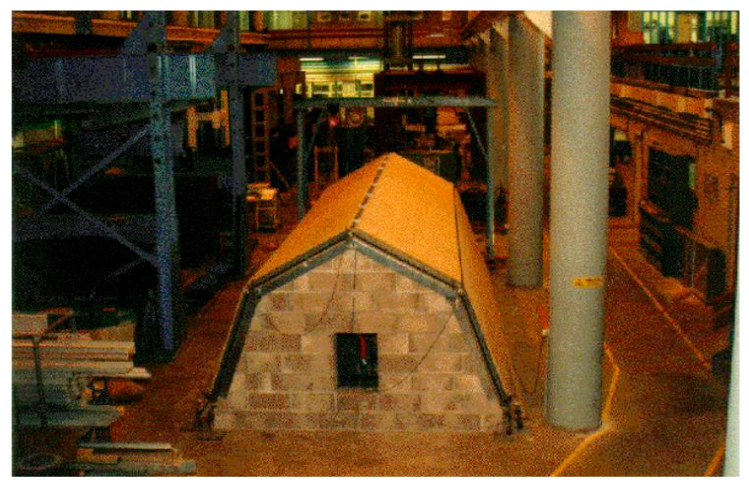

Figure 2.9 Full scale folded plate roof structure model tested by Wan Badaruzzaman (1994)

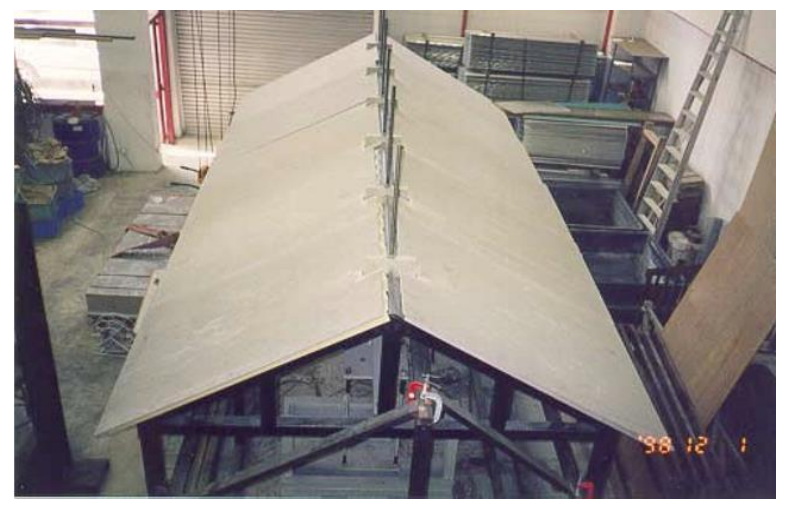

Figure 2.10 Complete model of PSSDB folded roof plate tested in the laboratory by Ahmed et al. (2000) 
Ahmed et al. (2000) conducted experimental and finite element studies to investigate the potential of the PSSDB folded plate structures considering two different support conditions along with both symmetrical and unsymmetrical loading conditions. Figure 2.11 illustrates the loading conditions.

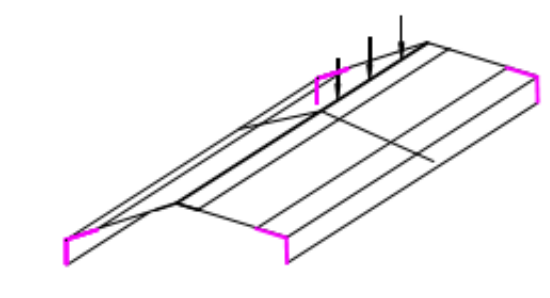

Unsymmetrical Loading in Case 2

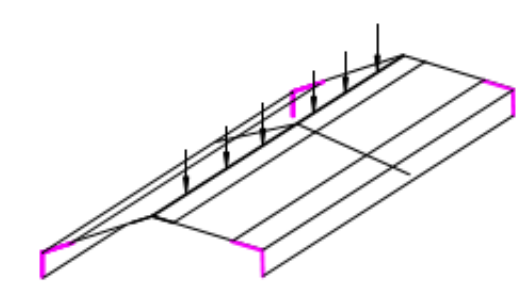

Symmetrical Loading in Case1

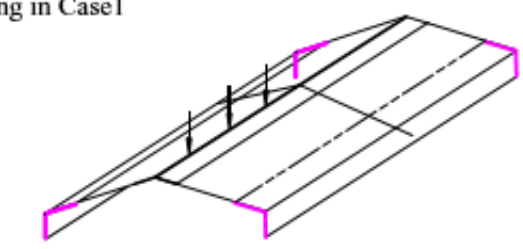

Unsymmetrical Loading in Case 3

Figure 2.11 Load conditions on model structures (Ahmed et al., 2000)

For the finite element study, the profiled steel sheeting was modelled as an equivalent orthotropic plate to reduce the computer time and memory requirements. In order to include the biaxial shear deformation two directional "dummy" plate elements was proposed in modelling the connections between the PSS and dry-board. Compared to the simple support conditions, it was observed that fixing the angle ridge plates at the end frame supports reduced the mid span central ridge deflections by approximately $25 \%$. As a result, the rigid plates were recommended to be fixed to the end frames to stiffen the whole structure for the practical use of folded plate structures. The central deflection of the model was found to reduce by $39.7 \%$ and $34.7 \%$ for free and fixed supported connections, respectively due to the addition of the dry-board in the PSSDB system. Subsequently, Ahmad and Badaruzzaman (2002) suggested an improvement to the previously proposed model that led to a reduction in the percentage discrepancy from $59.31 \%$ to $33.95 \%$. The folded plate roof model consisted of assembled PSSDB panels that were connected individually using ridge connection plates. The newly proposed model suggested the implementation of modeling the profiled steel sheet as an isotropic plate element and model the connections using "joint" elements instead of "dummy" plates. Despite the slight overestimation of the real deflections, the new model was able to predict satisfactory structural behavior and displayed the potential to be used in practice of the PSSDB folded plate model (Ahmed et al., 2000). 
Awang and Badaruzzaman (2009) extended the study with an innovative idea to assess the bending behavior of a "reversed" PSSDB panel for the application in a roofing system under an out-of plane uniform load. Figure 2.12 shows the test set-up of the PSSDB roof system.

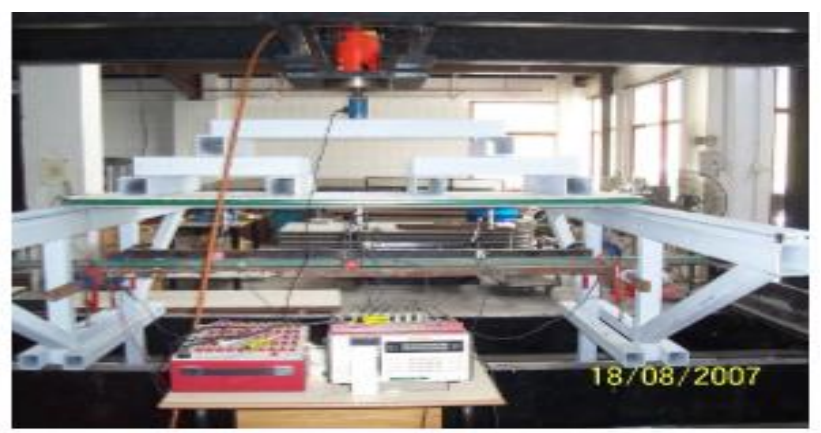

Figure 2.12 A typical test set-up (Awang and Badaruzzaman, 2010)

The stiffness value in the reversed position of the panel system was found out to be identical to the one in normal position. However, in the reversed position, the cross-sectional area of the PSS subjected to compressive bending stresses was greater than the sample in the normal direction due to the change in position of the neutral axis of the composite section. It was noted that the maximum and ultimate loads for the reversed panel was reduced due to local buckling of the PSS under compressive stress (Figure 2.13). Moreover, the application of timber strip in the PSSDB roof panel system enhanced the load bearing structural system as it increased the flexural stiffness of the composite PSSDB roof panel without the timber strip by $35.8 \%$. Therefore, it was concluded that this composite roof panel system reduced the self-weight of the component of the structure. It was proven to be economical and environmental friendly by removing the skeletal internal bracing of normal roof truss construction (Awang and Badaruzzaman, 2009).

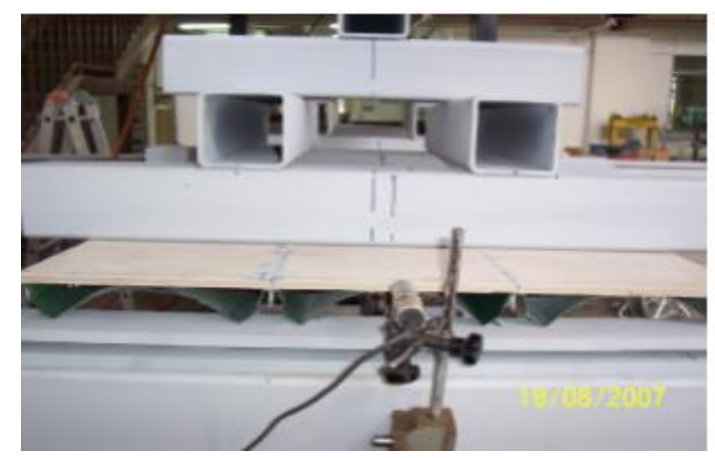

Figure 2.13 Buckling of lower flange of the profiled steel sheet (Awang and Badaruzzaman, 2009) 
Further studies conducted on PSSDB panels to form the complete roof of two school modules were reported by Awang and Badaruzzaman (2011). The deformation characteristics of the panels were theoretically and experimentally tested under uniform top load. Based on the finite element method (FEM), theoretical model of roof system was proposed. The proposed FEM was validated with full scale experimental tests on the actual roof system. The full scale PSSDB roof system was found to exceed the deflection limit under service load. It was recommended that employing stiffer PSS, different types of boards, closer screw spacing or reducing the roof span would improve the composite system. The elevations of the school module where the roof has been installed is shown in Figure 2.14 (Awang and Badaruzzaman, 2011).

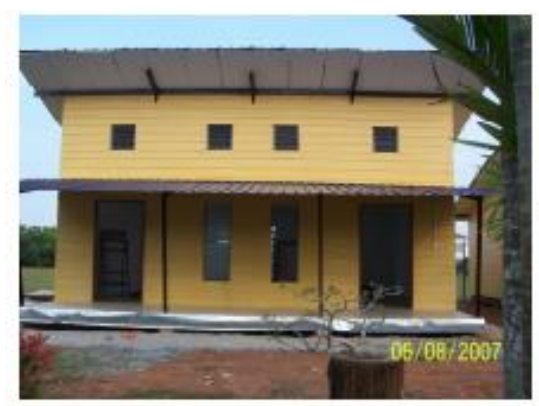

(a) Front elevation

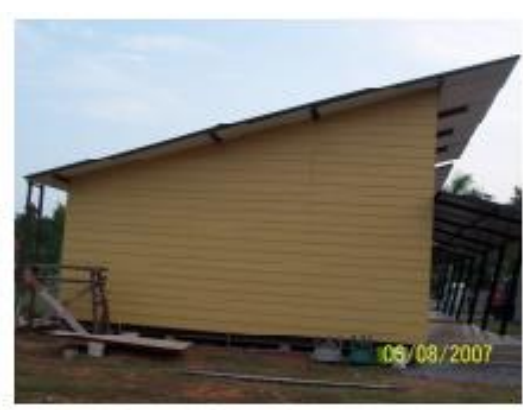

(b) Side elevation

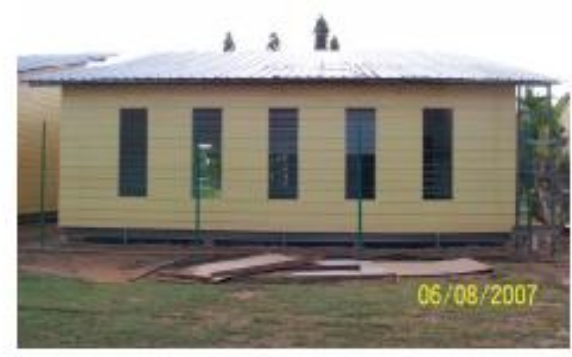

(c) Rear elevation

Figure 2.14 Plan and elevation view of the PSSDB roof in the school module (Awang and Badaruzzaman, 2011)

\subsubsection{PSSDB as Walling Unit}

Different innovative panel systems had been developed and described in earlier publications by Wright and. Gallocher (1995), Hossain and Wright (1998), and McKinley and Boswell (2002). In the building construction, load bearing wall panels are structurally efficient and economical in transferring loads to the foundation. It has been used to a great extent on many major construction projects; especially in high-rise residential blocks. Research works have been carried out by Jekale 
(1992) and Mengesha (1992) to study the behavior of PSSDB panel as a walling unit. PSSDB composite panels have good potential to be exploited as load bearing wall panels. Besides being lightweight, it is able to fulfill the general requirements in constructing load-bearing structures in terms of the load-carrying capacity, stiffness and durability (Hamzah and Wan Badaruzzaman, 2009). An extensive research on the behavior of cold-formed steel lined with plasterboard for both load bearing and non-load bearing wall for residential and commercial buildings (Telue and Mahendran 2001, Xie and Chapman 2006, Majid and Wan Badaruzzaman, 2013).

A novel form of composite walling system consisting of double skinned steel sheet panel with concrete-infill was investigated by Hossain and Wright (1998). Small-scale model tests were tested to study the structural behavior of the composite wall under in-plane shear and explore its potential to be used as a lateral load resisting system. The results for small-scale model tests and behavioral aspects of the composite wall to be used as a lateral load resisting system were based on load-deflection response, strength, stiffness, failure modes, strain condition and sheet-concrete interaction. The effect of modes application of load either through both steel and concrete or through concrete only on the behavior of composite wall was investigated. Moreover, analytical models for the shear strength and stiffness of the composite walls was developed and the performance of the design equations was validated with those obtained by experimental results. Figure 2.15 shows a schematic drawing of the composite walling system (Hossain and Wright, 1998).

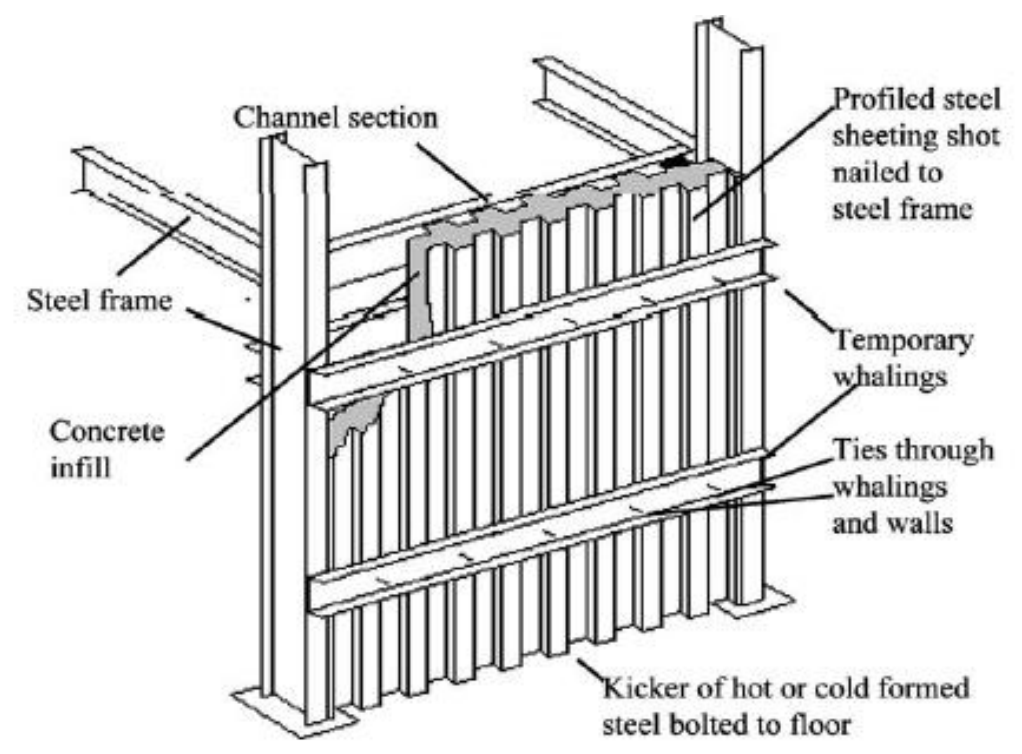

Figure 2.15 Schematic diagram of a composite walling system (Hossain and Wright, 2004) 
The combination of the profiled steel sheet and dry-board creates complete and incomplete interactions. The dry-board component is said to improve the strength and stiffness of PSS (Shokory and Badaruzzaman, 2000). Mengesha (1992) conducted a detailed study on the incomplete interaction between the PSS and DB, where the DB component enhanced the PSS from local buckling and curling of flange when subjected to compressive axial loading. Self-tapping self-driving screws were found to carry only a small portion of the compressive load where local buckling is evident when connected at discrete positions in the composite panel. The PSSDB panel can either fail due to the components of the wall panel or its connection. Furthermore, failure in the PSS component may occur due to local buckling, if the yield stress reached the top flange section or at the intersection between the flange and the web. Local buckling failure causes bending stiffness in the transverse direction and is likely to occur due to bonding defects or loose connections. Meanwhile, failure in the DB component may occur through longitudinal compressive action, transverse bending action, tension perpendicular to the DB surface or even buckling of the DB. However, the screwed connections can either fail in shear or tension.

In thin-walled elements, the profile shape of the steel sheet changes the effectiveness of the cross-section of the wall. The thinner the PSS, the more susceptible it is to local buckling. This phenomenon was investigated under effective width concept in determining the bearing capacity of the structure theoretically. It was observed when the load increased beyond the buckling load then the deformation changed in magnitude and shape. The change in deformation is linked to the axial stiffness in the steel sheet. Rhodes (2003) essentially considered degrees of freedom of the buckled deformed shape in the analysis. Vafa et al. (2013) examined the effect of varying the cover width of the panel to strength-to-width ratio. The study suggested that optimizing the cross-section of the PSS would enhance the PSSDB composite system.

A study conducted by Majid and Badaruzzaman (2013), assessed the structural performance of twelve full scaled PSSDB wall panel system under axial load using locally available materials such as PEVA45, Cliplock 610 and Primaflex dry-board. Double and single sheathed composite panels consisting of profiled steel sheet sandwiched between dry-boards connected by screws on both sides were used for this study. These tests were conducted until failure to investigate the maximum load the composite wall can sustain and to assess the behavior of both the profile steel sheet and dry board. The composite structure consisted of profiled steel sheet and dry board sheathed at both sides with a series of screws. The experimental results prove that the proposed 
composite wall panel display good load bearing capacity as a wall unit. Results display that the composite panel with PEVA45 at screw spacing of $200 \mathrm{~mm}$ sustained load of $62 \%$ higher than the wall panel assembled with Cliplock 610. Moreover, the strength of the double sheathed with PEVA45 was increased by $31 \%$ compared to that of the single sheathed PSSDB panels. Whereas, the strength capacity for the double sheathed panel with Cliplock 610 was almost $37 \%$ higher than that of the single sheathed panels. The profiled steel sheet played a vital role in sustaining the axial load whereas the dry board was found to carry a small portion of the load as well as delay the lateral buckling. The local buckling of the profiled steel sheet is shown in Figures 2.16(a-c), while Figures 2.16(d-f) display failure that occurred in the form of transverse cracks at mid-height of the dry-board (Majid \& Badaruzzaman, 2013).

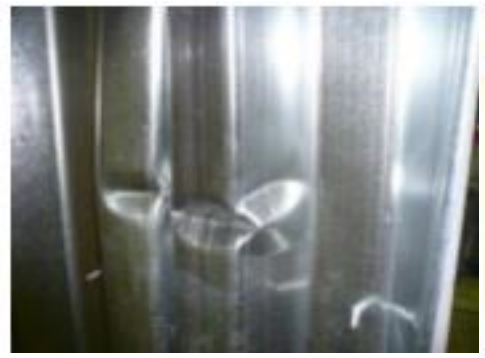

(a)

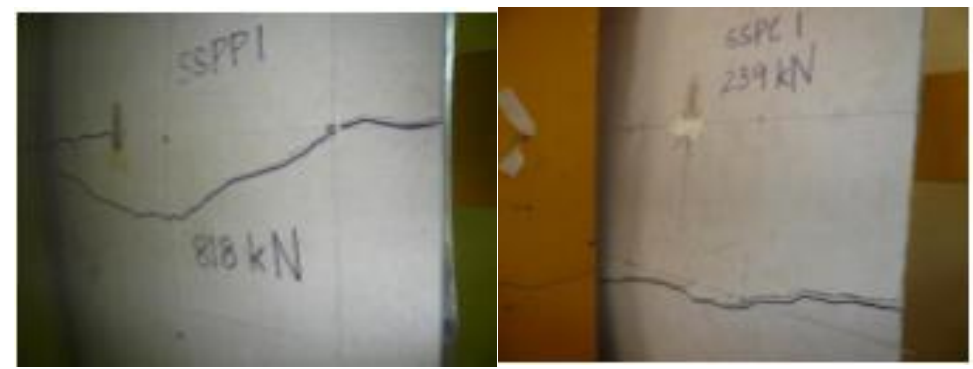

(d)

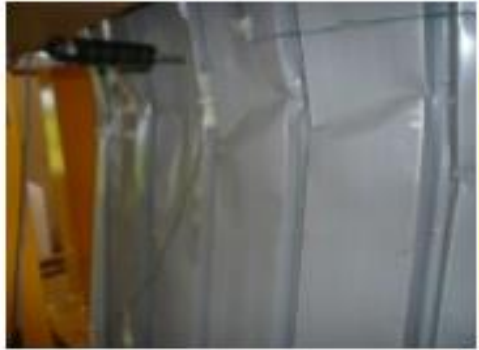

(b)

(e)

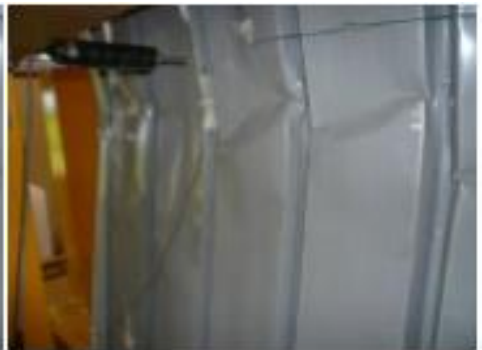

(c)

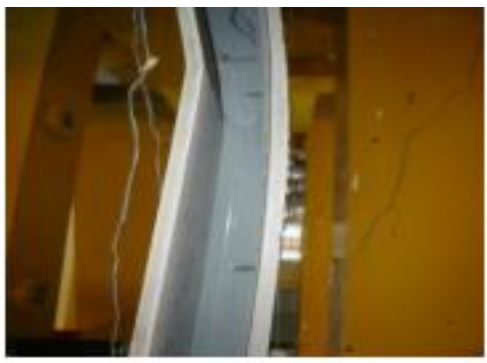

(f)

Figure 2.16 Mode of failure of PSS and dry board of the double sheathed composite PSSDB Wall Panel System (Majid \& Badaruzzaman, 2013).

Hamzah and Badaruzzaman (2009) conducted a study to determine the effect of screw spacing in order to evaluate the structural performance of the PSSDB wall panel under axial compressive loading using finite element analysis. The $78 \mathrm{~mm}$ thick wall panels are sized $3000 \mathrm{~mm}$ by $3000 \mathrm{~mm}$ with a square opening of $1200 \mathrm{~mm}$ by $1200 \mathrm{~mm}$, and butt joints located vertically in the dry boards. The screw spacing chosen for the study ranged between $100 \mathrm{~mm}$ to $500 \mathrm{~mm}$, with an addition of $100 \mathrm{~mm}$ in every individual model. The results show a single curvature deformation 
profile of the PSSDB wall panel and that maximum lateral displacement was observed at twothirds wall panel height and critical sections at the upper corners of the square opening. Results obtained via finite element analysis of the PSSDB walls, display that screw spacing of $200 \mathrm{~mm}$ possesses an ideal arrangement. Figure 2.17 shows the failure of the panel at the corners of the opening during the experiment. Figure 2.18 illustrates that both vertical and horizontal axial deflection increased with the increase in connector spacing from $100 \mathrm{~mm}$ to $500 \mathrm{~mm}$ (Hamzah \& Badaruzzaman, 2009).
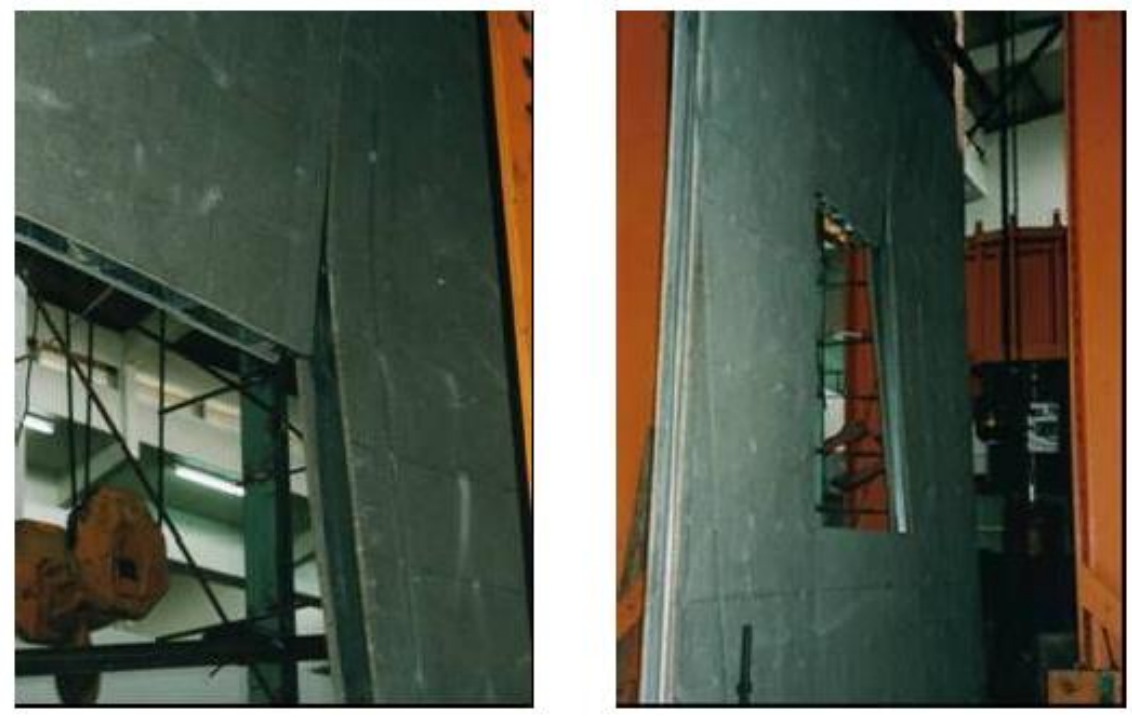

Figure 2.17 Failure at the corner of opening during experiment (Hamzah \& Badaruzzaman, 2009)

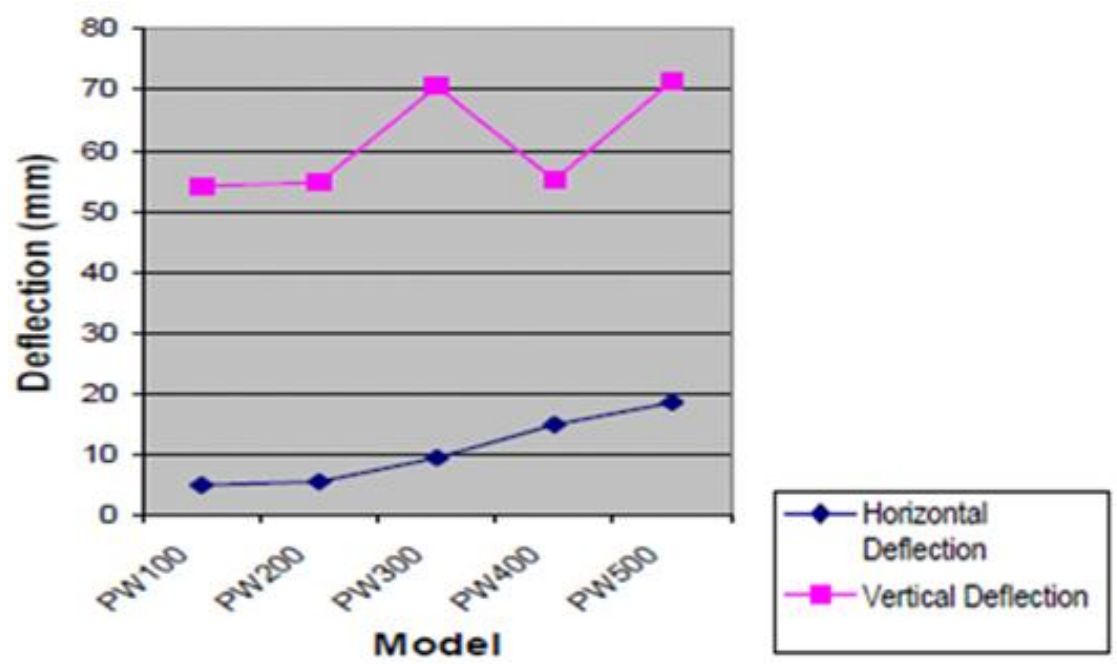

Figure 2.18 Deflection vs. screw spacing for the models (Hamzah and Wan Badaruzzaman 2002) 
The edge distance of $100 \mathrm{~mm}$ is said to be practical as it has an effect on the structural performance of the composite wall panel system. Local buckling failure was initiated due to the imperfection of the profile in PSS. Consequently, critical elastic stress occurred prior to the overall buckling failure of the panel. Furthermore, the butt joint present in the dry-board distorted the stress distribution above the opening from being transferred to the edges of the opening, thus affecting the structural behavior of PSSDB panel (Hamzah \& Badaruzzaman, 2009).

\subsubsection{PSSDB Panels with Concrete Infill}

The effect of introducing infill materials on the structural performance of the composite PSSDB floor system was explored and reported by several researchers (Shodiq 2004, Wan Badaruzzaman et al. 2002, Seraji et al. 2013, Jaffar et al. 2016). Very limited research was conducted to assess the structural performance of PSSDB wall panels with infill materials (Badaruzzaman et al. 2004). Experimental results of Badaruzzaman et al. (2002) conclude that concrete infill (grade 30) have significant contribution in increasing the stiffness and strength of the PSSDB floor panels. Followed by the research conducted by Shodiq (2004), where he demonstrated that the stiffness and strength of the PSSDB floor system with normal concrete infill was $20.2 \%$ and $61.0 \%$ higher compared to those without infill. The concrete infill increases the stiffness and its effect on delaying the onset of local buckling of the upper flange under compression of the PSS.

Seraji et al. (2014) conducted non-linear finite element analysis using ABAQUS to study the effect of membrane action in improving the flexural capacity in the PSSDB floor system. The composite system with concrete infill for continuous and practical spans, with and without topping concrete were investigated. The simulation model was developed based on the testing set-up as illustrated in Figure 2.19, to apply displacement control loading.
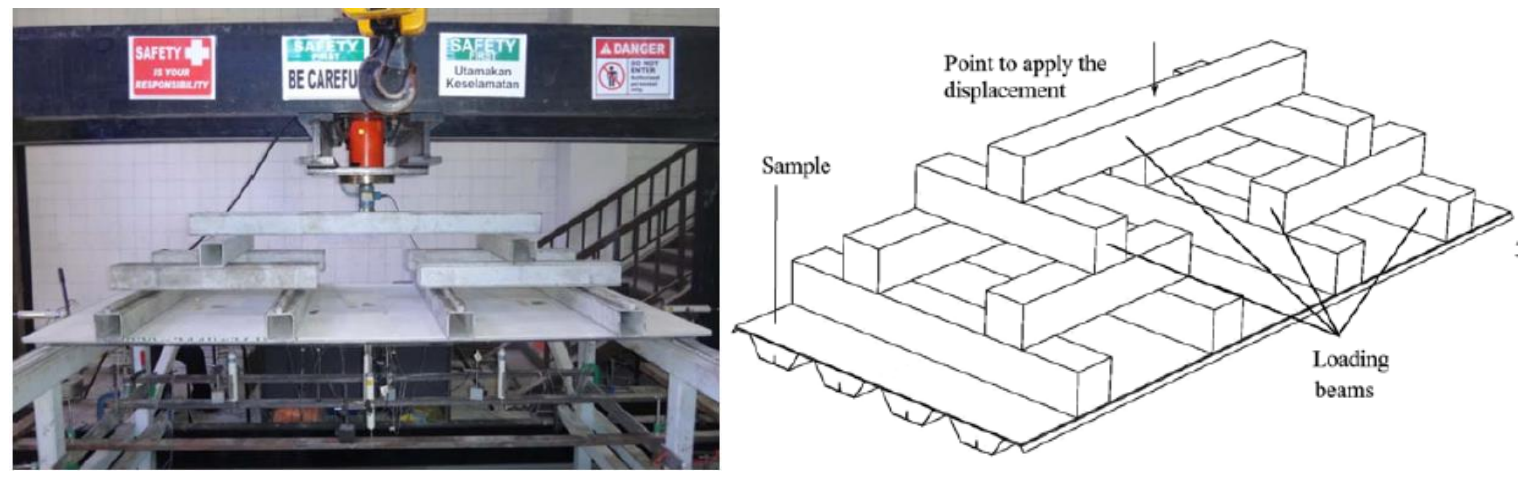

Figure 2.19 Experimental test set-up (left) and FEM loading system (right) (Seraji et al., 2014) 
The outcome of the study imposed that applying the membrane action theory in the PSSDB slab, predicts higher flexural capacity up to more than three times. However, restricting the translation and rotation of the slab ends induces compressive membrane action which depends on the span length and slab thickness. Preventing the in-plane movement in the slab ends reduced the vertical deflection in the central region of the slab and early appearance of local buckling in the top flange of the steel sheeting. Analysis results indicate that the arching action in the slab in first steps of loading causes the drastic improvement in the deflection limit load of the slab in serviceability limit state deflection (Seraji et al., 2014).

Further research conducted by Jaffar et al. (2016) on PSSDB floor panels of various configuration with an eco-friendly infill material (without cement content) known as geo-polymer concrete as an alternative to the previously adopted normal concrete. The study emphasized its effect on the strength and stiffness of PSSDB floor system. The tests were performed on various full-size and half-size dry board PSSDB floor models, under uniformly distributed transverse loads. The structural performance (panel strength, infill contact stiffness and mid-span deflection) of the PSSDB floor system was influenced by geo-polymer concrete infill and dry board size. Results show that the panels with geo-polymer concrete infill with half-size dry board (HFGBC) have $43 \%$ higher rigidity and $12 \%$ rise in ultimate load compared to the panels with full size dry board with normal concrete (FBNC) (Figure 2.15). This was due to better natural adhesion or bonding in between the geo-polymer concrete with the dry board and profiled steel sheet. Moreover, experimental tests were further validated by finite element analysis of the PSSDB floor panels. Figure 2.20 shows similar experimental and FEM failure pattern, where local buckling occurs at the top flanges and part of the webs of the PSS within the area of the mid-span (Figure 2.21). Figure 2.22 shows the effect of the slip of the infill at one end of the sample for both the experiment and FEM (Jaffar et al., 2016). 

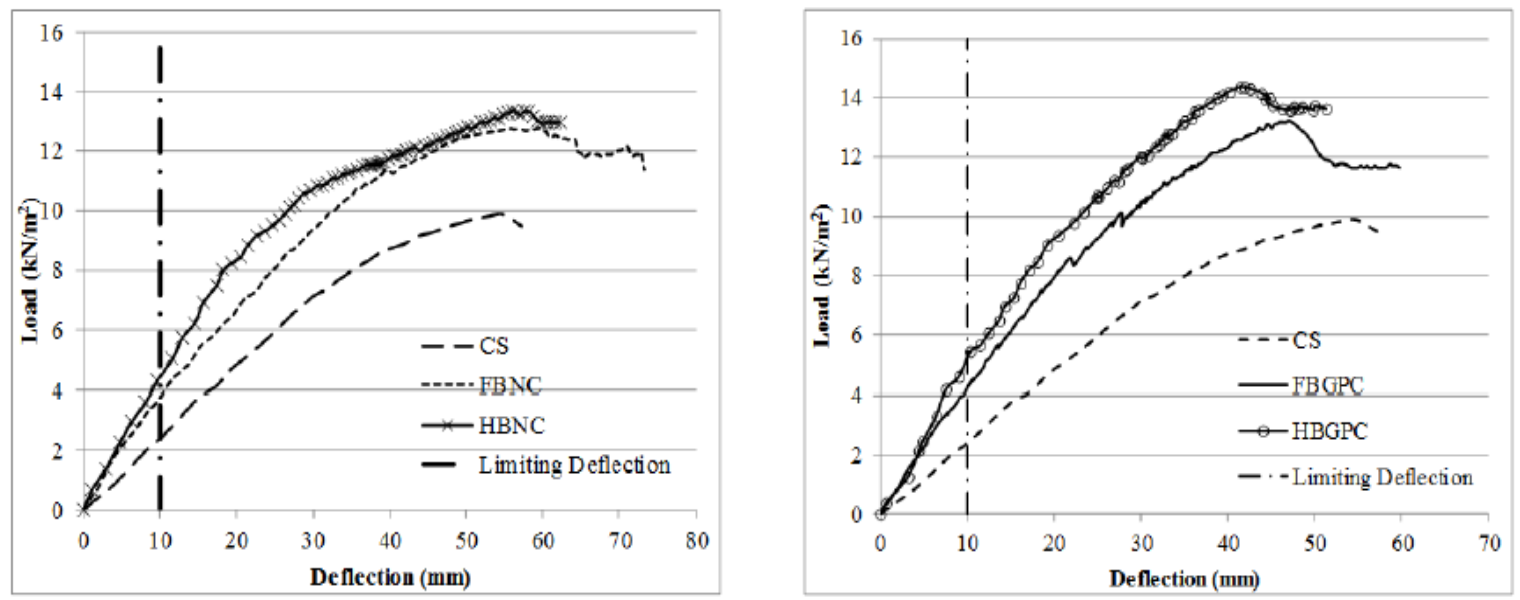

Figure 2.20 Load-deflection response for the control sample (CS) vs. (a) different normal concrete panels and (b) geopolymer concrete panels (Jaffar et al., 2016).
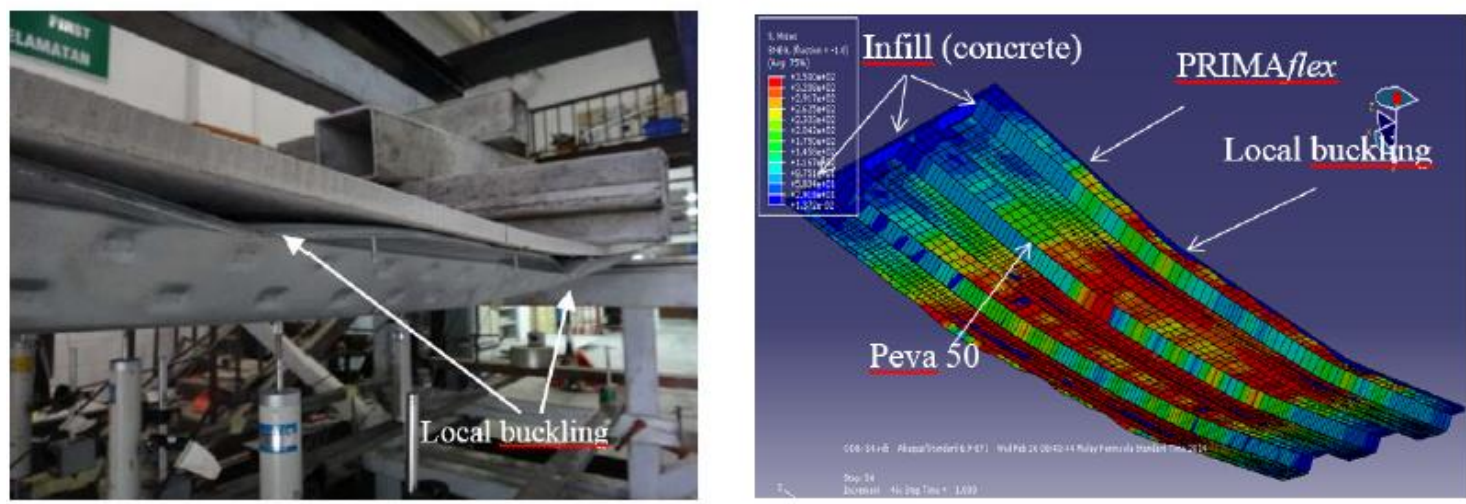

Figure 2.21 Local buckling of PSS (Jaffar et al., 2016)
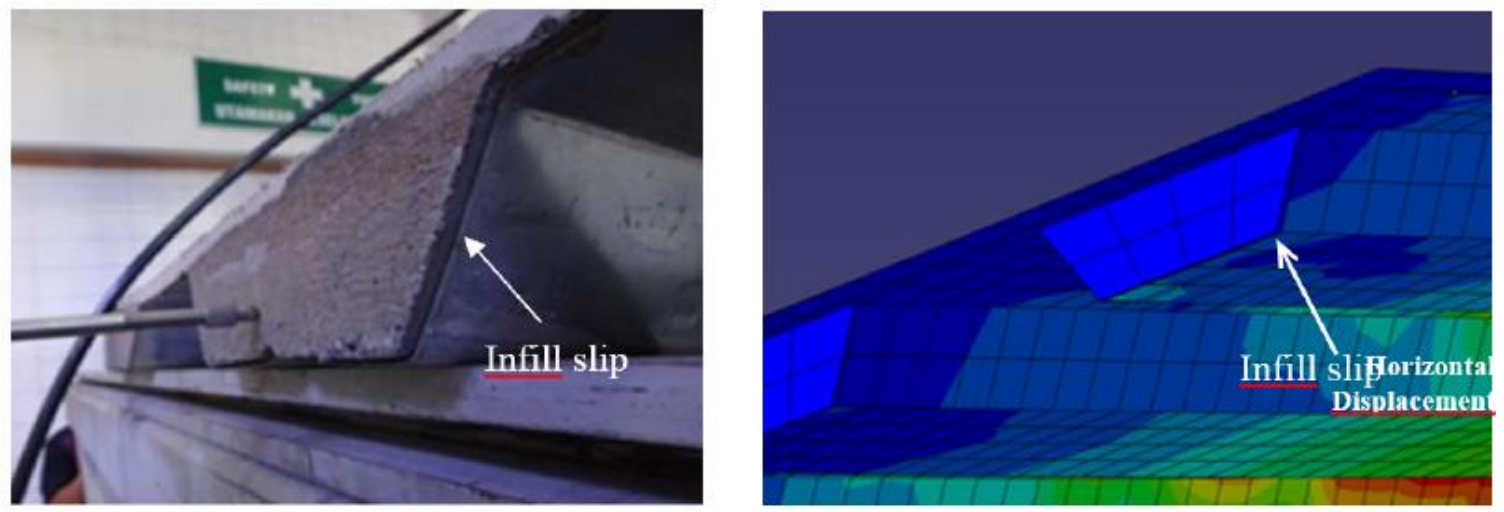

Figure 2.22 Experimental Model and FEM displaying horizontal slip of PSSDB infill (Jaffar et al., 2016) 
Experimental tests to assess the load bearing capacity of PSSDB wall panels with and without concrete infill was conducted and reported by Badaruzzaman et al. (2004). The PSSDB system consisted of $0.48 \mathrm{~mm}$ thick Ajiya Cliplock attached to $10 \mathrm{~mm}$ thick cemboard on one side and $10 \mathrm{~mm}$ thick cemplank on the other side via self-drilling, self-tapping screws at $200 \mathrm{~mm}$ center to center as shown in Figure 2.23. Polystyrene mortar was used as in-fill material in the tested panels.

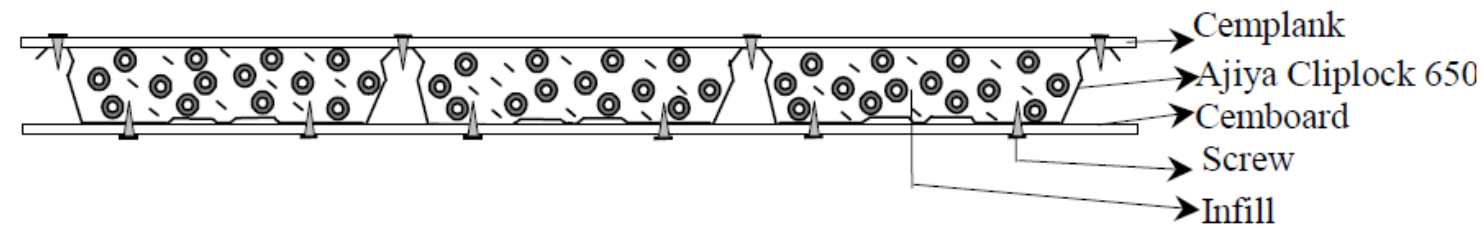

Figure 2.23 Cross-section of the tested PSSDB panel (Badaruzzaman et al., 2004)

Results obtained prove that the wall panels with infill material can sustain an ultimate load 5 times more than that of the panels without infill materials. Table 2.1 shows that the spacing of the screws play a vital role in increasing or decreasing the strength of the composite panels without infill material compared to those with an infill material. This phenomenon occurs because the strength of the panels without infill material solely depend on the interaction between the PSSDB components provided by the screwed connections. However, some degree of interaction exists in the panels with infill material by the natural bonding of the polystyrene mortar with cemplank and steel sheeting. Figure 2.24 shows a typical section of the composite panel after failure (Badaruzzaman et al., 2004).

Table 2.1 Axial load capacity of PSSDB panels with and without in-fill

\begin{tabular}{|l|c|c|c|}
\hline Connector & \multicolumn{2}{|l|}{ PSSDB Wall Samples } & \multirow{2}{*}{ Remarks } \\
\hline Screw spacing & $\begin{array}{c}\text { without } \\
\text { infill concrete }\end{array}$ & $\begin{array}{c}\text { with } \\
\text { infill concrete }\end{array}$ \\
\hline & Load $(\mathrm{kN})$ & Load $(\mathrm{kN})$ & \\
\hline At 2 middle ribs & 28 & 158.3 & Increase in strength by $60 \%$ \\
\hline At every rib & 44.8 & 182.0 & Increase in strength by $15 \%$ \\
\hline
\end{tabular}




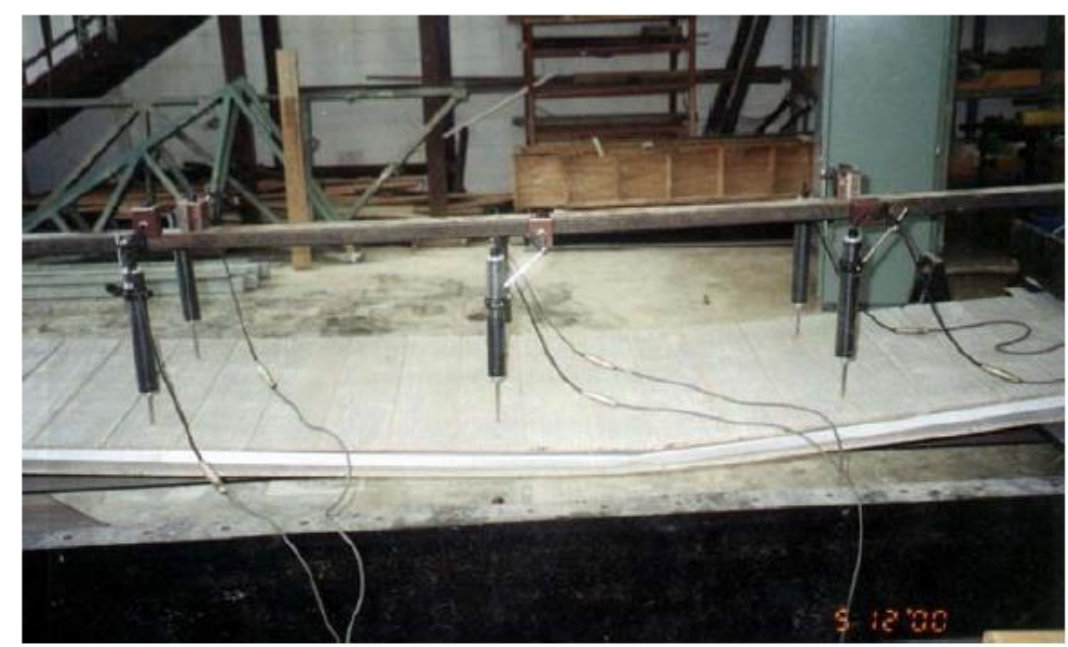

Figure 2.24 Typical sample failure mode of the concrete infilled PSSDB wall panel

(Badaruzzaman et al., 2004)

The research was extended by Shakeel (2012) and Hossain \& Shakeel (2012) at Ryerson University to study the axial load behavior of PSSDB wall panels with and without an infill material known as engineered cementitious composite (ECC). The structural performance of eight tested wall panels with and without concrete infill (ECC) having varying geometric properties and connector spacing were investigated based on axial strength, load-deformation response, stiffness, stress-strain characteristics and failure modes. Moreover, analytical models were developed to determine the axial load capacity and interaction between the components of the PSSDB walls. The results indicate that that decreasing the screw spacing significantly improved the load bearing capacity of the composite panels by $63 \%$ and $53 \%$, respectively for panels with and without concrete infill. The effect of the screwed connection on the axial strength was more evident in panels without infill rather than the infilled panels. Besides, the presence of ECC infill was found to increase the ultimate load and buckling load by $98 \%$ to $138 \%$, and $190 \%$ to $233 \%$, respectively when compared to panels without infill. The load-deflection response and failure modes of the PSSDB wall panels having constant rows of spacers with and without concrete infill are shown in Figure 2.25 and Figure 2.26, correspondingly. Figure 2.27 shows that the increase in the heightto-width ratio $(\mathrm{h} / \mathrm{w})$ and connector-to-spacing ratio $(\mathrm{s} / \mathrm{h})$ decreases the ultimate and buckling load capacity of the panels. 

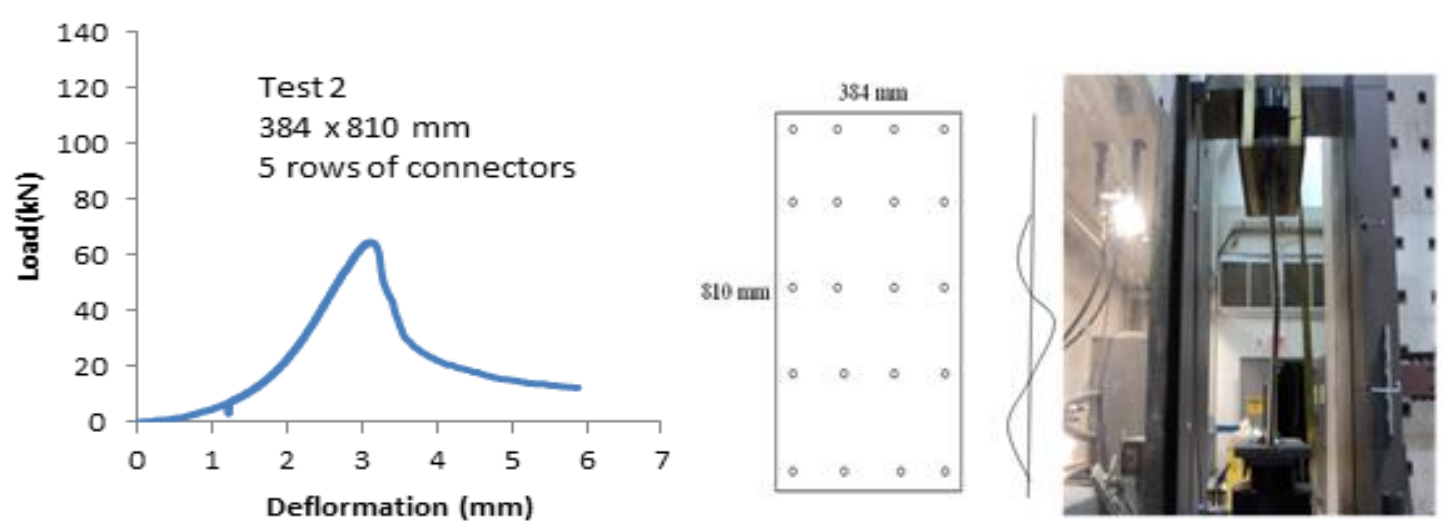

Figure 2.25 Load-deflection response and failure mode of PSSDB panel without concrete infill

(Shakeel, 2012)
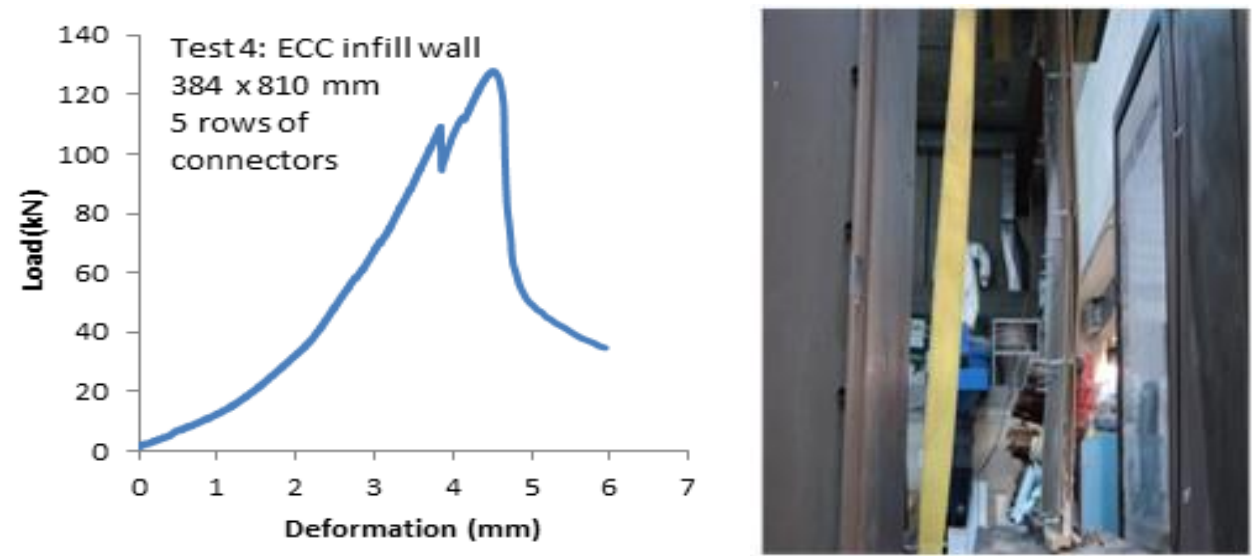

Figure 2.26 Load-deflection response and failure mode of PSSDB panel with ECC infill

(Shakeel, 2012)

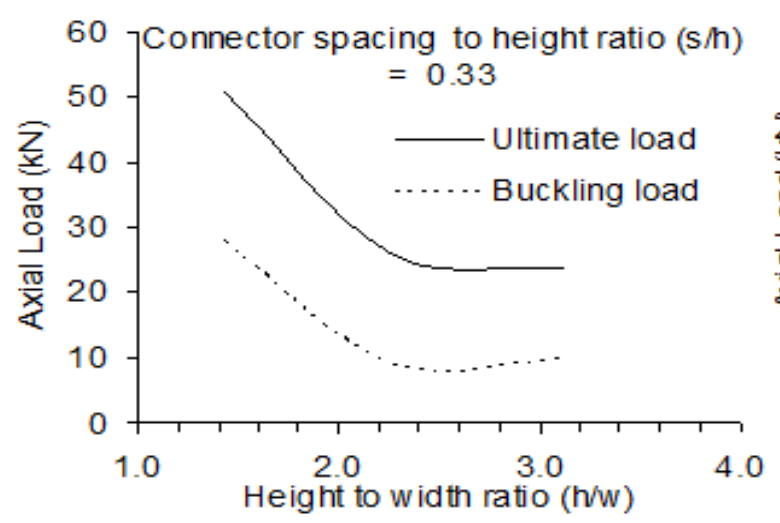

(a)

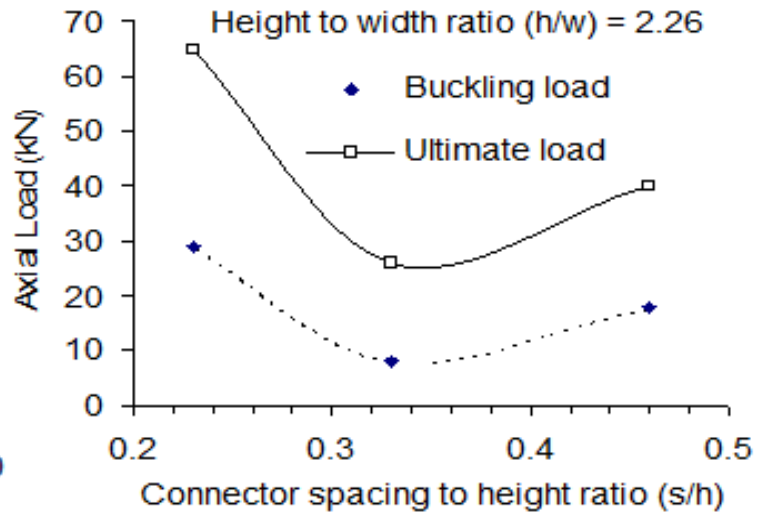

(b)

Figure 2.27 Effect of (a) h/w ratio and (b) s/h ratio on axial load (Shakeel, 2012; Hossain and Shakeel 2012) 
Lastly, the developed theoretical models were found to be dependent on the failure modes, which in turn was dependent on the $\mathrm{h} / \mathrm{w}$ and $\mathrm{s} / \mathrm{h}$ ratio. Increase in $\mathrm{s} / \mathrm{h}$ and $\mathrm{h} / \mathrm{w}$ was said to reduce the interaction between the components due to local buckling and instability, thus reducing the axial load capacity (Figure 2.28). Furthermore, Figure 2.28 also illustrates that the presence of ECC infill improved the interaction between the components (PSS and DB), thus increasing the buckling load capacity accompanied by reduced local instability. Therefore, the study concluded that the tested PSSDB axial walls are feasible and have the potential to be used in the modern industrialized construction (Shakeel, 2012; Hossain and Shakeel 2012)
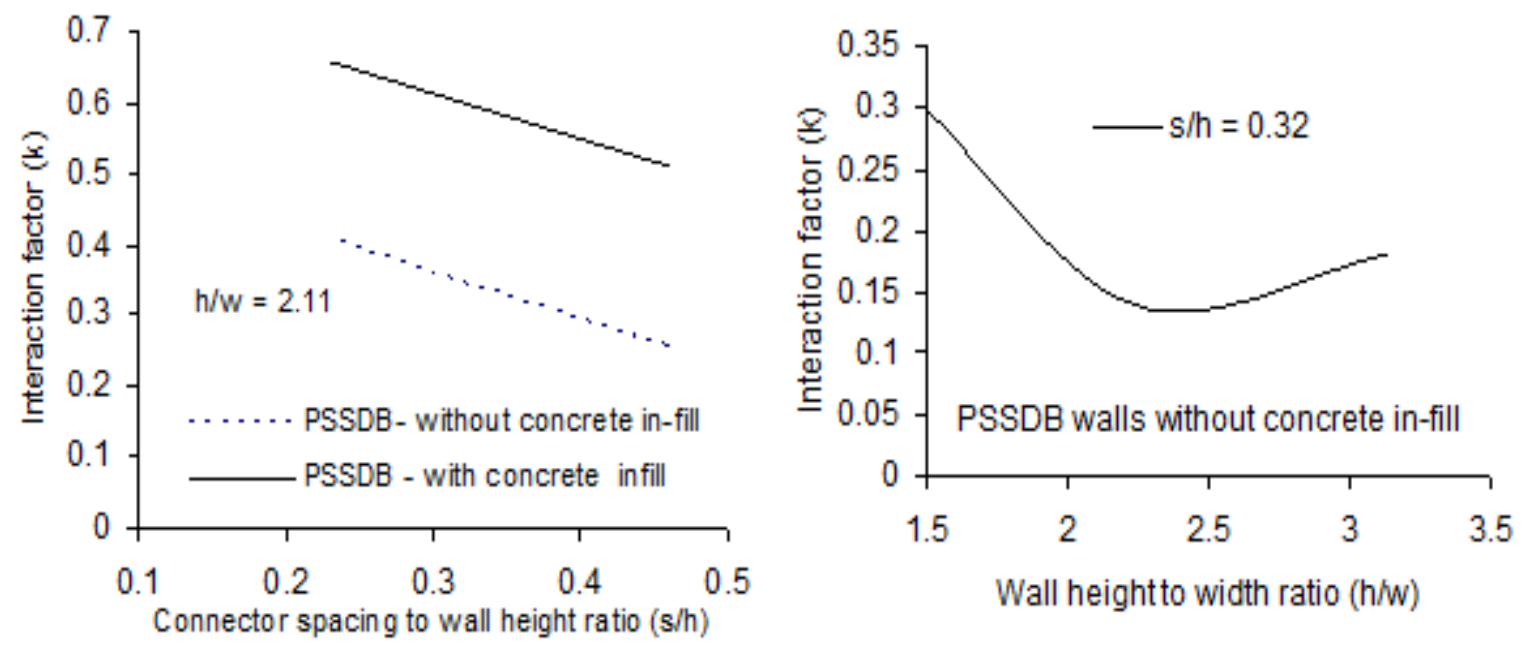

Figure 2.28 Interaction factor for PSSDB wall panels (Shakeel, 2012)

\subsection{Practical Application and Advantages of using PSSDB System}

Research studies have confirmed that the PSSDB panels can practically be used as a load bearing wall and roof system like the flooring system, as it was originally intended. Various commercial projects have implemented the use of the PSSDB system. The first ever BCCFP floor system that was commercially implemented in the refurbishment work at the 5-star Hyatt Hotel in Kota Kinabalu, Sabah, Malaysia, in 1997 (Figure 2.29). The floor area covered approximately 5000 square feet that involved the lobby and atrium areas. It was designed to cater for a dead load of $2.0 \mathrm{kN} / \mathrm{m}^{2}$, and an imposed load of $5.0 \mathrm{kN} / \mathrm{m}^{2}$ with a stringent deflection limit to avoid cracking of an assortment of marbles, slates, tiles and stones profile finish. A second commercial project in 1997, involving the floor system was at UiTM Tower, Shah Alam, Malaysia. In 2000, another significant achievement was the construction of a 3-storey Distance Learning Centre (PJJ) at UKM with successful implementation of the flooring system (Figure 2.30). The adoption of the system 
resulted in lower foundation and overall building costs. Other completed projects involved an exhibition gallery and a solar house, at Universiti Kebangsaan Malaysia, as well as a private house in Bangi, Malaysia shown in Figure 2.31 (Badaruzzaman et al., 2003). Moreover, for the first time, PSSDB roof panel system was commercially implemented in two classroom modules at Sekolah Kebangsaan Telok Mas, Melaka, Malaysia (Figure 2.32). The roof system was designed to cater for a dead load of $0.31 \mathrm{kN} / \mathrm{m}^{2}$ and an imposed load of $0.25 \mathrm{kN} / \mathrm{m}^{2}$ (Awang \& Badaruzzaman, 2010).
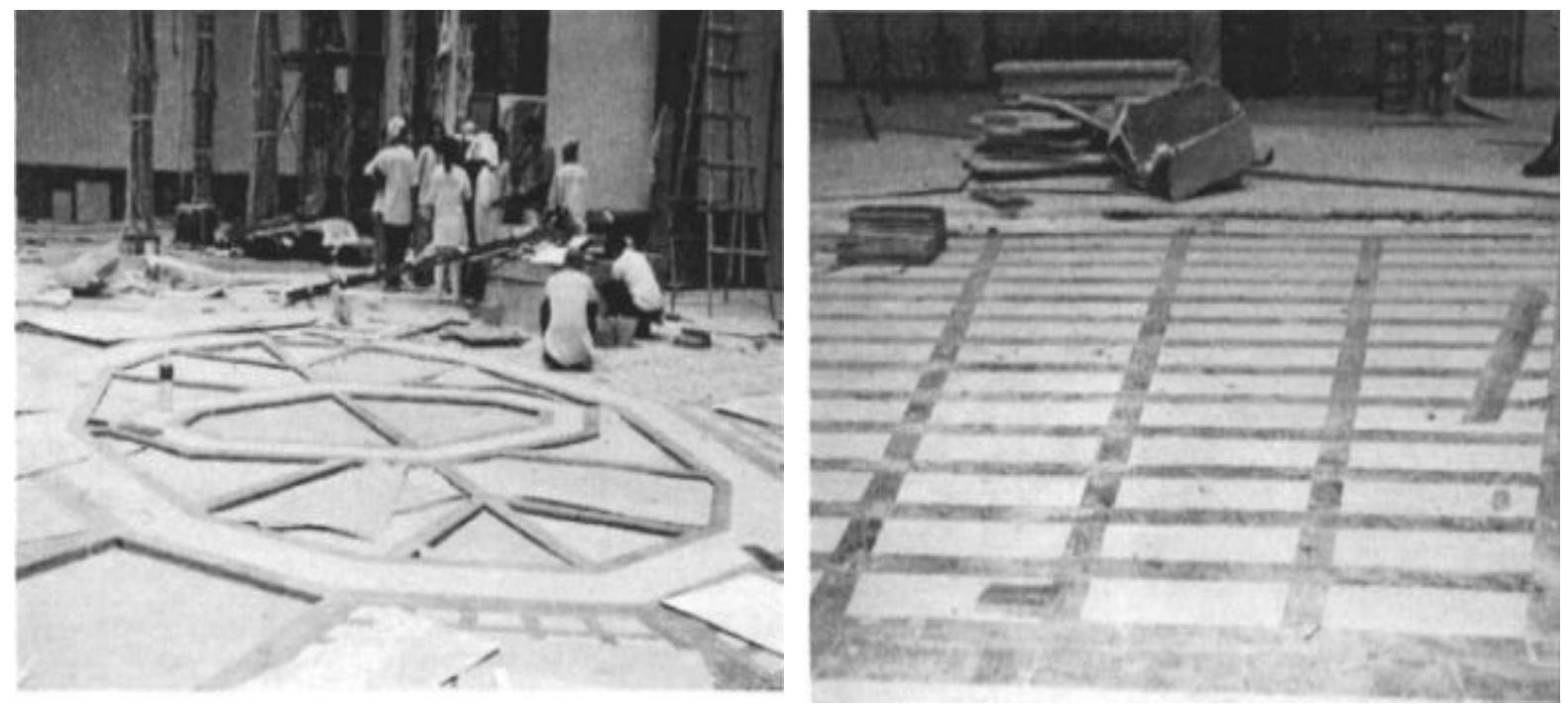

Figure 2.29 View of the BCCFP floor at the Hyatt Hotel during construction (left) and tiles placed on the BCCFP floor at the Hyatt Hotel (right) (Badaruzzaman et al., 2003)

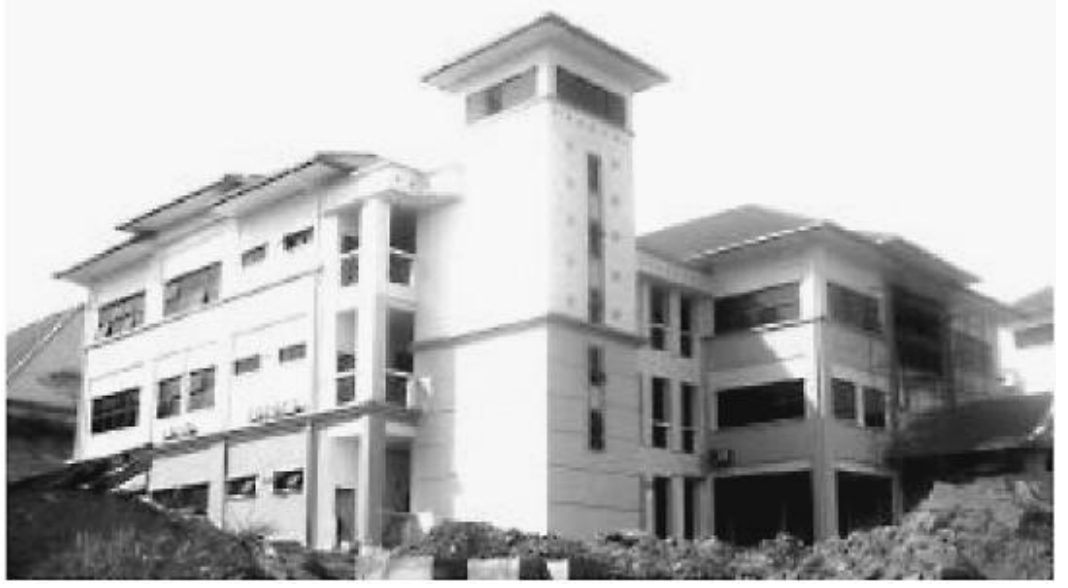

Figure 2.30 A view of the new three-storey distance learning center, UKM (Badaruzzaman et al., 2003) 

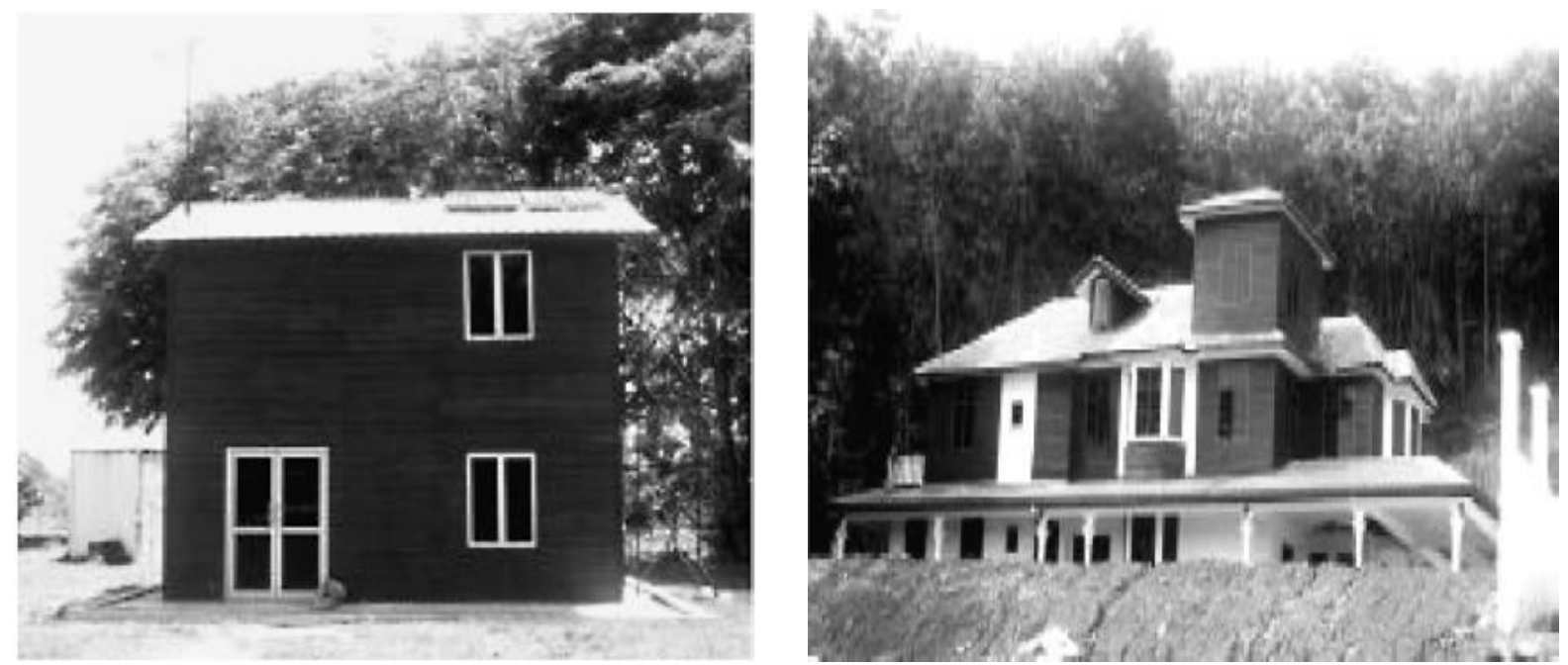

Figure 2.31 A solar house at UKM (left) and a private house in Bangi, Malaysia (right)

(Badaruzzaman et al., 2003)

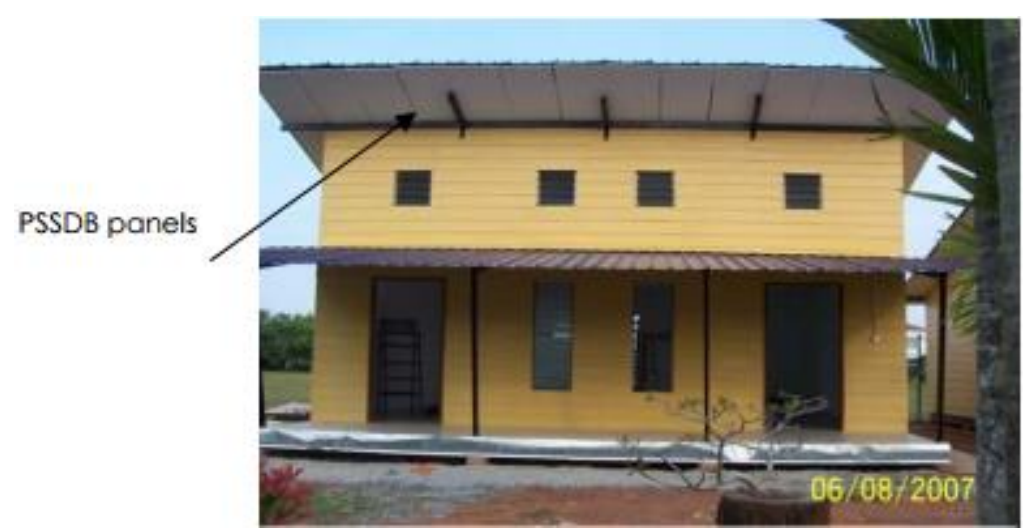

Figure 2.32 PSSDB roof panels (Awang \& Badaruzzaman, 2010)

The implementation of this innovative system has several advantages over traditional systems:

- Makes the construction process simpler as it does not require any formwork thus decreasing on-site labor time. In addition, the use of unskilled labor quickens erection process which further reduces costs.

- Due to its lightweight, the PSSDB system can be easily transported. Moreover, the profiled steel sheeting and board can be piled on top of each other during transportation

- Renovation work that include the PSSDB panels is much easier to handle

- When used as roofing system, it makes an extra living space with internal bracing of normal roof truss construction (Shanmugam, Thevendran, \& Liew, 1998)

- Requires shorter construction time thus quickening the completion time 
- Reduces the usage of heavy equipment on site

- Superb thermal and sound barrier

- Increases building quality

- Increases durability

- Fewer wastage of materials

- Superior structural integrity

\subsection{Review Conclusion}

This chapter reviews the overall structural behavior of the innovative PSSDB composite panel when used as flooring, roofing and walling units in buildings and also proven its feasibility to use this system in the practical application. Various aspects of this system have been exploited by many researchers. However, more research is required to understand the structural performance of PSSDB wall panels with a combination of different types of wooden board, profiled steel sheet, connectors and concrete infill. Based on the literature review, it can be concluded that no research has been conducted on the shear behavior of PSSDB composite wall panel. Also, very limited computational modeling of double sheathed composite wall panels was conducted under axial and shear loading.

This proposed research will conduct finite element analysis in predicting the structural behavior of composite PSSDB walls under shear and axial loading. It will focus on the development of finite element models of double sheathed composite axial and shear wall panels using trapezoidally corrugated steel sheet (spandek), plywood and bolt-nut spacers. Furthermore, the influence of various factors (longitudinal screw spacing/dimensions of the panel/rectangular opening/with and without concrete infill/single sheathing) on the structural performance of experimentally tested PSSDB walls will be assessed through FEA and analytical investigations, thus developing design guidelines. Modified code-based axial and shear equations are also developed to determine axial and shear strength capacities of such PSSDB system that will aid engineers and designers. The current research will contribute to the advancement of the knowledge of using PSSDB wall panels as a sustainable alternative to traditional forms of construction (floor, roofing and walling systems). 


\section{CHAPTER 3: EXPERIMENTAL, ANALYTICAL AND FINITE ELEMENT MODELING OF PSSDB PANELS UNDER AXIAL LOADING}

\subsection{Introduction}

Experimental study has been performed by research group at Ryerson (Hossain et al. 2015) to investigate the structural performance of PSSDB wall panels under axial loading. Ten rectangular wall panels of varying width and height were tested to failure to study the basic requirements in creating load-bearing structures. The aim of conducting these experiments was to examine the effect of various geometric, connections and material test parameters in determining the structural behavior of PSSDB load bearing wall panels. The performance of such walls was assessed based on load-deformation response, strength and failure modes under axial loading. Finite element and analytical models are developed and validated based on the experimental results.

\subsection{Experimental Study}

\subsubsection{PSSDB Specimen Design, Material Properties, Axial Load Test Set-up, Instrumentation and Testing}

Composite PSSDB wall panels, comprising of $0.48 \mathrm{~mm}$ thick profiled steel sheet (PSS) sandwiched between double skins of hard plywood dry board (DB) of $6 \mathrm{~mm}$ thickness (Figure 3.1) had been tested in the laboratory, under axial loading. To secure the connection between the pair of boards and the profiled steel sheet, connections consisting of $6 \mathrm{~mm}$ diameter bolt-nut spacer assembly were used. The three or five rows of fasteners or connectors were used as shown Figure 3.1. Ten different wall specimens (pierced or non-pierced and with or without concrete in-fill) having variable height (h), width (w), hole dimension (b x l) and connector spacing (s) were tested under axial compressive loading as shown in Figure 3.1 and as summarized in Table 3.1. Six walls were tested without concrete in-fill and four with concrete in-fill in the troughs of the profiled steel sheet. 


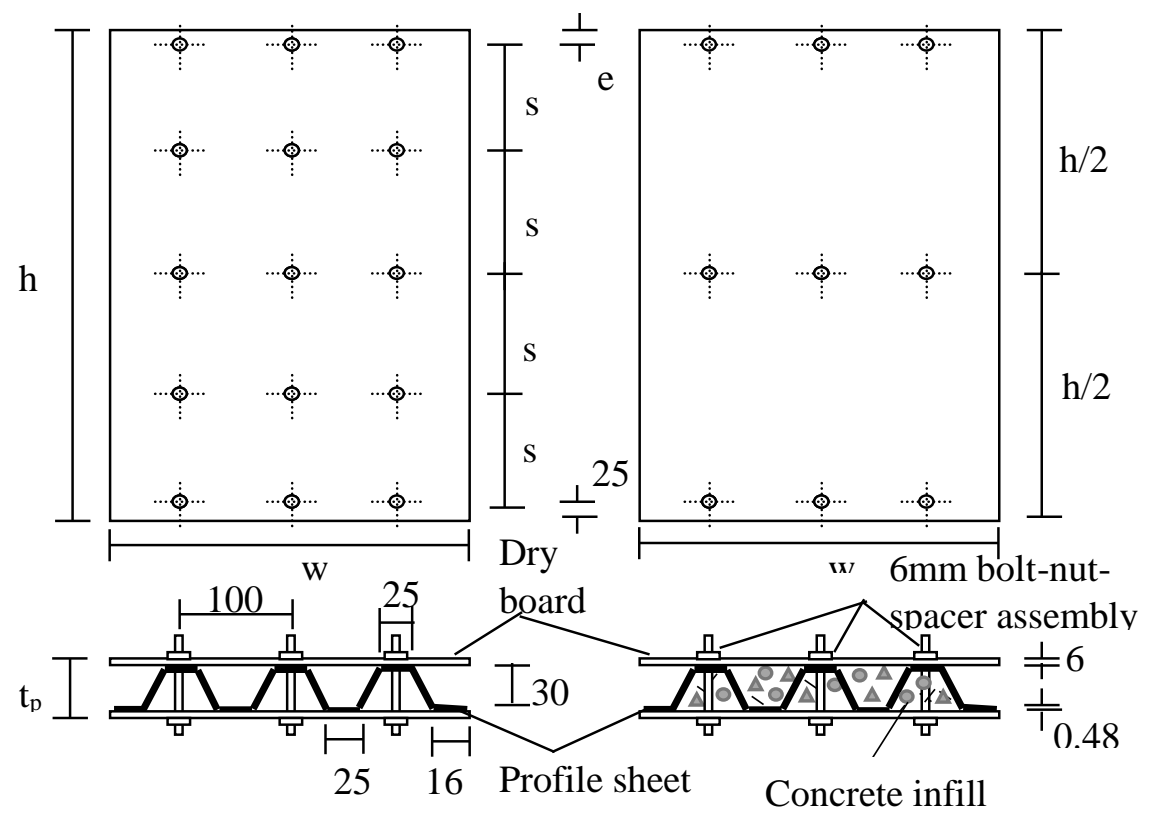

Figure 3.1 Schematic drawing showing details and dimensions of PSSDB sandwiched wall panels (dimensions in $\mathrm{mm}$ )

Table 3.1 Geometric specifications of the axial PSSDB wall panels

\begin{tabular}{|c|c|c|c|c|c|c|c|c|}
\hline \multirow[t]{2}{*}{$\begin{array}{l}\text { PSSDB } \\
\text { Panel } \\
\text { Design }\end{array}$} & \multirow{2}{*}{$\begin{array}{l}\text { Height } \\
(\mathrm{mm}) \\
\mathrm{h}\end{array}$} & \multirow{2}{*}{$\begin{array}{l}\text { Width } \\
(\mathrm{mm}) \\
\mathrm{w}\end{array}$} & \multirow{2}{*}{$\begin{array}{l}\text { Thickness } \\
\text { (mm) } \\
\mathrm{t}_{\mathrm{p}}\end{array}$} & \multicolumn{2}{|c|}{$\begin{array}{c}\text { Hole } \\
\text { Dimension } \\
(\mathrm{mm}) \\
\text { Width Height }\end{array}$} & \multirow{2}{*}{$\begin{array}{c}\text { Edge } \\
\text { Distance } \\
(\mathrm{mm}) \\
\mathrm{e}\end{array}$} & \multirow{2}{*}{$\begin{array}{c}\begin{array}{c}\text { Vertical } \\
\text { Spacing } \\
\text { of fastener } \\
(\mathrm{mm})\end{array} \\
\mathrm{s}\end{array}$} & \multirow[t]{2}{*}{$\begin{array}{l}\text { Row of } \\
\text { Spacers/ } \\
\text { fasteners }\end{array}$} \\
\hline & & & & 1 & $\mathrm{~b}$ & & & \\
\hline A1 & 890 & 325 & 42 & - & - & 25 & 420 & 3 \\
\hline A2 & 1200 & 325 & 42 & - & - & 25 & 575 & 3 \\
\hline A3 & 890 & 325 & 42 & - & - & 25 & 197.5 & 5 \\
\hline A4 & 1200 & 325 & 42 & - & - & 25 & 275 & 5 \\
\hline A5 & 476 & 325 & 42 & - & - & 25 & 213 & 3 \\
\hline A6* & 900 & 310 & 42 & - & - & 25 & 425 & 3 \\
\hline A7* & 1200 & 310 & 42 & - & - & 25 & 575 & 3 \\
\hline A8* & 900 & 310 & 42 & 260 & 90 & 25 & 425 & 3 \\
\hline A9* & 500 & 310 & 42 & - & - & 25 & 225 & 3 \\
\hline A10 & 900 & 310 & 42 & 260 & 90 & 25 & 425 & 3 \\
\hline
\end{tabular}


The PSS was made of aluminum/zinc alloy coated steel having standard thickness of 0.48 $\mathrm{mm}$ with flutes of $30 \mathrm{~mm}$ depth (Figure 3.2). The material properties of the PSS and DB were obtained via coupon tests and tabulated in Table 3.2. The yield strength, ultimate strength and modulus of elasticity (E) of PSS were 598.17MPa, 643.46MPa and $235 \mathrm{GPa}$, respectively. The tensile strength and modulus of elasticity of DB were $25.25 \mathrm{MPa}$ and $4 \mathrm{GPa}$, respectively.

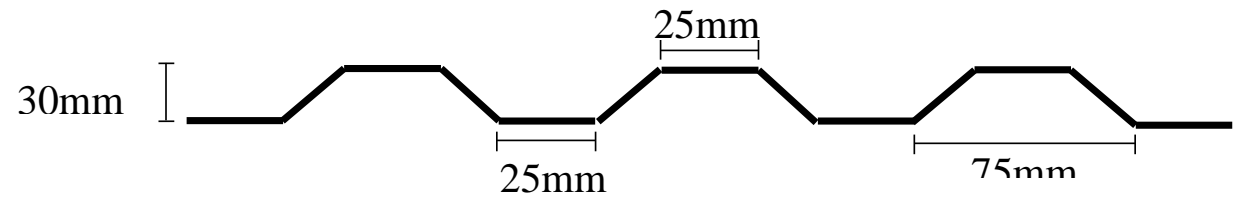

Figure 3.2: Geometry of profiled steel sheet

Table 3.2 Material properties

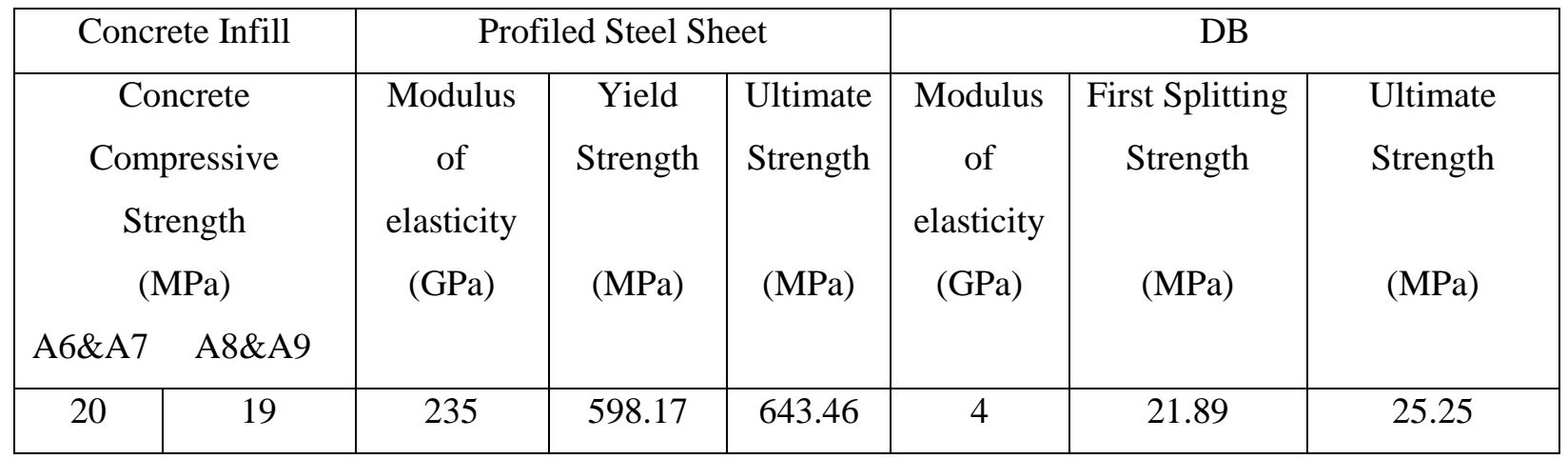

A normal concrete with $8 \mathrm{~mm}$ (maximum size) stone aggregate was used as in-fill material and its strength was determined using control specimens in the laboratory. The profiled steel sheetdry board assembly acts as a formwork during casting for the composite walls with in-fill concrete. Concrete was poured vertically in the troughs of the sheeting. Control specimens for concrete were casted in the form of cylinders to determine the strength and modulus of elasticity. The PSSDB panels with concrete in-fill were air cured in the laboratory until the day of testing. The material properties of each components in the PSSDB panels (PSS, DB and concrete) are tabulated in Table 3.2 .

The PSSDB wall panels were tested in the MTS testing machine under axial loading, as shown in Figure 3.3. The axial load was applied in increments at the top surface of the wall panel until the specimens reached the point of failure. During the testing, a computer aided data acquisition system was used to observe the load-deformation response. Linear voltage displacement transducers (LVDTs) were installed to record both axial and lateral displacement. 
During loading history the initiation of first crack, local or global buckling, connection failure and overall failure modes of the PSSDB panels were recorded.

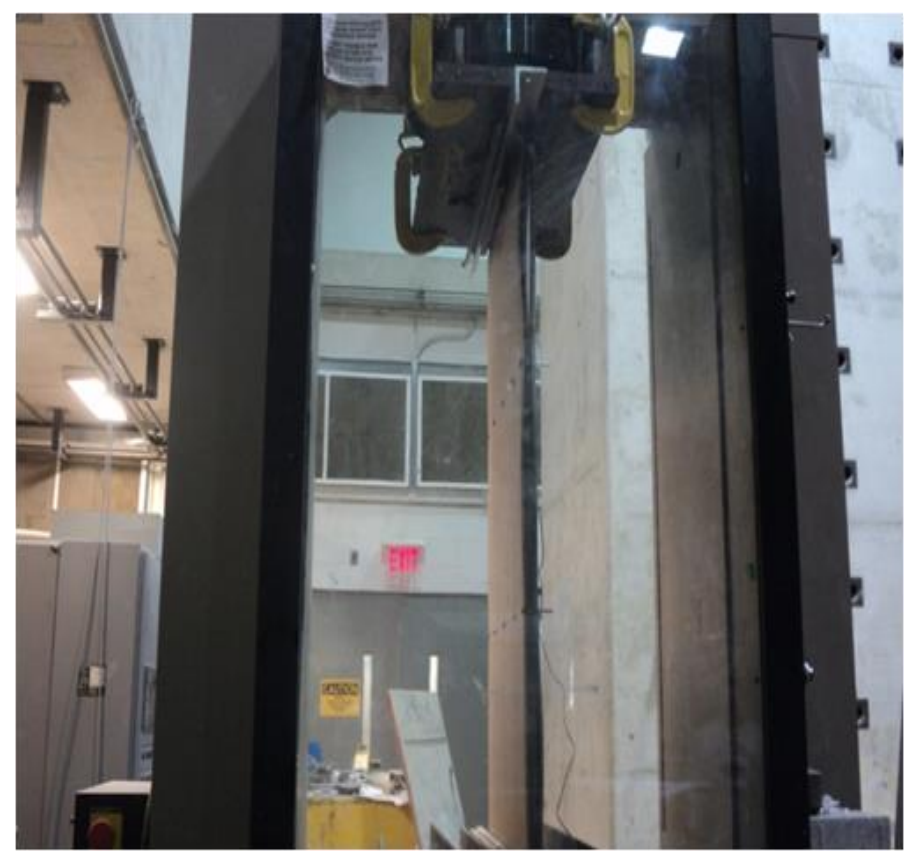

Figure 3.3 MTS test set-up for PSSDB wall panel subjected to axial loading

\subsubsection{Test Results and Discussions}

To understand the structural behavior of the PSSDB composite panels, load-deformation responses and associated failure modes are discussed. The experimental mode of failure for the PSSDB composite panels are discussed and tabulated in Table 3.3 summarizes the findings of the tests in terms of load and deflection at 1st concrete cracking, 1st buckling of DB and 1st buckling of PSS as well as peak load (ultimate) and deflection. The failure modes of all the panels are also indicated and explained in the Table 3.3. Local buckling was evident in all the panels tested under compressive axial loading. The values recorded in Table 3.3 are discussed in section 3.2.2.1 to 3.2.2.5. 
Table 3.3 Test observation for the composite panels

\begin{tabular}{|c|c|c|c|c|c|c|c|c|c|c|}
\hline \multirow{3}{*}{$\begin{array}{l}\text { Axial } \\
\text { Panel }\end{array}$} & \multirow{3}{*}{$\mathrm{h} / \mathrm{w}$} & \multicolumn{2}{|c|}{$\begin{array}{l}1^{\text {st }} \text { Concrete } \\
\text { Cracking }\end{array}$} & \multicolumn{2}{|c|}{$\begin{array}{c}1^{\text {st }} \text { Buckling of } \\
\text { Board }\end{array}$} & \multicolumn{2}{|c|}{$\begin{array}{c}1^{\text {st }} \text { Buckling of } \\
\text { Sheet }\end{array}$} & \multicolumn{2}{|c|}{$\begin{array}{c}\text { Ultimate } \\
\text { Capacities }\end{array}$} & \multirow{3}{*}{$\begin{array}{l}\text { Failure } \\
\text { Mode }\end{array}$} \\
\hline & & Load & Def. & Load & Def. & Load & Def. & Load & Def. & \\
\hline & & $(\mathrm{kN})$ & $(\mathrm{mm})$ & $(\mathrm{kN})$ & $(\mathrm{mm})$ & $(\mathrm{kN})$ & $(\mathrm{mm})$ & $(\mathrm{kN})$ & $(\mathrm{mm})$ & \\
\hline A1 & 2.74 & -- & -- & 13.60 & 1.54 & 18.80 & 2.18 & 32.80 & 4.92 & $\mathrm{LC}+\mathrm{BB}$ \\
\hline $\mathrm{A} 2$ & 3.69 & -- & -- & 9.60 & 1.28 & 31.60 & 4.22 & 32.00 & 4.32 & OB \\
\hline A3 & 2.74 & -- & -- & 8.00 & 1.31 & 36.00 & 2.55 & 42.00 & 3.49 & $\mathrm{LC}+\mathrm{BB}$ \\
\hline A4 & 3.69 & - & -- & 16.00 & 0.64 & 49.20 & 2.38 & 49.60 & 2.55 & OB \\
\hline A5 & 1.46 & - & -- & 14.25 & 1.48 & 32.00 & 2.37 & 36.50 & 8.93 & $\mathrm{LC}+\mathrm{BB}$ \\
\hline A6* & 2.90 & 16.00 & 0.95 & 60.00 & 2.19 & 72.00 & 2.72 & 90.00 & 3.99 & $\mathrm{OB}$ \\
\hline A7* & 3.87 & 20.00 & 1 & 40.00 & 1.51 & 66.00 & 3.38 & 66.00 & 3.38 & OB \\
\hline A8* & 2.90 & 12.00 & 1.28 & 16.00 & 1.52 & 46.00 & 3.64 & 46.40 & 4.22 & $\mathrm{LC}+\mathrm{BB}$ \\
\hline A9* & 1.61 & 12.00 & 1.06 & 30.00 & 3.39 & 64.00 & 10.42 & 64.00 & 10.42 & $\mathrm{LC}+\mathrm{BB}$ \\
\hline A10 & 2.90 & - & -- & 12.00 & 2.54 & 28.00 & 8.94 & 28.40 & 10.27 & OB \\
\hline
\end{tabular}

\subsubsection{Influence of Connections}

Typical axial load-deformation responses for the test panels are compared in Figure 3.4. The initial load-deformation responses showed almost linear-elastic behavior until reached to the peak load. Test panels with same dimensions and with increased row of PSS-DB connections showed higher load-bearing capacity. A1 panel (with 3 rows of connections) carried a load of $32.8 \mathrm{kN}$, whereas panel A3 (with 5 rows of connections) carried an ultimate load of $42 \mathrm{kN}$ (an increase of about $28 \%$ ). For A1, tearing of board at the top spacers was observed at $26 \mathrm{kN}$. Furthermore, local crushing and buckling was observed at $32 \mathrm{kN}$ and $42 \mathrm{kN}$, respectively for A1 and A3. Failure of both panels were due to local crushing at the top loaded end and buckling of the edge plate between the bolted connections. Similar response was observed when the panels A2 and A4 having an increased h/w ratio with 3 and 5 rows of connections, respectively were tested. In the A2 panel, first buckling of board was observed at an applied load of $9.6 \mathrm{kN}$ followed by buckling of sheet at $31.6 \mathrm{kN}$ before it failed at about $32 \mathrm{kN}$. On the other hand, buckling of board was observed in the A4 panel at an applied load of $16 \mathrm{kN}$ followed by the buckling of sheet at $49.2 \mathrm{kN}$ and failed after sustaining an ultimate load of $49.6 \mathrm{kN}$. A4 panel (with 5 rows of fasteners) increased the axial load- 
bearing capacity of the panel by 55\% when compared to the A2 panel (with 3 rows of fasteners). Both components (DB and PSS) in the A2 and A4 panels buckled thus leading to overall buckling failure. Therefore, an increase in connection increased the initial stiffness and ultimate load capacity but decreased post-peak deformation capacity of the wall panels (Figure 3.4).

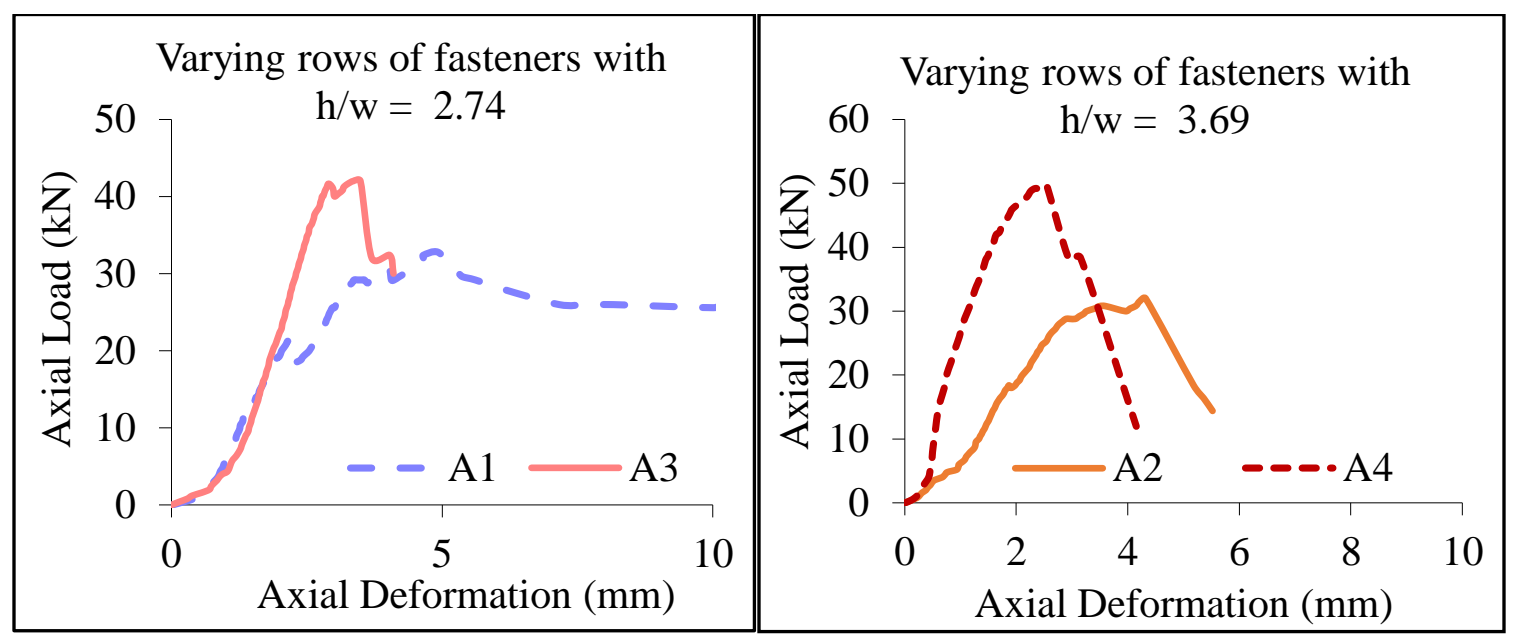

Figure 3.4: Load-deformation responses of PSSDB panels with 3 and 5 rows of connections

\subsubsection{Effect of Height to Width Ratio (h/w) of Walls Having Same Rows (3 or 5) of Connections}

Analysis of the load-deformation responses and data presented in Table 3.3 shows the effect of varying $\mathrm{h} / \mathrm{w}$ on the load bearing capacity of the walls. It displays that increase in the slenderness ratio $(\mathrm{h} / \mathrm{w})$ with constant connector spacing decreases the load bearing capacity of the composite panels (Fig. 3.5a). The load-deformation responses shown in Figure 3.5(b) contradicts the plot shown in Figure 3.5(a) because the A3 panel $(\mathrm{h} / \mathrm{w}=2.74)$ carried lower axial load capacity than A4 $(\mathrm{h} / \mathrm{w}=3.69)$. It can be seen that the A4 panel carried an ultimate load of $49.6 \mathrm{kN}$, whereas the A3 panel carried an ultimate load of $42 \mathrm{kN}$. This was due to local crushing observed at the top loaded end in the A3 panel, whereas only buckling of the components were observed in the A4 panel. 


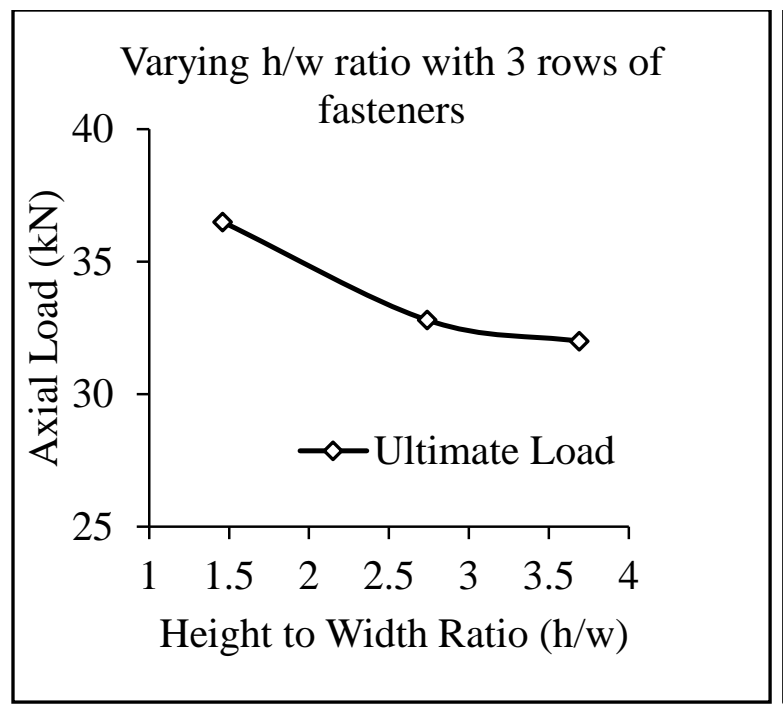

(a)

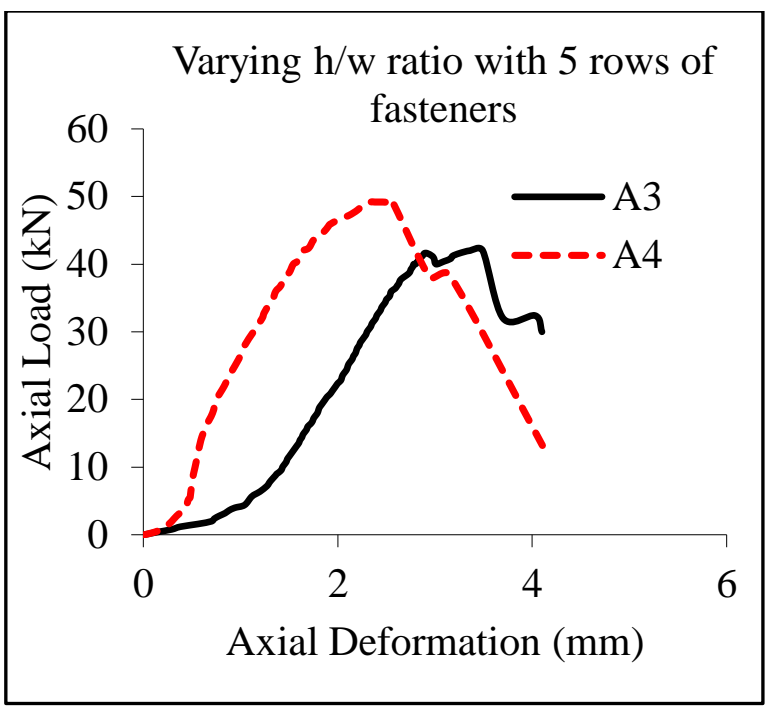

(b)

Figure 3.5: (a) Effect of height-to-width (h/w) ratio on axial load and (b) load-deformation response with varying $\mathrm{h} / \mathrm{w}$ and 5 rows of spacers

\subsubsection{Filled Composite Panels with Varying Heights and Constant Rows of Spacers}

Figure 3.6 shows load-deformation responses of filled PSSDB composite panels with varying heights. It can be seen that the A6 (h/w=2.9) panel carried an ultimate load of $90 \mathrm{kN}$, whereas A7 $(\mathrm{h} / \mathrm{w}=3.87)$ and $\mathrm{A} 9(\mathrm{~h} / \mathrm{w}=1.61)$ panels carried an ultimate load of $66 \mathrm{kN}$ and $64 \mathrm{kN}$, respectively. As the slenderness ratio (h/w) in A6 and A7 increased from 2.9 to 3.97, the load carrying capacity of the panels decreased by $36 \%$. However, despite A9 having the lowest slenderness ratio, it sustained an ultimate load lower than A6 and A7 due to local crushing at the top loaded end and buckling of the edge plate between the bolted connections. Both A6 and A7 test panels failed by overall buckling. Moreover, several cracks were observed at various load points for the three composite panels. Buckling failure of board and sheet was observed prior to failure of the panels. 


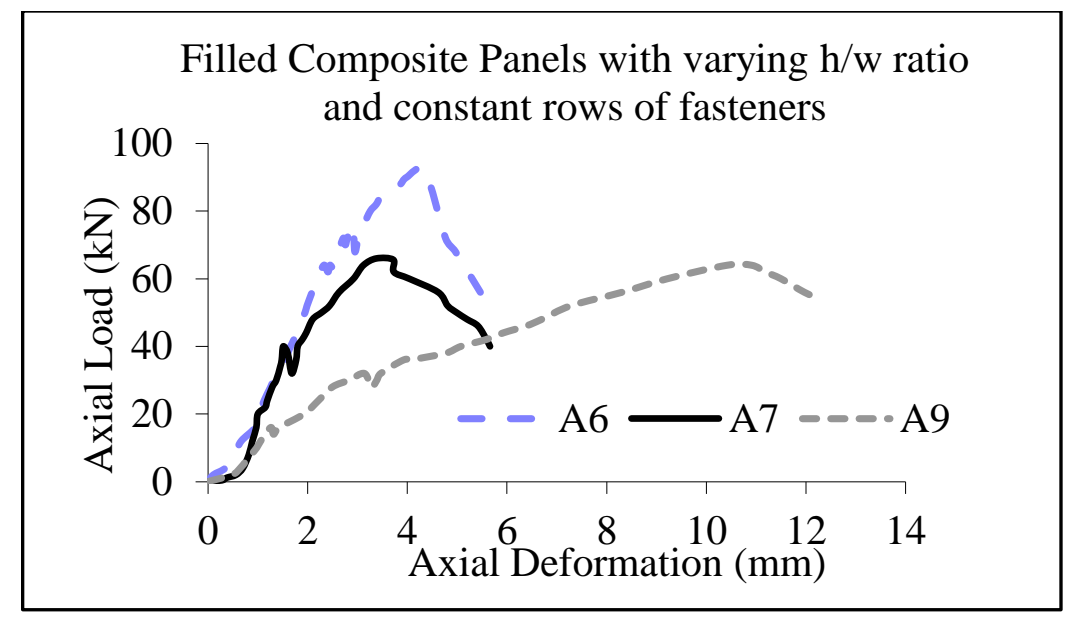

Figure 3.6 Load-deformation response of composite wall with altering h/w ratio and constant rows of fasteners

\subsubsection{Unperforated Filled and Unfilled Composite Panels}

The effect of the concrete infill on unperforated walls were analyzed using the load-deformation responses plotted in Figure 3.7 and the data presented in Table 3.3. A1 panel $(\mathrm{h} / \mathrm{w}=2.74$ with 3 rows of fasteners) without infill is compared with an infilled A6 panel (h/w=2.9 with 3 rows of fasteners). An approximated analysis is derived due to the 5\% difference in the slenderness ratio. It can be seen that the concrete infilled panel (A6) sustained greater ultimate load and higher stiffness, whereas the unfilled panel (A1) showed prolonged deformation with lower load bearing capacity. A6 panel with concrete-infill carried $174 \%$ higher axial load capacity than the unfilled panel.

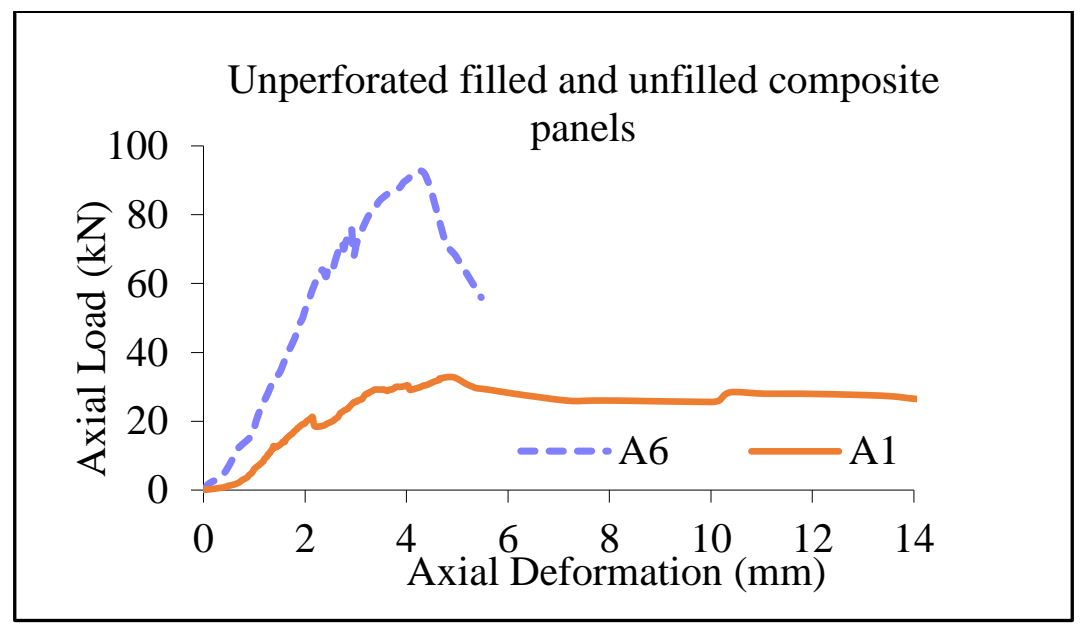

Figure 3.7: Load-deformation response of perforated filled and unfilled composite panels 


\subsubsection{Perforated Filled and Unfilled Composite Panels}

Figure 3.8 shows the load-deformation responses for the filled (A8) and unfilled (A10) perforated composite panels. Both test panels have constant slenderness ratio and rows of fasteners. It can be seen that the filled composite panel sustained $64 \%$ higher ultimate load than its unfilled counterpart. In the filled composite panel, cracks were noticed at an applied load of $12 \mathrm{kN}$ and $24 \mathrm{kN}$. Buckling of board and sheet were also observed alongside of cracks. At $46.4 \mathrm{kN}$, local crushing at the top loaded end and buckling of the edge plate between the bolts caused the filled composite to fail. In contrast, the unfilled panel displayed buckling of board at $12 \mathrm{kN}$ and buckling of sheet was observed at an applied load of $28 \mathrm{kN}$ and failed due to overall buckling at about $28 \mathrm{kN}$. Similar to the unperforated test panels, the infilled panels displayed increased stiffness and load carrying capacity with decreased post-peak deformation.

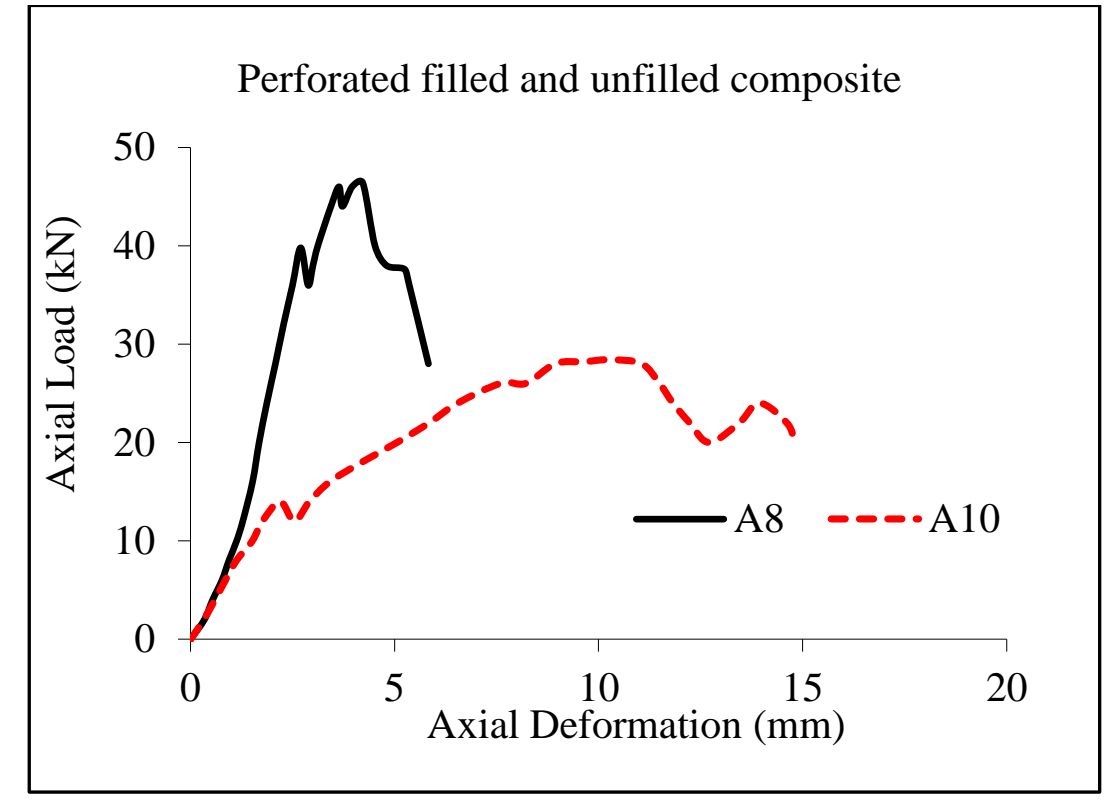

Figure 3.8 Load-deformation response of filled and unfilled composite with an opening

\subsubsection{General Experimental Findings}

The critical sections in the PSSDB wall panel are detected to help understand its effect in determining the structural behavior, when axial load is applied. Failure of the composite wall panels depends on: dimension of the panel, rows of spacers, presence of opening and presence of concrete infill in the voids/troughs of the profiled steel sheet. No significant failure was observed at the fasteners connecting the PSS and the board together. 


\subsection{Development of Theoretical Models}

\subsubsection{Axial Load Capacity of PSSDB walls with and without concrete infill}

Theoretical models have been developed to further investigate the load bearing capacity of the pierced and non-pierced PSSDB walling/panel system, with and without concrete infill. Moreover, the results obtained via the theoretical analysis are compared with the experimental results. The overall mode of failure and the interaction between each components of the composite wall on the load bearing capacity is also determined.

In constructing load bearing structures, PSSDB composite wall panels has proven its ability to fulfill general requirements such as load bearing capacity, stiffness and durability. The combination of PSS and DB produces complete and incomplete interactions. Generally, the dry board enhances the strength and stiffness of the profiled steel sheet (Badaruzzaman et. al, 2002). Mengesha (1992) conducted a detailed study on the incomplete interaction of PSSDB panels subjected to compressive axial loading. The DB component was found to enhance the PSS from local buckling and flange curling. Furthermore, self-tapping self-driving screws used are capable of carrying only a small portion of the compressive load, thus considered as a compatible connection. When the screws are connected at discrete positions in the composite panel, local buckling in the screws were quite certain.

In general, failure of the composite panel may be due to the PSS or DB or connection. Local buckling failure in PSS is said to occur if the yield stress reaches the top flange section or at the intersection between the flange and the web, thus causing bending stiffness in the transverse direction. Moreover, it can also be as a result of the bonding defects or loose connections in the PSSDB panels. Meanwhile, failure in dryboard may happen through longitudinal compressive action, transverse bending action, tension perpendicular to the DB surface or even buckling of the DB, whilst failure in screws can be either in shear or tension (Hamzah \& Badaruzzaman, 2009).

In thin-walled elements, the profile geometry along steel sheet alters the effectiveness of the cross section of the wall. The thinner the PSS, the more it is susceptible to local buckling. In determining the structural bearing capacity, effective width concept was investigated, whereby increasing the load beyond the buckling load along with the change of deformation in magnitude and shape. The change of deformed shape is associated with the axial stiffness in the steel sheet (Hamzah \& Badaruzzaman, 2009). 
As recommended by Benayoune and Wan Badaruzzaman (2000), the ultimate load for composite panel can be taken as the failure load based on the strength capability of the individual components. Taking into consideration the effective width and local buckling, a semi-empirical equation (BS5950, 1995) was developed, by adding a reduction factor, $\mathrm{k}$ in analysing the crushing load for short wall panels.

The ultimate strength of slender members in the post-buckling state is computed using the effective width concept introduced by Von-Kármán (Bedair, 2003, Paik and Thayamballi, 2003). The concept is based on the replacement of non-linear stress distribution acting on the entire width of the plate by two equivalent uniform blocks distributed over two reduced effective widths.

Figure 3.9 shows a typical effective width model for plate under uniform compression, where the actual longitudinal stress distribution, $\sigma_{x}$ is represented by the dotted curve and the two rectangular blocks denote the effective width, $b_{e}$. The magnitude of the uniform stress of each block is assumed to be equal to the actual stress at the edge of the plate. The two blocks, each of width $\frac{b_{e}}{2}$ are also assumed to have the same area as the actual stress distribution. Both edges carry maximum stress in the post-buckling state while the central region of the plate remains unstressed, by using this simplified concept. Hence only a fraction of the width is considered in resisting the applied compression. The simplified stress distribution enables designers to deal with highly nonlinear analysis in post-buckling range. This concept is also applicable to PSSDB walls subjected to axial loading.

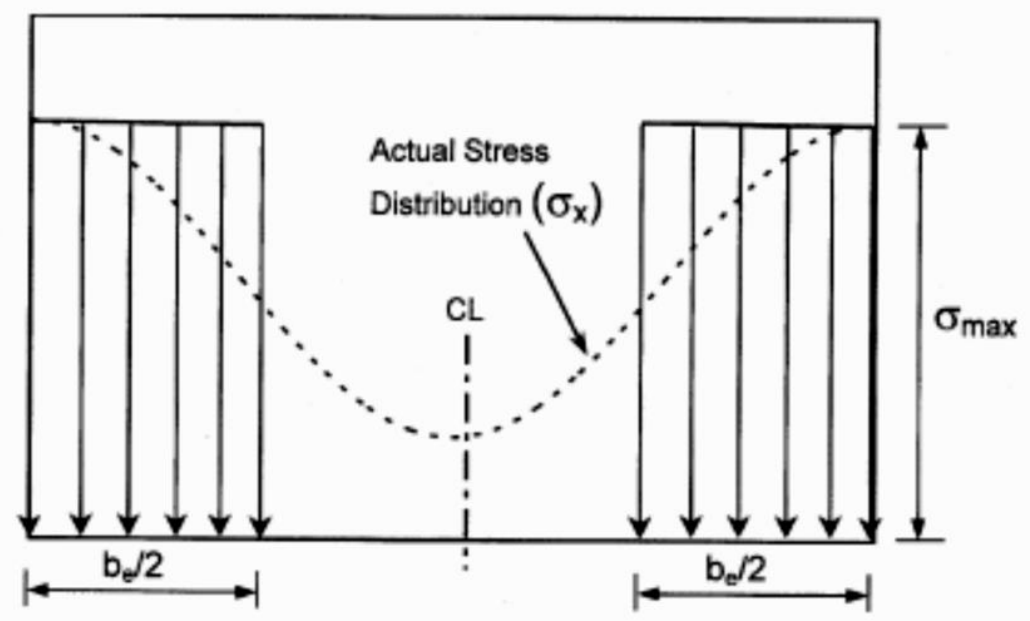

Figure 3.9 Typical effective width model for plate under uniform compression (Bedair, 2000) 
Based on uniform compression and straight longitudinal edges, Von-Kármán suggested the following relationship (Eq. 3.1) for effective width $\left(b_{e}\right)$ of plate/panel subjected to in-plane axial loading (Bedair 2003, Paik and Thayamballi, 2003):

$\frac{b_{e}}{b}=\sqrt{\frac{\sigma_{c r}}{\sigma_{\max }}}$

where $\mathrm{b}$ is the width of the panel/plate, $\sigma_{c r}$ is the critical stress and $\sigma_{\max }$ is the maximum edge stress

Buckling stress $\left(\sigma_{c r}\right)$ for plate subjected to axial loading can be obtained using Eq. 3.2:

$\sigma_{c r}=\frac{4 \pi^{2} E}{12\left(1-v^{2}\right)} \frac{t^{2}}{b^{2}}$

where $\mathrm{E}$ is the modulus of elasticity of the plate material, vis the Poisson's ratio of the material, $\mathrm{t}$ is the thickness of the plate

Following Von-Kármán, other researchers have proposed various effective width formulae for the plates under uniform compression. Some are empirical based on small scale testing while others are analytical using simple assumptions. Winter proposed an empirical expression (Eq. 3.3) that was based on extensive tests taking into account the initial plate imperfection (Bedair 2003, Paik and Thayamballi, 2003; Hossain and Wright, 1998):

$\frac{b_{e}}{b}=\sqrt{\frac{\sigma_{c r}}{\sigma_{\max }}}\left(1-0.25 \sqrt{\frac{\sigma_{c r}}{\sigma_{\max }}}\right)$

Benayoune and Wan Badaruzzaman (2000) suggested that the ultimate load bearing capacity of composite walls is taken as the failure load based on the strength capability of the individual element. Taking into consideration the effective width and local buckling, a semi-empirical equation was developed by adding reduction factor $k$ in analyzing the crushing load for short wall panels. Eq. 3.4 is used to obtain the axial load capacity of short PSSDB walls (Hamzah \& Badaruzzaman, 2009). The presence of the concrete core in the PSSDB wall panels will further improve the degree of interaction by improving the buckling load of the DB and PSS and delaying deformation of the composite panels. Experimental results proved that infilled concrete had significant contribution in increasing the load bearing capacity of the PSSDB walls. Eq. 3.4 and Eq. 3.5 are used to determine theoretical value of the ultimate axial load for the PSSDB walling system without $\left(\mathrm{P}_{\mathrm{u}}\right)$ and with $\left(\mathrm{P}_{\mathrm{uc}}\right)$ concrete infill. These equations were derived by using equivalent transformed section (transforming dry board and concrete to steel) of the PSSDB panels. 
PSSDB without concrete core:

$$
P_{u}=\left(A_{s}+n A_{b}\right) k \sigma_{y}
$$

PSSDB with concrete core:

$P_{u c}=\left(A_{s}+n_{1} A_{d b}+n_{2} A_{c c}\right) k \sigma_{y}$

$n=n_{1}=\frac{E_{d b}}{E_{p s s}} ; n_{2}=\frac{E_{c c}}{E_{p s s}}$

Where $\mathrm{P}_{\mathrm{u}}$ and $\mathrm{P}_{\mathrm{uc}}$ are the axial load capacity of wall without concrete core and with concrete core, respectively, $\mathrm{A}_{\mathrm{s}}$ is the cross-sectional area of PSS, $\mathrm{n}, \mathrm{n}_{1}, \mathrm{n}_{2}$ are the modular ratios, $\mathrm{A}_{\mathrm{db}}$ is the crosssectional area of pair of dry board, $A_{c c}$ is the cross-sectional area of concrete core, $E_{c c}$ is the modulus of elasticity of concrete core, $\mathrm{E}_{\mathrm{pss}}$ is the modulus of elasticity of PSS, $\mathrm{E}_{\mathrm{db}}$ is the modulus of elasticity of DB, $\sigma_{\mathrm{y}}$ is the yield strength of PSS and $\mathrm{k}$ is the interaction factor (for full interaction with no local buckling failure $\mathrm{k}=1.0$ ). However, the interaction factor was then determined by the ratio of the experimental results over the theoretical results.

\subsubsection{Buckling of PSSDB Wall Panels}

Euler equation can be used in analyzing elastic buckling load of the composite panels because as the height of the wall increases, failure tends to be due to overall buckling. The axial buckling load capacity $\left(\mathrm{P}_{\mathrm{cr}}\right)$ of the PSSDB composite walls are obtained by converting the wall cross-section into an equivalent transformed steel section as per the Eq. 3.6 (Hamzah et al., 2009):

$P_{c r}=\frac{\pi^{2} E_{S} I_{C}}{(K H)^{2}}$

where $\mathrm{K}$ is the effective length factor (1.0 for pin ended as is the case for current study and 0.5 for fixed ended), $I_{c}$ is the second moment of area of the equivalent transformed steel section of the PSSDB walls with or without concrete core.

\subsubsection{Analysis of Theoretical Models}

In order to investigate the influence of different test parameters such as geometric specifications, material properties, and filled or unfilled panels, experimental data were used to analyze and validate the performance of theoretical model based on load bearing capacity and observed failure modes. Eq. 3.4 and 3.5 are used to determine the analytical axial load capacities of PSSDB walls with and without concrete core, assuming full interaction with no local buckling failure. Detailed 
calculations are shown in Appendix A. The analytical values are then compared with those obtained from experimental tests to determine the interaction parameter, $\mathrm{k}$. In addition, buckling load capacity for the axially loaded walls was calculated using Eq. 3.6 considering them as slender wall panels. The validity of the developed theoretical models is assessed in connection with the observed failure mode of the system.

Table 3.4 presents the experimental and theoretical axial load capacities, interaction parameter, and geometric parameters $(\mathrm{h} / \mathrm{w}$ and $\mathrm{s} / \mathrm{h}$ ). Experimental results show that the performance of the theoretical models depends on the failure mode and the failure modes depend on the $\mathrm{h} / \mathrm{w}$ and $\mathrm{s} / \mathrm{h}$ ratios. It can be seen that the axial load capacity determined using Euler's Eq. $3.6\left(\mathrm{P}_{\mathrm{cr}}\right)$ gives results close to that of the experimental tests and that none of the panels reached the theoretical crushing load $\left(\mathrm{P}_{\mathrm{u}}\right)$ as full interaction was assumed. However, Eq. 3.4 should be calibrated with the interaction parameter, $\mathrm{k}$. It can be obtained using the ratio, experimental load over the theoretical load.

Furthermore, PSSDB walls with concrete infill demonstrated improved interaction between the profiled steel sheet and DB thus increasing buckling load capacity and reduced local instability. The use of concrete infill in the panels (A6 to A8) changes the failure modes when compared to the panels without concrete infill, as experimental load capacities were higher than buckling loads but lower than the crushing load.

It can also be observed from Table 3.4 that an increase in $\mathrm{s} / \mathrm{h}$ ratio decreases the interaction factor, as it tends to induce local buckling and instability that considerably decreases the interaction between the components of the PSSDB panels, thus reducing the load-bearing capacity. An increase in the interaction factor was seen in the pierced wall with concrete infill (A8) compared to the pierced panel without concrete infill (A10). PSSDB walls with concrete infill demonstrated improved interaction between the profiled steel sheet and dry-board thus increasing buckling load capacity and reduced local instability. 
Table 3.4 Comparison of theoretical with experimental results

\begin{tabular}{|c|c|c|c|c|c|c|c|c|}
\hline \multirow[t]{2}{*}{$\begin{array}{c}\text { Specimen } \\
\text { Type }\end{array}$} & \multirow[t]{2}{*}{$\mathrm{h} / \mathrm{w}$} & \multirow[t]{2}{*}{$\mathrm{s} / \mathrm{h}$} & $\begin{array}{c}\text { Experimental } \\
\text { Axial Load } \\
\text { Capacity }(\mathrm{kN})\end{array}$ & \multicolumn{3}{|c|}{$\begin{array}{c}\text { Analytical Axial Load } \\
\text { Capacity } \\
(\mathrm{kN})\end{array}$} & \multicolumn{2}{|c|}{$\begin{array}{c}\text { Ratio, } \\
\text { k }\end{array}$} \\
\hline & & & $\mathrm{P}_{\exp }$ & $\mathrm{P}_{\mathrm{u}}$ & $\mathrm{P}_{\mathrm{uc}}$ & $\mathrm{P}_{\mathrm{cr}}$ & $\mathrm{P}_{\mathrm{exp}} / \mathrm{P}_{\mathrm{u}}, \mathrm{P}_{\mathrm{uc}}$ & $\mathrm{P}_{\text {exp }} / \mathrm{P}_{\text {cr }}$ \\
\hline A1 & 2.73 & 0.47 & 32.8 & 40.15 & - & 56.81 & 0.82 & 0.58 \\
\hline $\mathrm{A} 2$ & 3.69 & 0.48 & 32 & 40.15 & - & 31.25 & 0.80 & 1.02 \\
\hline A3 & 2.73 & 0.24 & 42 & 40.15 & - & 56.81 & 1.05 & 0.74 \\
\hline A4 & 3.69 & 0.24 & 49.6 & 40.15 & - & 31.25 & 1.24 & 1.60 \\
\hline A5 & 1.46 & 0.45 & 35.25 & 40.15 & - & 56.81 & 0.88 & 0.62 \\
\hline A6 & 2.90 & 0.45 & 90 & - & 130.50 & 71.94 & 0.69 & 1.25 \\
\hline A7 & 3.87 & 0.48 & 64 & - & 130.50 & 40.47 & 0.49 & 1.58 \\
\hline A8 & 2.90 & 0.47 & 46.4 & - & 130.50 & 71.94 & 0.36 & 0.64 \\
\hline A9 & 1.61 & 0.45 & 64 & - & 130.50 & 67.85 & 0.49 & 0.94 \\
\hline A10 & 2.90 & 0.47 & 28 & 63.15 & - & 71.94 & 0.45 & 0.39 \\
\hline
\end{tabular}

\subsubsection{Summary of Theoretical Findings}

The interaction between the components in the composite wall panels and the load-bearing capacity was emphasized. Analytical models for the axial strength of composite PSSDB walls were developed, based on existing theoretical models. Introducing a suitable interaction factor in the developed equation can lead to more accurate results. The accuracy of the derived equations was assessed based on the results obtained experimentally. Experimental axial load is compared with theoretical buckling and crushing loads to understand the failure of the PSSDB walls.

\subsection{Finite Element Modelling of PSSDB walls}

Finite element (FE) models for pierced as well as non-pierced PSSDB composite walls were developed using ABAQUS/CAE to predict the structural behavior under axial loading. The composite wall panels consisting of a profiled steel sheet sandwiched between two boards were analyzed using ABAQUS/Standard. This chapter discusses the development of numerical models based on experimental tests performed. A parametric study was conducted to investigate the performance of the composite wall with varying dimensions, board/steel sheet thickness, rows of fasteners, steel strength, and concrete strength. 


\subsubsection{ABAQUS/Standard and ABAQUS/Explicit}

ABAQUS/CAE is the abbreviation for "Complete ABAQUS Environment" that offers an efficient interface for creating, editing submitting, monitoring, and evaluating results obtained via ABAQUS/Standard and ABAQUS/Explicit simulations (Yang, 2017). This software is employed to conduct finite element analysis of complex non-linear engineering problems. It consists of various modules that help in defining every aspect of the modelling process. ABAQUS/Standard and ABAQUS/Explicit are integrated analysis tools present in ABAQUS/CAE.

ABAQUS/Standard is a general purpose finite element module that implicitly solves a set of equations at every solution increment. It allows to perform analysis for static and low-speed dynamic events where highly accurate stress is very vital. It has the capability to analyze various linear as well as non-linear problems. Equilibrium is achieved using several iterations in the implicit procedure. Furthermore, it is ideal to evaluate static and dynamic stress/displacement, steady-state transport, heat transfer, thermal stress, electromagnetic, coupled pore fluid flow and stress, mass diffusion, acoustic and shock problems. It supports general contact between all or multiple areas of the assembled bodies (Abaqus 6.12 Analysis User's Manual, 2012).

ABAQUS/Explicit is a special-purpose finite element module that uses an explicit integration scheme to solve highly non-linear systems with many complex contacts under transient loads. It uses small increments and is suitable to simulate brief transient dynamic events. It is ideal to analyze dynamic stress/displacement, steady-state transport, heat transfer, acoustic, Eulerian, coupled Eulerian-Lagrangian, discrete element, smoothed particle hydrodynamics and annealing problems. It supports general contact between all or multiple areas of the assembled bodies (Abaqus 6.12 Analysis User's Manual, 2012).

\subsubsection{Components of PSSDB Panel}

\subsubsection{Dry Board Model}

Wood is a highly anisotropic and heterogeneous material. It is considered as brittle in tension and shear while it is ductile in compression. ABAQUS does not provide a standard model to simulate wood behavior when the material undergoes both elastic and plastic deformations perpendicular to the grain. The mechanical properties of wood can be easily described at the linear-elastic stage. However, difficulties arise when defining the non-linear properties of wood. An accurate approach to model the non-linear behavior of wood using ABAQUS is to use UMAT subroutine programmed in FORTRAN language to implement the rheological wood model that accounts for 
the increment of stress and behavior of wood (Mirianon et al., 2008). Nevertheless, for simplicity of this study the non-linear properties of wood are defined using the crushable foam plasticity model. A detailed explanation of crushable foam plasticity model is provided in section 23.3 .5 of the Abaqus User's Guide (2014).

This model uses linear isotropic elasticity and isotropic hardening model to define the mechanical properties of wood. A simple uniaxial compression test is sufficient to define the evolution of the yield surface. The hardening curve used in the plastic behavior describes the uniaxial compression yield stress as a function of the corresponding plastic strain. The isotropic hardening model uses a yield surface that is an ellipse centered at the origin in the p-q stress plane as shown in Figure 3.10 (Abaqus Analysis User's Guide, 2014).

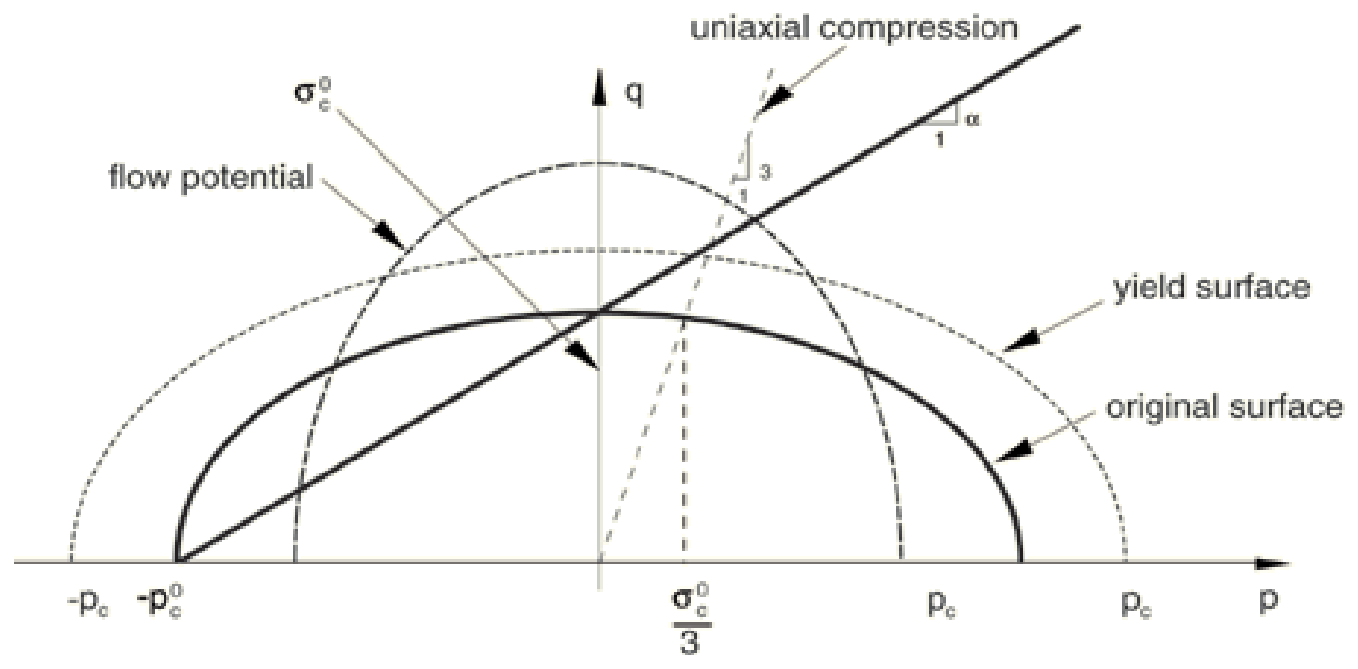

Figure 3.10 Crushable foam model with isotropic hardening: yield surface and flow potential in the p-q stress plane (Abaqus Analysis User's Guide, 2014).

The yield surface $(\mathrm{F})$ for the isotropic hardening model is defined using Eq. 3.8. Table 3.5 presents the material definition parameters for the design of the wood model.

$F=\sqrt{q^{2}+\alpha^{2} p^{2}}-B=0$

$\mathrm{p}=-\frac{1}{3} \operatorname{trace} \sigma$

$\mathrm{q}=\sqrt{\frac{3}{2} \mathrm{~S}: \mathrm{S}}$ 
$S=\sigma+p I$

$\mathrm{B}=\alpha \mathrm{p}_{\mathrm{c}}=\sigma_{\mathrm{c}} \sqrt{1+\left(\frac{\alpha}{3}\right)^{2}}$

Where $q$ is the mises stress, $\mathrm{S}$ is the deviatoric stress, $p$ is the pressure stress, $\mathrm{B}$ is the size of the (vertical) $\mathrm{q}$-axis of the yield ellipse, $\alpha$ is the shape factor of the yield ellipse that defines the relative magnitude of the axes, $p_{c}$ is the yield stress in hydrostatic compression $\sigma_{c}$ is the absolute value of the yield stress in uniaxial compression and $\mathrm{E}_{\mathrm{db}}$ is the modulus of elasticity of dry-board.

Table 3.5 Material properties of wood

\begin{tabular}{|c|c|c|c|c|c|c|c|}
\hline \multirow[b]{2}{*}{$\begin{array}{l}\text { Wood } \\
\text { Type }\end{array}$} & \multirow[b]{2}{*}{$\begin{array}{c}\text { Thickness } \\
\text { (mm) }\end{array}$} & \multicolumn{2}{|c|}{ Elastic } & \multicolumn{4}{|c|}{ Crushable Foam Plasticity } \\
\hline & & (MPa) & $\begin{array}{c}\text { Poisson's } \\
\text { ratio } \\
v_{p}\end{array}$ & $\begin{array}{c}\text { Compression } \\
\text { Yield Stress } \\
\text { Ratio }\end{array}$ & $\begin{array}{c}\text { Hydrostatic } \\
\text { Yield Stress } \\
\text { Ratio }\end{array}$ & $\begin{array}{l}\text { Yield } \\
\text { Stress }\end{array}$ & $\begin{array}{c}\text { Uniaxial } \\
\text { Plastic } \\
\text { Strain }\end{array}$ \\
\hline Plywood & 6 & 4000 & 0.23 & 2 & 0.22 & 4 & 0 \\
\hline
\end{tabular}

\subsubsection{Steel Model}

The material properties of steel were determined from the tensile coupon test. ABAQUS uses true (Cauchy) stress and logarithmic strain to perform the finite element analysis of steel. The nominal (engineering) stress and strain values were obtained in terms of initial sectional area and gauge length of coupon via tensile coupon test (Rafiei, 2011). Eq. 3.9 and Eq. 3.10 derived by Lubliner (1990) are used to obtain the true stress $\left(\sigma_{\text {true }}\right)$ and logarithmic plastic strain $\left(\varepsilon_{l n}^{p l}\right)$. Table 3.6 displays the material properties and Figure 3.11 shows a constitutive model that was used to define the material properties of the profiled steel sheet.

$\sigma_{\text {true }}=\sigma_{\text {nom }}\left(1+\varepsilon_{\text {nom }}\right)$

$\varepsilon_{l n}^{p l}=\ln \left(1+\varepsilon_{\text {nom }}\right)-\frac{\sigma_{\text {true }}}{E_{s}}$

Where $\sigma_{\text {nom }}$ is the nominal stress, $\varepsilon_{\text {nom }}$ is the nominal strain and $\mathrm{E}_{\mathrm{pss}}$ is the modulus of elasticity 
Table 3.6 Material properties of profiled steel sheet

\begin{tabular}{|c|c|c|c|c|c|}
\hline \multirow{2}{*}{$\begin{array}{c}\text { Thickness } \\
(\mathrm{mm})\end{array}$} & \multicolumn{3}{|c|}{ Elastic } & \multicolumn{3}{c|}{ Plastic } \\
\cline { 2 - 6 } & $\mathrm{E}_{\mathrm{pss}}(\mathrm{MPa})$ & Poisson's ratio, $v$ & Stress and Strain & Point 1 & Point 2 \\
\hline \multirow{2}{*}{0.48} & 235000 & \multirow{2}{*}{0.3} & True stress (MPa) & 598.17 & 598.17 \\
\cline { 4 - 6 } & & Plastic strain & 0 & 0.001 \\
\hline
\end{tabular}

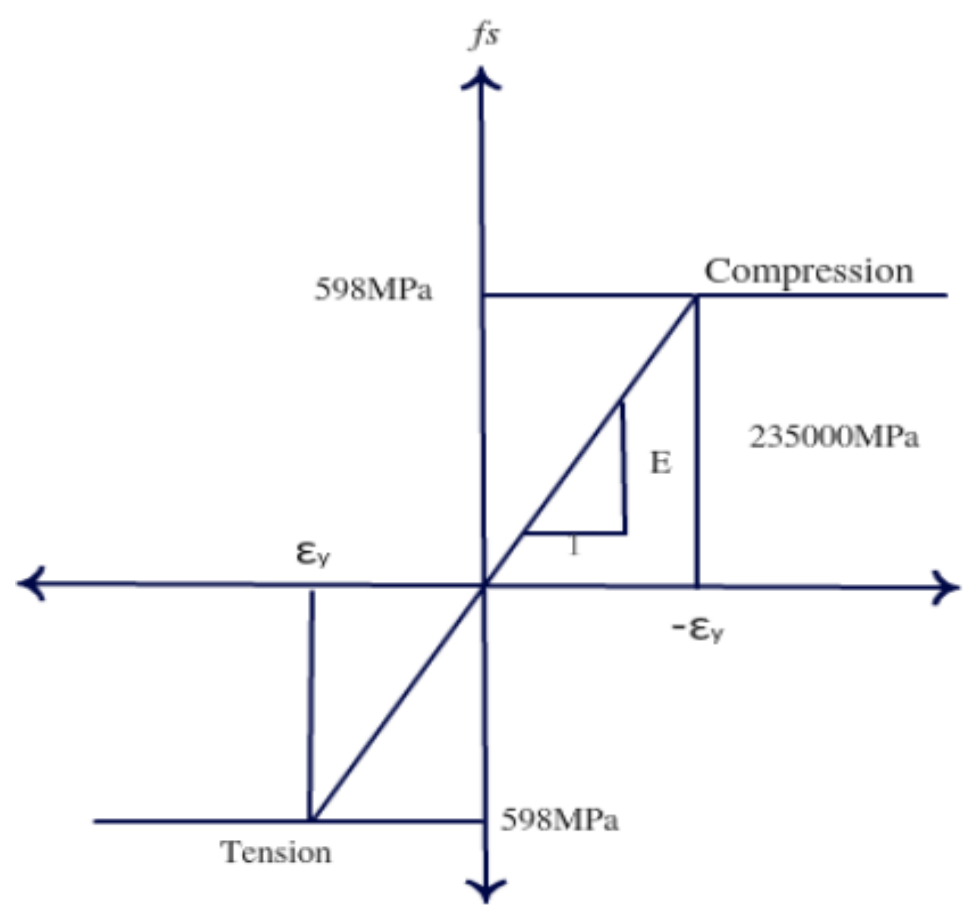

Figure 3.11 Constitutive model of profiled steel sheet

\subsubsection{Concrete Model}

Concrete behavior can be simulated in three different fundamental models in ABAQUS/CAE; i.e., smeared crack concrete model in ABAQUS/Standard, brittle cracking model in ABAQUS/Explicit and the concrete damaged plasticity model in both ABAQUS/Standard and ABAQUS/Explicit. These three models are designed to help model plain and reinforced concrete, and other similar quasi-brittle materials in all types of structures such as beams, trusses, shells and solids (Abaqus 6.12 Analysis User's Manual, 2012).

Concrete damaged plasticity model in ABAQUS/Standard was used in the simulation of the concrete infilled PSSDB wall panels. This model is a continuum, plasticity-based, damage model of concrete. The two failure mechanisms that the model assumes are tensile cracking and compressive crushing of the concrete material. The concepts of isotropic damaged elasticity along 
with isotropic tensile and compressive plasticity is used to represent the non-linear behavior of concrete. It is suitable for applications where concrete is subjected to monotonic, cyclic, and/or dynamic loading under low confining pressures. It takes into account the degradation of the elastic stiffness induced by plastic straining both in tension and compression (Abaqus 6.12 Analysis User's Manual, 2012). Table 3.7 shows the material properties for the concrete model.

Table 3.7 Material properties for the concrete model

\begin{tabular}{|c|c|c|c|c|c|c|c|}
\hline \multirow[b]{2}{*}{$\begin{array}{c}\text { Concrete } \\
\text { Core }\end{array}$} & \multicolumn{2}{|c|}{ Elastic } & \multicolumn{5}{|c|}{ Concrete Damaged Plasticity } \\
\hline & $\begin{array}{c}\mathrm{E}_{\mathrm{c}} \\
(\mathrm{MPa})\end{array}$ & $\begin{array}{l}\text { Poisson's } \\
\text { ratio, } v\end{array}$ & $\begin{array}{l}\text { Dilation } \\
\text { Angle }\end{array}$ & Eccentricity & $\mathrm{f}_{\mathrm{b} 0 / \mathrm{f}_{\mathrm{c} 0}}$ & K & $\begin{array}{l}\text { Viscosity } \\
\text { Parameter }\end{array}$ \\
\hline $\begin{array}{l}\text { Normal } \\
\text { Concrete }\end{array}$ & 22025 & 0.2 & 30 & 0.1 & 1.16 & 0.67 & 0.0001 \\
\hline \multicolumn{8}{|c|}{$\begin{array}{l}\mathrm{E}_{\mathrm{c}} \text { : Modulus of Elasticity of concrete; } \mathrm{f}_{\mathrm{b} 0 / \mathrm{f}_{\mathrm{c} 0} \text { : ratio of initial equibiaxial compressive yield stress to initial uniaxial }} \\
\text { compressive yield stress; } \mathrm{K} \text { : ratio of the second stress invariant on the tensile meridian to that on the } \\
\text { compressive meridian, at initial yield for any given value of the pressure invariant such that the maximum } \\
\text { principal stress is negative }\end{array}$} \\
\hline
\end{tabular}

\subsection{Uniaxial Tensile Stress Behavior}

The uniaxial tensile response of concrete (Figure 3.12) is assumed to be characterized by damaged plasticity. The stress-strain response shows a linear elastic relationship until it reaches the failure stress $\left(\sigma_{t 0}\right)$ which corresponds to the onset of micro-cracking in the concrete material. Beyond the failure stress, the formation of micro-cracks are macroscopic with a softening stress-strain response which induces strain localization in the concrete structure (Abaqus 6.12 Analysis User's Manual, 2012). 


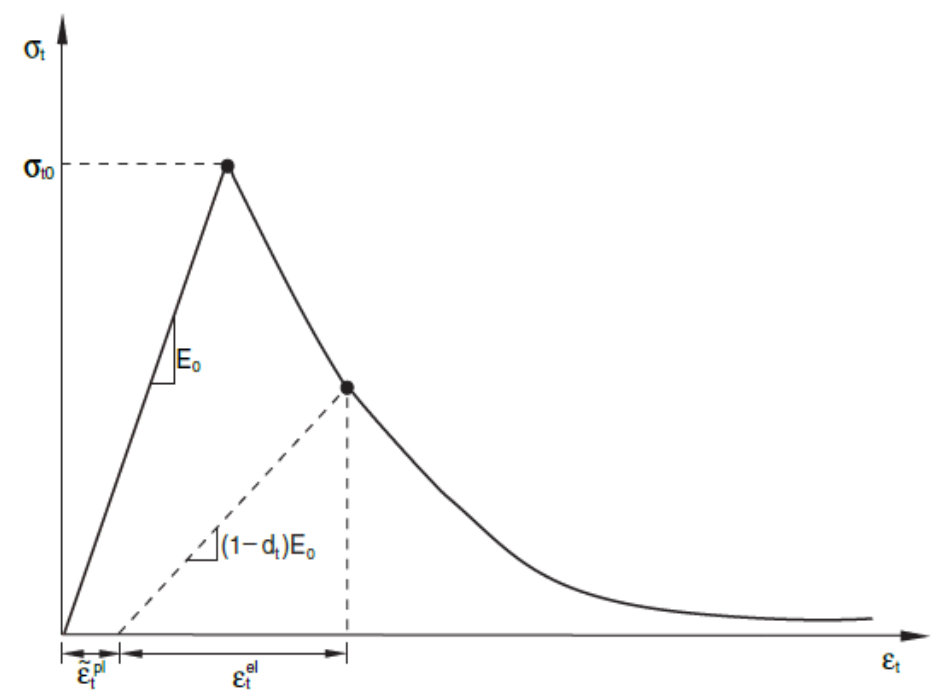

Figure 3.12 Response of concrete to uniaxial loading in tension (Abaqus 6.12 Analysis User's Manual, 2012).

\subsection{Uniaxial Compressive Stress Behavior}

The uniaxial compressive response of concrete shown in Figure 3.13 (a), is assumed to be characterized by damaged plasticity. The response is linear until the initial yield point $\left(\sigma_{c 0}\right)$. In the plastic regime the response is typically characterized by stress hardening proceeded with strain softening beyond the ultimate stress $\left(\sigma_{c u}\right)$. The elastic stiffness of the materials is degraded (damaged) when the concrete specimen is unloaded from any point on the strain softening branch thus weakening the unloaded response as shown in the stress-strain curve. Tensile damage and compressive damage represents the degradation of the elastic stiffness. Both damage variables are assumed to be functions of the plastic strains, temperature and field variables. The damage variables can range between zero (undamaged material) to one (total loss of strength) (Abaqus 6.12 Analysis User's Manual, 2012). 


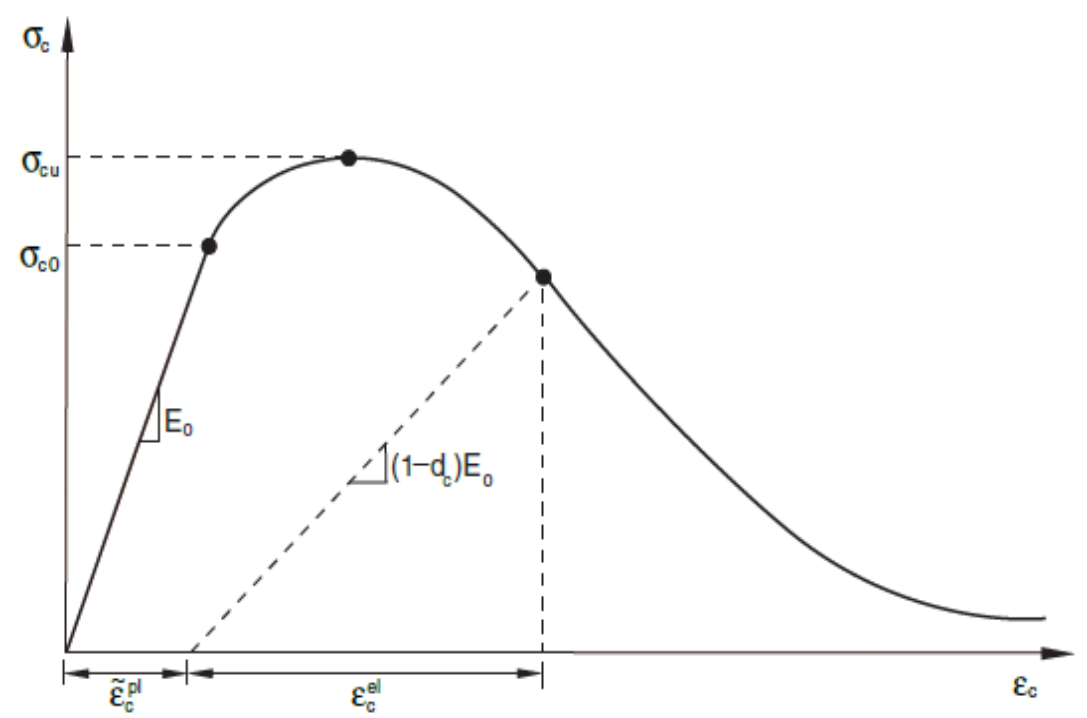

Figure 3.13 (a) Response of concrete to uniaxial loading in compression (Abaqus 6.12 Analysis User's Manual, 2012).

\subsection{Stress-Strain Relationship in Concrete}

The compressive stress-strain relationship for the concrete model proposed by Popovics was incorporated to simulate the concrete behavior in compression. The value of compressive stress $\left(f_{c}\right)$ is a function of concrete strain $\left(\varepsilon_{c}\right)$ that can be derived using Eq. 3.11 (Popovics 1973). Figure 3.13 (b) shows the stress-strain curve for varying compressive strengths of concrete.

$\frac{f_{c}}{f^{\prime} c}=\frac{n\left(\varepsilon_{c} / \varepsilon_{0}\right)}{n-1+\left(\varepsilon^{\varepsilon_{c}} / \varepsilon_{0}\right)^{n K}}$

$\mathrm{n}=0.8+\frac{\mathrm{f}_{\mathrm{c}} \mathrm{c}}{17}$ or $\mathrm{n}=\frac{\mathrm{E}_{\mathrm{c}}}{\mathrm{E}_{\mathrm{c}}-\mathrm{E}_{\mathrm{c}}^{\prime}}$

$\mathrm{E}_{\mathrm{c}}=6900+3300 \sqrt{\mathrm{f}_{\mathrm{c}}^{\prime}}$

$\mathrm{E}_{\mathrm{c}}^{\prime}=\frac{\mathrm{f}_{\mathrm{c}}^{\prime}}{\varepsilon_{0}}$

$\varepsilon_{0}=\frac{\mathrm{f}_{\mathrm{c}}^{\prime}}{\mathrm{E}_{\mathrm{c}}}\left(\frac{\mathrm{n}}{\mathrm{n}-1}\right)$

$\mathrm{K}=1.0 \quad$ when $\left(\varepsilon_{\mathrm{c}} / \varepsilon_{0}\right) \leq 1.0$

$\mathrm{K}=0.67+\frac{\mathrm{f}_{\mathrm{c}}^{\prime}}{62} \geq 1.0 \quad$ when $\left(\varepsilon_{\mathrm{c}} / \varepsilon_{0}\right)>1.0$ 
Where $f_{c}^{\prime}$ is the ultimate compressive strength of concrete, $\mathrm{n}$ is the curve-fitting factor, $E_{c}$ is the initial tangent modulus, $E_{c}^{\prime}$ is the tangent modulus of concrete at $f_{c}^{\prime}, \varepsilon_{0}$ is the strain when $f_{c}$ reaches $f_{c}^{\prime}$, and $K$ is a factor to control the slope of the stress-strain curve

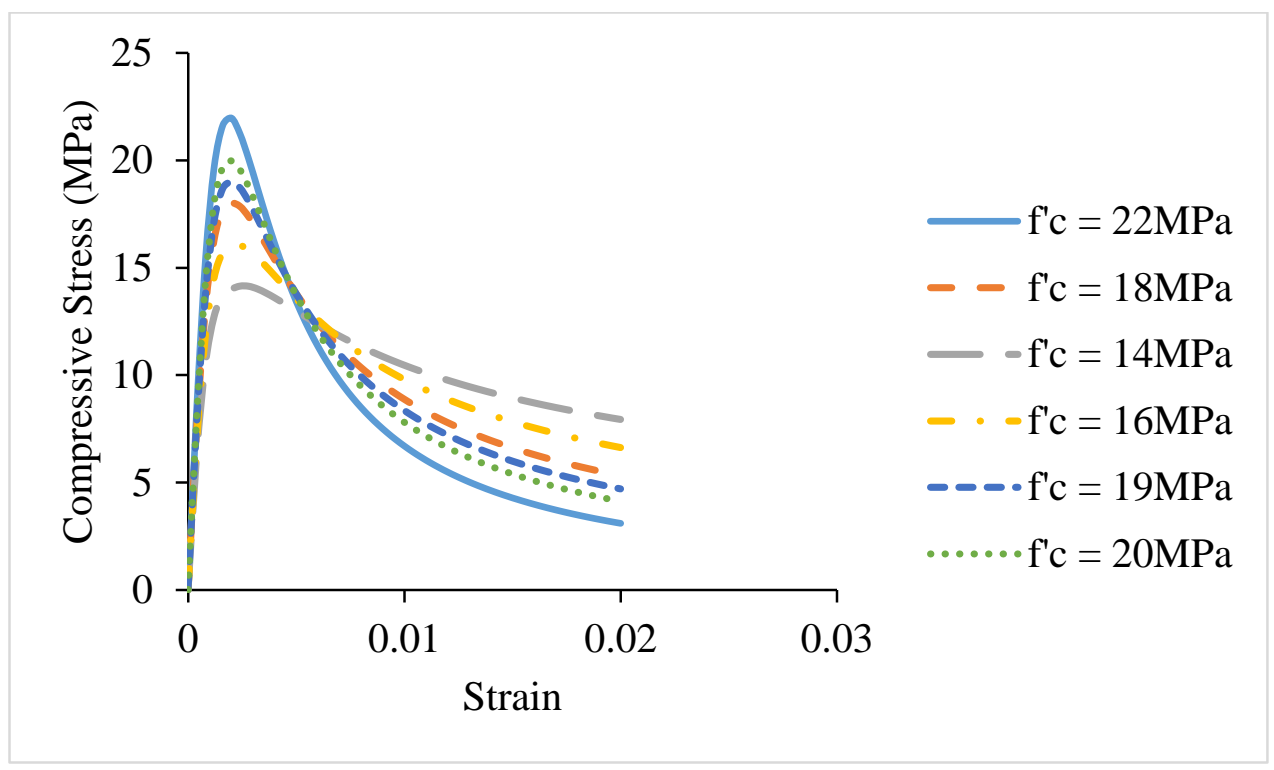

Figure 3.13 (b) Compressive stress-strain curve for the different compressive strengths

\subsection{Tensile Damage and Compressive Damage}

Uniaxial tension damage variable was tabulated as a function of yield stress and cracking strain, whereas uniaxial compression damage variable was tabulated as a function of yield stress and inelastic (crushing) strain. The damage variables are treated as non-decreasing material point quantities, in Abaqus. At any increment during the analysis, the new value of each damage variable is obtained as the maximum between the value at the end of the previous increment and the value of the corresponding to the current state. Usually, excessive damage might have a critical effect on the rate of convergence, hence choosing the appropriate damage properties is important. It is suggested to refrain using values greater than 0.99 , which corresponds to a $99 \%$ reduction of the stiffness (Abaqus 6.12 Analysis User's Manual, 2012).

\subsubsection{Description of FE Model}

In order to investigate the structural behavior of the PSSDB wall panels under axial loading, simplified finite element models were simulated using the different modules present. A set of nonpierced and pierced composite PSSDB panels were modeled using $0.48 \mathrm{~mm}$ thick profiled steel 
sheet that is sandwiched between two $6 \mathrm{~mm}$ thick boards connected via discrete fasteners. Both sets of load bearing wall panels were further investigated using concrete infill.

\subsubsection{Parts, Element Assignment, Mesh}

Three dimensional PSSDB composite walls were created using three main components, namely profiled steel sheet, dry-boards and fasteners. The boards were modeled as solid elements using linear hexahedral elements (C3D8R), whereas the profiled steel sheet was modeled as shell element using linear quadrilateral shell element (S4R). Like boards, profiled concrete core adopted linear hexahedral elements (C3D8R) for panels with concrete infill. Material and section properties were assigned to the elements, accordingly. Meshing technique and the type of element are specified in the mesh module. Reduced integration and hourglass control elements are used for this study which consists of only one integration point located at the element's centroid as shown in Figure 3.14. The description of stress/displacements of the element types used are presented in Table 3.8.

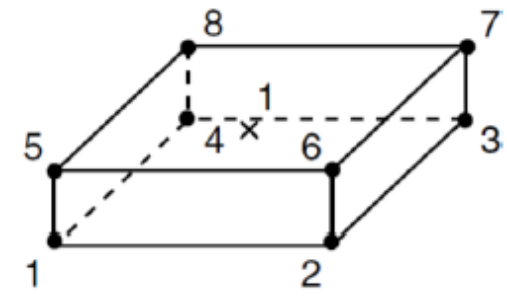

Continuum 3D, 8-noded reduced integration element (C38DR)

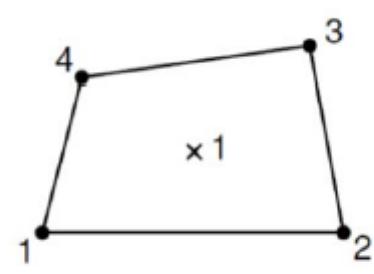

Shell, 4-noded reduced integration (S4R)

Figure 3.14 Integration points for linear elements (Rafiei, 2011)

Table 3.8 Description of stress/displacements elements (Rafiei, 2011)

\begin{tabular}{|l|l|}
\hline Element & Description \\
\hline $\begin{array}{l}\text { Linear Hexahedral Element } \\
\text { (C3D8R) }\end{array}$ & $\begin{array}{l}\text { 8-node linear brick element with reduced-integration and hourglass } \\
\text { control. 3D stress family with uniform strain and linear geometric } \\
\text { order. This element consists of only single integration point. }\end{array}$ \\
\hline $\begin{array}{l}\text { Linear Quadrilateral Shell } \\
\text { Element (S4R) }\end{array}$ & $\begin{array}{l}\text { 4-node linear thick shell with reduced integration and hourglass } \\
\text { control. Shell family with uniform strain and geometric order. This } \\
\text { element consists of only single integration point. }\end{array}$ \\
\hline
\end{tabular}


Reduced integration uses a lower-order integration to form the element stiffness and reduces computational time. In the linear reduced-integration elements, hour-glassing is a numerical problem which tend to be too flexible. In order to limit the propagation of hourglass modes, a small amount of artificial "hourglass stiffness" are introduced. When greater number of elements are used in the model, the hourglass stiffness is more effective at restraining the hourglass modes if reasonable fine mesh is used, the linear reduced integration elements provide reliable results (Rafiei, 2011). The parts, mesh and assigned elements used in this study are presented in Figure 3.15 to 3.17. Figure 3.17 (b) displays the load-deformation responses of the axially loaded wall with three different mesh sizes $25 \mathrm{~mm}, 35 \mathrm{~mm}$ and $45 \mathrm{~mm}$. It can be deduced that using finer mesh (mesh size $=25 \mathrm{~mm}$ ) produced results closer to that of the experimental despite the increase in computational time.

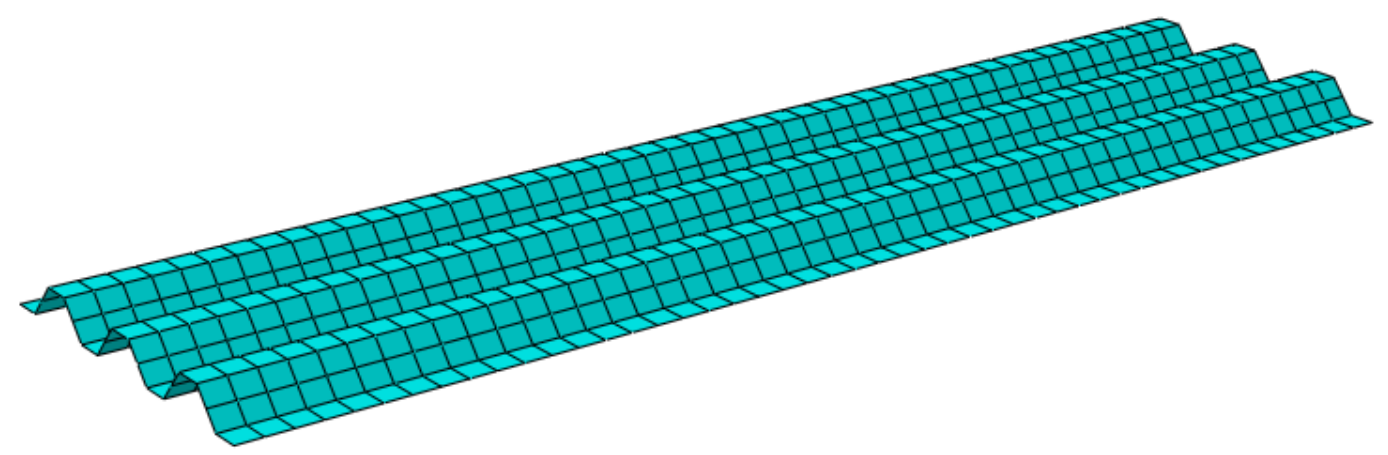

Figure 3.15 Profiled steel sheet- linear quadrilateral shell element (S4R)

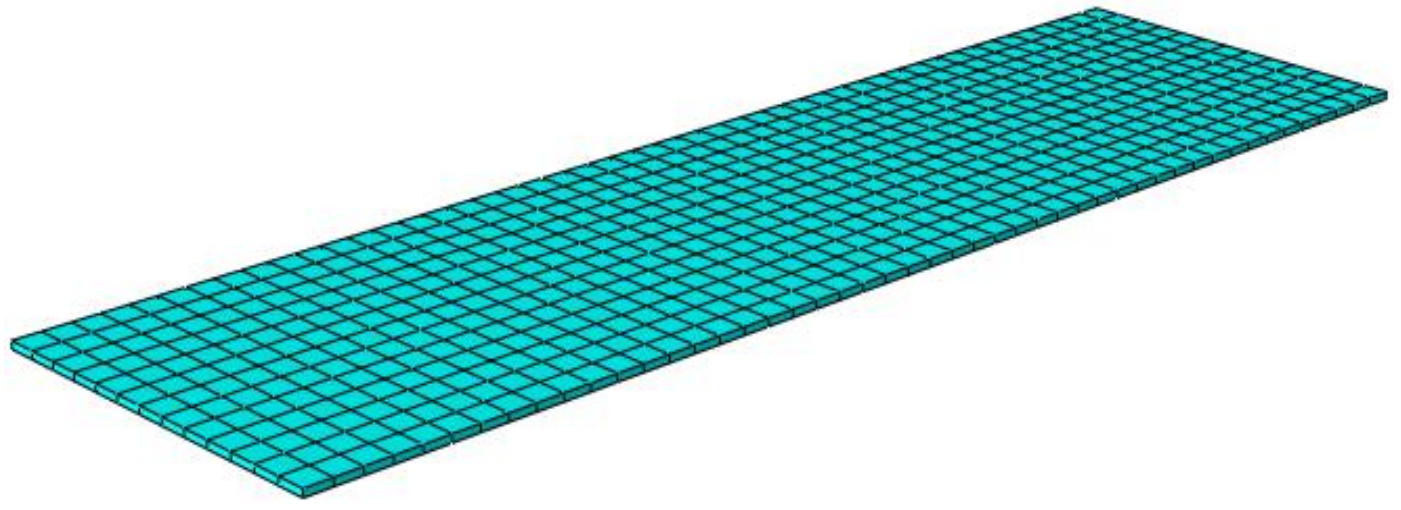

Figure 3.16 Dry board - linear hexahedral solid element (C3D8R) 


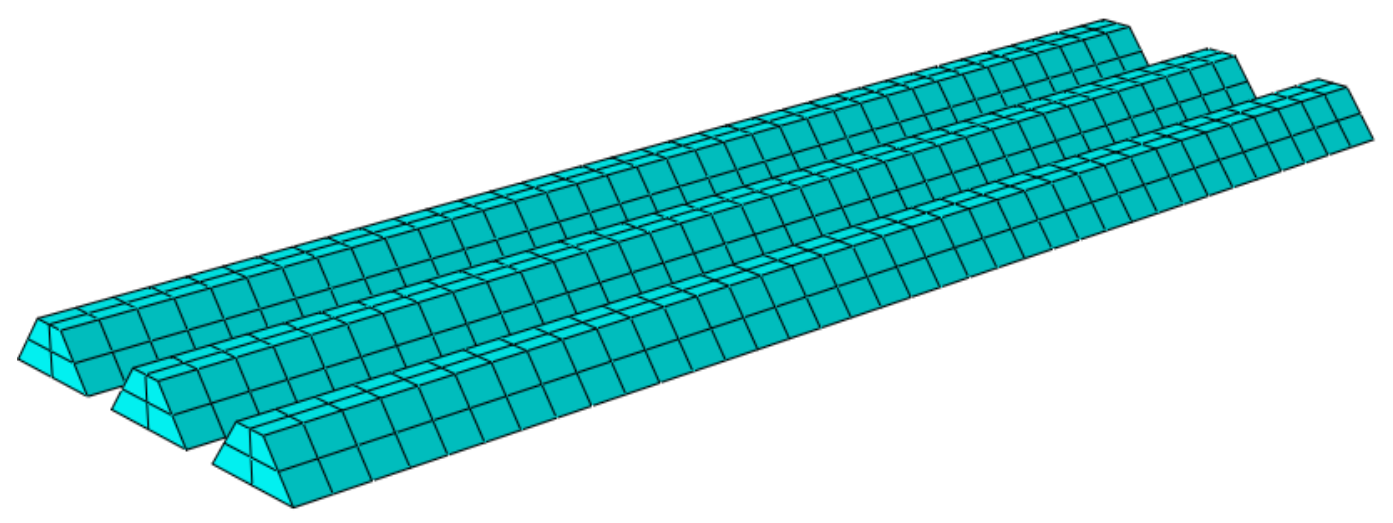

Figure 3.17 (a) Profiled concrete core -linear hexahedral solid element (C3D8R)

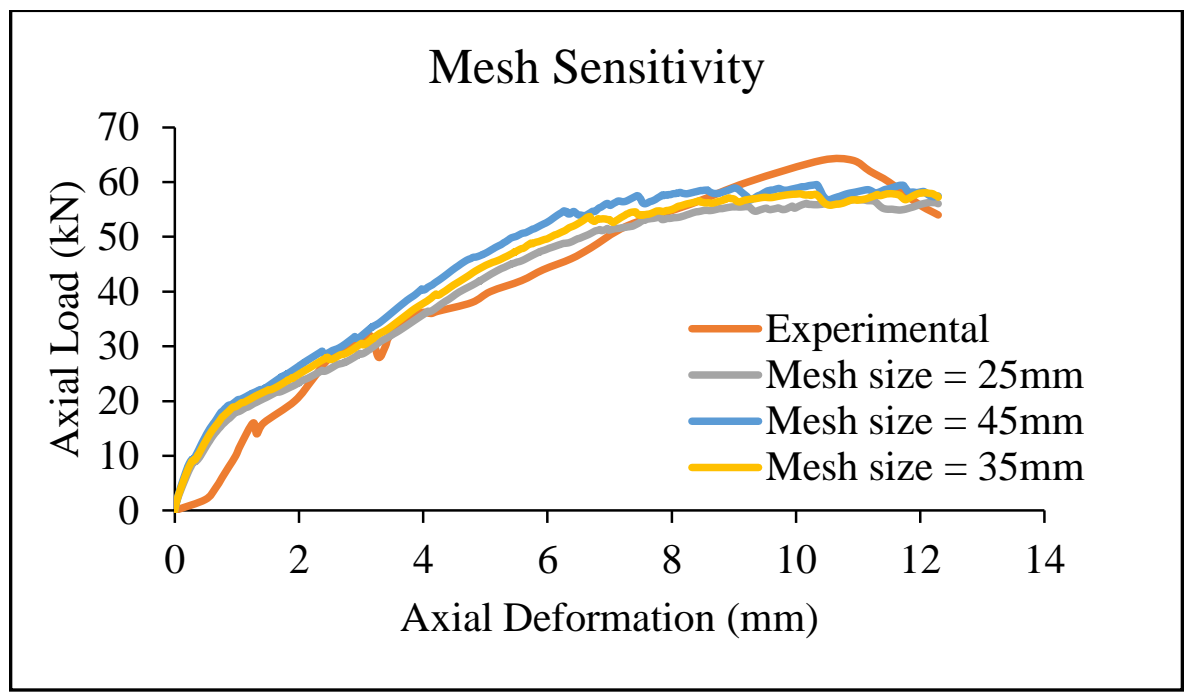

Figure 3.17 (b) Mesh sensitivity analysis with displacement control

\subsubsection{Assembly of Parts, Step and Contact/Interactions}

In the Assembly module, all part instances are assembled and placed geometrically together. Using bolt and nut connection to connect the elements together makes the model more sophisticated for analysis hence, discrete fasteners were used instead. The attachment toolset allows users to create attachment points and lines between selected faces where discrete fasteners can be defined. Figure 3.18 shows the assembly of discrete fasteners in the non-pierced panel, followed by Figure 3.19 that displays the layout of the rows of fasteners used in the pierced unfilled and filled panels. 


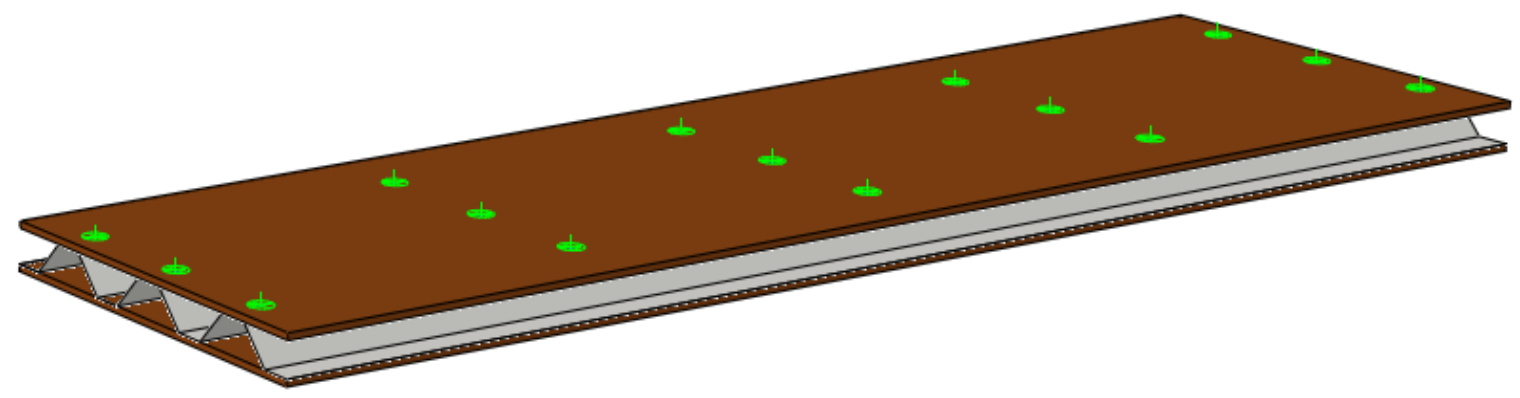

Figure 3.18 Assembled PSSDB composite panel with discrete fasteners aligned
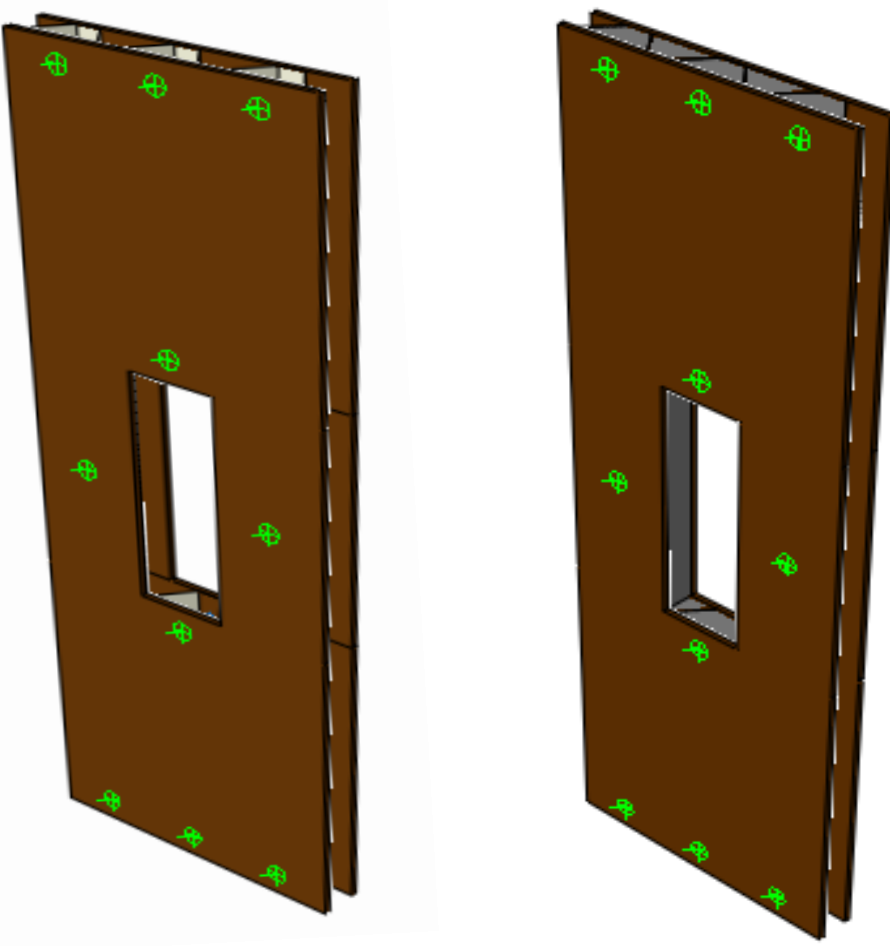

Figure 3.19 Pierced unfilled (left) and filled (right) PSSDB panel

The step module allows to create a sequence of one or more steps to perform static or dynamic analysis. The steps used for this study were Initial and Static General with the Nlgeom setting in ABAQUS/Standard to carry out the non-linear analysis of the walls. Defining the interaction between the elements is very crucial during the numerical simulation of the models. Steel-wood interaction and steel-concrete interaction are defined for the elements in the step module. The interaction between the surfaces of the elements is defined using "contact interaction" and "interaction properties". The surfaces in contact are identified in the assembly module and 
paired using "surface-to-surface" contact interaction. The potential contact surfaces were assigned an interaction property. Tangential contact behavior and normal contact behavior were specified in the interaction properties. Friction coefficients of 0.3 and 0.62 were assigned for the tangential behavior between the steel-wood and concrete-wood interfaces, respectively. The static friction for wood and metals were obtained from the Engineered Materials Handbook (ASM International Handbook Committee, 1987). The friction formulation was selected to be "frictionless" for the tangential behavior in the PSSDB panels with concrete infill. Secondly, default options for Pressure-Overclosure (Hard contact) and "Constraint enforcement method" was selected for the normal contact behavior. Furthermore, separation after contact was allowed. The connections between the elements contribute to the composite action of the PSSDB wall panels.

\subsubsection{Boundary Condition and Displacement Control Analysis}

There are two methods, namely load-control analysis and displacement-control analysis to determine the load-bearing capacity of the composite walls. In the load-control analysis, an incremental load is applied on the structure via the amplitude toolset to obtain significant results. However, in the displacement control analysis an incremental displacement is applied via the amplitude toolset to obtain an ultimate load as reaction forces acting on the structure. The amplitude toolset in ABAQUS helps input the rate at which the load/displacement is applied with time.

Displacement-control analysis was chosen for this study to obtain the ultimate load-bearing capacity for the PSSDB wall panels. Due to convergence errors, load-control analysis was found to be insufficient compared to displacement-control analysis to perform non-linear analysis of this structure. Loading of the composite wall was obtained by allocating a prescribed displacement at the reference point while defining a uniform distribution in the boundary condition. The reference point was positioned at the top of the panel. The reference point was constrained in the y-direction using kinematic coupling, as shown in Figure 3.20. All three displacement degree of freedoms $(\mathrm{U} 1=\mathrm{U} 2=\mathrm{U} 3=0)$ were restrained at the bottom of the tested composite panels. 


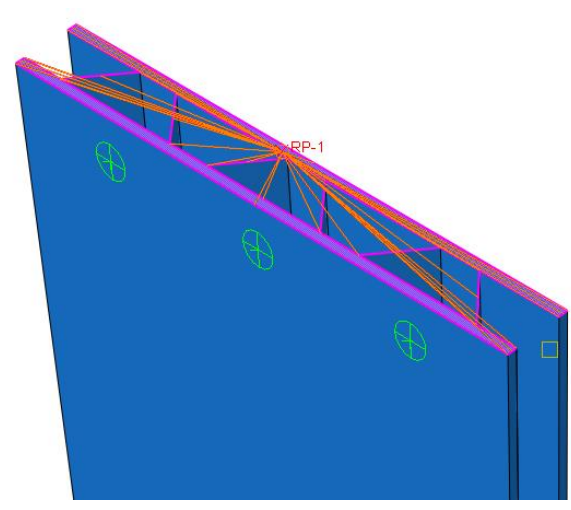

Figure 3.20 Location of reference point and constraining y-direction using kinematic coupling

\subsubsection{Finite Element Results: Axial Load-Deformation Response}

The results presented herein are based on the deflection profile, load-deformation response, failure modes and stress contours shown in layers of front board, rear board and profiled steel sheet and composite panel as a whole. Typical load-deformation response and deformed shape of the PSSDB composite wall panels were recorded and then compared. All tested PSSDB walls display similar load-deformation response with linear-elastic behavior until it reached the point of failure. Consequently, after the point of failure, there was a rapid increase in deformation with decrease in load.

Panels with constant rows of fasteners and varying $\mathrm{h} / \mathrm{w}$ ratio and vice versa were investigated to determine the influence on the load-bearing capacity of the walls. Figure 3.21 shows the variation of the load-deformation response of the non-pierced PSSDB wall panels without concrete infill. After the peak load, overall failure for the panels commenced due to buckling failure of the PSSDB composite panels. When compared to the shorter wall, the slender PSSDB wall panel showed a prolonged post-peak descending branch. Comparison of the ultimate load values shows that there was a $43 \%$ increase in the load-bearing capacity of the PSSDB wall panels when the height-to-width ratio decreased as seen during the experimental tests. Furthermore, it was also found out that decreasing longitudinal screw spacing or increasing the number of the row spacers significantly improved the load-bearing capacity of the PSSDB wall panels. Comparison of the ultimate load values show that there was a $48 \%$ increase in the load-bearing capacity of the PSSDB wall panels when the number of row fasteners increased from 3 to 5 . No significant failure was observed at the fasteners connecting the dry-board and the profiled steel sheeting. The deflection 
profile and the deformed shape showing displacements of the axially loaded panels are shown in Figure 3.22 and Figure 3.23.

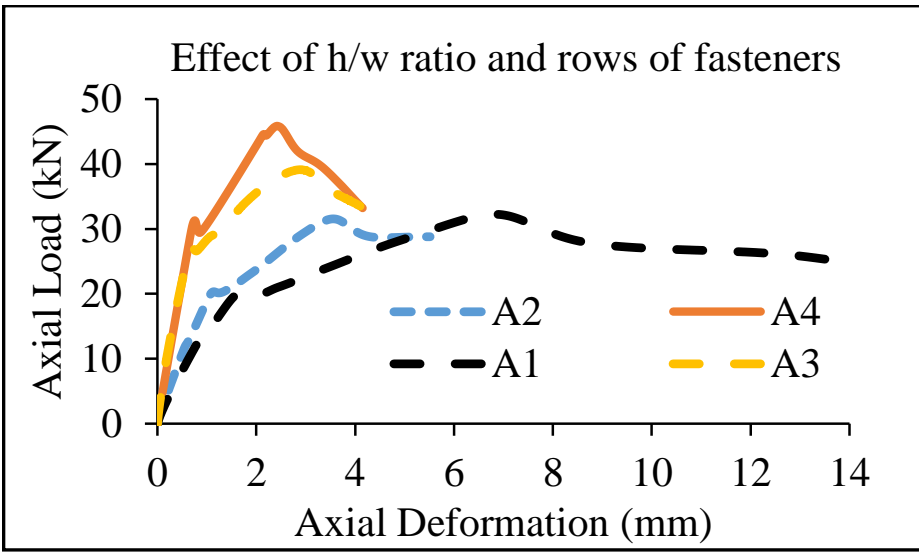

Figure 3.21 Axial load-deformation response comparing PSSDB panels with varying h/w ratio and rows of fasteners
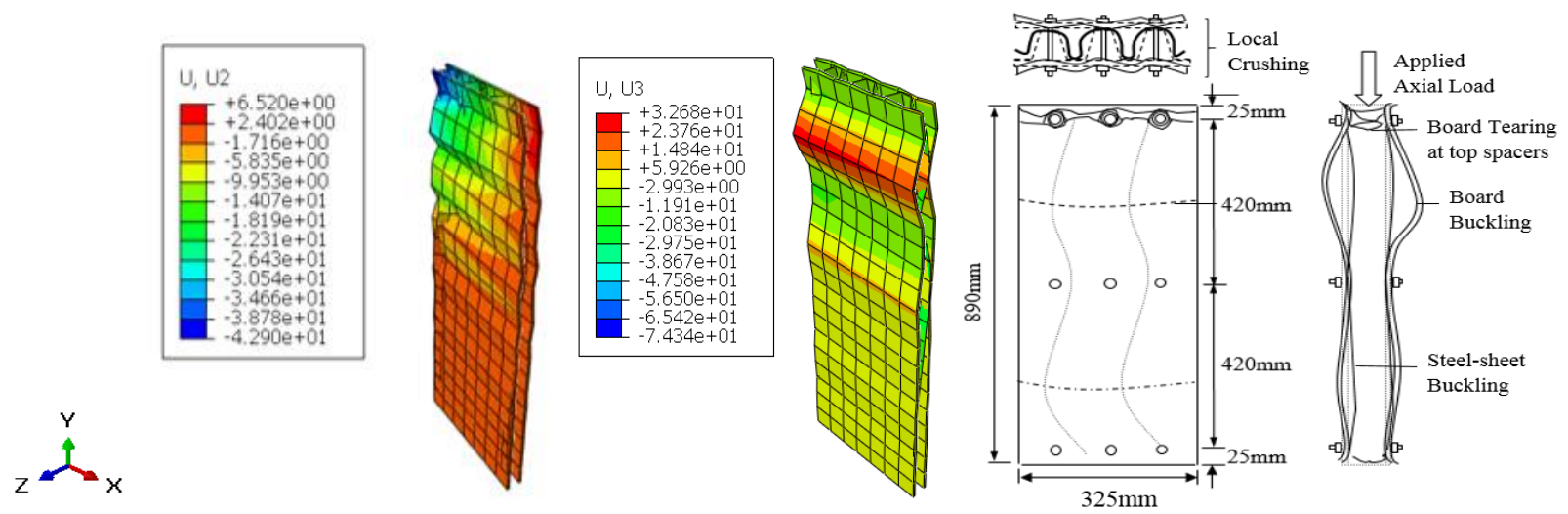

(a)
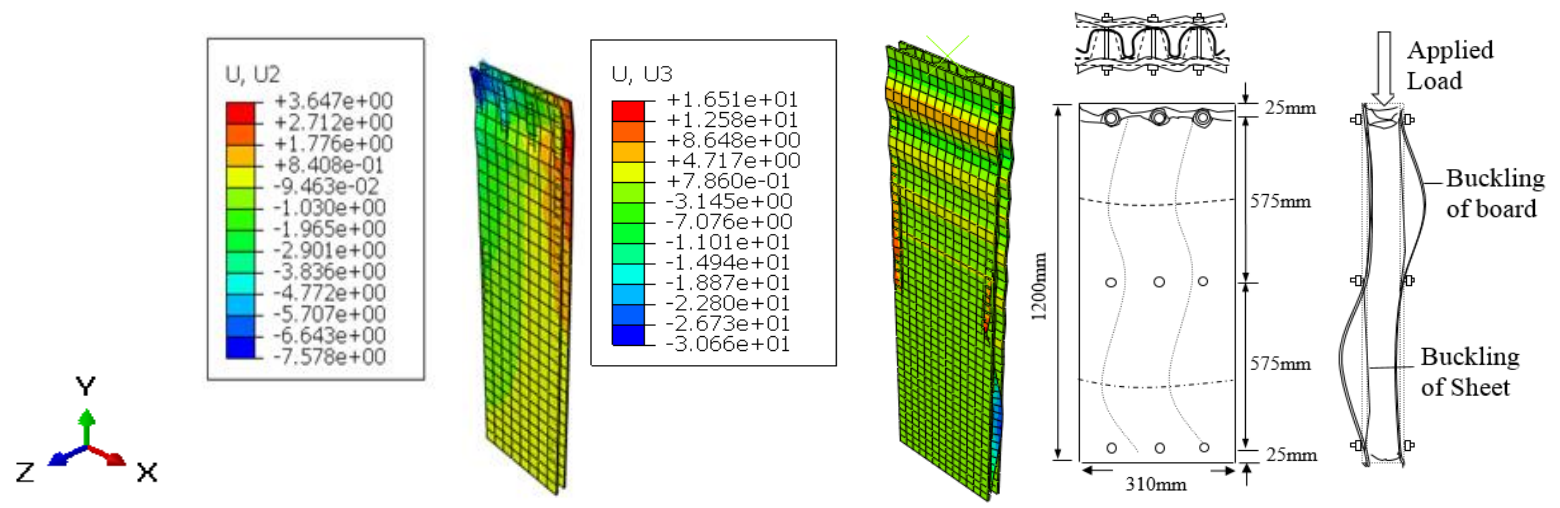

(b)

Figure 3.22 Displacements (mm) and deformed shape of the PSSDB panels at the end point of FEA run for (a) A1 (b) A2 

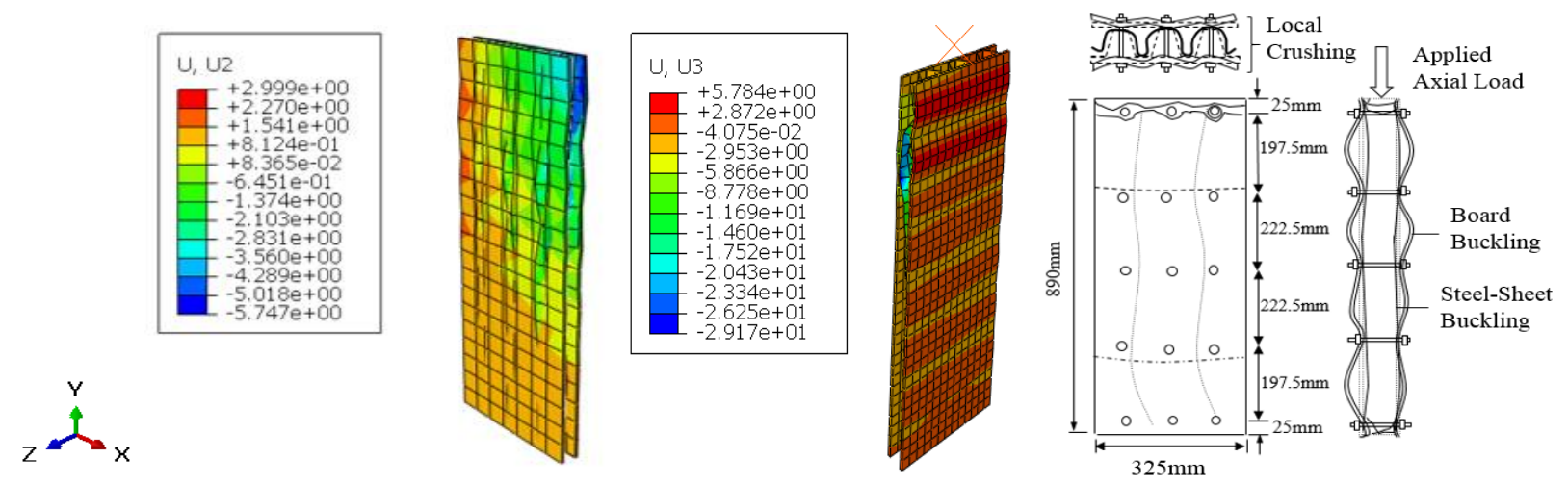

(a)
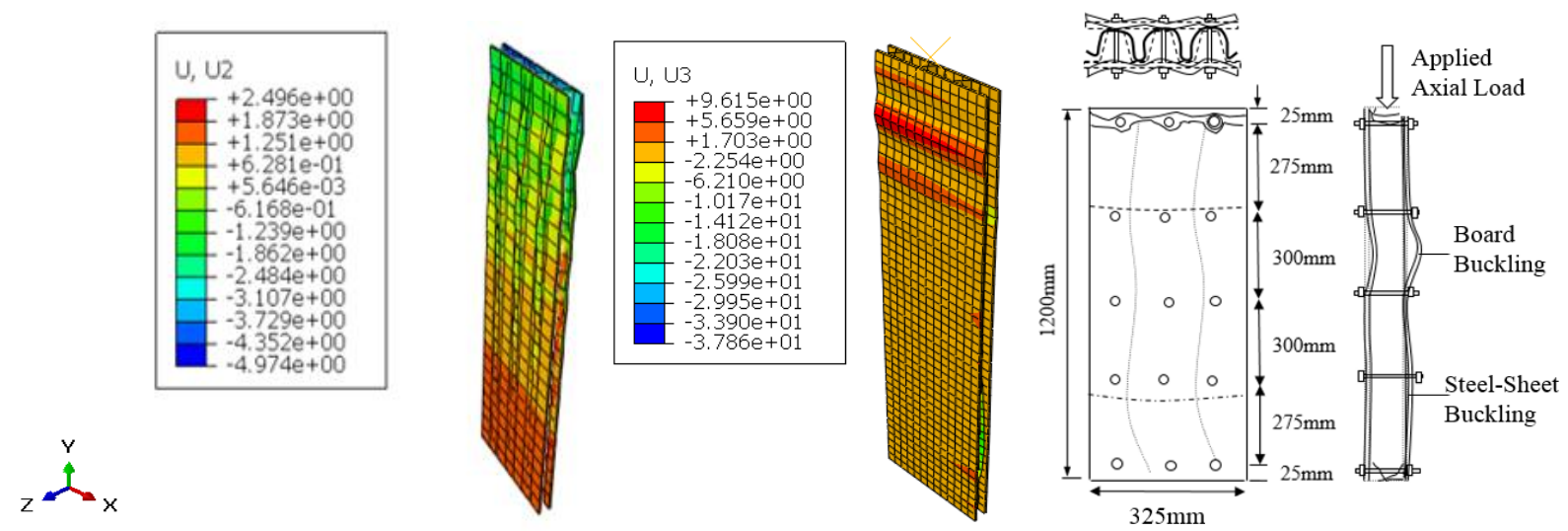

(b)

Figure 3.23 Displacements (mm) and deformed shape of the PSSDB panels at the end point of the FEA run for (a) A3 (b) A4

The use of concrete infill in the troughs of the PSS enhanced the structural performance of the PSSDB composite panels. Three panels of varying heights with constant number of row spacers were analyzed. Figure 3.24 shows the load-deformation response of the three tested panels. The ultimate loads carried by the concrete in-filled panels are $56 \mathrm{kN}, 76 \mathrm{kN}$, and $59 \mathrm{kN}$, respectively when the heights of the panels increased from $500 \mathrm{~mm}$ to $1200 \mathrm{~mm}$. The non-pierced in-filled wall with an effective dimension of $900 \mathrm{~mm}$ x 310mm exhibited higher load-bearing capacity compared to the panel with an effective dimension of $1200 \mathrm{~mm} \times 310 \mathrm{~mm}$. Comparison of the ultimate load values shows that the shorter panel $(900 \mathrm{~mm} \times 310 \mathrm{~mm})$ carried $29 \%$ higher axial load than the tall slender PSSDB wall panel $(1200 \mathrm{~mm}$ x 310mm). Similar behavior was noticed during the experimental tests thus proving that the increase in $\mathrm{h} / \mathrm{w}$ ratio decreases the load bearing capacity of the panels. The increase in performance can also be due to the natural adhesion or bonding in 
between the normal concrete with the wooden board and profiled steel sheet. Figure 3.25 shows the deflection profile and the deformed shape of the tested panels.

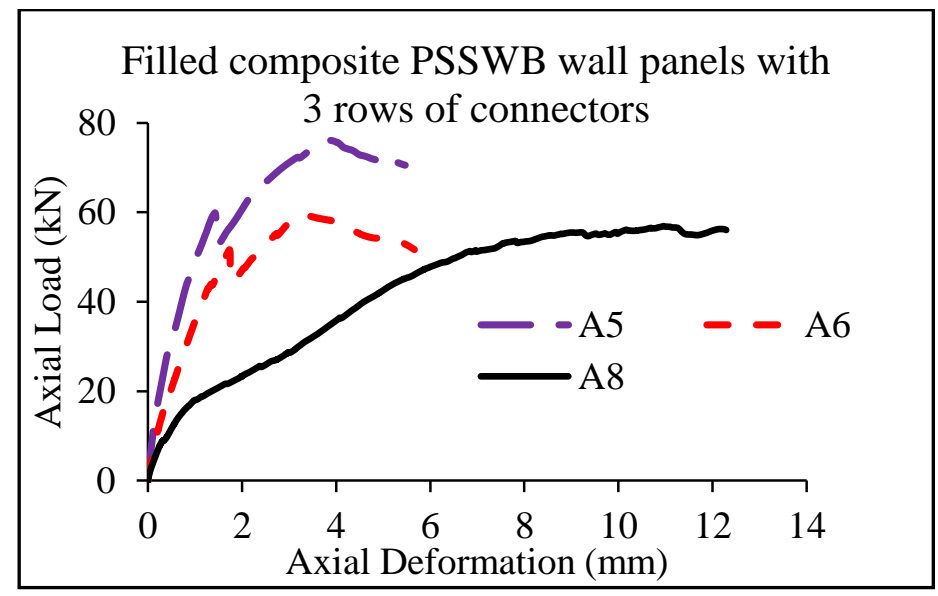

Figure 3.24 Axial load-deformation response comparing filled composite (A5, A6 and A8)

PDDSB panels with varying heights and 3 rows of spacers
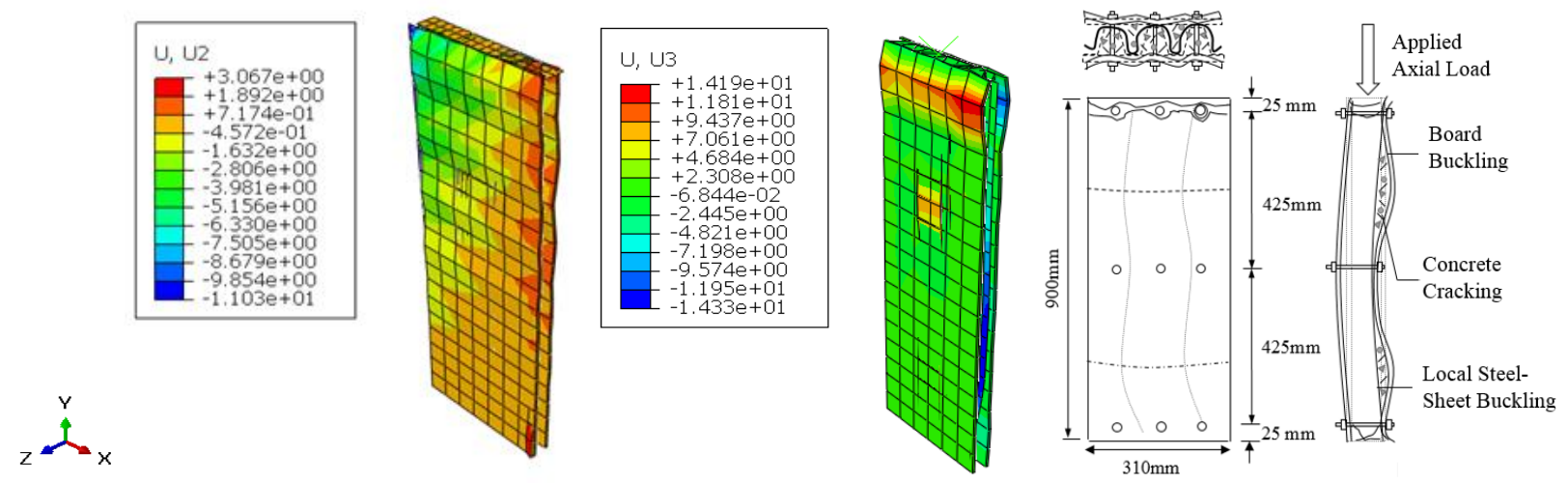

(a)
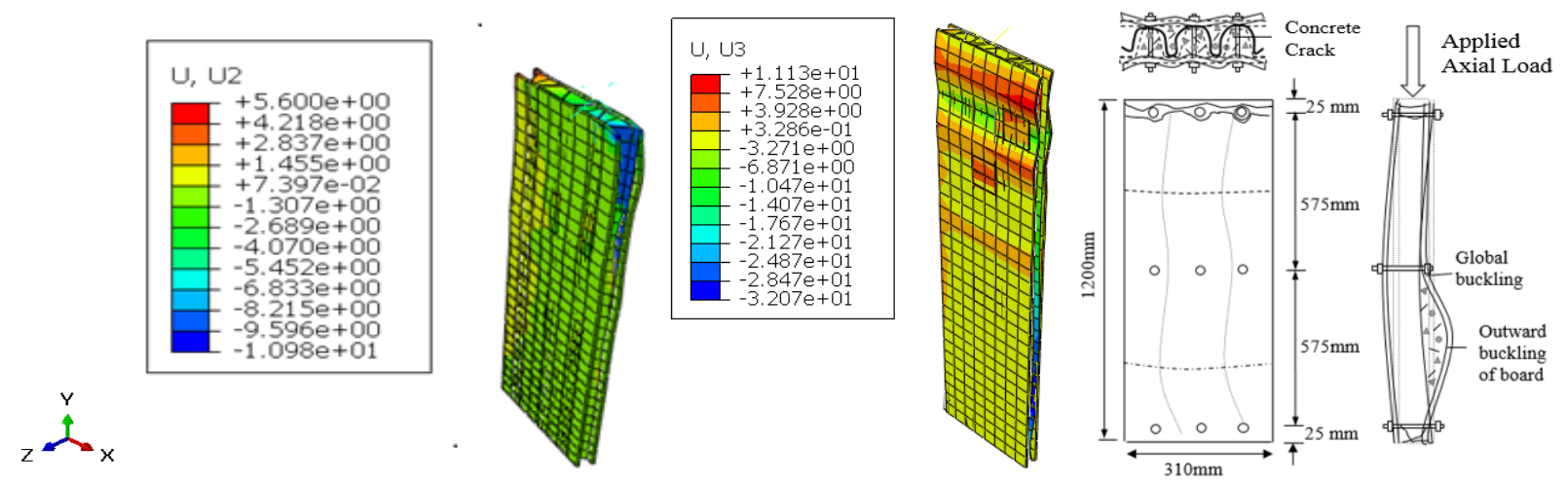

(b)

Figure 3.25 Displacements $(\mathrm{mm})$ and deformed shape of filled PSSDB panels at the end point of FE run with varying heights and 3 rows of spacers (a) A5 (b) A6 

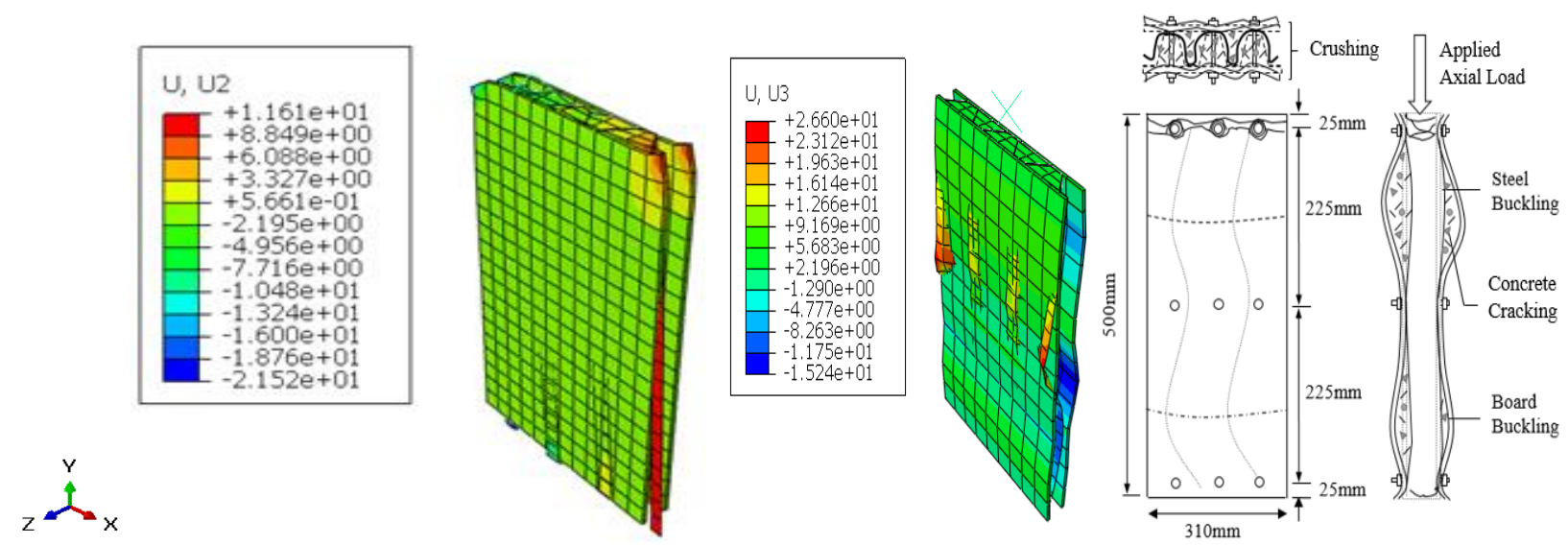

Figure 3.25 (c) Displacements (mm) and deformed shape of filled PSSDB panels (A8) at the end point of FE run

The load-deformation curves for the perforated PSSDB panels with and without concrete infill are presented in Figure 3.26. The filled composite panel with a rectangular opening was able to sustain more load than the perforated unfilled composite panel. Critical areas were indicated at the areas above the opening in the pierced panels. Reduction in the cross-sectional area of the wall panel contributed to higher stresses at the corners of the opening. The filled panel (A7) carried $68 \%$ more load than the unfilled panel (A9). Figure 3.27 shows the deflection profile and deformed shape of both the panels.

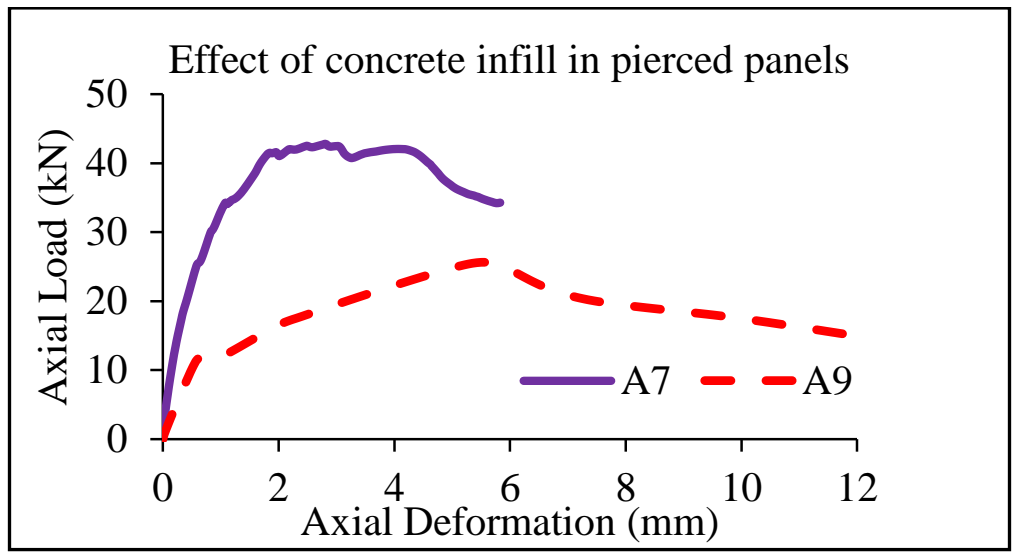

Figure 3.26 Axial load-deformation response comparing filled and unfilled pierced PSSDB panels 


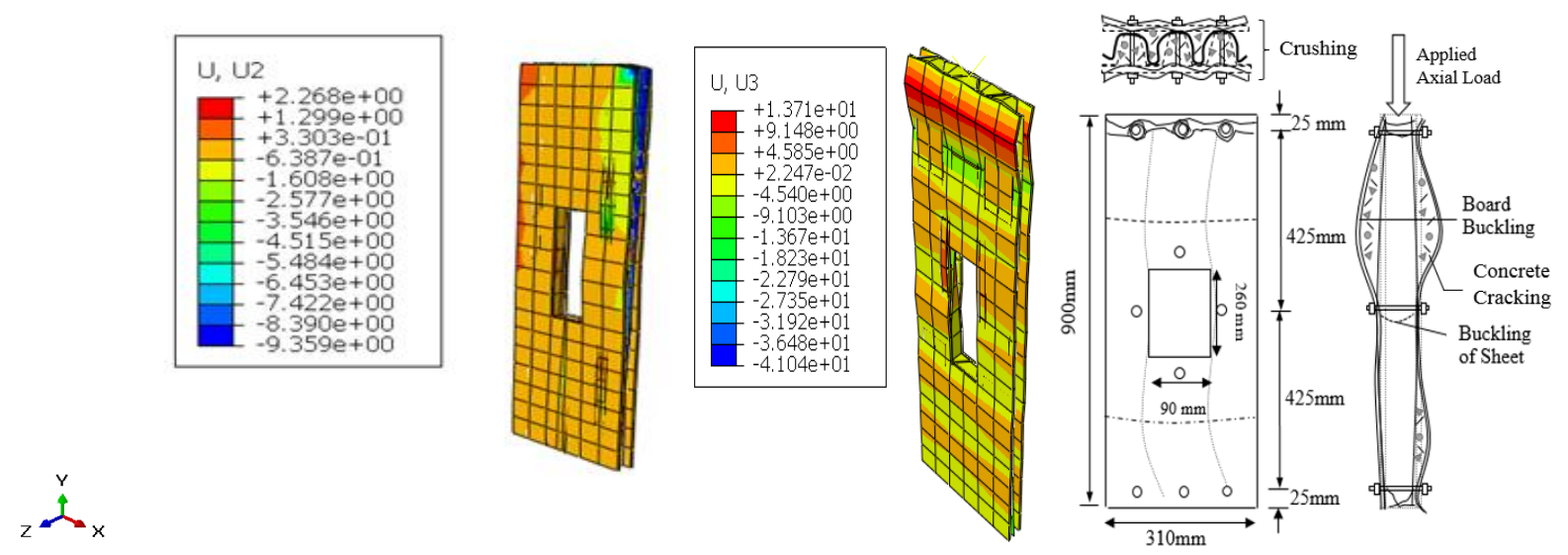

(a)
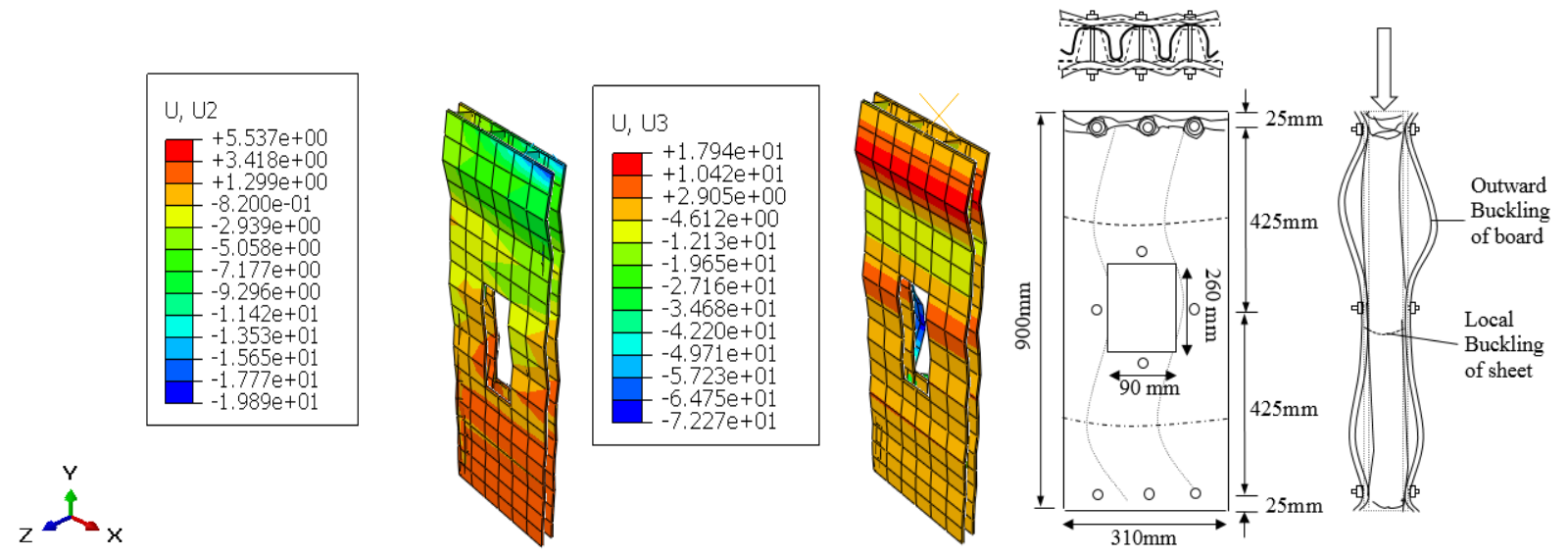

(b)

Figure 3.27 Displacements (mm) and failure mode of pierced (a) filled (A7) and (b) unfilled (A9) PSSDB panels at the end point of FE run

\subsubsection{Stress Contour Plots of PSSDB Composite Panels}

The failure phenomenon in the PSSDB composite wall panels was scrutinized with the aid of stress contour plots at $50 \%$ of the ultimate load, at the ultimate load and at the end of FE run, as shown in Figures 3.28 to 3.36. The variation of stress in the y-direction (S22) of the individual elements (front board, rear board, and PSS) were recorded. The color contour plots were used to observe the stress concentration in the composite panels. Low stress areas were presented in blue whereas high stress regions were presented in red. All models displayed similar profiles of stress contours with the front board and rear board being equally stressed up. Contour diagrams exhibited stress concentration around the holes for pierced panels. 


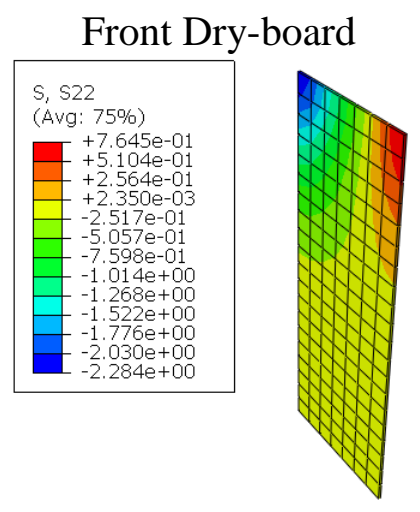

Front Dry-board
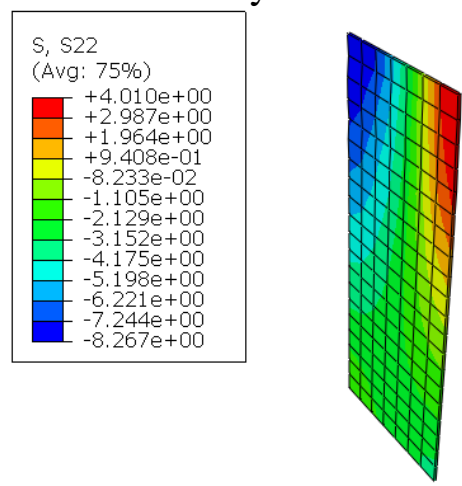

Front Dry-board
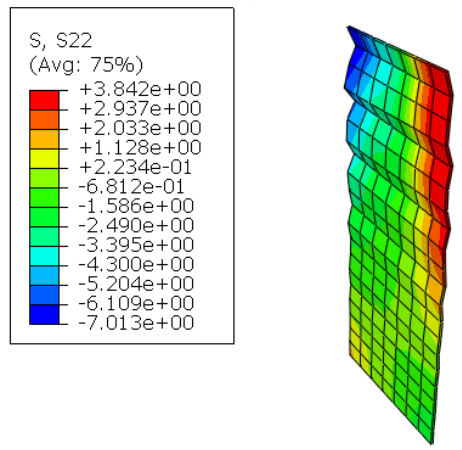
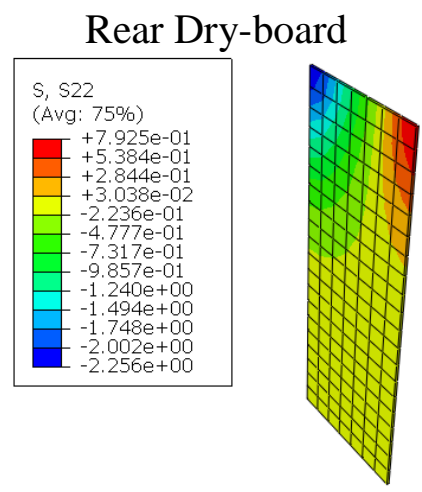

(a)

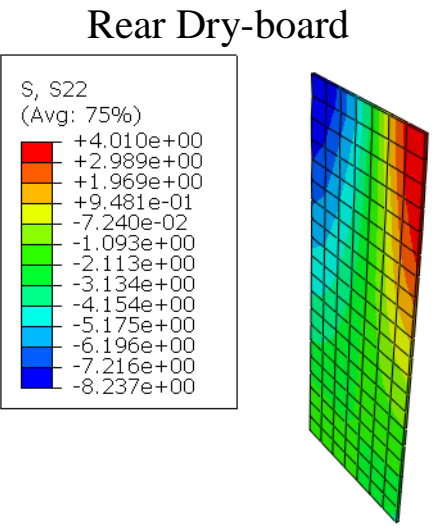

(b)

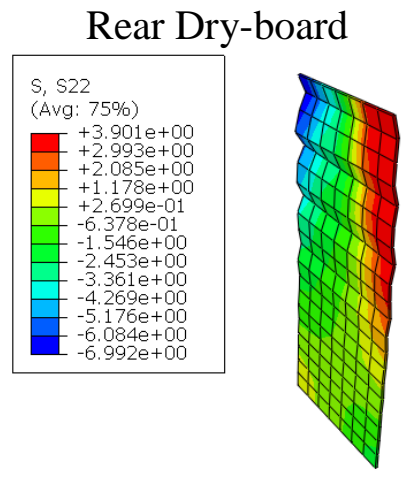

Steel Sheet
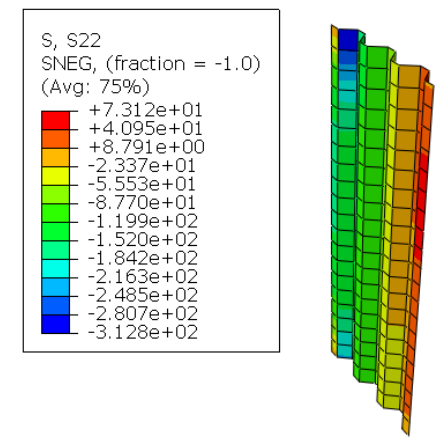

Steel Sheet
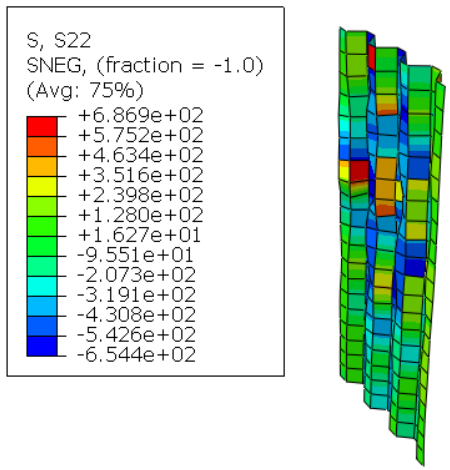

Steel Sheet
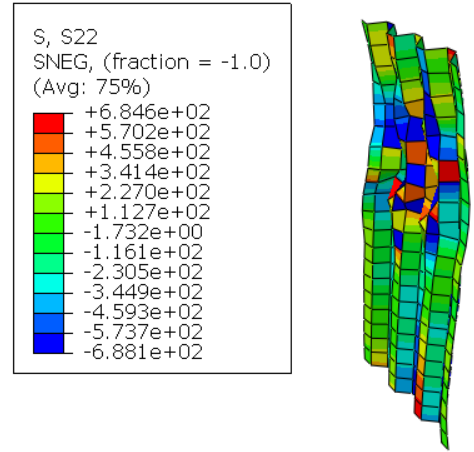

(c)

Figure 3.28 Maximum compressive principal stress, S22 (MPa) at (a) 50\% of ultimate load, (b) ultimate load, and (c) end point of FE run for A1 (without in-fill) 


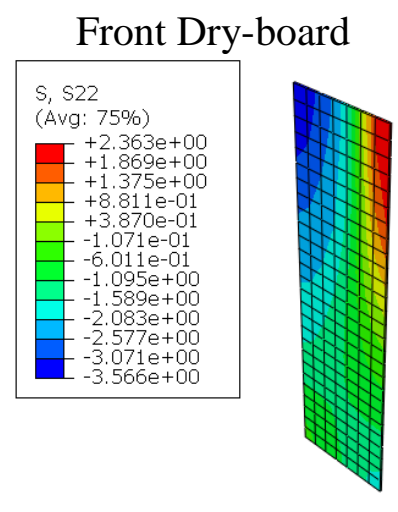

Front Dry-board

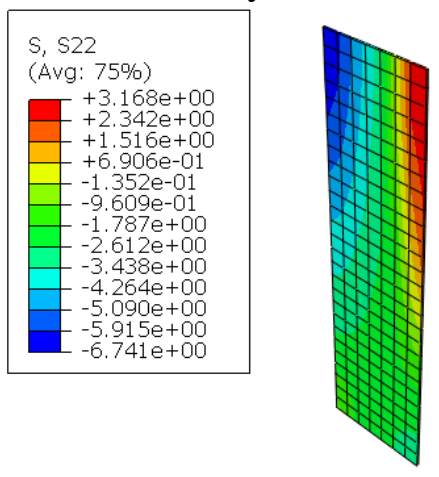

Front Dry-board
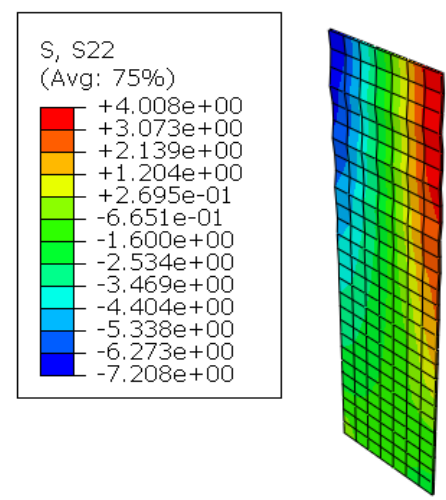

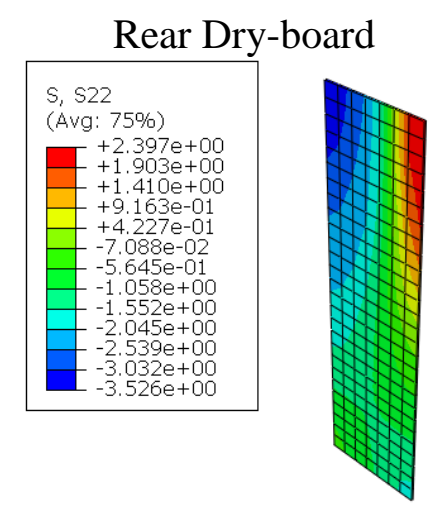

(a)

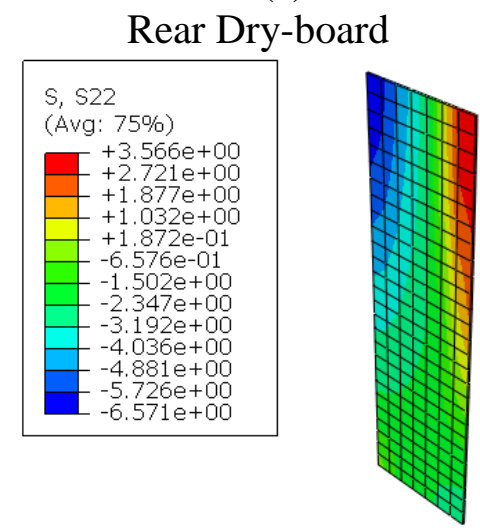

(b)

Rear Dry-board
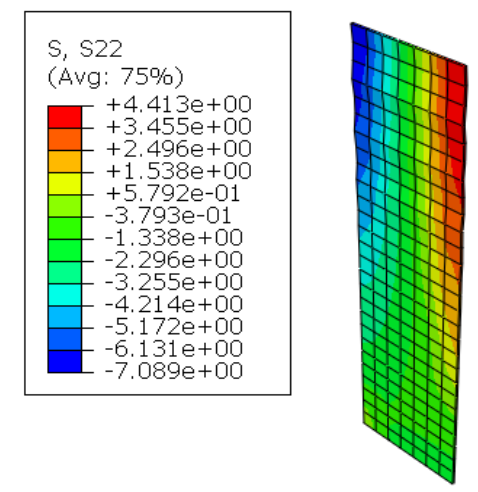

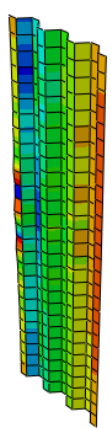

Steel Sheet
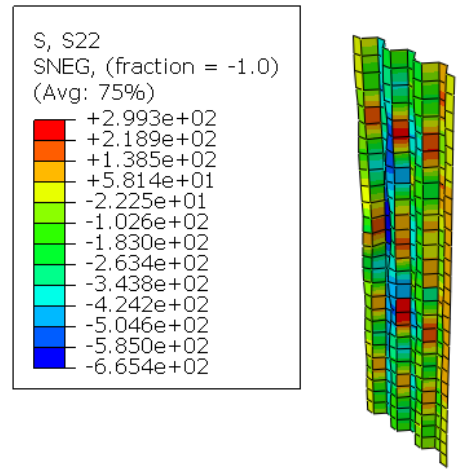

Steel Sheet
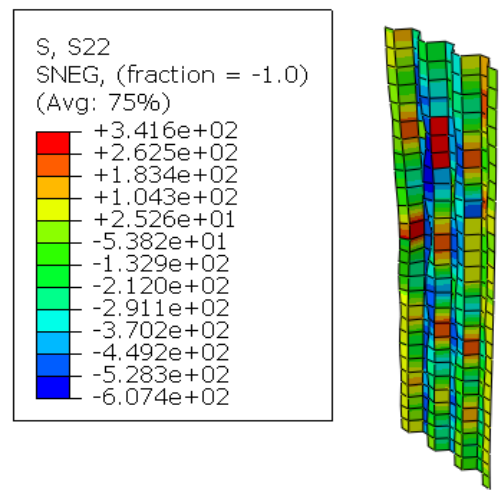

(c)

Figure 3.29 Maximum compressive principal stress, S22 (MPa) at (a) $50 \%$ of ultimate load, (b) ultimate load, and (c) end point of FE run for A2 (without in-fill) 
Front Dry-board

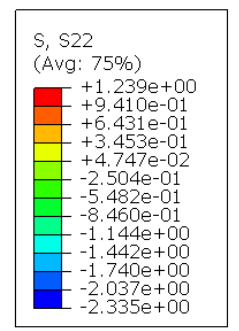

Rear Dry-board

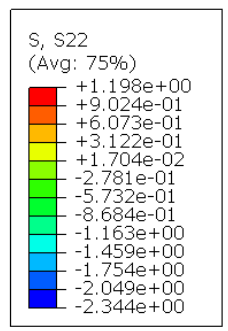

Steel Sheet

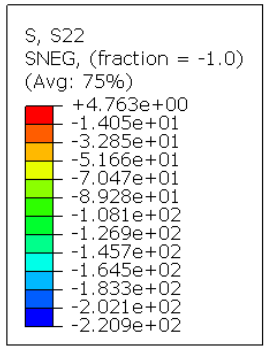

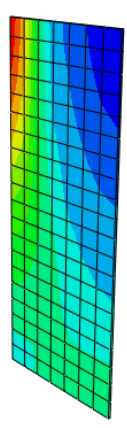

(a)

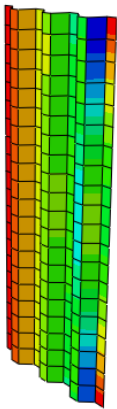

Steel Sheet
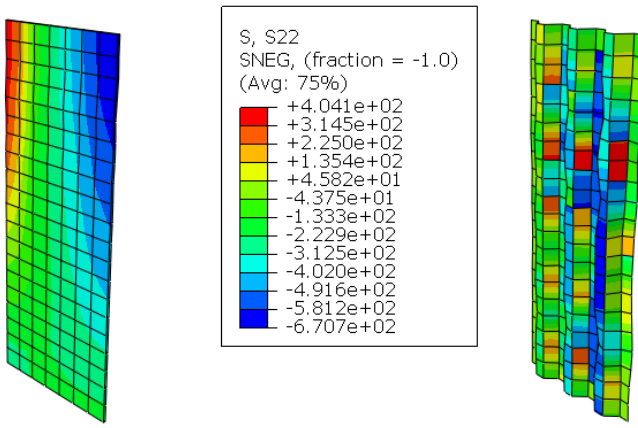

(b)
Steel Sheet

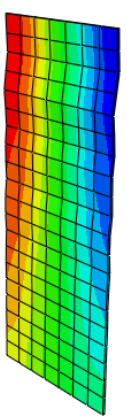

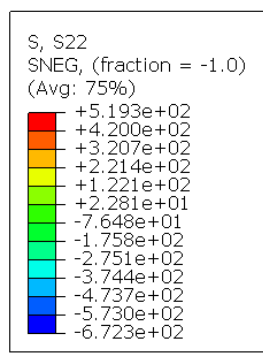

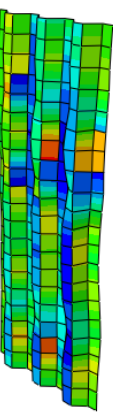

(c)

Figure 3.30 Maximum compressive principal stress, S22 (MPa) at (a) 50\% of ultimate load, (b) ultimate load, and (c) end point of FE run for A3 (without in-fill) 
Front Dry-board

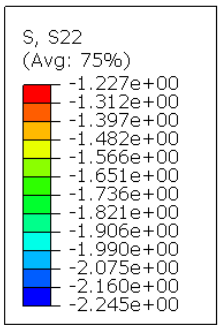

Rear Dry-board

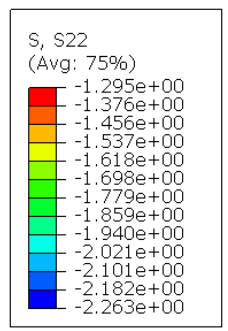

Steel Sheet
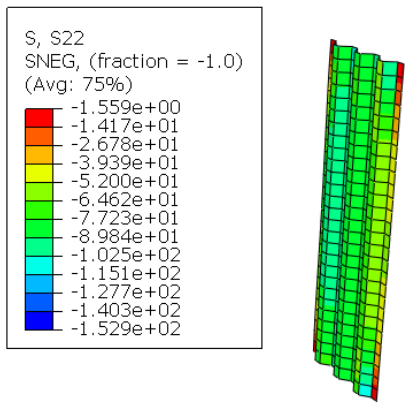

(a)

Front Dry-board
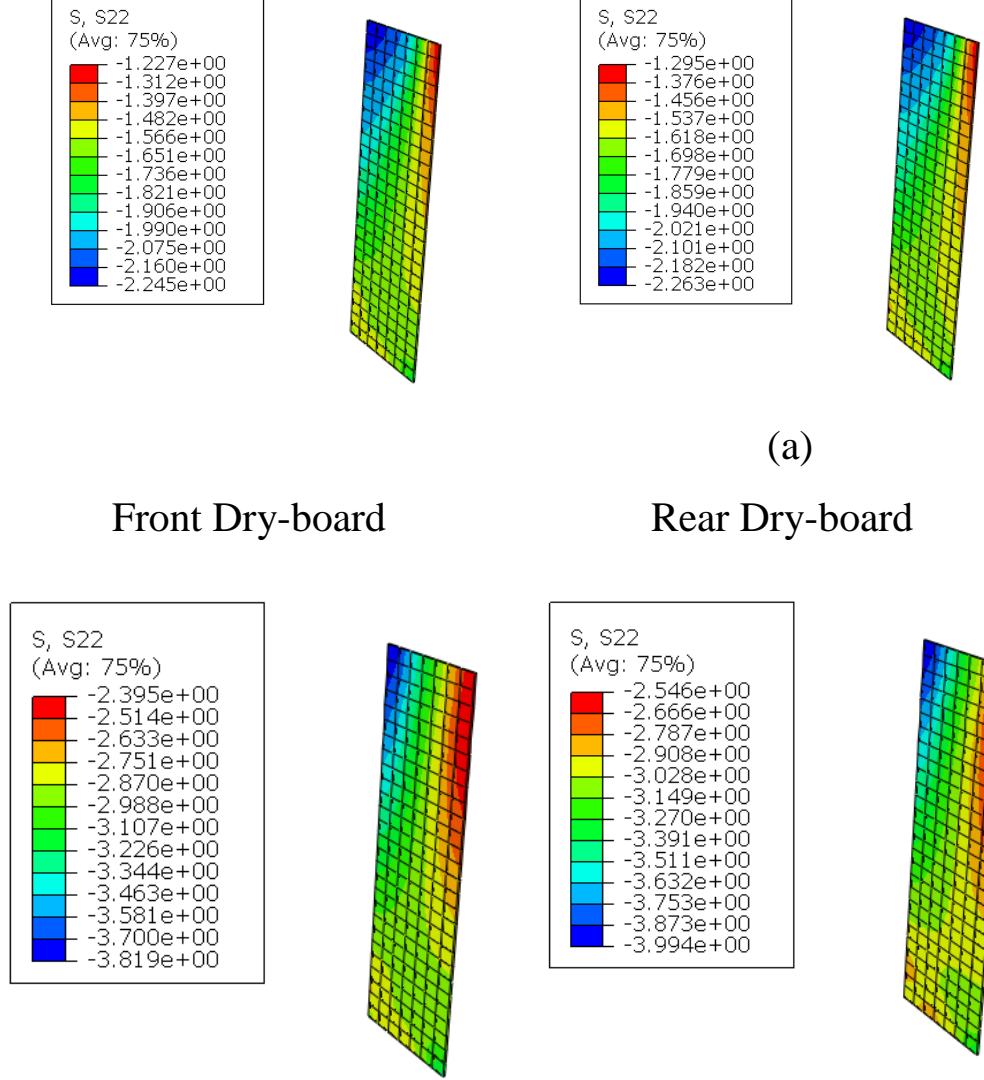

Rear Dry-board

Steel Sheet

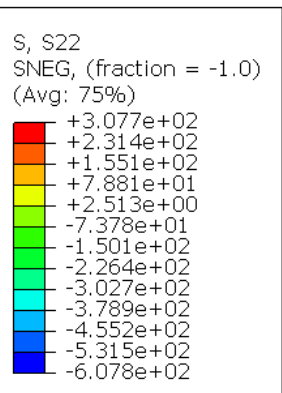

\section{Steel Sheet}
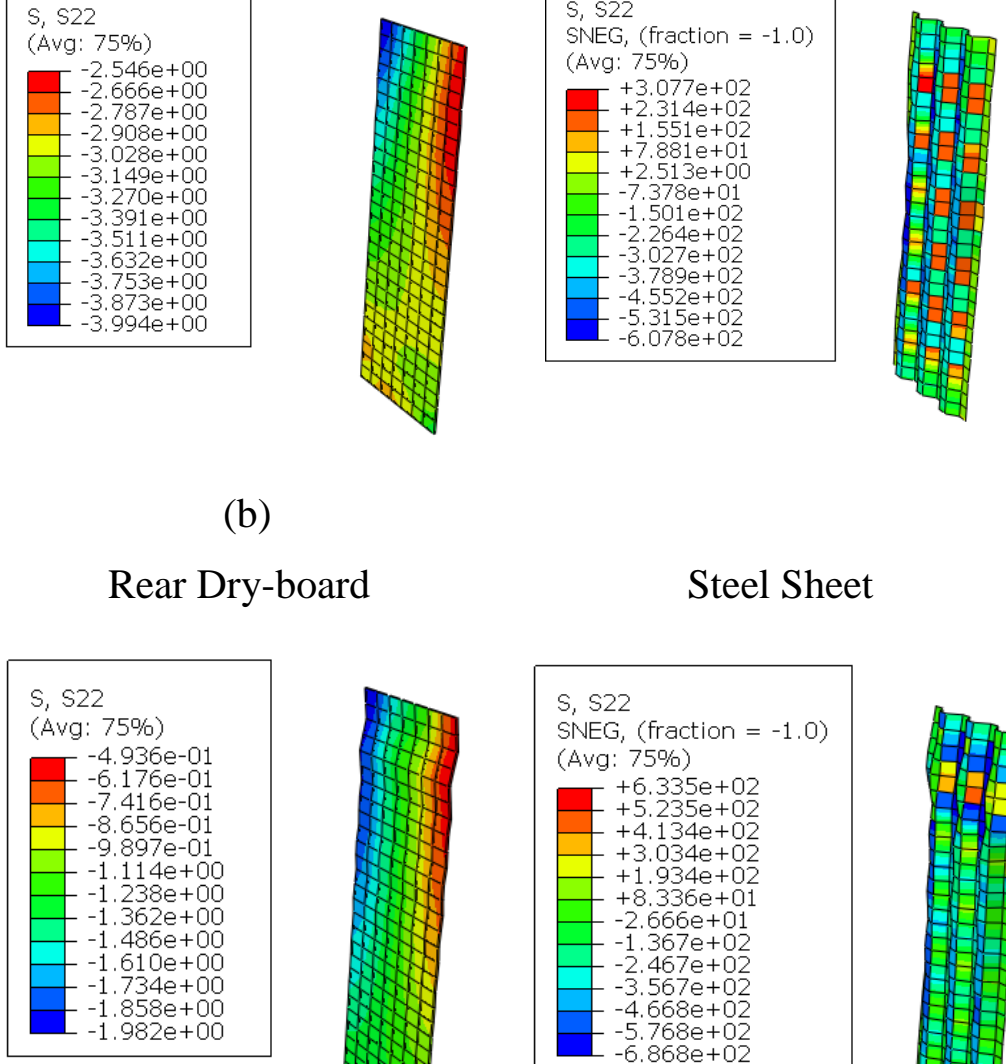

(b)
Front Dry-board

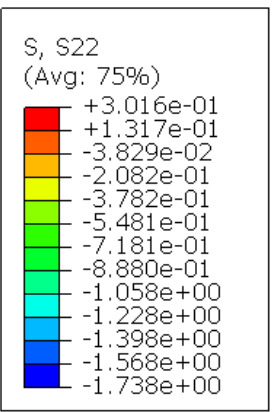

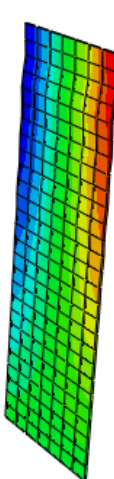

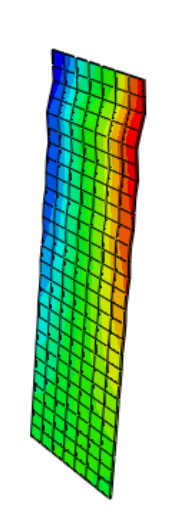

Rear Dry-board
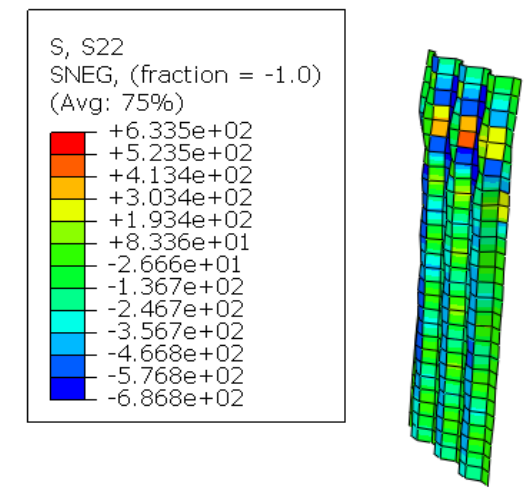

(c)

Figure 3.31 Maximum compressive principal stress, S22 (MPa) at (a) $50 \%$ of ultimate load, (b) ultimate load, and (c) end point of FE run for A4 (without infill) 
Front Dry-board

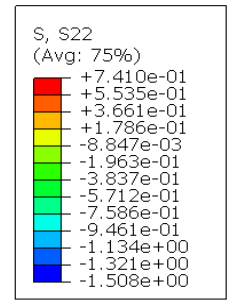

Rear Dry-board

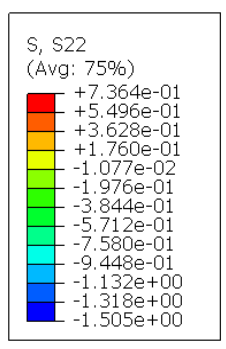

Steel Sheet
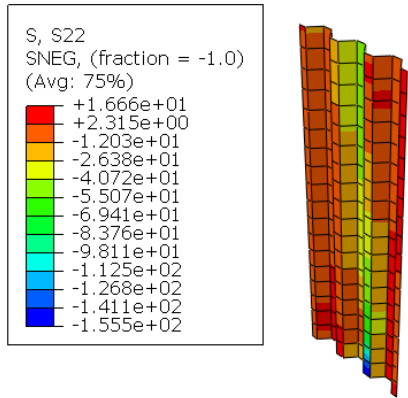

(a)

Front Dry-board

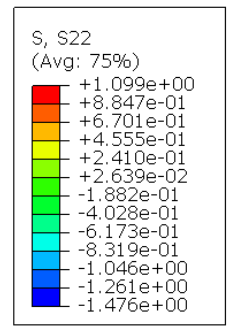

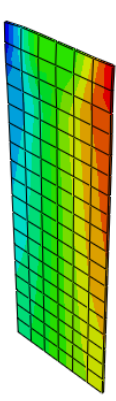

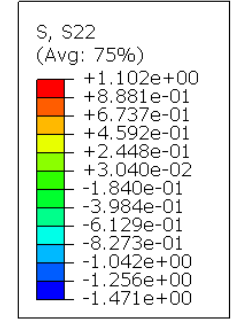

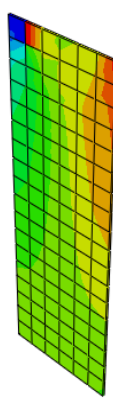

\section{Steel Sheet}
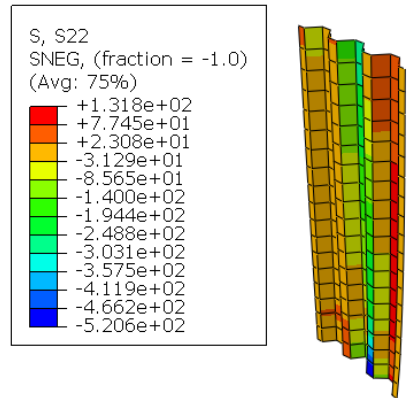

Front Dry-board
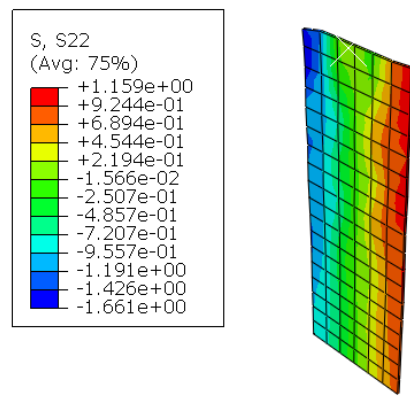

(b)

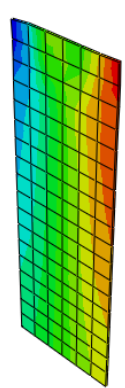

)

Rear Dry-board

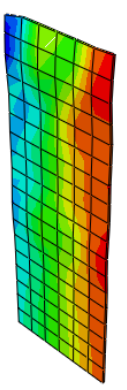

Steel Sheet

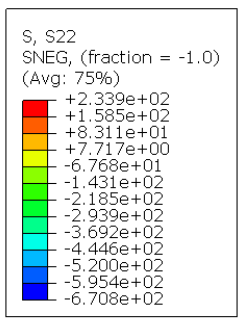

(c)

Figure 3.32 Maximum compressive principal stress, S22 (MPa) at (a) 50\% of ultimate load, (b) ultimate load, and (c) end point of FE run for A5 (with infill) 
Front Dry-board
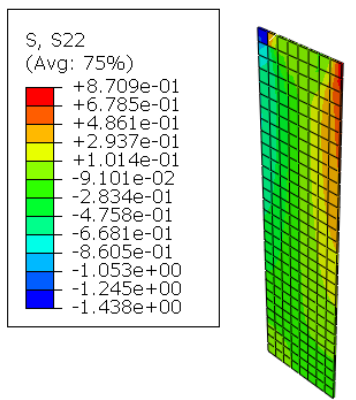

Front Dry-board

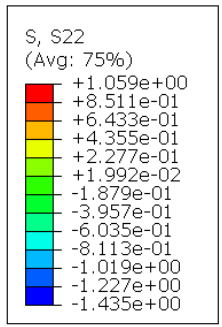

Rear Dry-board

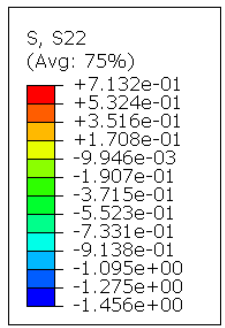

Steel Sheet

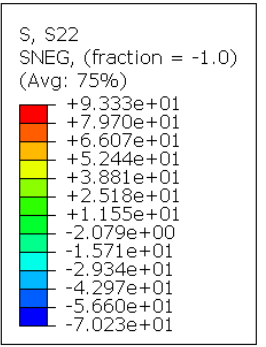

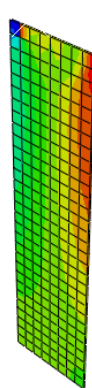

(a)

Rear Dry-board
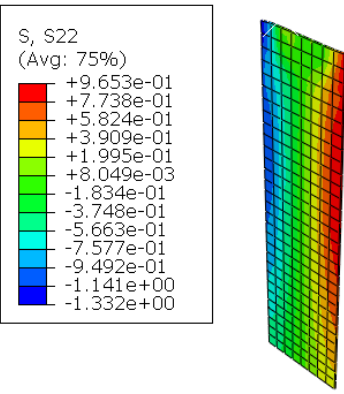

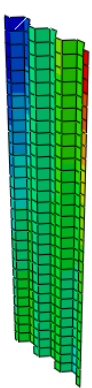

Steel Sheet
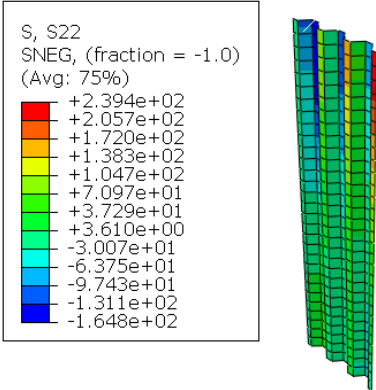

(b)

Rear Dry-board

Steel Sheet
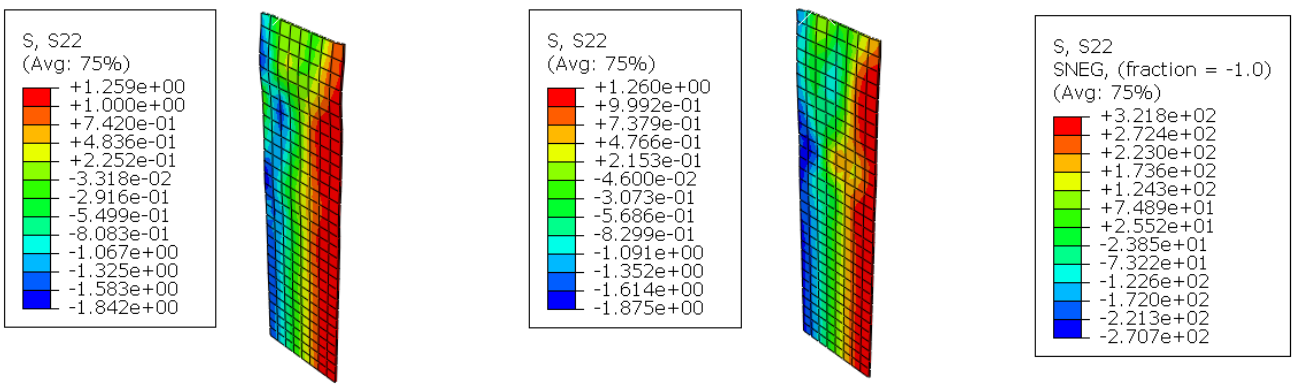

(c)

Figure 3.33 Maximum compressive principal stress, S22 (MPa) at (a) $50 \%$ of ultimate load, (b) ultimate load, and (c) end point of FE run for A6 (with infill) 
Front Dry-board
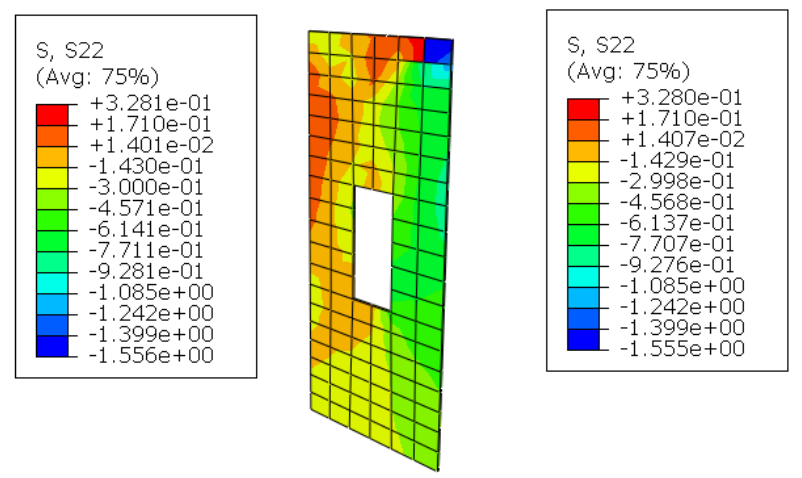

Front Dry-board
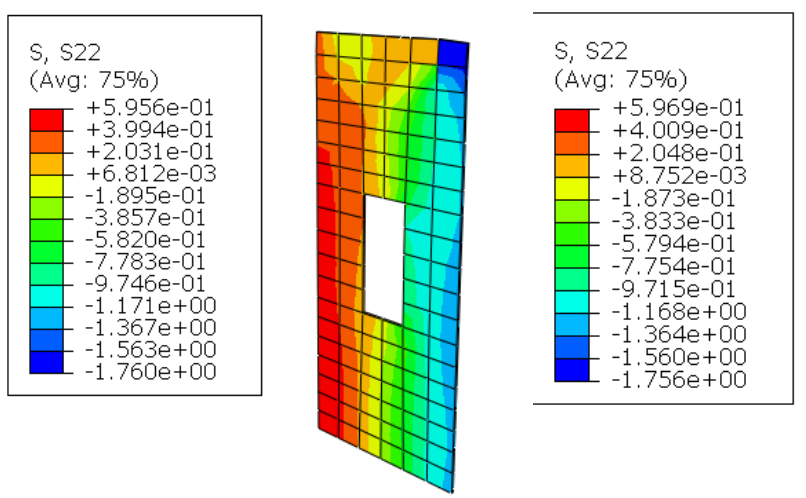

\section{Front Dry-board}
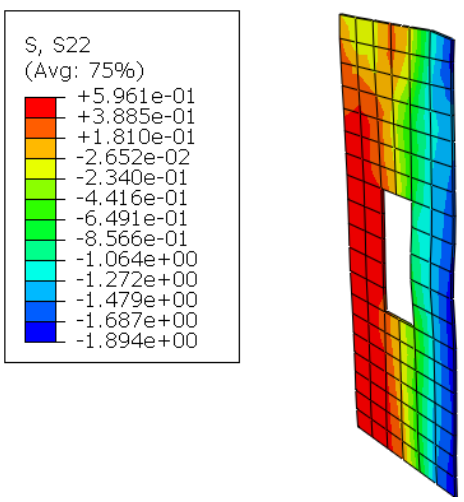

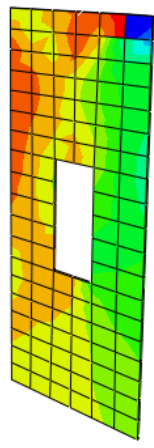

(a)

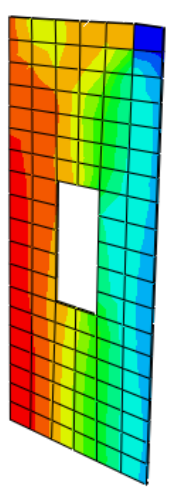

(b)

Steel Sheet
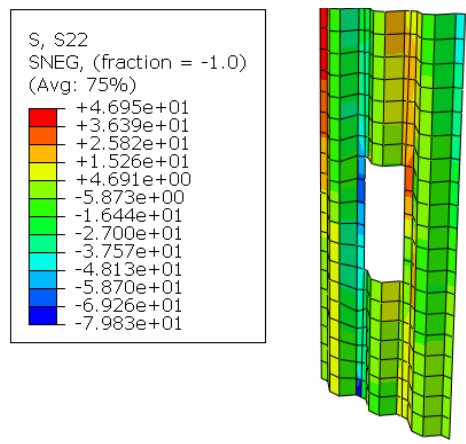

\section{Steel Sheet}
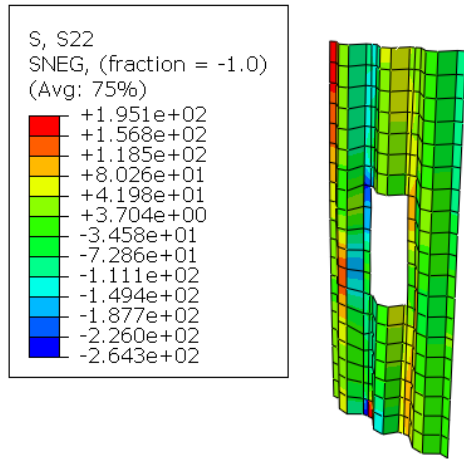

Steel Sheet
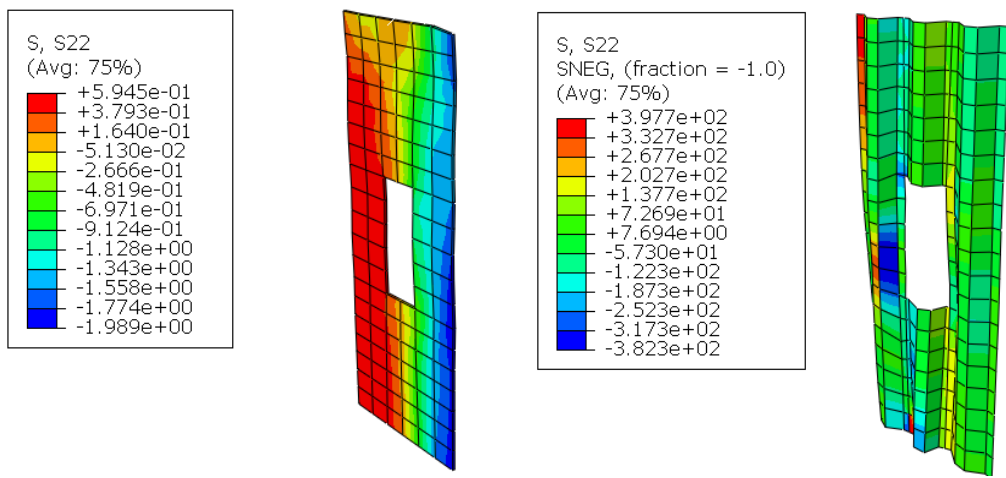

(c)

Figure 3.34 Maximum compressive principal stress, S22 (MPa) at (a) 50\% of ultimate load, (b) ultimate load, and (c) end point of FE run for A7 (with infill) 
Front Dry-board
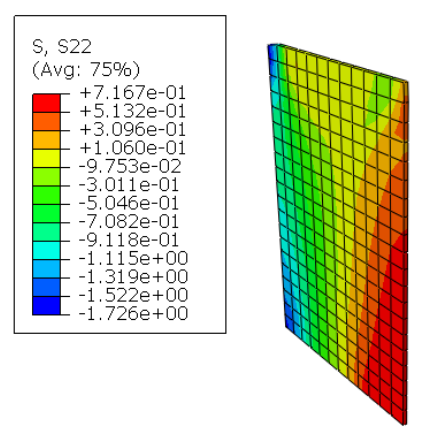

Front Dry-board
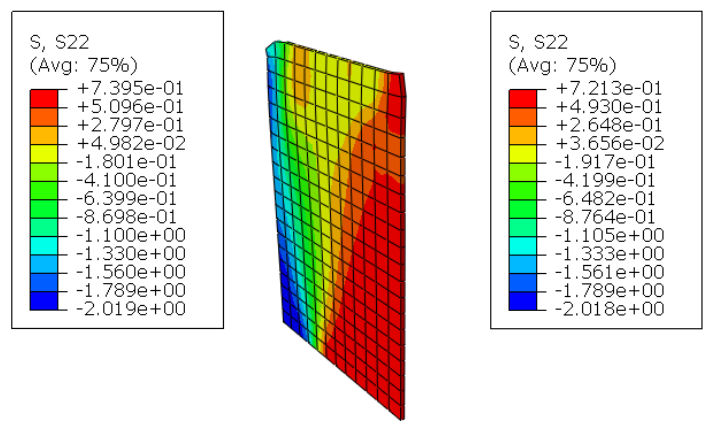

(a)
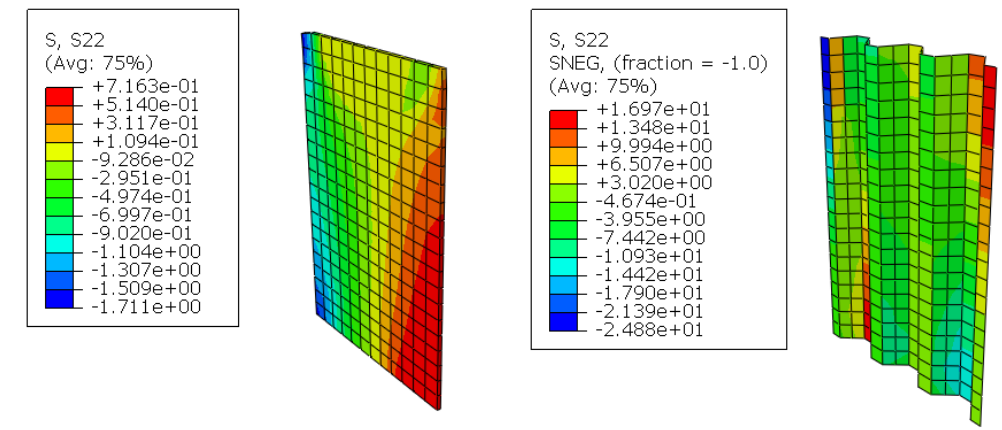

Rear Dry-board

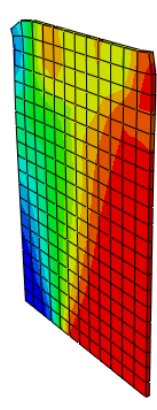

(b)

Front Dry-board
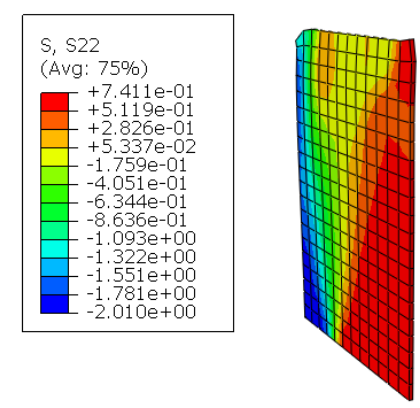

Rear Dry-board

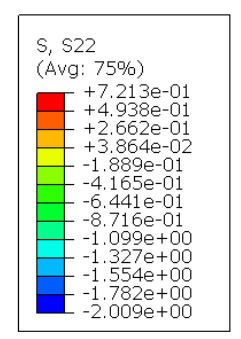

Steel Sheet
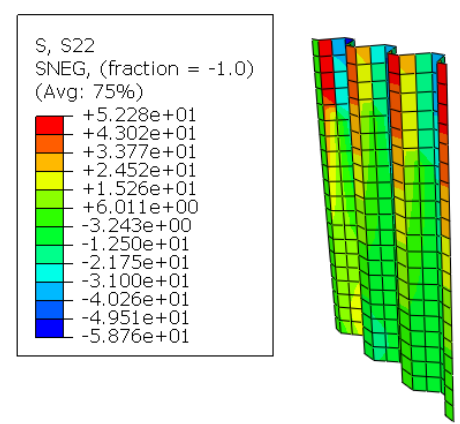

Steel Sheet

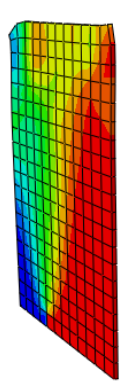

(c)

Figure 3.35 Maximum compressive principal stress, S22 (MPa) at (a) $50 \%$ of ultimate load, (b) ultimate load, and (c) end point of FE run for A8 (with infill) 
Front Dry-board

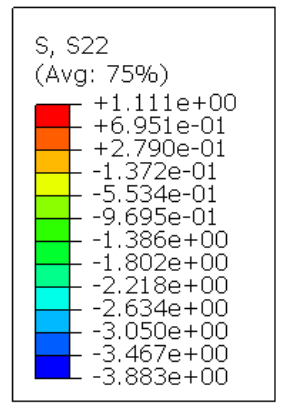

Rear Dry-board

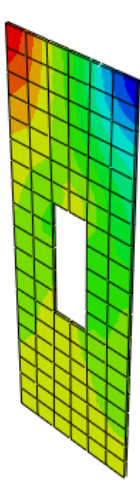

Steel Sheet

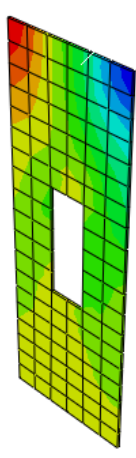

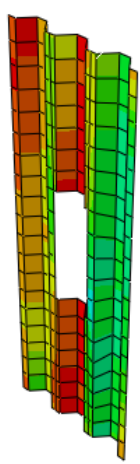

(a)

Front Dry-board
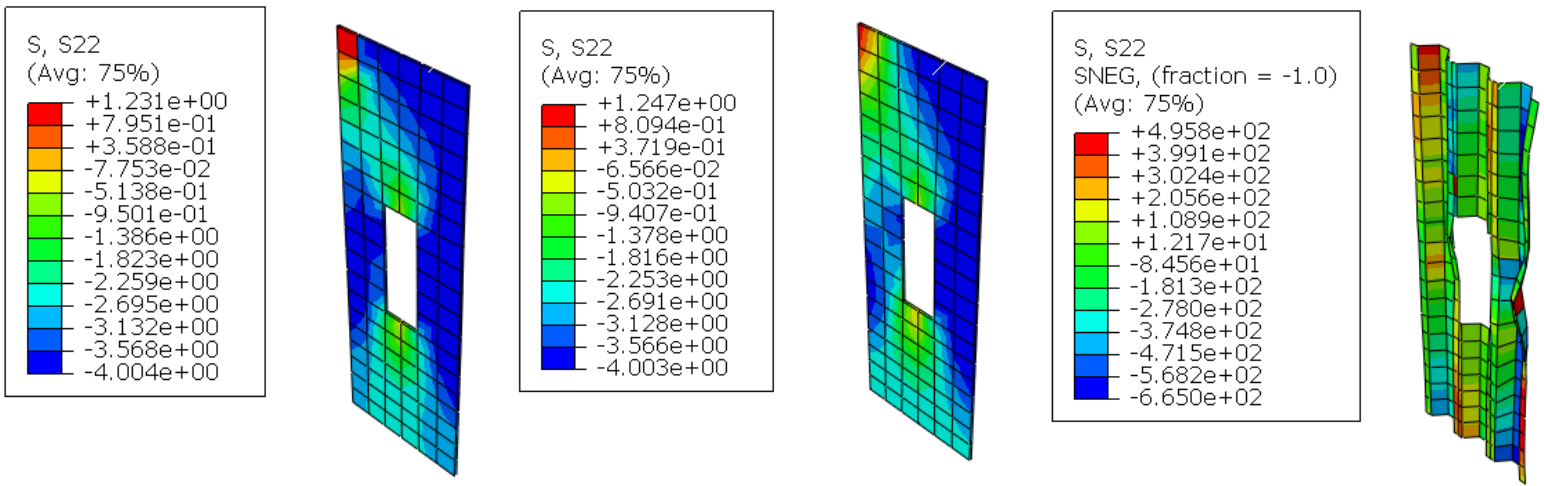

(b)

Front Dry-board
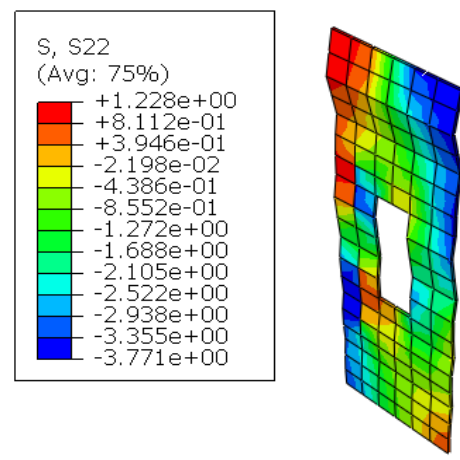

Steel Sheet
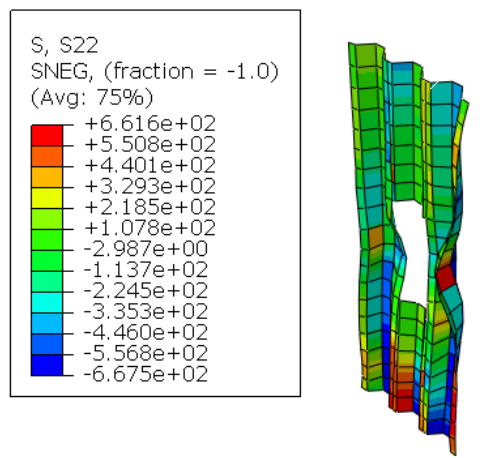

(c)

Figure 3.36 Maximum compressive principal stress, S22 (MPa) at (a) 50\% of ultimate load, (b) ultimate load, and (c) end point of FE run for A9 (without infill) 
Table 3.9 and Table 3.10 present the summary of the maximum positive and negative compressive principle stresses developed on each of the components of the PSSDB system. The PSS stress values indicate that the steel sheet has not yielded (did not exceed the yield strength of steel $F_{y}=598.17 \mathrm{MPa}$ ) at peak (ultimate) load for some of the walls not for all. Buckling mode failure was observed in most of the PSSDB panels accompanied by local crushing. From Table 3.9 and 3.10, it is also noted that the principal stress in the board exceed the elastic buckling stress of 4.74 $\mathrm{MPa}$ in some of the panels. Based on the finite element findings, the elastic buckling stress was expected to reduce, as the loss in the interaction between the wooden board and profiled steel sheet decreased the load-bearing capacity of the PSSDB wall panel (with the increase in screw spacing).

Table 3.9 Summary of the maximum positive compressive principal stress values in the PSSDB panels

\begin{tabular}{|c|c|c|c|c|c|c|c|c|c|}
\hline \multirow[b]{3}{*}{$\begin{array}{l}\text { Axial } \\
\text { Panels }\end{array}$} & \multicolumn{9}{|c|}{ Maximum Positive Compressive Principal Stress (S22) (MPa) } \\
\hline & \multicolumn{3}{|c|}{ Front Board } & \multicolumn{3}{|c|}{ Rear Board } & \multicolumn{3}{|c|}{ Steel Sheet } \\
\hline & $\begin{array}{l}50 \% \\
\text { of Ult. } \\
\text { Load }\end{array}$ & $\begin{array}{c}\text { Ult. } \\
\text { Load }\end{array}$ & Failure & $\begin{array}{c}50 \% \text { of } \\
\text { Ult. } \\
\text { Load }\end{array}$ & $\begin{array}{l}\text { Ult. } \\
\text { Load }\end{array}$ & Failure & $\begin{array}{c}50 \% \text { of } \\
\text { Ult. } \\
\text { Load }\end{array}$ & $\begin{array}{l}\text { Ult. } \\
\text { Load }\end{array}$ & Failure \\
\hline A1 & 0.76 & 4.01 & 3.84 & 0.79 & 4.01 & 3.90 & 73.12 & 686.90 & 684.60 \\
\hline $\mathrm{A} 2$ & 2.36 & 3.17 & 4.01 & 2.39 & 3.56 & 4.41 & 87.28 & 299.30 & 341.60 \\
\hline A3 & 1.20 & 2.32 & 2.96 & 1.23 & 2.05 & 2.57 & 4.763 & 404.10 & 519.30 \\
\hline A4 & - & - & 0.30 & - & - & - & - & 307.80 & 633.50 \\
\hline A5 & 0.74 & 1.10 & 1.16 & 0.74 & 1.10 & 1.17 & 16.66 & 131.80 & 233.90 \\
\hline A6 & 0.87 & 1.06 & 1.26 & 0.71 & 0.97 & 1.26 & 93.33 & 239.40 & 321.80 \\
\hline A7 & 0.33 & 0.60 & 0.60 & 0.33 & 0.60 & 0.60 & 46.95 & 195.10 & 397.70 \\
\hline A8 & 0.72 & 0.74 & 0.74 & 0.72 & 0.72 & 0.72 & 16.97 & 52.280 & 67.14 \\
\hline A9 & 1.11 & 1.23 & 1.23 & 1.11 & 1.2 & 1.21 & 17.58 & 495.80 & 661.60 \\
\hline
\end{tabular}

Failure: at the end of FE run; Ult. load: Peak load; Elastic buckling stress of DB as per Eq. 3.2 is $4.74 \mathrm{MPa}$ 
Table 3.10 Summary of the maximum negative stress values in the PSSDB composite panels

\begin{tabular}{|c|c|c|c|c|c|c|c|c|c|}
\hline \multirow[b]{3}{*}{$\begin{array}{l}\text { Axial } \\
\text { Panels }\end{array}$} & \multicolumn{9}{|c|}{ Maximum Negative Compressive Principal Stress (S22) (MPa) } \\
\hline & \multicolumn{3}{|c|}{ Front Board } & \multicolumn{3}{|c|}{ Rear Board } & \multicolumn{3}{|c|}{ Steel Sheet } \\
\hline & $\begin{array}{c}50 \% \text { of } \\
\text { Ult. } \\
\text { Load }\end{array}$ & $\begin{array}{c}\text { Ult. } \\
\text { Load }\end{array}$ & Failure & $\begin{array}{l}50 \% \\
\text { of Ult. } \\
\text { Load }\end{array}$ & $\begin{array}{c}\text { Ult. } \\
\text { Load }\end{array}$ & Failure & $\begin{array}{c}50 \% \text { of } \\
\text { Ult. } \\
\text { Load }\end{array}$ & $\begin{array}{c}\text { Ult. } \\
\text { Load }\end{array}$ & Failure \\
\hline A1 & 2.28 & 8.27 & 7.01 & 2.26 & 8.24 & 6.99 & 312.80 & 654.40 & 688.10 \\
\hline A2 & 3.56 & 6.74 & 7.21 & 3.53 & 6.57 & 7.08 & 300.00 & 665.40 & 607.40 \\
\hline A3 & 2.34 & 5.85 & 5.75 & 2.34 & 6.08 & 5.67 & 220.00 & 670.70 & 672.30 \\
\hline A4 & 2.25 & 3.82 & 1.73 & 2.26 & 3.99 & 1.98 & 152.0 & 607.80 & 686.80 \\
\hline A5 & 1.51 & 1.48 & 1.66 & 1.51 & 1.47 & 1.82 & 155.50 & 520.60 & 670.80 \\
\hline A6 & 1.44 & 1.44 & 1.84 & 1.45 & 1.33 & 1.87 & 70.23 & 164.80 & 270.70 \\
\hline A7 & 1.56 & 1.76 & 1.90 & 1.55 & 1.75 & 1.98 & 79.83 & 264.30 & 382.30 \\
\hline A8 & 1.73 & 2.02 & 2.01 & 1.71 & 2.01 & 2.01 & 24.88 & 58.760 & 77.60 \\
\hline A9 & 3.88 & 4.00 & 3.77 & 3.88 & 4.00 & 3.91 & 139.70 & 665.00 & 667.50 \\
\hline & & & & 4. & $\mathrm{~Pa}$ & & & & \\
\hline
\end{tabular}

\subsubsection{Comparison of Experimental and FEA Results}

Axial load-deformation responses from FE analysis (FEA) are compared with those obtained from experiments in Figures 3.37(a-b) and the results are summarized in Table 3.11. The ultimate/peak load capacity of the PSSDB composite walls based on the FEA was about $9.5 \%$ less than the experimentally tested models. The ratio of experimental to FEA load ranged between 1.02 and 1.18 while ratio of deflection ranged between 0.80 and 1.17 . Due to the complexity of the computational modeling, only the peak load and its corresponding deflection were compared with the experimental results. The difference in the results showed good simulation of the finite element models of the axially loaded composite walls considering the limitations in modeling. Moreover, the simulated stresses, failure mode and buckling patterns in the PSSDB walls were comparable with the experimentally obtained results. 

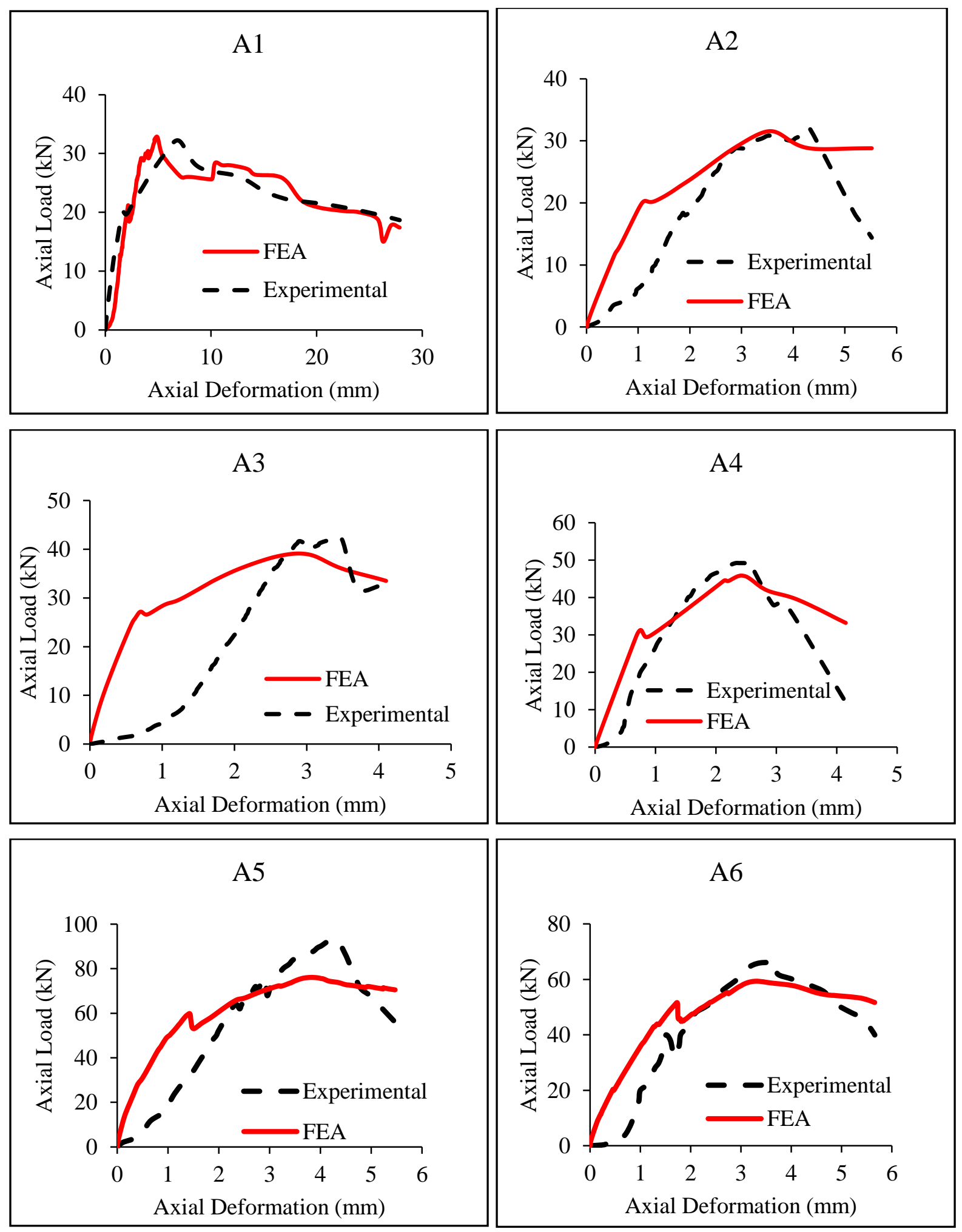

Figure 3.37 (a) Comparison of experimental and FEA axial load deformation response of PSSDB panels 

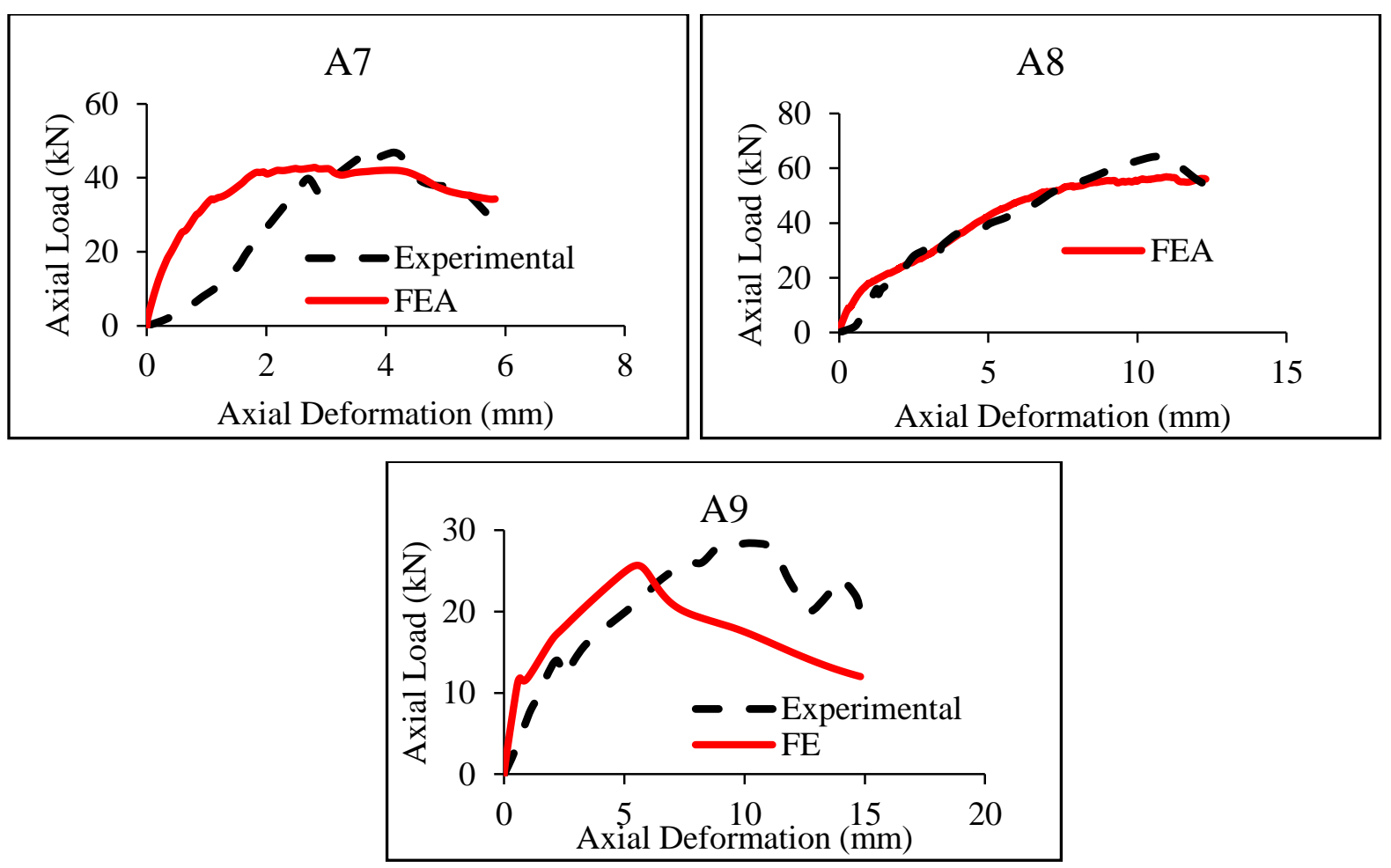

Figure 3.37 (b) Comparison of experimental and FEA axial load deformation response of PSSDB panels

Table 3.11 Summary of experimental and FEA results

\begin{tabular}{|c|c|c|c|c|c|c|c|c|c|}
\hline \multirow{3}{*}{$\begin{array}{l}\text { PSSDB } \\
\text { Panels }\end{array}$} & \multicolumn{3}{|c|}{$\begin{array}{l}\text { Geometric dimension } \\
\qquad(\mathrm{mm})\end{array}$} & \multirow{2}{*}{\multicolumn{2}{|c|}{$\begin{array}{c}\text { Experimental } \\
\text { Results }\end{array}$}} & \multirow{2}{*}{\multicolumn{2}{|c|}{$\begin{array}{c}\text { FEA } \\
\text { Results }\end{array}$}} & \multirow{2}{*}{\multicolumn{2}{|c|}{$\begin{array}{c}\text { Experimental/ } \\
\text { FEA }\end{array}$}} \\
\hline & Height & Width & Ratio & & & & & & \\
\hline & $\begin{array}{c}\mathrm{h} \\
(\mathrm{mm})\end{array}$ & $\begin{array}{c}\mathrm{W} \\
(\mathrm{mm})\end{array}$ & $\mathrm{h} / \mathrm{w}$ & $\begin{array}{l}\text { Peak } \\
\text { Load } \\
(\mathrm{kN})\end{array}$ & $\begin{array}{l}\text { Disp. } \\
(\mathrm{mm})\end{array}$ & $\begin{array}{l}\text { Peak } \\
\text { Load } \\
(\mathrm{kN})\end{array}$ & $\begin{array}{l}\text { Disp. } \\
(\mathrm{mm})\end{array}$ & $\begin{array}{l}\text { Peak } \\
\text { Load } \\
(\mathrm{kN})\end{array}$ & $\begin{array}{l}\text { Disp. } \\
(\mathrm{mm})\end{array}$ \\
\hline A1 & 890 & 325 & 2.74 & 32.80 & 4.92 & 32.20 & 6.54 & 1.02 & 0.80 \\
\hline A2 & 1200 & 325 & 3.69 & 32.00 & 4.32 & 31.00 & 3.76 & 1.03 & 1.15 \\
\hline A3 & 890 & 325 & 2.74 & 42.00 & 3.49 & 39.10 & 2.99 & 1.07 & 1.17 \\
\hline A4 & 1200 & 325 & 3.69 & 49.60 & 2.55 & 45.90 & 2.49 & 1.08 & 1.02 \\
\hline A5 & 900 & 310 & 2.90 & 90.00 & 3.99 & 76.00 & 3.83 & 1.18 & 1.04 \\
\hline A6 & 1200 & 310 & 3.87 & 66.00 & 3.38 & 59.30 & 3.33 & 1.08 & 1.02 \\
\hline A7 & 900 & 310 & 2.90 & 46.40 & 4.22 & 42.00 & 4.01 & 1.10 & 1.05 \\
\hline A8 & 500 & 310 & 1.61 & 64.00 & 10.42 & 56.00 & 10.14 & 1.14 & 1.03 \\
\hline A9 & 900 & 310 & 290 & 28.40 & 10.27 & 25.00 & 5.99 & 1.14 & 1.71 \\
\hline
\end{tabular}




\subsubsection{Parametric Study}

In order to identify the factors that affect the structural performance of the composite walls, a series of parametric studies have been performed using control specimens verified in the previous section. The effect of varying the thickness of the board and steel, and yield strength of PSS was investigated using A4 composite panel without concrete infill as the control specimen. On the other hand, in order to study the effect of varying the compressive strength of the infill material, A9 composite panel with concrete infill is used as the control specimen. At the end of this section, Table 3.12 presents a summary of the findings of the parametric study.

\subsubsection{Effect of Varying the Geometric Properties of the Board and PSS}

Three specimens having the same, material properties, screw spacing, and effective dimension of $1200 \mathrm{~mm}$ by $325 \mathrm{~mm}$ are investigated to study the influence of having $6 \mathrm{~mm}, 12 \mathrm{~mm}$ and $18 \mathrm{~mm}$ board thickness, respectively. Figure 3.38 shows the variation of the load-deformation responses for composite panels with varying board thicknesses. It can be observed that the ultimate load bearing capacity of the PSSDB panels increases with the use of thicker board. The ultimate load bearing capacity obtained for $\mathrm{t}_{\mathrm{b} 2}=12 \mathrm{~mm}$ and $\mathrm{t}_{\mathrm{b} 3}=18 \mathrm{~mm}$ is $58 \mathrm{kN}$ and $77 \mathrm{kN}$, respectively, which is higher than wall with $\mathrm{t}_{\mathrm{b} 1}=6 \mathrm{~mm}$ by $26 \%$ and $67 \%$, correspondingly. This phenomenon shows that thicker boards have sufficient resistance to support increased concentrated load. PSSDB panels with constant connector spacing and thicker boards increases the stiffness of the composite panels. The stiffness is defined as the slope of the initial straight line part of the load-deformation curve. However, thinner boards with closer screw spacing may produce the same or better panel stiffness compared to that of the thicker boards with wider screw spacing. Therefore, for practical considerations, the board should have enough resistance to support reasonable concentrated loads.

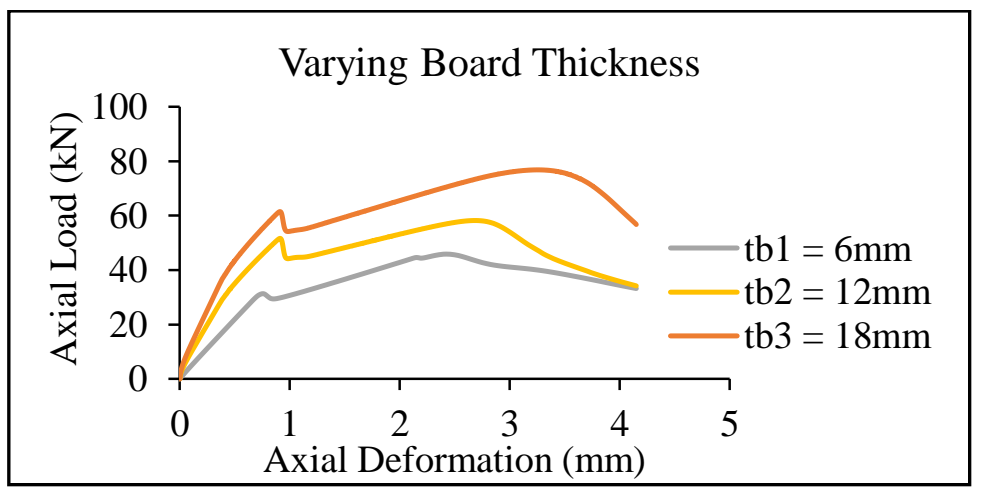

Figure 3.38 Axial load-deformation response of PSSDB panels with varying thickness of the DB 
Figure 3.39 demonstrates the comparison of load- deformation curves of altering the profiled steel sheet thickness $(0.48 \mathrm{~mm}, 0.6 \mathrm{~mm}$ and $1.25 \mathrm{~mm})$ on the performance of the PSSDB composite wall panels. The tested specimens have the same material properties, screw spacing and effective dimension of $1200 \mathrm{~mm}$ by $325 \mathrm{~mm}$. It can be observed that the ultimate load bearing capacity of the PSSDB panels increases with the increase of the thickness of the profiled steel sheet. The ultimate load of the walls obtained by using PSS thickness of $0.6 \mathrm{~mm}$ and $1.25 \mathrm{~mm}$ are $55 \mathrm{kN}$ and $85 \mathrm{kN}$, respectively, which is higher than that with $\mathrm{t}_{\mathrm{s} 1}=0.48 \mathrm{~mm}$ by $20 \%$ and $85 \%$, correspondingly. This phenomenon occurred because increasing the steel sheet thickness decreases its bending and delays the cracking of the board and vice versa. Therefore, steel sheeting thickness has an impact in the load-bearing capacity of the PSSDB walls and hence, need to be taken into consideration while designing the PSSDB system.

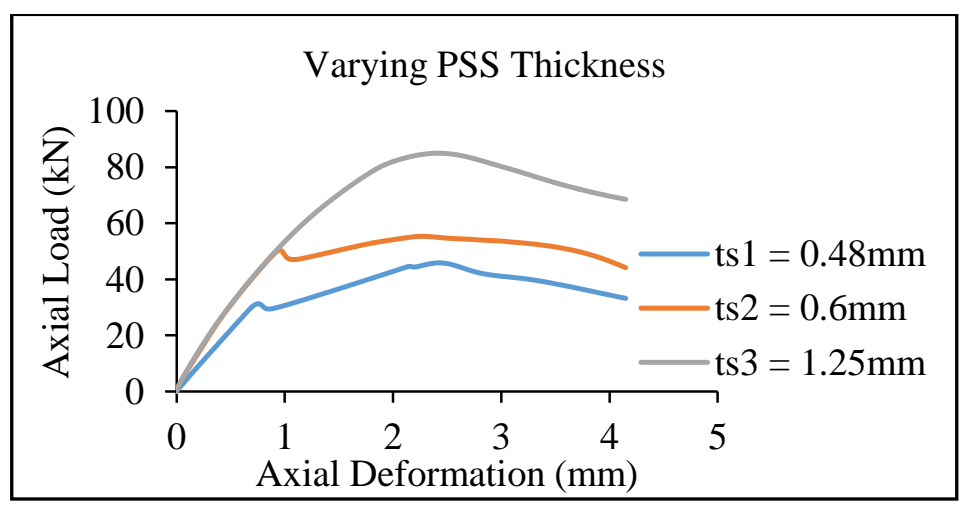

Figure 3.39 Axial load-deformation response of PSSDB panels with varying thickness of the PSS

\subsubsection{Effect of Varying the Material Properties of PSS and Concrete Core}

Figure 3.41 displays the axial load- deformation responses walls using low $\left(\mathrm{F}_{\mathrm{y} 1}=250 \mathrm{MPa}\right)$, mild $\left(\mathrm{F}_{\mathrm{y} 2}=350 \mathrm{MPa}\right)$ and high strength $\left(\mathrm{F}_{\mathrm{y} 3}=598.17 \mathrm{MPa}\right)$ profiled steel sheet. The load carrying capacity of the composite panel increases with the increase of yield strength of steel. PSS made of high strength steel has the advantage of maintaining the corrugated shape firmly and provide high resistance to buckling, denting or damage. High strength steel is able to increase the load bearing capacity by $92 \%$, when compared to the low and mild strength steel. 


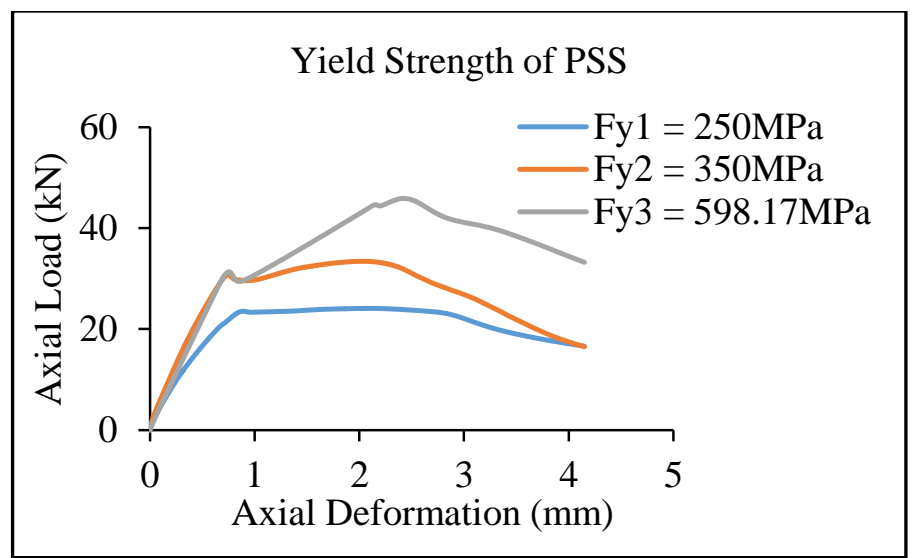

Figure 3.40 Axial load-deformation response of varying the yield strength (Fy) of PSS

Figure 3.41 shows the load-deformation response of increasing the compressive strength of the concrete infill (19MPa, 25MPa and 30MPa). The CDP parameters are provided using Eq. 3.11 and the concrete tensile strength was assumed to be $10 \%$ of the compressive strength of concrete. It can be observed that the ultimate load bearing capacity of the PSSDB panels increases by $7 \%$ with the increase in the compressive strength of concrete. The concrete infill in the voids of the panel supports more load and enhances the strength of the PSSDB composite system.

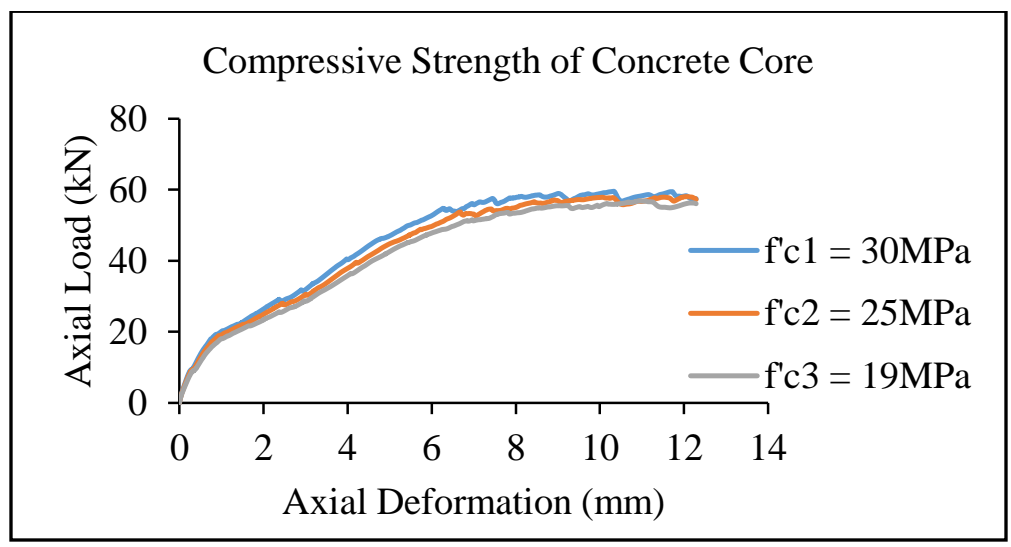

Figure 3.41 Axial Load-deformation response of varying compressive strength of concrete infill 
Table 3.12 Summary of results from parametric studies

\begin{tabular}{|c|c|c|c|}
\hline \multirow[b]{2}{*}{$\begin{array}{c}\text { Material/Geometric } \\
\text { Properties }\end{array}$} & & \multicolumn{2}{|c|}{ FEA } \\
\hline & & $\begin{array}{l}\text { Ultimate Load } \\
\qquad(\mathrm{kN})\end{array}$ & $\begin{array}{l}\text { Displacement } \\
\text { (mm) }\end{array}$ \\
\hline \multirow{3}{*}{$\begin{array}{l}\text { Thickness of board, } \\
t_{b}(\mathrm{~mm})\end{array}$} & 6 & 46 & 2.42 \\
\hline & 12 & 59 & 2.71 \\
\hline & 18 & 77 & 3.25 \\
\hline \multirow{3}{*}{$\begin{array}{c}\text { Thickness of steel, } \\
t_{\mathrm{s}}(\mathrm{mm})\end{array}$} & 0.48 & 46 & 2.42 \\
\hline & 0.6 & 55 & 2.6 \\
\hline & 1.2 & 85 & 2.43 \\
\hline \multirow{3}{*}{$\begin{array}{c}\text { Yield Strength of } \\
\text { PSS, } \\
\mathrm{F}_{\mathrm{y}}(\mathrm{MPa})\end{array}$} & 250 & 24 & 2.11 \\
\hline & 350 & 33 & 2.07 \\
\hline & 598.17 & 46 & 2.42 \\
\hline \multirow{3}{*}{$\begin{array}{l}\text { Comp. Strength of } \\
\text { Concrete, } \\
\mathrm{f}_{\mathrm{c}}(\mathrm{MPa})\end{array}$} & 19 & 56 & 12.19 \\
\hline & 25 & 58 & 11.76 \\
\hline & 30 & 60 & 10.32 \\
\hline
\end{tabular}

\subsubsection{Summary of FEA Findings}

Efficient finite element models were developed to predict the structural behavior of the PSSDB composite panels subjected to axial compression loading in terms of load-deformation response, failure modes and stress characteristics with quicker computation time and reasonably accurate results. The tested models with various configurations were able to investigate the effects of having several rows of spacers/connections along the height and width of the walls, with and without concrete infill, and an opening in the middle of the wall. The analysis results indicate that increase in the number of row spacers/connections or decrease in screw/connection spacing improved the load carrying capacity of the composite wall. Tall slender walls with maximum number of row spacers also tend to increase the axial load capacity. However, pierced PSSDB composite panels with or without concrete infill were more likely to carry less load and fail due to overall buckling.

The performed parametric study on the axial panels provided valuable information on the effect of varying material and geometric properties of the individual components of the PSSDB system. Increase in material or geometric properties displayed significant increase in the loadbearing capacity. In order to initiate full composite action and enhance the axial strength of the 
PSSDB walls, combination of the right material or geometric properties of the individual components is crucial.

One of the limitations of the FE model was defining the non-linear properties of wood in ABAQUS, as it does not provide a standard model to simulate the wood behavior when it undergoes both elastic and plastic deformations. However, an alternate option exhibiting similar behavior of wood was used, as suggested in the ABAQUS manual. Despite the limitations, the developed FE models were found to be capable of simulating the structural behavior of the composite axial panels accurately.

FEA results show good agreement with the values obtained via experimental tests. Therefore, the developed models in this study can be utilized to conduct parametric studies and obtain reasonably accurate results for preliminary design consideration. 


\section{CHAPTER 4: EXPERIMENTAL, ANALYTICAL AND FINITE ELEMENT MODELING OF PSSDB PANELS UNDER SHEAR LOADING}

\subsection{Introduction}

This chapter describes a series of experiments performed by research group at Ryerson (Hossain et al., 2015) to assess the shear behavior of wall panels under various loadings. Tests on composite PSSDB wall panels and their associated components (dry-board, profiled steel sheet and concrete core) bounded by pin-ended rigid frame and without frame were tested under in-plane shear simulating framed-shear wall and cantilever shear wall systems, respectively. The performance of such shear wall systems was assessed based on shear load-deformation response, shear strength and failure modes. Theoretical models for calculating shear strength of such PSDDB shear wall systems are developed. Finite element model for cantilever PSSDB shear wall system is also developed to simulate shear-load deformation response, deformed shapes/failure modes, and stress-strain characteristics based on experimental results. Experimental, theoretical and finite element results are compared.

\subsection{Experimental Program}

\subsubsection{PSSDB Specimen Design, Material Properties and Shear Load Test set-up, Instrumentation and Testing}

Two sets of tests were performed to assess the structural performance of the PSSDB wall panels under in-plane shear. The first set (designated S-series) simulated in-plane shear behavior of panels connected to a pin-ended boundary frame acted as a shear rig as presented in Table 4.1. The second set (designated as A1 and B1-series in Table 4.1) investigated cantilever PSSDB panels without boundary frame subjected to horizontal shear load at the top.

In S-series, eleven panels were tested comprising of individual profiled steel sheeting (PSS), individual dry-board (DB) and their combination (single PSS and single DB) representing a composite PSSDB walls connected to the boundary frame of the shear rig through variable number of horizontal (H) and vertical (V) fasteners (Table 4.1). The panels had overall dimensions of 1000 $\mathrm{mm} \times 850 \mathrm{~mm}$ or $1000 \mathrm{~mm} \times 475 \mathrm{~mm}$. The PSSDB composite panels had an overall thickness of $36 \mathrm{~mm}$. Either both vertical and horizontal fasteners or only vertical fasteners were used to secure the connection between DB-PSS or DB or PSS to the pin ended boundary frame of the shear rig 
as shown in Figure 4.1. A rectangular opening of $260 \mathrm{~mm} \times 180 \mathrm{~mm}$ at the center was used for the pierced panels.
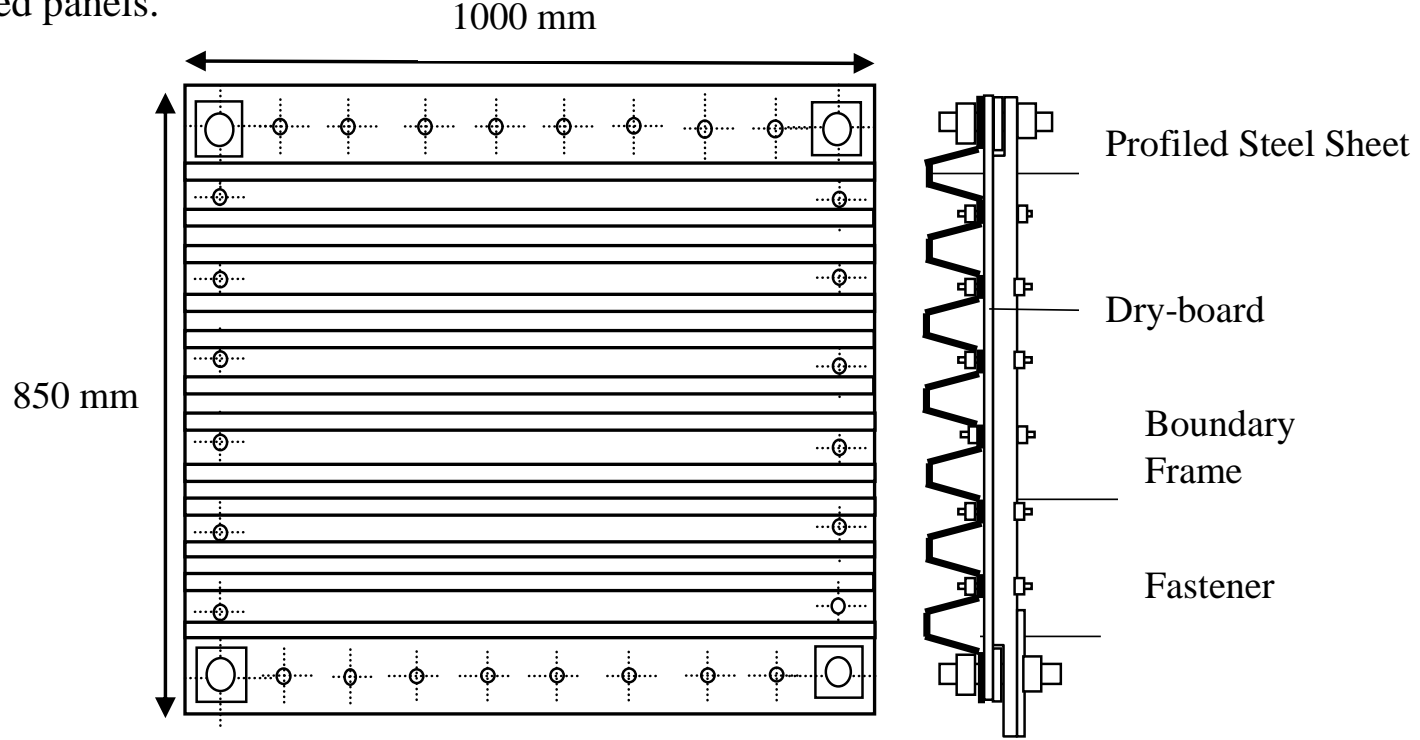

Figure 4.1 Schematic drawing and cross-section of the S-series

In the $2^{\text {nd }}$ set, eight PSSDB wall panels without boundary frame in cantilever configuration were tested under horizontal in-plane shear loading. An individual profiled steel sheet assembled with a single dry board as well as a profiled steel sheet sandwiched between two dry boards were used to make the walls. Threaded rods and spacers were used in the panels to transfer shear loads from the steel sheet to the dry board. Moreover, the effect of introducing concrete infill in the troughs of the PSS on the structural behavior of the PSSDB walls was also studied. The first series (A1) consisted of four non-pierced and pierced composite PSSDB wall panels with and without concrete infill made of a single dry board and a single profiled steel sheet. Likewise, the second series (B1) consisted of four non-pierced and pierced composite PSSDB wall panels with and without concrete infill made of a single sheet sandwiched between two dry boards. A1 and B1 series panels had an overall dimension of $475 \mathrm{~mm}$ x $900 \mathrm{~mm}$ x $36 \mathrm{~mm}$ and $475 \mathrm{~mm}$ x $900 \mathrm{~mm}$ x $42 \mathrm{~mm}$, respectively. To secure the connection between the DB and PSS, $10 \mathrm{~mm}$ diameter threaded rods with nuts and washers were used. The cross-section for the A1 and B1 panels are shown in Figure 4.2(a). The schematic drawing of the assembly of the non-pierced and pierced PSSDB panels (A1 and B1 Series) showing fastener configurations is shown in Figure 4.2(c). The nonpierced PSSDB composite panels had no intermediate fasteners as used above and below the 
opening/hole in case of pierced panels. The detailed configurations of the tested panels are shown in Table 4.1.
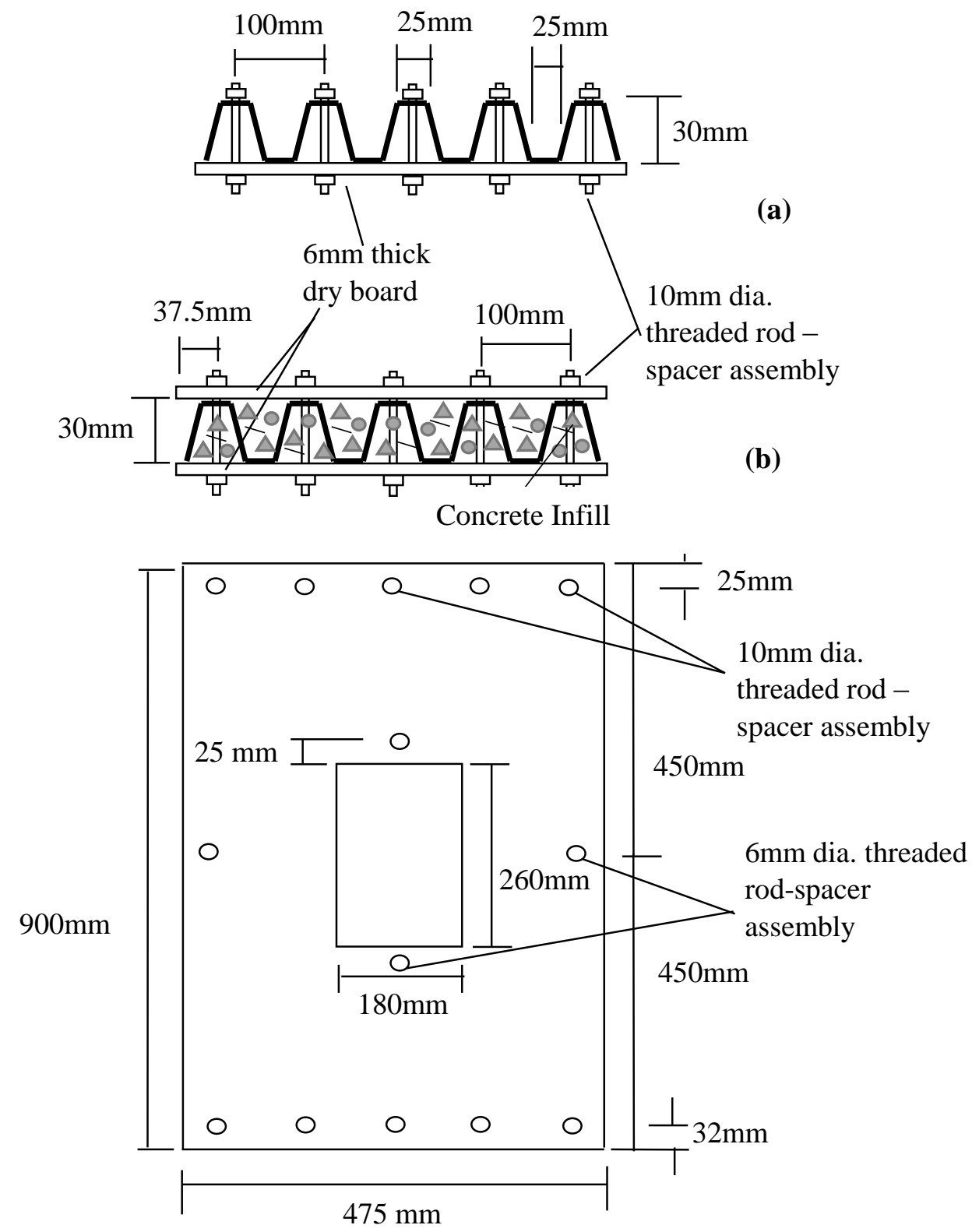

(c)

Note: For non-pierced PSSDB shear walls no intermediate spacers except for the two edge spacers only

Figure 4.2 (a) Cross-section of A1-series (b) cross-section of B1-series (c) schematic diagram of the pierced and non-pierced PSSDB shear wall panels (A1 and B1 Series) 
Table 4.1 Test configuration of the panels

\begin{tabular}{|c|c|c|c|c|cc|}
\hline $\begin{array}{c}\text { Panel specimen } \\
\text { Designation }\end{array}$ & Components & $\begin{array}{c}\text { Length } \\
(\mathrm{mm})\end{array}$ & $\begin{array}{c}\text { Width } \\
(\mathrm{mm})\end{array}$ & $\begin{array}{c}\text { Fasteners on each side } \\
\text { of the frame } \\
\text { Vertical }\end{array}$ \\
\hline \multicolumn{5}{|c|}{ Horizontal } \\
\hline S1-DB & DB only & 1000 & 850 & 6 & 8 \\
\hline S2-PSS & PSS only & 1000 & 850 & 6 & 8 \\
\hline S3-DB & DB only & 1000 & 850 & 6 & - \\
\hline S4-PSSDB & PSS + DB & 1000 & 850 & 6 & - \\
\hline S5-PSS & PSS only & 1000 & 850 & 6 & - \\
\hline S6-PSSDB & PSS + DB & 1000 & 475 & 5 & $1^{*}$ \\
\hline S7-PSS & PSS only & 1000 & 475 & 5 & - \\
\hline S8-DB & DB only & 1000 & 475 & 5 & - \\
\hline S9p-PSSDB & PSS + DB with hole & 1000 & 475 & 5 & $1^{*}$ \\
\hline S10p-PSS & PSS only with hole & 1000 & 475 & 5 & - \\
\hline S11p-DB & DB only with hole & 1000 & 475 & 5 & - \\
\hline
\end{tabular}

\begin{tabular}{|c|c|c|c|c|c|}
\hline $\begin{array}{c}\text { A1 series - with or } \\
\text { without concrete in-fill } \\
\text { (A1np, A1p, A1npc, } \\
\text { A1pc) }\end{array}$ & $\begin{array}{l}\text { PSS-DB - with or } \\
\text { without hole }\end{array}$ & 900 & 475 & 3 & 5 \\
\hline $\begin{array}{c}\text { B1 series- with or } \\
\text { without concrete in-fill } \\
\text { (B1np, B1p, B1npc, } \\
\text { B1pc) }\end{array}$ & $\begin{array}{l}\text { DB-PSS-DB: with or } \\
\text { without hole }\end{array}$ & 900 & 475 & 3 & 5 \\
\hline
\end{tabular}

DB- Dry board; PSS- profiled steel sheet

Spacing of fasteners, $\mathrm{s}=100 \mathrm{~mm}$, Edge distance, $\mathrm{e}=50 \mathrm{~mm}$ (S-series), p: pierced and the hole size is 260x180mm, A1 series: Single board + Single steel sheet, B1 series: Double board + Single steel sheet

In A1 npc or A1pc: A1: identifies the series; np or p: for non-pierced or pierced; c: for composite or concrete in-filled 
The panels were made of $0.48 \mathrm{~mm}$ thick trapezoidal profile steel sheet with flutes of $30 \mathrm{~mm}$ deep assembled with $6 \mathrm{~mm}$ thick plywood dry board as described in Chapter Three. The material properties of the PSS were obtained via coupon test. The yield and ultimate strength of PSS were 598.17MPa and 643.46 MPa, respectively. The first splitting and ultimate strength of plywood DB were determined. The modulus of elasticity of PSS ( $\left.\mathrm{E}_{\mathrm{pss}}\right)$ and plywood DB $\left(\mathrm{E}_{\mathrm{db}}\right)$ were $200 \mathrm{GPa}$ and $4 \mathrm{GPa}$, respectively. The material properties of each components of the PSSDB panels are tabulated in Table 4.2.

Table 4.2 Material properties of PSSDB panels

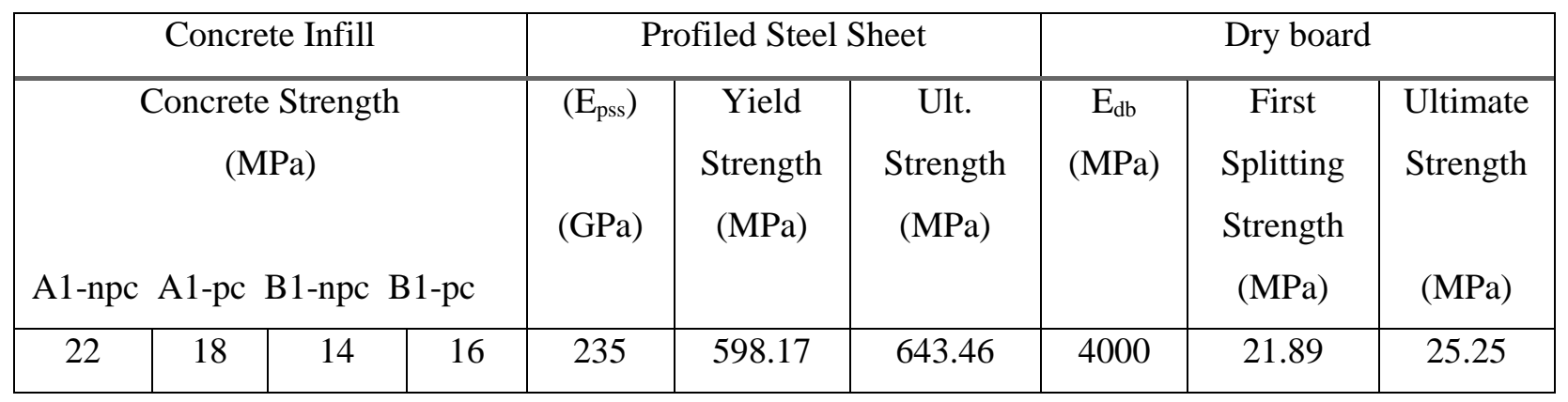

Tests were performed on S and A1-B1 series to provide information on the shear strength, effect of boundary conditions, load transfer mechanism and failure modes of the panels. Prior to testing, the wall panels were assembled in the boundary frame of the shear rig (in S-series) as shown in Figure 4.3 (a-b)) through fasteners and the assembled panels were connected to the loading frame through corner bolts. On the other hand, for the A1-B1 series, wall panel was connected to base frame made of steel channel through the row of fasteners (threaded rod-washernut assembly) existed at the bottom the wall and the steel channel was then connected to the strong floor of the laboratory (Figure $4.4(a-b))$. A guide channel was attached to the top of the wall through the existing row of fasteners. Moreover, for the concrete infilled PSSDB walls (A1 and B1 series), the PSS-DB assembly acted as a formwork to cast the concrete. The infill material used was normal concrete and its strength was determined using control specimens in the laboratory. Control specimens for concrete were casted in the form of cylinder to determine the strength and modulus of elasticity. The panels and control specimens were air cured in the laboratory until testing.

For the S-series, vertical load was applied through a load cell at the bottom the panel (as shown in Figure 4.3) in increments, whereas for the A1-B1 series, horizontal shear load was applied uniformly at the top surface of the wall panel (through the steel guide channel and load 
cell as shown in Figure 4.4) until the failure of the specimens. LVDT was used to record the lateral/shear displacements during testing. During the testing, computer aided data acquisition system was used to observe the load-deformation response throughout the loading history. The tests were conducted until failure to investigate the maximum load the composite wall panels could sustain. Experimental observations such as the first initiation of crack, buckling and overall failure modes of the tested PSSDB panels were recorded. Figure 4.3 and Figure 4.4 show the experimental test set-ups of the panels tested with boundary frame in S-series and those tested under horizontal loading at the top in cantilever configuration, respectively.

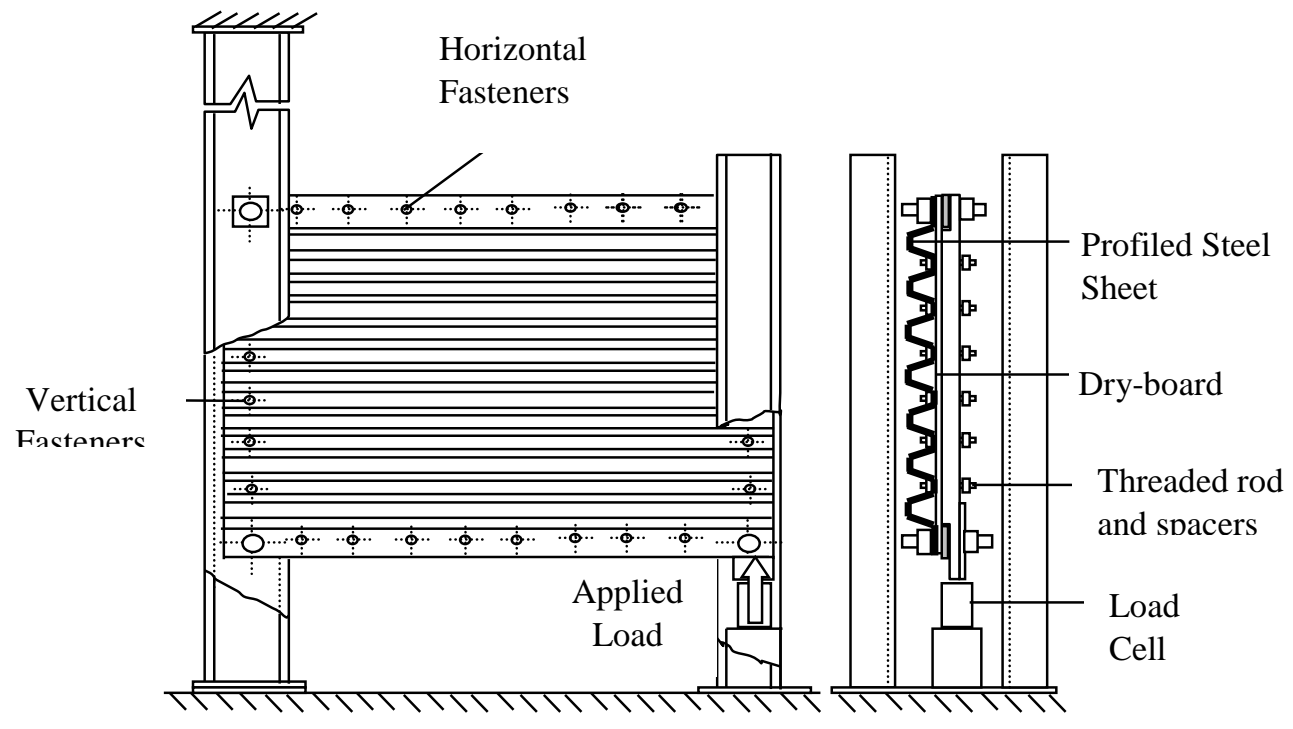

Figure 4.3 (a) Schematic drawing of the experimental set-up for the S-series panels bounded by rigid frames

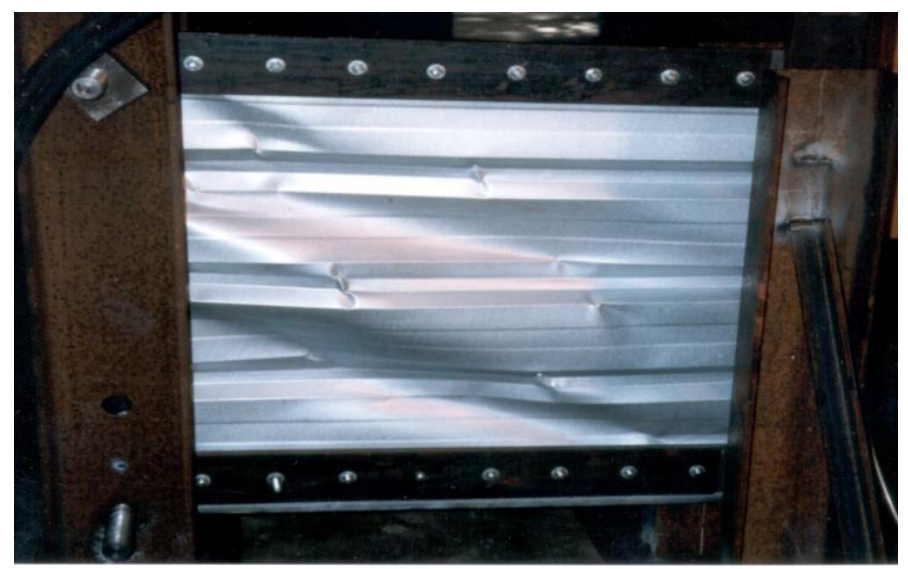

Figure 4.3 (b) Experimental set-up for the S-series panels bounded by rigid frames 


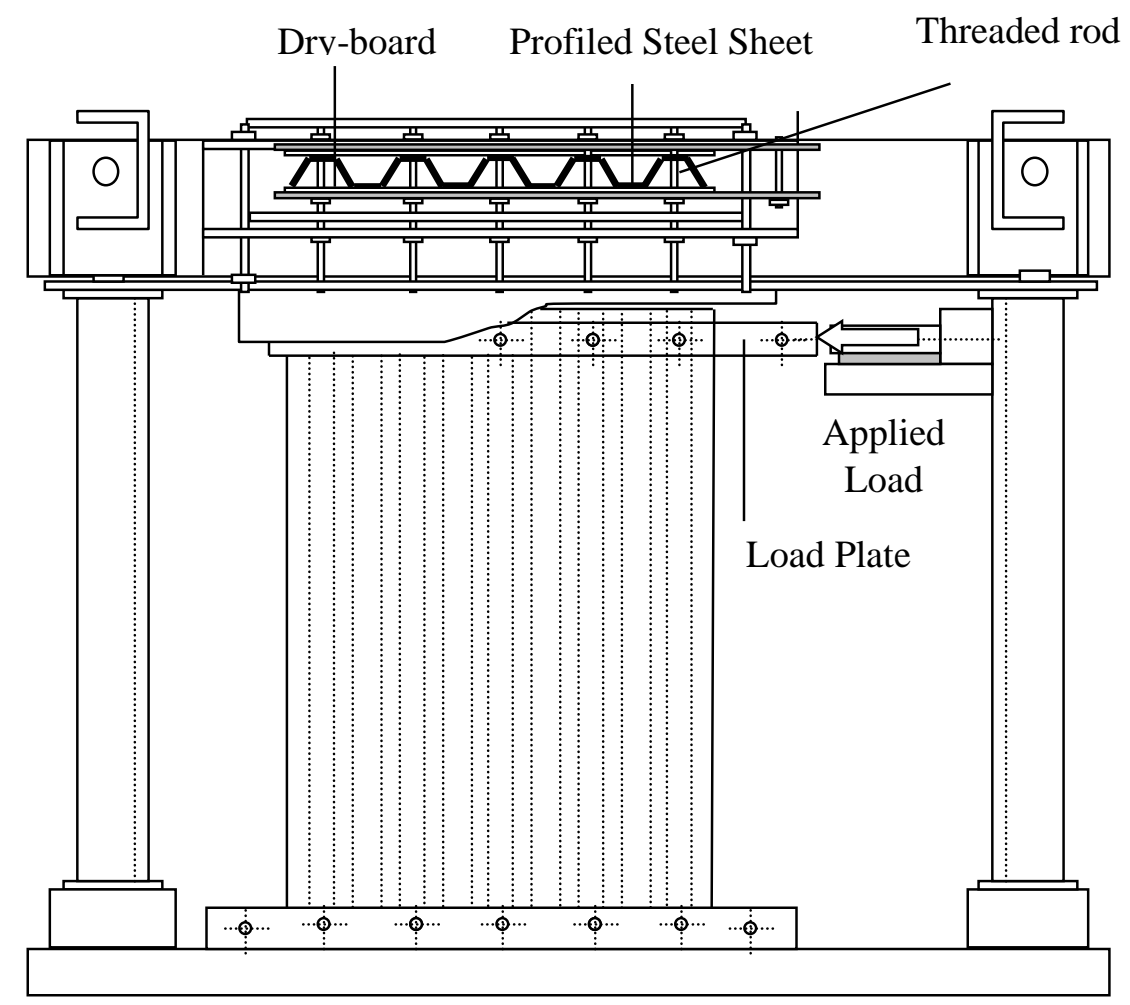

Figure 4.4 (a) Schematic drawing of the experimental set-up for A1-B1 series wall panels subjected to horizontal shear loading
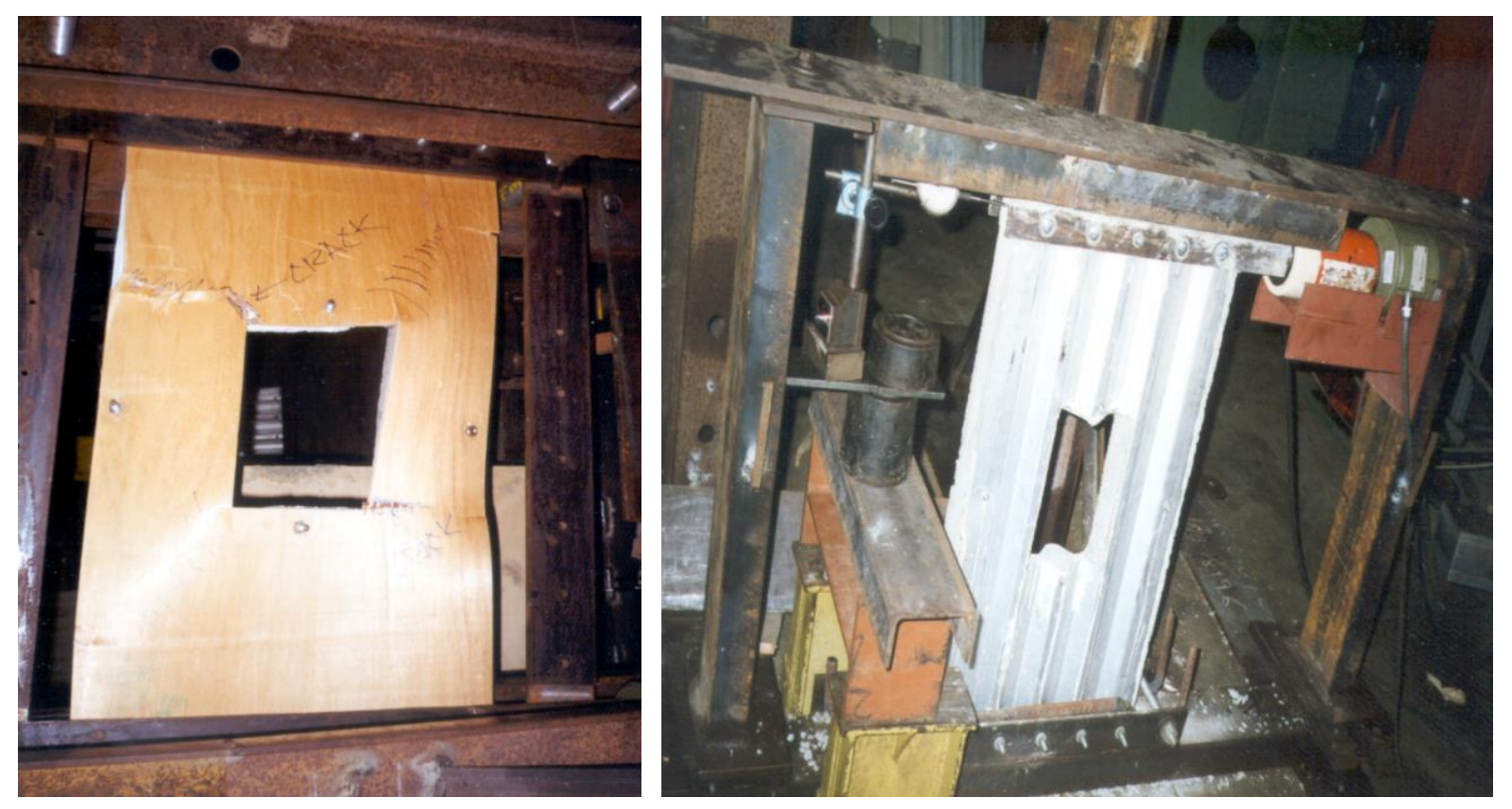

Figure 4.4 (b) Experimental set-up for A1-B1 series wall panels subjected to horizontal shear loading 


\subsubsection{Test Observation: Failure Mode and Shear Load-Deformation Response}

The structural performance of the PSSDB composite wall panels subjected to shear loading is assessed based on load-deformation response, shear strength and modes of failure. Loaddeformation responses of the test panels tested under similar conditions are superimposed and discussed. Table 4.3 summarizes the experimental results of the tested panels and explained in section 4.2.2.1 to 4.2.2.5.

\subsubsection{Effect of panel-frame connectors/fasteners in individual and composite PSSDB panels (S-series)}

Figure 4.5 (a) shows the shear load-deformation response of dry board and steel sheet panels. The dimensions for all the dry board and steel sheet panels were kept constant. Dry board panels with both vertical and horizontal fasteners (S1-DB) sustained an ultimate load of $19.01 \mathrm{kN}$ (Table 4.3) whereas the board with vertical fasteners (S3-DB) carried an ultimate load of 7.82kN (Table 4.3) Dry board panel with only vertical fasteners carried 59\% lower shear load compared to that with both vertical and horizontal fasteners. Buckling was observed at an applied load of $15.6 \mathrm{kN}$ in S1DB. Both panels failed due to development of diagonal tension and compression fields as shown in Figure 4.6. Likewise, the steel sheet panels displayed similar load-deformation response as the dry board panels. PSS panels with only vertical fasteners (S5-PSS) carried 70\% lower shear load compared to that with both vertical and horizontal fasteners (S2-PSS) (Figure 4.5 (b)). The first buckling failure in the S2-PSS panel was observed at the top end at an applied load of $15.64 \mathrm{kN}$. Both the PSS panels failed due to tearing at end boundary/connection (Figure 4.7).

Figure 4.5 (c) shows the load-deformation response of the individual components (S3-DB and S5-PSS) and the composite panel (S4-PSSDB) with vertical fasteners only. The DB and the PSS component carried an ultimate load of $7.80 \mathrm{kN}$ and $8.72 \mathrm{kN}$, respectively. However, the PSSDB composite panel sustained an ultimate load of $24.06 \mathrm{kN}$, which is approximately $46 \%$ higher than summation of its components (PSS and DB). For the S4-PSSDB panel, buckling of DB is observed at an applied load of $4.21 \mathrm{kN}$ followed by tearing failure in the PSS at about $16.84 \mathrm{kN}$. The failure pattern of the composite PSSDB panel is shown in Figure 4.8. 


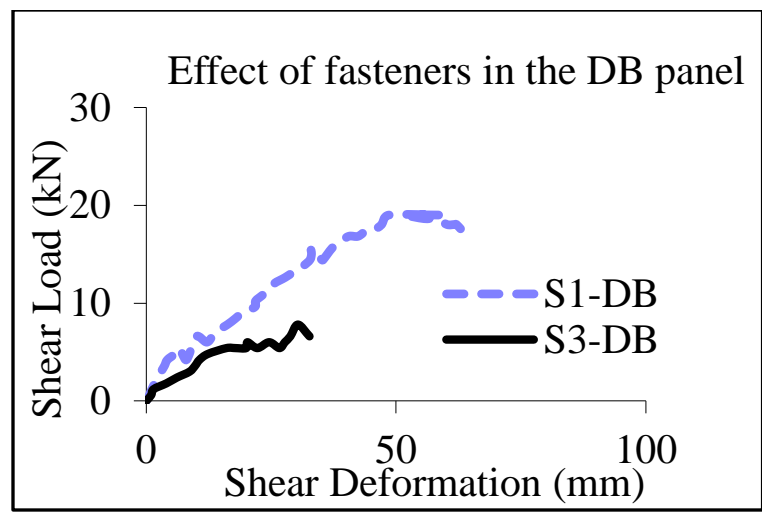

(a)

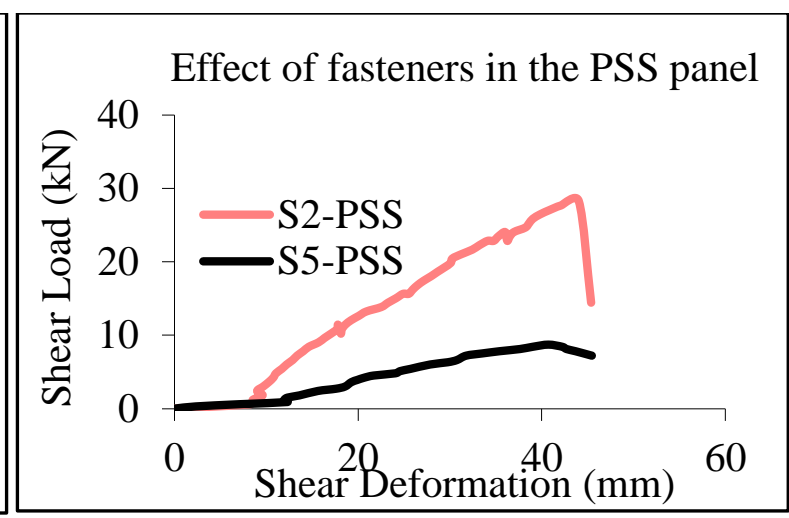

(b)

Figure 4.5 Load-deformation response of (a) DB with both vertical and horizontal fasteners (S1DB) and vertical fasteners only (S3-DB) (b) PSS with both vertical and horizontal fasteners (S2PSS) and vertical fasteners only (S5-PSS)

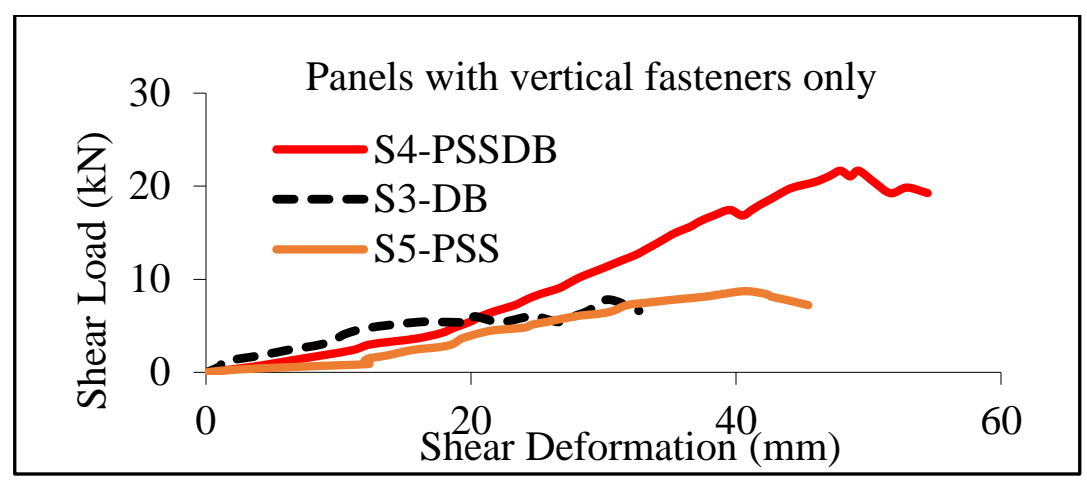

(c)

Figure 4.5 (c) Load-deformation response of panels and vertical fasteners only (S3-DB, S5-PSS and S4-PSSDB)

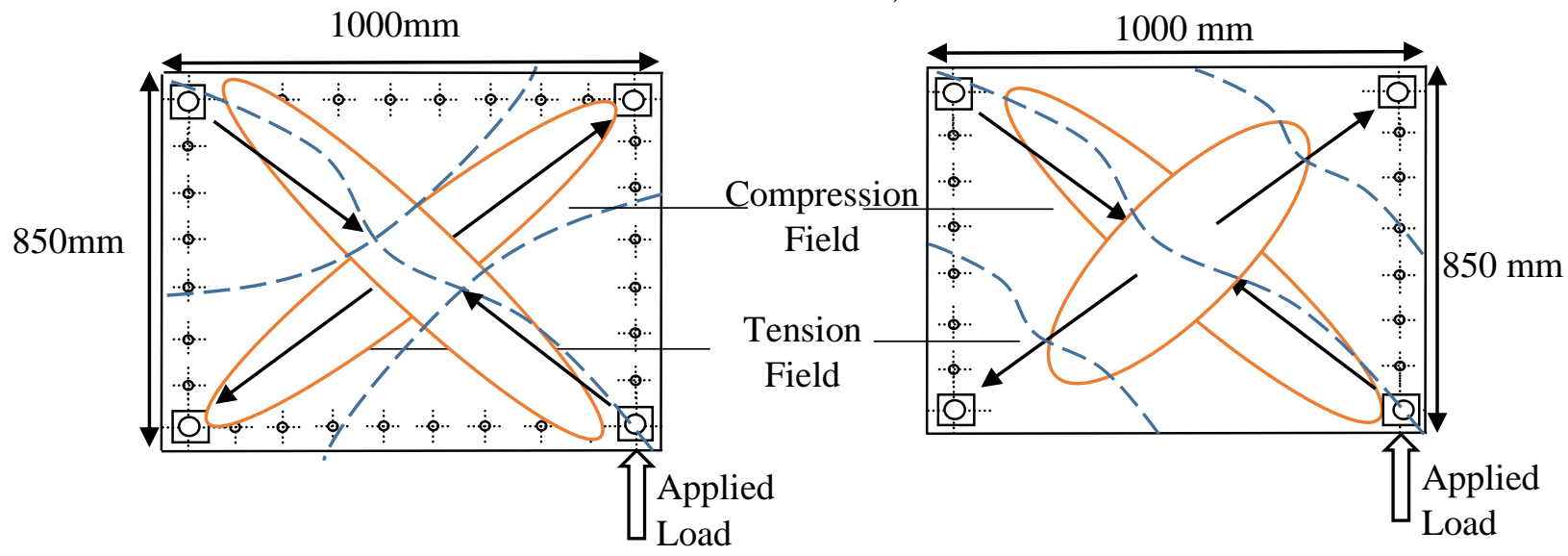

Figure 4.6 Failure pattern of DB panel with both vertical and horizontal fasteners (S1DB) (left) and with vertical fasteners only (S3-DB) (right) 


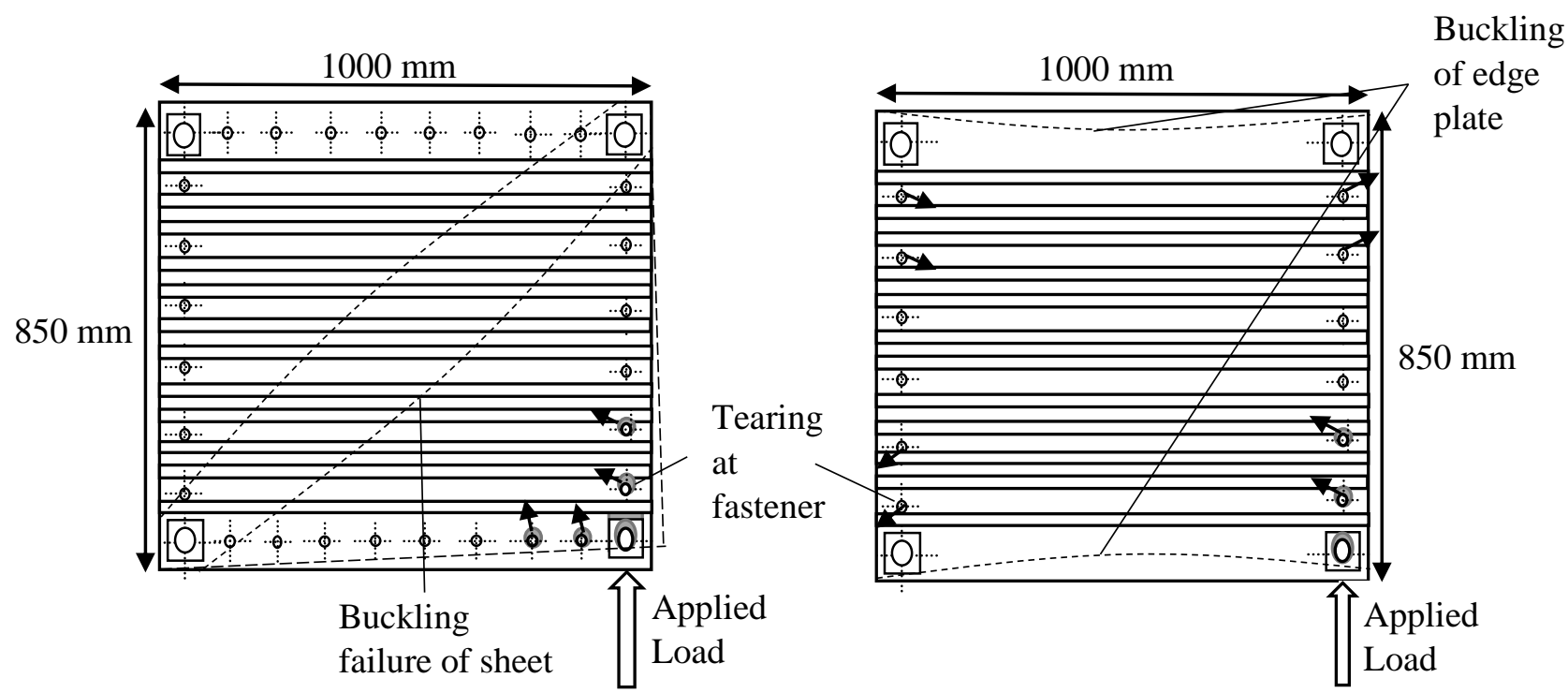

Figure 4.7 Failure pattern of PSS with both vertical and horizontal fasteners (S2-PSS) (left) and vertical fasteners only (S5-PSS) (right)

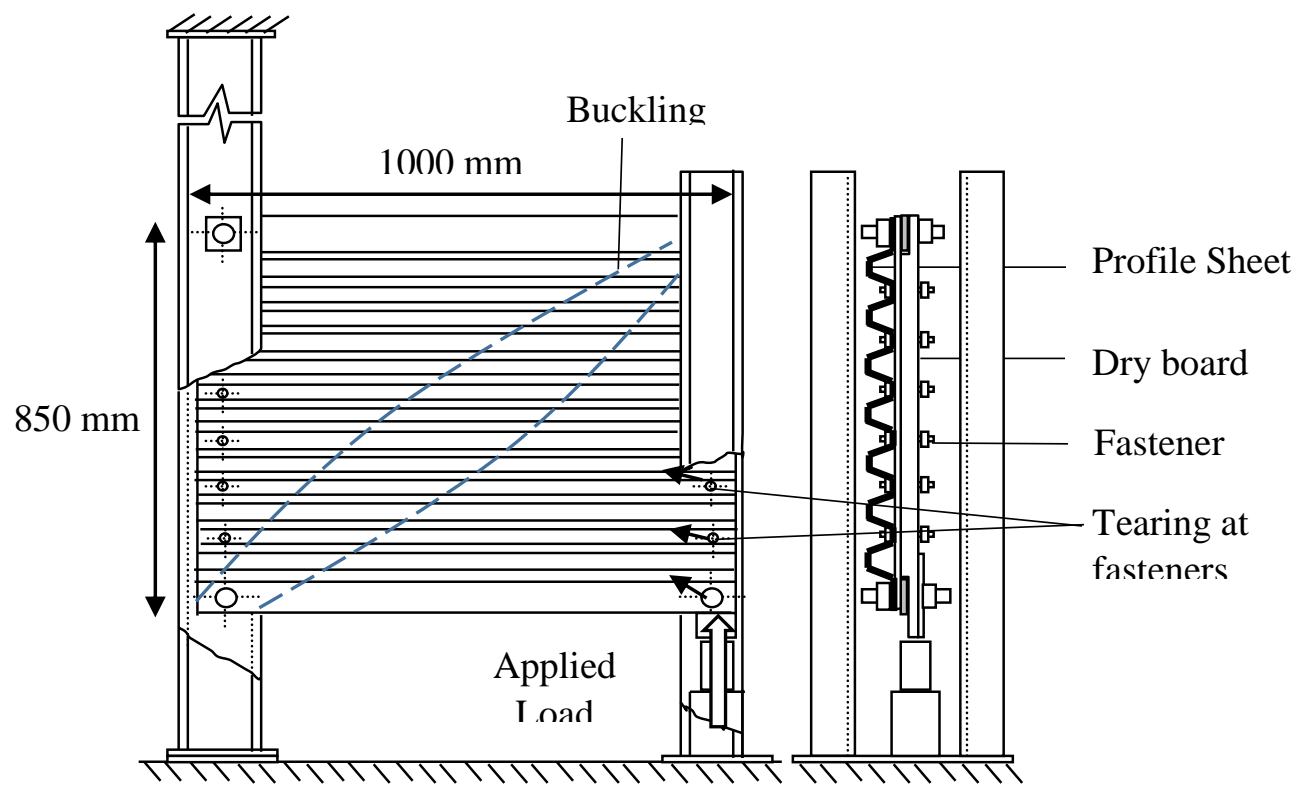

Figure 4.8 Failure pattern of the PSSDB panel (S4-PSSDB)

\subsubsection{Non-Pierced and Pierced Composite Panel with Both Vertical and Horizontal Fasteners (S-series)}

Shear load-deformation responses for the non-pierced (S6-PSSDB) as well as the pierced wall (S9p-PSSDB) panels are plotted in Figure 4.9. It can be seen that the non-pierced composite panel was able to sustain greater ultimate load than that of the pierced panel. Both panels had the same dimensions with both vertical and horizontal fasteners. Comparison of the ultimate load values 
displayed $88 \%$ increase in the load-bearing capacity of the non-pierced PSSDB wall. Buckling of the non-pierced panel was observed at an applied load of $6.6 \mathrm{kN}$ along with tearing of the sheet at an applied load of $7.2 \mathrm{kN}$. Characteristic failure through tearing of sheet and dry board at connecters and supports were noticed, as shown in Figure 4.10. However, for the pierced panels, propagation of tension field commenced at $3 \mathrm{kN}$. Full tension field and buckling of sheeting at edges were observed at an applied load of $3.9 \mathrm{kN}$. At an applied load of $4.5 \mathrm{kN}$ and $4.8 \mathrm{kN}$, buckling of sheet and tearing of both sheet and board were observed, respectively. The composite panel failed due to development of diagonal tension and compression combined in both dry board and sheet, though no bolt failure at hole location at boundary occurred. The corrugation profile was distorted as shown in Figure 4.11.

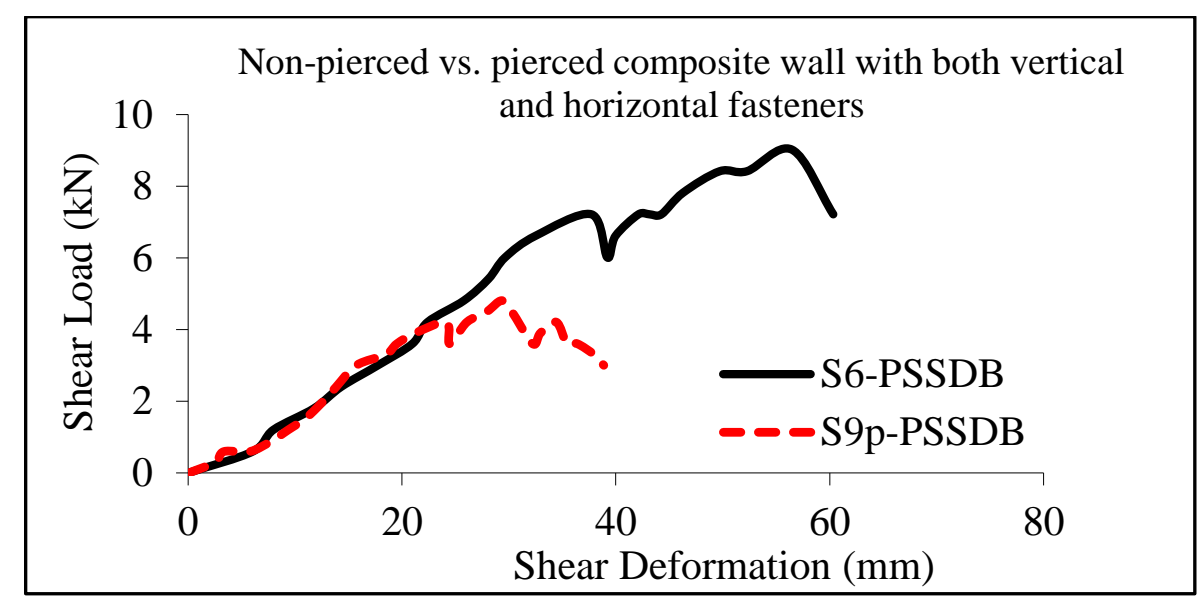

Figure 4.9 Load-deformation response of non-pierced (S6-PSSDB) and pierced (S9p-PSSDB) composite wall with both vertical and horizontal fasteners 


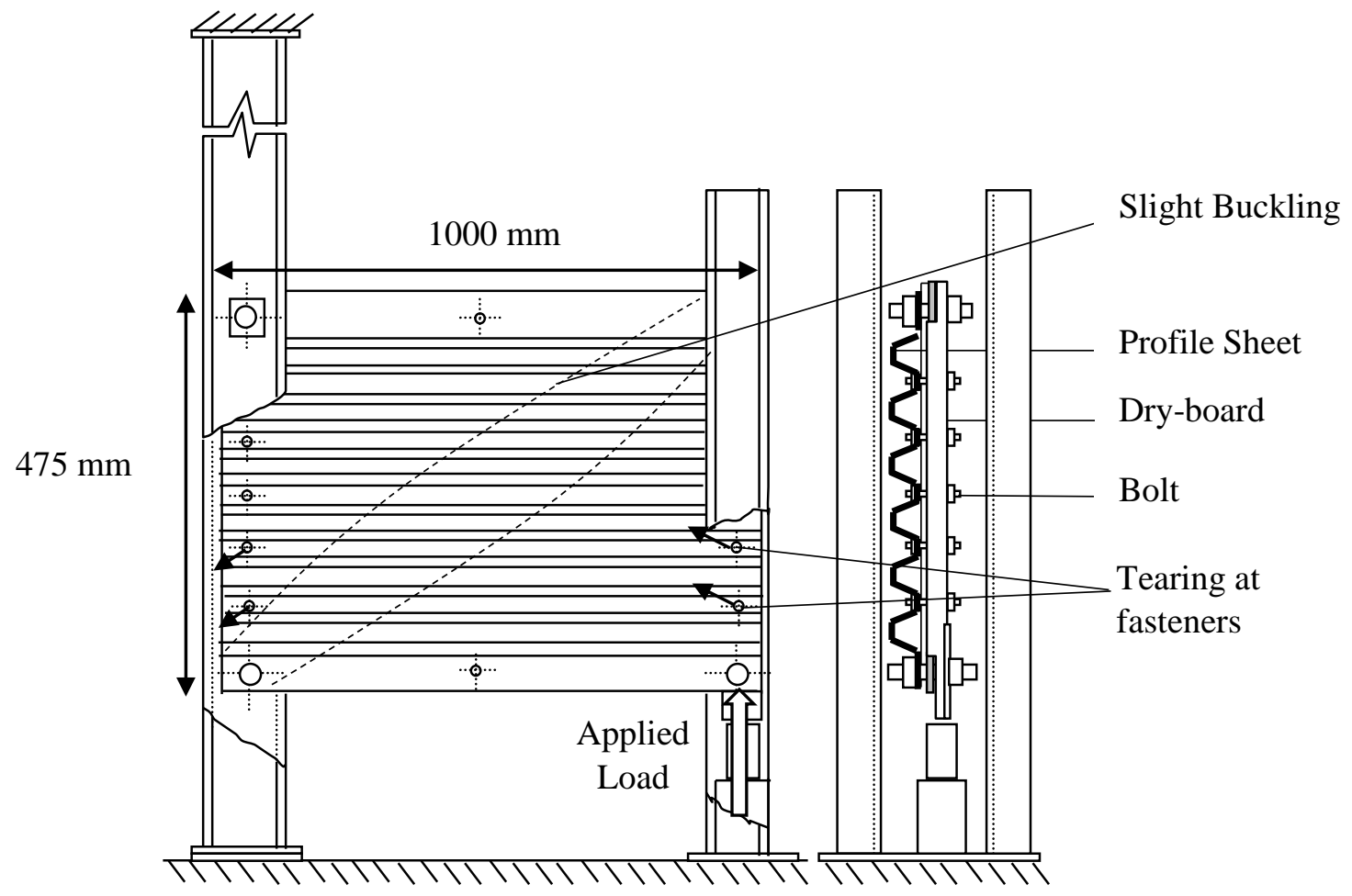

Figure 4.10 Schematic drawing displaying failure mode of non-pierced composite panel (S6-PSSDB)

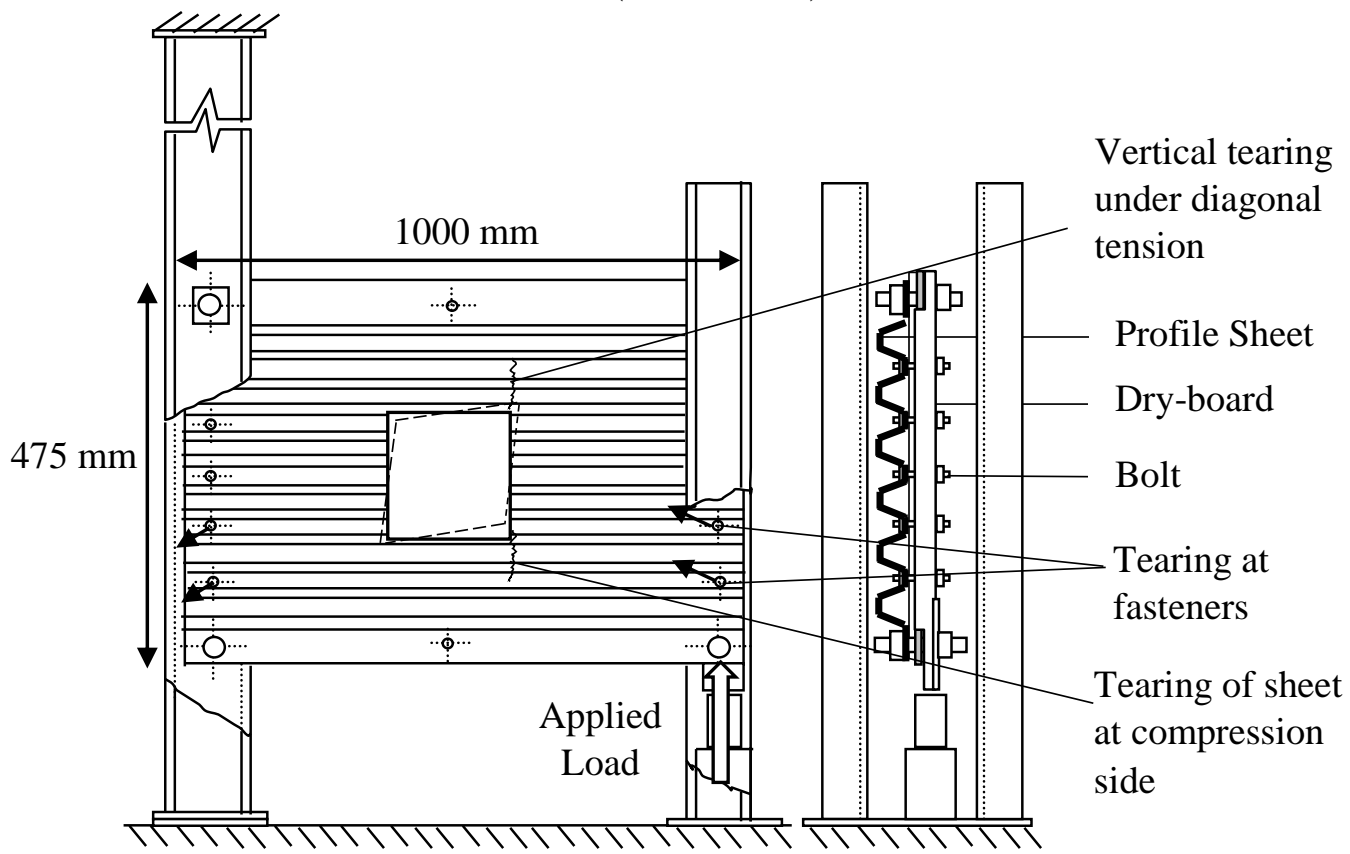

Figure 4.11 Schematic drawing displaying failure mode of pierced composite panel (S9p-PSSDB) 


\subsubsection{Non-Pierced and Pierced Profiled Steel Sheet with Vertical Fasteners Only (S-series)}

Shear load-deformation responses for the non-pierced (S7-PSS) and pierced (S10p-PSS) steel sheet panels in Figure 4.12, display an increase in load with the increase of deformation. Both panels had the same dimensions with vertical fasteners only. The load capacity of the non-pierced and pierced PSS panels were $6.32 \mathrm{kN}$ and $3.31 \mathrm{kN}$, respectively. Based on the obtained ultimate loads, it can be seen that the non-pierced steel sheet was able to sustain $90 \%$ more load than its pierced counterpart. For non-pierced panel, at $5.41 \mathrm{kN}$, buckling sound was heard followed by buckling at the top edge of the panel noticed at an applied load of $5.71 \mathrm{kN}$. Tearing of fasteners at the boundary was observed with no visible failure at the sheeting area. Failure was due to tearing at the boundary and due to the development of tension and compression fields (Figure 4.13 (a)) accompanied by the distortion and loss of geometry. For the pierced sheet panel, buckling of the panel was observed at an applied load of $1.2 \mathrm{kN}$. At $3.3 \mathrm{kN}$, buckling was observed in the tensile zone at the unloaded end and tearing was observed in the compression zone at the loaded end. The buckling and tearing failure were due to the development of tension and compression fields (Figure $4.13(b))$.

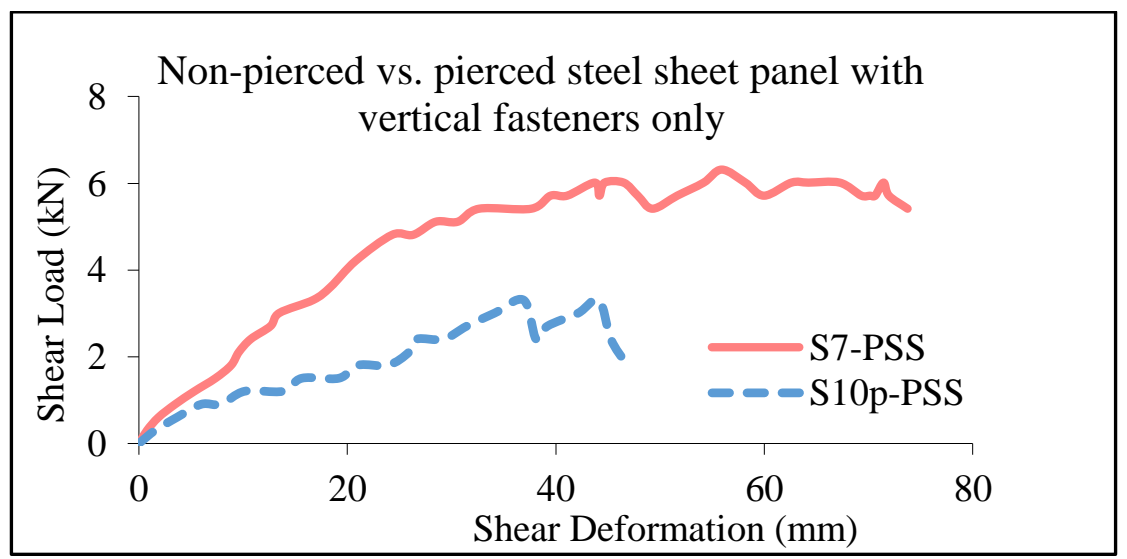

Figure 4.12 Load-deformation response of non-pierced (S7-PSS) and pierced steel sheet panel (S10p-PSS) with vertical fasteners only 


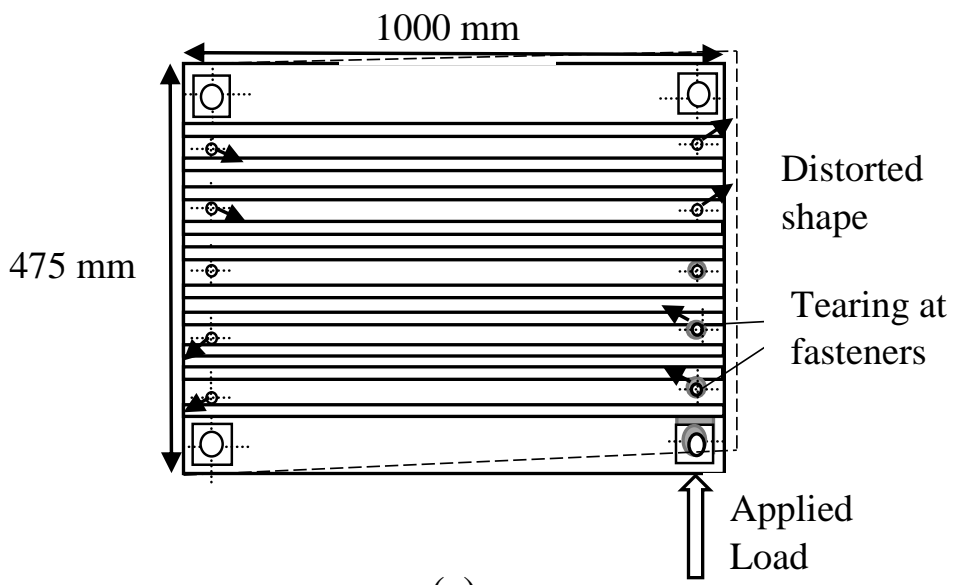

(a)

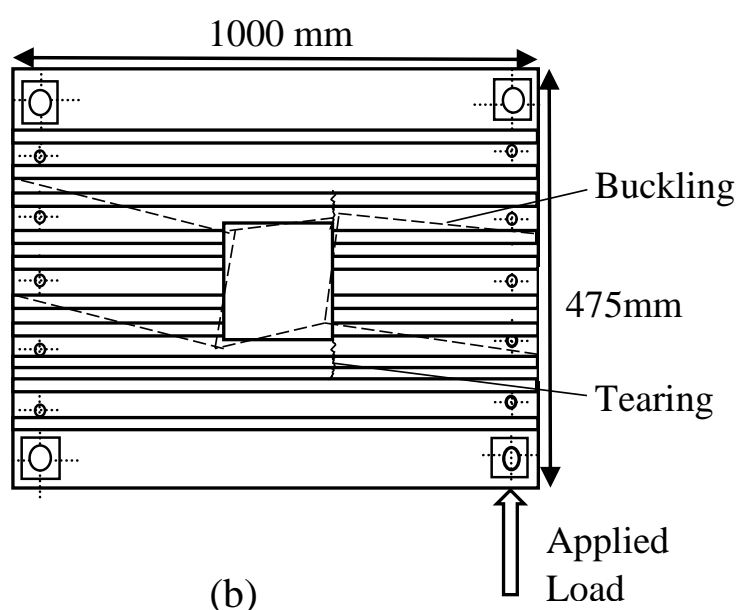

(b)

Figure 4.13 Failure patterns of (a) non-pierced (S7-PSS) and (b) pierced steel sheet (S10p-PSS) with vertical fasteners

\subsubsection{Non-Pierced vs. Pierced Dry Boards with Vertical Fasteners Only (S-series)}

Shear load-deformation responses for the non-pierced (S8-DB) and pierced (S11p-DB) DB panels are shown in Figure 4.14. Both panels had same dimensions with identical vertical fasteners only. The non-pierced DB panel carried an ultimate load of $2.12 \mathrm{kN}$, whereas the pierced panel carried an ultimate load of $1.5 \mathrm{kN}$. The non-pierced panel displayed buckling at an applied load of $1.2 \mathrm{kN}$, followed by the development of crack at $2.4 \mathrm{kN}$ (Figure 4.15 (a)). On the other hand, the pierced wall displayed buckling of board at an applied load of $0.9 \mathrm{kN}$. At an applied load of $1.2 \mathrm{kN}$, cracking at compression zone was observed with further development of cracks noticed at $1.5 \mathrm{kN}$. The pierced panel failed due to tearing at the compression zone. This failure was due to the development of diagonal tension and compression in dry board though no bolt failure at boundary was observed, as shown in Figure 4.15 (b).

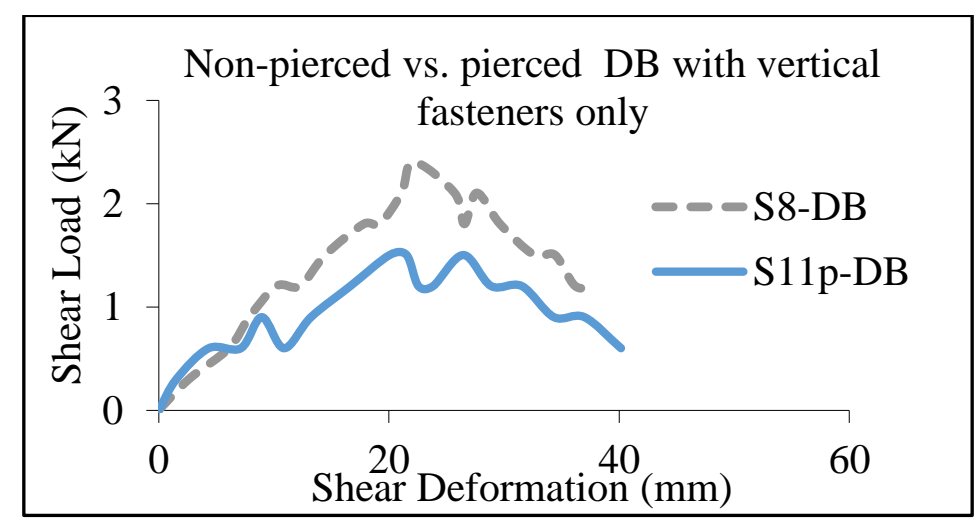

Figure 4.14 Load-deformation responses of non-pierced and pierced DB panels with vertical fasteners 

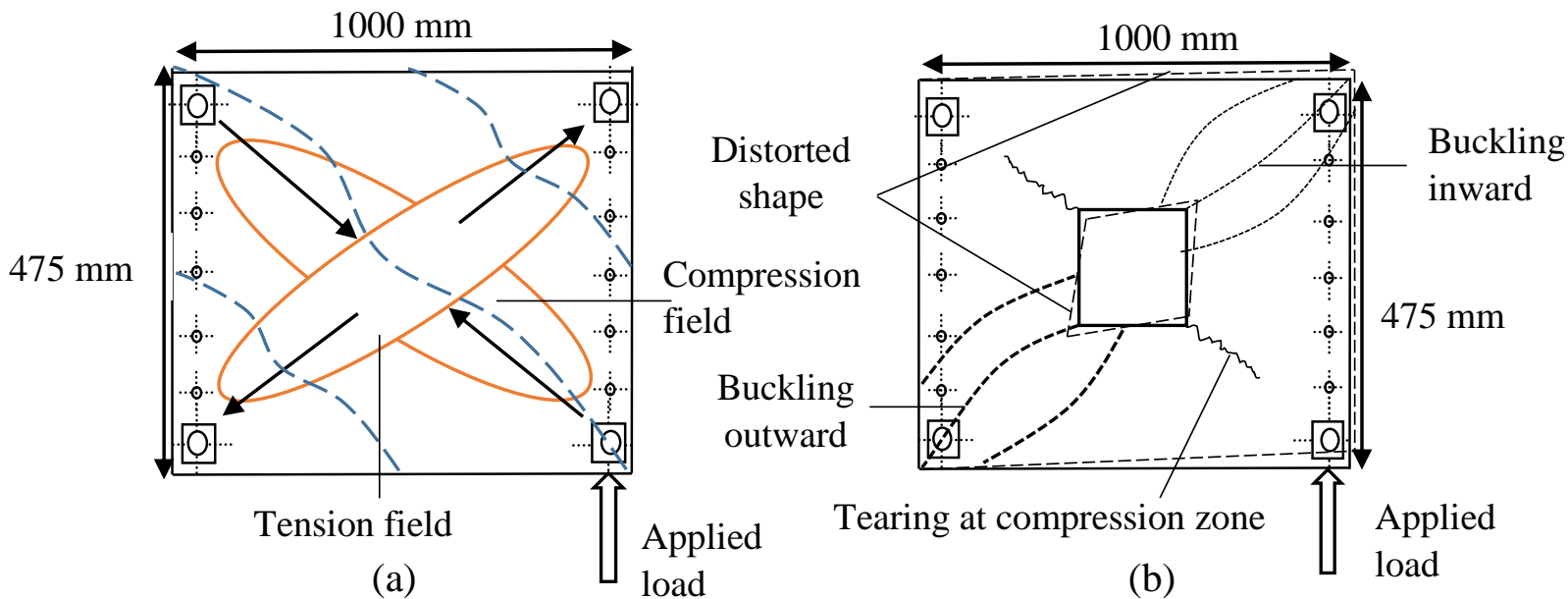

Figure 4.15 Failure patterns of (a) non-pierced (S8-DB) and (b) pierced (S11p-DB) panels with vertical fasteners only

\subsubsection{Summary of Experimental Findings for S-Series}

Table 4.3 summarizes the ultimate load and its corresponding deformations of the test panels in the S-series. DB and PSS panels bounded by both vertical and horizontal fasteners show greater shear load capacity than its counterparts with vertical fasteners only. S1-DB and S3-DB failed due to the development of diagonal tension and compression fields, whereas S2-PSS and S5-PSS failed due to tearing at end boundary/connection. The results also show that the PSSDB (S4-PSSDB) panel was able to sustain higher shear strength than the summation of the individual contributions from the DB (S3-DB) and PSS (S5-PSS). In the S4-PSSDB buckling and tearing failure was observed in the DB and PSS panel, respectively. Moreover, the presence of an opening in the S9p-PSSDB, S10p-PSS, and S11p-DB panels showed significant reduction in the shear load capacity than its non-pierced counterparts (S6-PSSDB, S7-PSS and S8-DB). Characteristic failure through tearing of sheet and dry board at connecters and supports were noticed in the S6-PSSDB panel. Furthermore, failure in the S7-PSS panel was due to tearing at the boundary and due to the development of tension and compression fields accompanied by the distortion and loss of geometry. Buckling failure was observed in the S8-DB panel. Tearing at the hole location along with buckling failure was evident in the pierced panels. 
Table 4.3 Experimental results for S-series

\begin{tabular}{|c|c|c|c|}
\hline Panel Specimen & Ult. Load $(\mathrm{kN})$ & Max. def.(mm) & Failure Mode \\
\hline S1-DB & 19.01 & 52.43 & Tearing at fastener \\
\hline S2-PSS & 28.87 & 44.03 & Tearing at fastener \\
\hline S3-DB & 7.82 & 30.36 & Tearing at fastener \\
\hline S4-PSSDB & 24.06 & 49.25 & Tearing at fastener \\
\hline S5-PSS & 8.73 & 40.72 & Tearing at fasteners \\
\hline S6-PSSDB & 9.02 & 56.48 & Tearing at fasteners \\
\hline S7-PSS & 6.32 & 55.93 & Buckling \\
\hline S8-DB & 2.12 & 22.14 & Tearing at hole + buckling \\
\hline S9p-PSSDB & 4.81 & 29.33 & Tearing at hole + buckling \\
\hline S10p-PSS & 3.31 & 36.91 & Tearing at hole + buckling \\
\hline S11p-DB & 1.44 & 26.46 & \\
\hline
\end{tabular}

\subsubsection{Structural Performance of Non-pierced and Pierced PSSDB Walls (A1-series)}

Table 4.4 summarizes the experimental test results of A1 series in terms load and deflection at $1^{\text {st }}$ buckling of DB, $1^{\text {st }}$ buckling of PSS and failure. Both components (DB and PSS) were found to be susceptible to local buckling in all the tested panels under shear loading. The initiation of cracking was determined from the cracking sound of concrete at about $20 \mathrm{kN}$, in the concrete infilled wall panel before it reached the point of failure. For the non-pierced A1 series, failure of the panels were due to localized instability as buckling and tearing occurred at the base. Tearing was noticed in the board as well as in the sheet. The load-deformation curve display that the non-pierced panel with concrete infill has higher load bearing capacity (about 15\%) than the wall without the concrete infill, as shown in Figure. 4.16 (a). It can be seen that the panel with infill can carry an ultimate load of $40 \mathrm{kN}$, whereas the panel without the infill carried an ultimate load of $35 \mathrm{kN}$.

Furthermore, for the pierced A1 series cracks at spacers (bottom of hole) were observed at an applied load of $27.5 \mathrm{~N}$. Failure occurred due to full mobilization of the A1-p shear wall, and cracks have been observed at $17.5 \mathrm{kN}$ with major loss of bond at bottom unloaded end for the A1pc shear walls. Tearing at the bottom loaded end was the cause of the failure in the A1-pc panels. The load-deformation curve display that the pierced panel with concrete infill has slightly higher load bearing capacity than the panel without the concrete infill (Figure. 4.16 (b)). It can be seen that the pierced panel with infill increased the load bearing capacity by $17 \%$. 


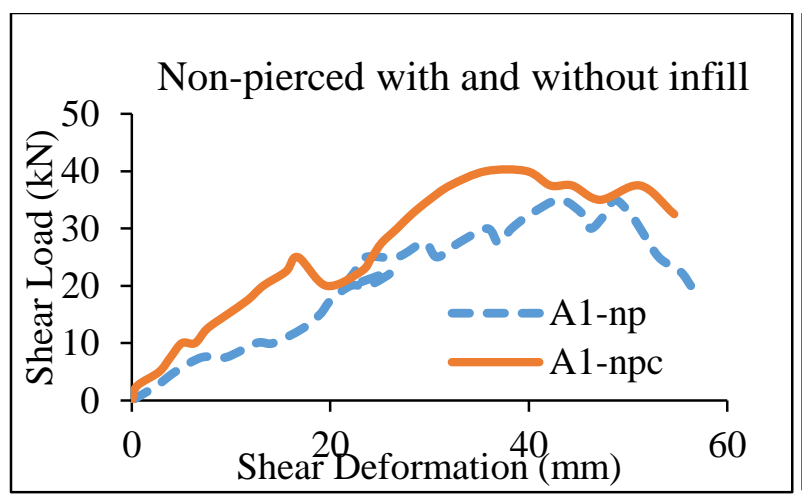

(a)

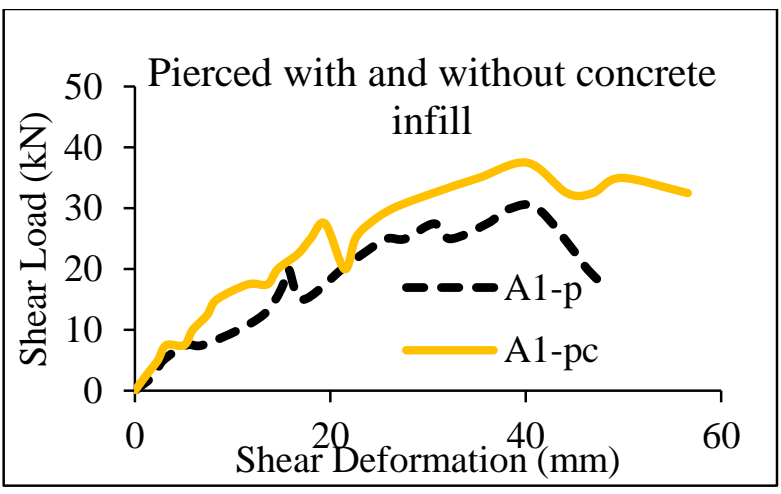

(b)

Figure 4.16 Load-deformation response of (a) non-pierced and (b) pierced PSSDB panels with and without concrete infill (A1-series)

\subsubsection{Structural Performance of Non-Pierced and Pierced B1-series}

Table 4.4 summarizes the experimental test results of B1 series in terms load and deflection at $1^{\text {st }}$ buckling of DB, $1^{\text {st }}$ buckling of PSS and failure. For the non-pierced wall without concrete infill (B1-np), failure occurred due to compression zone buckling and tearing of board. For the nonpierced wall with concrete infill, cracking sound was heard at $22.5 \mathrm{kN}$ and tearing at the bottom end was also observed. The second cracking sound was heard at $30.0 \mathrm{kN}$ load. Furthermore, buckling and failure at unloaded end bottom was noted, at $45.0 \mathrm{kN}$ load. The load-deformation curve display that the non-pierced panel with concrete infill has higher load bearing capacity than the wall without the concrete infill (Figure 4.17 (a)). It can be seen that the panel with infill carried $22 \%$ greater ultimate load than the panel without the infill.

For the pierced wall without concrete infill, buckling of internal sheeting at compression zone was noted. For the pierced wall with concrete infill, cracking sound was heard at $20.0 \mathrm{kN}$. Major separation was seen at an applied load of $32.5 \mathrm{kN}$. Figure 4.18 shows the cracking at the edge of the hole and buckling of board. The load-deformation curve display that the pierced panel with concrete infill has higher load bearing capacity than the wall without the concrete infill (Figure 4.17 (b)). It can be seen that the panel with infill can carry an ultimate load of 50kN, whereas the panel without the infill carried an ultimate load of $40 \mathrm{kN}$. 


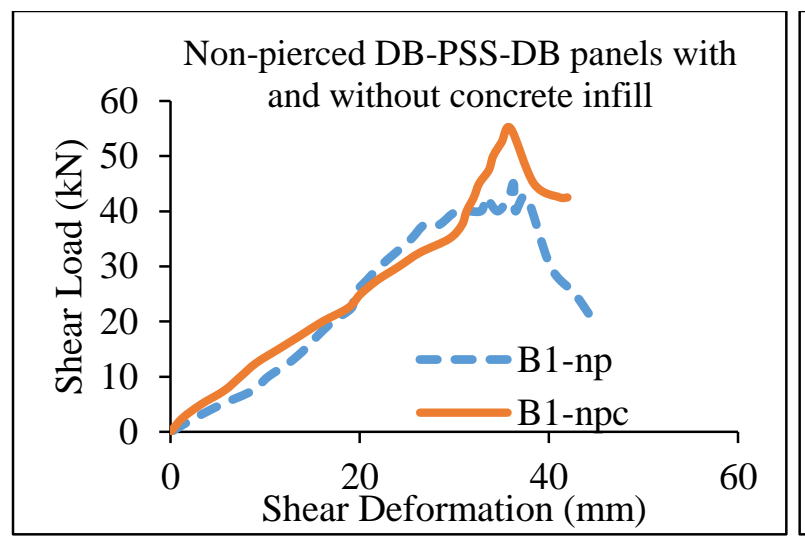

(a)

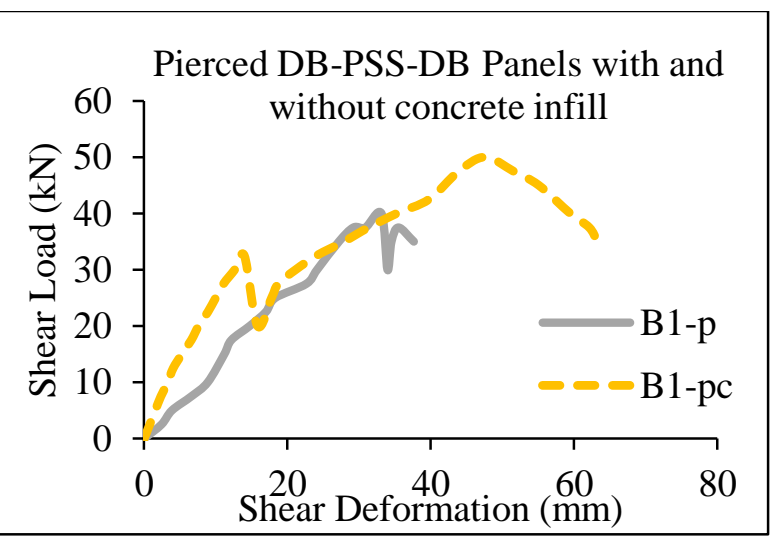

(b)

Figure 4.17 Load-deformation response of (a) non-pierced and (b) pierced DB-PSS-DB panels with and without concrete infill

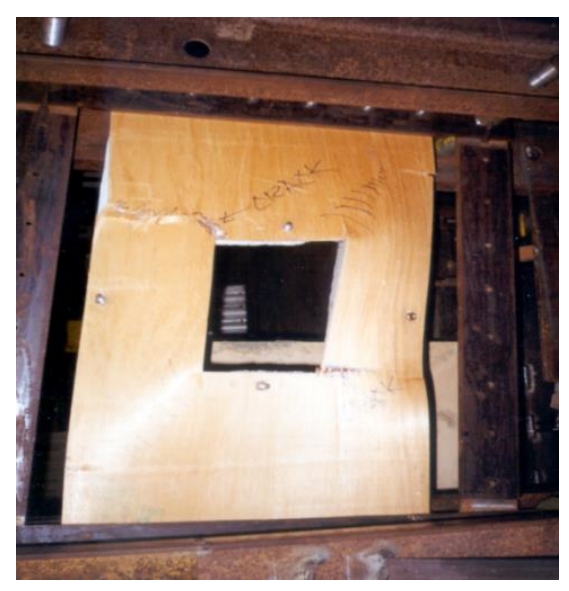

Figure 4.18 Experimental mode of failure

\subsubsection{Summary of Experimental Findings for A1 and B1-Series}

Table 4.4 summarizes the experimental test results of A1 and B1 series in terms load and deflection at $1^{\text {st }}$ buckling of DB, $1^{\text {st }}$ buckling of PSS and failure. The first buckling of board in the A1-np and B1-np was noticed at around $71 \%$ of the ultimate load in both the panels followed by buckling failure in the steel sheet at $7 \%$ and $11 \%$ of the ultimate load, respectively. Similar failure pattern was observed for the pierced panels without infill (A1-p and B1-p) along with tearing at the edge of the opening. Moreover, from Table 4.4 it can be deduced that the initiation of the first crack in A1-npc and B1-npc was observed at around 50\% and 59\% of the ultimate load, respectively followed by the buckling of board and steel sheet. Similar failure pattern was observed for the pierced panels with infill (A1-pc and B1-pc) along with tearing at the edge of the opening. 
Table 4.4 Experimental results for A1 and B1 Series

\begin{tabular}{|c|c|c|c|c|c|c|c|c|c|}
\hline \multirow{2}{*}{$\begin{array}{c}\text { Shear } \\
\text { Panel }\end{array}$} & \multicolumn{2}{|c|}{$\begin{array}{c}1^{\text {st }} \text { Concrete } \\
\text { Cracking Sound }\end{array}$} & \multicolumn{2}{|c|}{$\begin{array}{c}1^{\text {st }} \text { Buckling of } \\
\text { Board }\end{array}$} & \multicolumn{2}{|c|}{$\begin{array}{c}1^{\text {st }} \text { Buckling of } \\
\text { Sheet }\end{array}$} & \multicolumn{2}{|c|}{$\begin{array}{c}\text { Ultimate } \\
\text { Capacities }\end{array}$} & Failure Mode \\
\cline { 2 - 10 } & $\begin{array}{c}\text { Load } \\
(\mathrm{kN})\end{array}$ & $\begin{array}{c}\text { Def. } \\
(\mathrm{mm})\end{array}$ & $\begin{array}{c}\text { Load } \\
(\mathrm{kN})\end{array}$ & $\begin{array}{c}\text { Def. } \\
(\mathrm{mm})\end{array}$ & $\begin{array}{c}\text { Load } \\
(\mathrm{kN})\end{array}$ & $\begin{array}{c}\text { Def. } \\
(\mathrm{mm})\end{array}$ & $\begin{array}{c}\text { Load } \\
(\mathrm{kN})\end{array}$ & $\begin{array}{c}\text { Def. } \\
(\mathrm{mm})\end{array}$ & \\
\hline A1-np & -- & -- & 10.0 & 14.27 & 32.5 & 47.71 & 35.0 & 48.70 & Buckling \\
\hline A1-npc & 20.0 & 13.23 & 12.5 & 7.57 & 35.0 & 29.98 & 40.0 & 35.68 & Buckling \\
\hline A1-p & -- & -- & 7.5 & 6.91 & 27.5 & 30.64 & 30.0 & 38.45 & Buckling + Tearing at hole \\
\hline A1-pc & 17.5 & 11.59 & 27.5 & 19.48 & 35 & 35.2 & 37.5 & 40.17 & Buckling + Tearing at hole \\
\hline B1-np & -- & -- & 12.5 & 12.49 & 40.0 & 30.29 & 45.0 & 36.25 & Buckling \\
\hline B1-npc & 22.5 & 18.80 & 27.5 & 21.86 & 35.0 & 29.46 & 55.0 & 35.96 & Buckling \\
\hline B1-p & -- & -- & 10.0 & 8.90 & 37.5 & 29.22 & 40.0 & 33.14 & Buckling + Tearing at hole \\
\hline B1-pc & 20.0 & 7.60 & 32.5 & 13.99 & 37.5 & 31.33 & 50.0 & 47.63 & Buckling + Tearing at hole \\
\hline
\end{tabular}

\subsection{Development of Analytical Model for Shear resistance of Composite PSSDB Panels}

The analytical models are developed to determine the shear load capacity of the composite wall panels. The performance of the developed models are then validated through the results obtained by experimental tests. The overall mode of failure and the role of each component in the composite PSSDB panel on the load bearing capacity are investigated. The shear capacity of the proposed composite PSSDB wall panels is derived from the shear capacity of the DB, the shear capacity of the profiled steel sheet and the shear capacity of the concrete core (for panels with concrete infill).

\subsubsection{Buckling Shear Strength of Profiled Steel Sheet}

Since the early 1940s, profiled steel sheets have been used in floor construction (Wright et al., 1987). Many researchers had studied the behavior and design of corrugated steel plate shear walls subjected to in-plane shear loads. Studies on the rigidity, shear strength, diaphragm behavior and types of connection of the profiled steel deck to the top flange of floor/roof beams had been conducted based on experimental results (Bryan and El-Dakhakini, 1968; Hussain and Libove 1976; Davies and Lawson 1978; Davies 1977). The shear buckling capacity of a profiled steel sheet $\left(\mathrm{V}_{\mathrm{s}}\right)$ with simply supported edges (Fig. 4.16) can be expressed by Eq. 4.1 (Easley and McFarland 1969; Easley 1975): 
$V_{s}=36 H \frac{D_{x}^{1 / 4} D_{y}^{3 / 4}}{L^{2}}$

where $\mathrm{H}$ is the width of profiled steel sheet, $\mathrm{L}$ is the length parallel to the line of corrugation and $\frac{(a+b)}{(a+c)}$ (as per Fig. 4.19) is the length reduction factor.

Wright and Hossain (1997) studied the in-plane shear behavior of profiled steel sheet panels. To investigate the behavior of the profiled steel sheet panels under pure shear forces along a diagonal of the panel, panels were tested. Furthermore, analytical models have been developed to determine the shear strength and stiffness of the profiled steel sheeting and validated using the small scales model tests results and finite element analysis. The system in which the sheeting is attached to the boundary frame depends on the stiffness and strength of the corrugated sheeting. It was suggested that it is unwise to use the post-buckling shear reserves due to unstable and very rapid post-buckling behavior of the panel. Moreover, in order to validate the suitability of design equations, the values of several factors related to the mode of attachment of the sheeting to practical building frames were studied. The shear buckling capacity of profiled steel sheet depends on the type of connection of sheet to boundary frame, dimension of the sheet, modulus of elasticity of sheet, thickness and shape of profile. They proposed Eq. 4.2 for the critical shear buckling load $\left(V_{S}\right)$, similar to the equation suggested by Bergmann and Reissner with a buckling coefficient factor $(\beta)$ that depends on connection type of sheet to the boundary frame (Wright and Hossain, 1997):

$\mathrm{V}_{\mathrm{s}}=36 \beta \mathrm{H} \frac{\mathrm{D}_{\mathrm{x}}^{1 / 4} \mathrm{D}_{\mathrm{y}}^{3 / 4}}{\mathrm{~L}^{2}}(1 \leq \beta \leq 1.9)$

The orthotropic constants $\left(D_{x}\right.$ and $\left.D_{y}\right)$, for any cross-section of the corrugated sheets, as shown in Figure 4.18 are derived using the expression below:

$D_{y}=\frac{E_{s} t_{s}^{3}}{12\left(1-v^{2}\right)} \frac{(a+b)}{(a+c)}$

$D_{\mathrm{x}}=\frac{E_{s} t_{s}^{3}\left[\left(d / t_{s}\right)^{2}+1\right]}{6 \frac{(a+b)}{(a+c)}}$

Where $D_{x}$ is the bending stiffness per unit length about $x$-axis, $D_{y}$ is the bending stiffness per unit length about $y$-axis, $\beta$ is the buckling coefficient that depends on connection type of sheet to the boundary frame, $\mathrm{H}$ is the width of profiled steel sheet, $\mathrm{L}$ is the length parallel to the line of corrugation and $\frac{(a+b)}{(a+c)}$ (as per Fig. 4.19) is the length reduction factor. The buckling coefficient 
ranges from 1.00 to 1.72 . For simply supported conditions, $\beta$ can be considered as 1.00 and for clamped conditions, $\beta$ can be taken as 1.72 (Easley 1975; Hossain 1995; Wright and Hossain 1998)

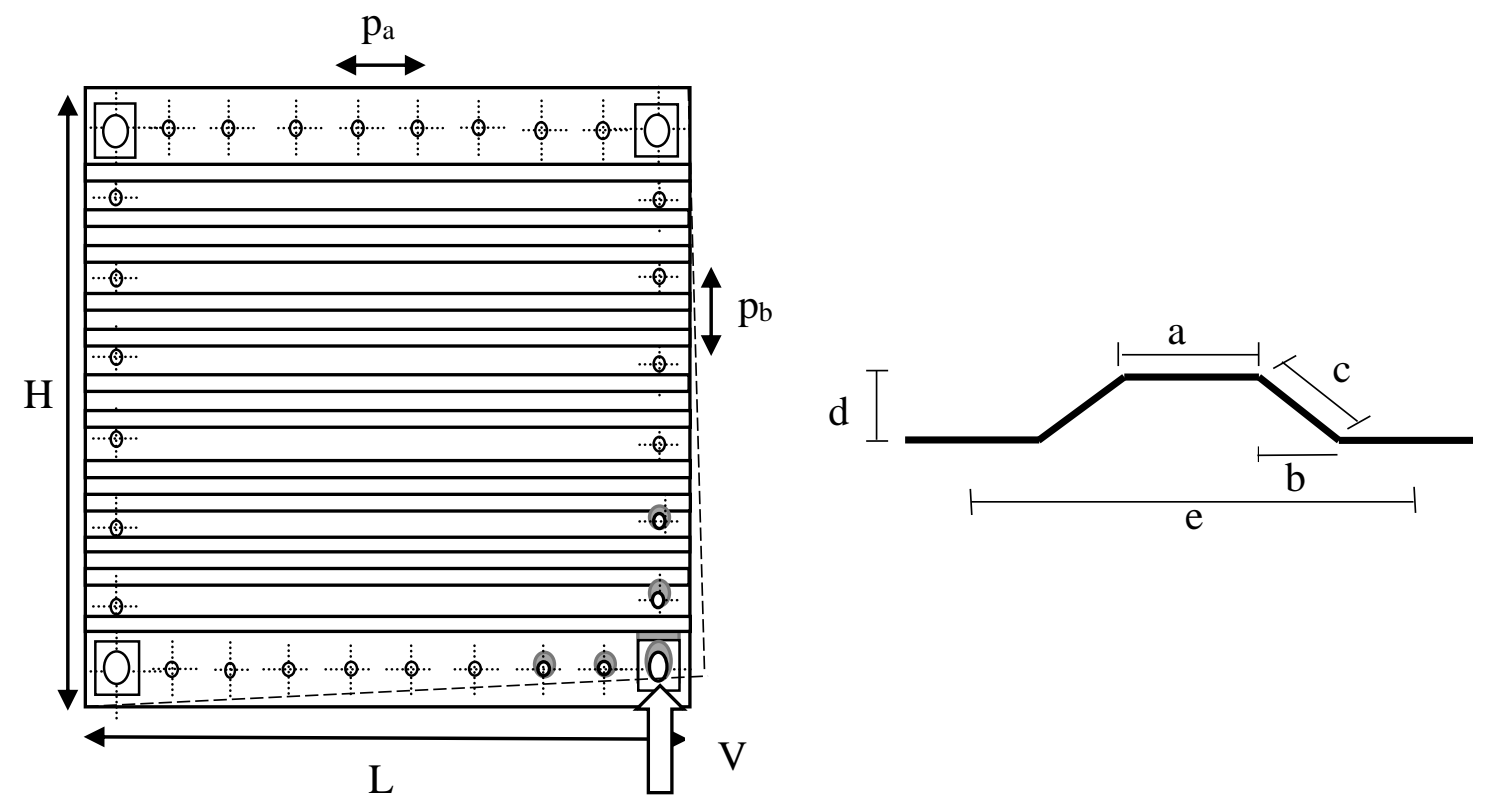

Figure 4.19 Panel bounded by pin ended rigid frame and cross-section of profiled steel sheet

\subsubsection{Local Shear Buckling and Global Shear Buckling Mode of Failure}

Local shear buckling occurs along the vertical edges of the rectangular flat sub-panels of the trapezoidal corrugated steel sheet. The elastic local shear buckling stress $\left(\tau_{c r, L}\right)$ can be derived by the classic plate buckling theory using Eq. 4.3:

$\tau_{c r, L}=k_{L} \frac{\pi^{2} E_{s}}{12\left(1-v^{2}\right)}\left(\frac{t_{s}}{w}\right)^{2}$

Assuming that the panel has simply supported edges, local shear buckling coefficient $\left(k_{L}\right)$ is calculated using Equation 4.3a below and is a function of the aspect ratio of the sub-panel, $\left(\frac{w}{h_{w}}\right)$.

$\mathrm{k}_{\mathrm{L}}=5.34+4\left(\frac{\mathrm{w}}{\mathrm{h}_{\mathrm{w}}}\right)^{2}$

$\mathrm{w}=\mathrm{a}+\mathrm{c}$

Where $t_{s}$ is the corrugated steel plate thickness, $w$ is the maximum fold width, $E_{s}$ is the modulus of elasticity of steel, $v$ is the Poisson's ratio of steel, $h_{w}$ is the height of the plate

Global buckling mode of failure governs in dense corrugations where diagonal buckling is observed throughout the web of the corrugated sheet as shown in Figure 4.20. Easley and McFarland $(1969,1975)$ investigated the general buckling behavior of light gauge corrugated shear 
diaphragms subjected to in-plane shear loads and derived equation for the shear buckling capacity of the corrugated steel sheet considering it as an orthotropic-plate buckling theory.

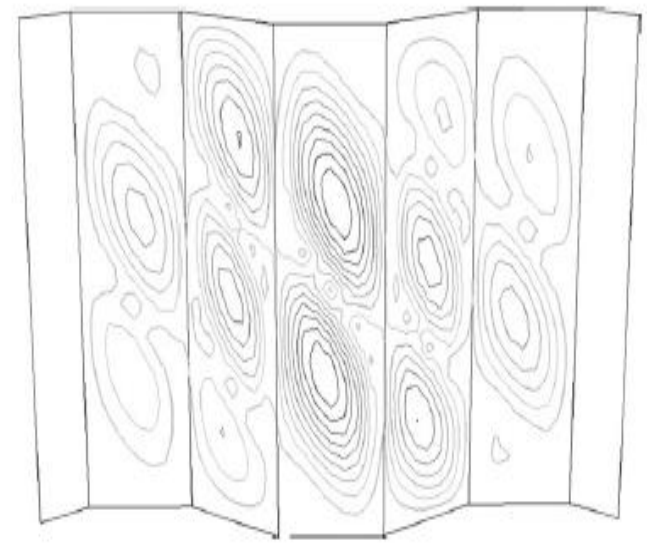

(a)

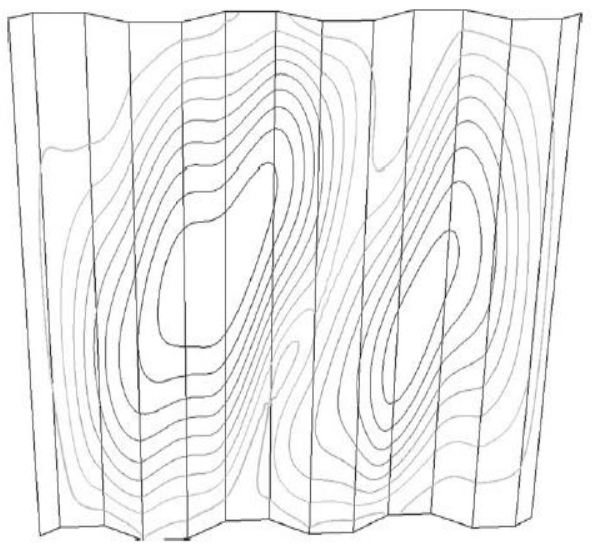

(b)

Figure 4.20 (a) Local shear buckling mode and (b) global shear buckling mode (Yi et. al., 2008)

The global and elastic local buckling of the profiled steel sheets are prevented by using intermediate interface connectors, to increase the nominal shear capacity of the composite wall. In order to prevent elastic local buckling, the distance between the intermediate fasteners, along the width and height of the composite shear walls should be optimized.

\subsubsection{Shear Capacity of the Profiled Steel Sheet Bounded by Frame with Fasteners}

The shear resistance of the profiled steel sheet panels may be governed by four modes of failure, and the minimum shear resistance amongst these can be taken as the ultimate shear load (Wright and Hossain, 1998):

(a) Failure at a line of seam fasteners (used to join profiled steel sheets - seam connection were not used in this study)

(b) Failure of connections between panel and frame

(c) Shear buckling of the profiled steel sheeting

(d) Gross distortion or collapse of the profile at the end of the sheeting

If the failure is desired in the connections/fasteners, the ultimate shear strength of the steel sheeting connected to the frame can be derived using shear strength of diaphragm for direct shear transfer as proposed by Bryan (1972) and Davies (1976). Shear capacities of the vertically and horizontally aligned fasteners are calculated using Eq. 4.4.

Shear strength due to sheet-beam or sheet-column fasteners: 
$V_{f}=\frac{F_{s b} \cdot L}{p_{a}}=\frac{F_{s c} \cdot H}{p_{b}}$

Where $p_{a}$ and $p_{b}$ are the spacing between the fasteners, $F_{s b}$ and $F_{s c}$ are the ultimate strength of one sheet-beam or sheet-column fastener respectively.

Plastic collapse at the extreme end of the profile causes gross distortion failure, although it cannot occur until the mechanism has spread some distance into the profile. This mode of failure is very crucial for sheeting having fasteners at alternate troughs rather than fasteners present at every trough. In order to prevent the possibility of gross distortion or collapse of the profile at ends, maximum shear force should not exceed (Davies and Bryan, 1982):

$\mathrm{V}_{\mathrm{S}}=\frac{0.9 \mathrm{t}_{\mathrm{s}}^{1.5} \mathrm{Hf}_{\mathrm{y}}}{\mathrm{e}^{0.5}}$ for fastener at every trough

$\mathrm{V}_{\mathrm{s}}=\frac{0.3 \mathrm{t}_{\mathrm{s}}^{1.5} \mathrm{Hf}_{\mathrm{y}}}{\mathrm{e}^{0.5}}$ for fastener at alternate trough

If the sheet-frame connection is adequately rigid, then the ultimate shear resistance of the profiled steel sheeting can be obtained using the critical buckling load equation (Eq. 4.2).

\subsubsection{Shear Strength of Profiled Concrete Core}

Based on biaxial stress conditions in the concrete, an analytical model (Eq. 4.7) can be used to calculate the shear strength of the profiled concrete core $\left(\mathrm{V}_{c}\right)$ by transforming the trapezoidal concrete core into an equivalent rectangular plain concrete core having an average thickness, $t_{e q}$ (as per Hossain 1995; Hossain and Wright 1998b; Easterling and Porter 1994a, 1994b):

$V_{c}=\frac{f^{\prime}{ }_{c} f_{t} t t_{e q} H}{f{ }_{c}+f^{\prime} t}$

where $f^{\prime}{ }_{c}$ is the cylinder compressive strength of concrete, $f^{\prime}{ }_{t}$ is the splitting tensile strength of concrete, $t_{e q}$ is the equivalent thickness of concrete panel and $\mathrm{H}$ is the width of the panel

\subsubsection{Shear Capacity of Plywood DB}

The theoretical equation to calculate the shear resistance of plywood sheath/DB is suggested in the "Engineering design in wood Manual O86-14)". The shear resistance of plywood can be obtained using Eq. 4.8 and Eq. 4.9. Based on Clause 11.5.1.2 in the manual, "factored shear resistance, Vp for a shear wall segment with wood-based structural panels is the smaller of the shear resistance value determined in terms of (a) and (b) as follows" (CSA, 2014):

a) Shear resistance governed by plywood sheathing/DB to framing connection strength resistance: 
$\mathrm{V}_{\mathrm{p}}=\emptyset \mathrm{v}_{\mathrm{d}} \mathrm{J}_{\mathrm{D}} \mathrm{n}_{\mathrm{s}} \mathrm{J}_{\mathrm{us}} \mathrm{J}_{\mathrm{s}} \mathrm{J}_{\mathrm{hd}} \mathrm{L}_{\mathrm{s}}$

$\emptyset=0.8 ; \mathrm{v}_{\mathrm{d}}=\frac{\mathrm{N}_{\mathrm{u}}}{\mathrm{s}}$

$\mathrm{J}_{\mathrm{D}}=1.3$ for nails and spikes used in diaphragms and shear wall construction $=1.0$ in all other cases

$\mathrm{J}_{\mathrm{s}}=1.0 \quad$ for $\mathrm{s} \geq 150 \mathrm{~mm}$

$=1-\left(\frac{150-\mathrm{s}}{150}\right)^{4.2}$ for $50 \mathrm{~mm} \leq \mathrm{s}<150 \mathrm{~mm}$

where $v_{d}$ is the specified shear strength for shear wall, $N_{u}$ is the lateral strength resistance of sheathing/DB to-framing connection along panel edges, per fastener, $\mathrm{s}$ is the fastener spacing along panel edges, $J_{D}$ is the adjustment factor for diaphragm and shear wall construction, $n_{s}$ is the number of shear planes in sheathing-to-framing connections, $J_{s}$ is the fastener spacing factor, $\mathrm{s}$ is the fastener spacing along panel edges, $J_{u s}$ is the strength adjustment factor for unblocked shear walls, $J_{h d}$ is the hold-down effect factor for shear wall segment, and $L_{s}$ is the length of shear wall segment parallel to direction of factored load.

b) Shear resistance governed by sheathing/DB panel buckling:

$\mathrm{V}_{\mathrm{p}}=\emptyset \mathrm{v}_{\mathrm{pb}} \mathrm{K}_{\mathrm{D}} \mathrm{K}_{\mathrm{S}} \mathrm{K}_{\mathrm{T}} \mathrm{L}_{\mathrm{s}}$

$\emptyset=0.8$

$\mathrm{v}_{\mathrm{pb}}=\mathrm{K}_{\mathrm{pb}} \frac{\pi^{2} \mathrm{t}^{2}}{300 \mathrm{bb}}\left(\mathrm{B}_{\mathrm{a}, 0} \mathrm{~B}_{\mathrm{a}, 90}^{3}\right)^{\frac{1}{4}}$

$\mathrm{K}_{\mathrm{pb}}=1.7(\eta+1) \exp \left(\frac{-\propto}{0.05 \eta+0.75}\right)+(0.5 \eta+0.8)$

$\alpha=\frac{\mathrm{a}}{\mathrm{b}}\left(\frac{\mathrm{B}_{\mathrm{a}, 90}}{\mathrm{~B}_{\mathrm{a}, 0}}\right)^{\frac{1}{4}}$

$\eta=\frac{2 B_{v}}{\sqrt{B_{a, 0} B_{a}, 90}}$

where $\mathrm{a}$ is the larger dimension of panel, $\mathrm{b}$ is the smaller dimension of panel, $B_{a, 0}$ is the axial stiffness of panel $0^{\circ}$ orientation, $B_{a, 90}$ is the axial stiffness of panel $90^{\circ}$ orientation, $B_{v}$ is the shearthrough-thickness rigidity, $\mathrm{t}$ is the panel thickness, $v_{p b}$ is the panel buckling strength of the most critical structural panel within the segment, $K_{p b}$ is the panel buckling factor, $K_{D}$ is the load duration factor, $K_{S}$ is the service condition factor, and $K_{T}$ is the treatment factor.

$K_{D}, K_{S}$, and $K_{T}$ are modification factors used in calculating the shear capacity of plywood. The specified strength capacity values for structural panels shall be multiplied by a service 
condition factor, $K_{S}$, as specified in Table 4.5. The treatment factor, $K_{T}$ is taken as 1.0, for untreated lumber in dry service condition (Table 4.6). It is also multiplied with the load duration factor $K_{D}$ (Table 4.7) where the standard term is 1.0 .

Table 4.5 Service condition factor, Ks (CSA, 2014)

\begin{tabular}{|c|c|c|c|}
\hline & & & $\mathrm{OSB}$ \\
\hline & Servi & ions & \\
\hline Property to be modified & Dry & Wet & Dry \\
\hline Specified strength capacity & 1.0 & 0.80 & 1.0 \\
\hline Specified stiffness and rigidity capacities & 1.0 & 0.85 & 1.0 \\
\hline
\end{tabular}

Table 4.6 Treatment factor, KT (CSA, 2014)

\begin{tabular}{|l|c|c|}
\hline \multicolumn{1}{|c|}{ Product } & Dry Service Conditions & Wet Service Conditions \\
\hline Untreated lumber & 1.00 & 1.00 \\
\hline Preservative-treated un-incised lumber & 1.00 & 1.00 \\
\hline $\begin{array}{l}\text { Preservative-treated incised lumber of } \\
\text { thickness 89 mm or less }\end{array}$ & \multicolumn{1}{|c|}{0.90} & 0.95 \\
\hline \multicolumn{1}{|c|}{ Modulus of elasticity } & \multicolumn{1}{|c|}{0.75} & 0.85 \\
\hline \multicolumn{1}{|c|}{ Other properties } & $\begin{array}{l}\text { See Clause 6.4.3.2 for effects of fire-retardant } \\
\text { treatment of CSA 2014 }\end{array}$ \\
\hline Fire-retardant-treated lumber & \multicolumn{2}{|c}{} \\
\end{tabular}


Table 4.7 Load duration factor, KD (CSA, 2014)

\begin{tabular}{|c|c|c|}
\hline Load Duration & $K_{D}$ & Explanatory Notes \\
\hline Short term & 1.15 & $\begin{array}{l}\text { Short-term loading means the condition of loading where the duration of } \\
\text { the specified loads is not expected to last more than } 7 \text { days continuously or } \\
\text { cumulatively throughout the life of the structure. } \\
\text { Examples include wind loads, earthquake loads, false work, and } \\
\text { formwork as well as impact loads. }\end{array}$ \\
\hline Standard term & 1.00 & $\begin{array}{l}\text { Standard term means the condition of loading where the duration of } \\
\text { specified loads exceeds that of short-term loading, but is less than long- } \\
\text { term loading. } \\
\text { Examples include snow loads, live loads due to occupancy, wheel loads } \\
\text { on bridges, and dead loads in combination with all of the above. }\end{array}$ \\
\hline Long term & 0.65 & $\begin{array}{l}\text { Long-term duration means the condition of loading under which a member } \\
\text { is subjected to more or less continuous specified load. } \\
\text { Examples include dead loads or dead loads plus live loads of such } \\
\text { character that they are imposed on the member for as long a period of time } \\
\text { as the dead loads themselves. Such loads include those usually occurring } \\
\text { in tanks or bins containing fluids or granular material, loads on retaining } \\
\text { wall subjected to lateral pressure such as earth and floor loads where the } \\
\text { specified load can be expected to be continuously applied, such as those in } \\
\text { buildings for storage of bulk materials. Loads due to fixed machinery } \\
\text { should be considered to be long term. }\end{array}$ \\
\hline \multicolumn{3}{|c|}{$\begin{array}{l}\text { Note: Load duration requires professional judgement by the designer. Explanatory notes in this Table provide } \\
\text { guidance to designers about the types of loads and load combination for which each modification factor should } \\
\text { be applied. }\end{array}$} \\
\hline
\end{tabular}

\subsubsection{Ultimate Shear Strength of Panel with Rectangular Opening}

Farzampour et al. (2015) investigated the behavior of unstiffened and corrugated steel plate shear walls (CSSW) with and without rectangular opening. Numerical parametric study was performed to compare both non-pierced as well as pierced corrugated and unstiffened panels with and without opening. The parameters included in this study were plate thickness, angle of corrugation, opening size and opening placement. For CSSW panels with optimized rectangular position, an ultimate strength prediction procedure was developed and proposed. The derived equation presented that 
regardless of the opening location, the ultimate shear strength analysis of pierced corrugated steel plate shear walls and simple steel plate shear walls (unstiffened) can be simplified by multiplying

"non-pierced" results with the factor of $\left(1-\frac{d_{o p}}{D}\right)$. Therefore, the ultimate shear strength of corrugated steel sheet wall (CSSW) with a rectangular opening can be presented by Eq. 4.10 (Farzampour et al., 2015):

$F_{s u(o p)}=F_{s u}\left(1-\frac{d_{o p}}{D}\right)$

where $F_{s u(o p)}$ is the ultimate strength capacity of CSSW with opening, $F_{s u}$ is the ultimate strength of a CSSW without opening, $d_{o p}$ is the diameter of the opening and $D$ is the diameter of the panel.

The diameter of the opening is calculated considering the length (l) and height (h) of the rectangular opening as follows:

$d_{o p}^{2}=l^{2}+h^{2}$

The diameter of the panel is calculated considering the length (L) and height of the panel as follows:

$D^{2}=L^{2}+H^{2}$

\subsubsection{Shear Resistance of the PSSDB Composite Wall Panels and its Components}

\subsubsection{S-Series}

Analytical models for the shear resistance of the individual components (DB and PSS) were developed, based on existing analytical models. Consequently, the analytical model for the shear resistance of the PSSDB composite walls was derived based on the combined strength of each components. Boundary condition of the panel plays a vital role in hindering the structural performance of the wall panels. The governance of the type of failure, whether failure at sheetframe connections or buckling of sheeting/DB depends on the boundary conditions of the panel. The equations derived for the pierced panels were multiplied with the factor proposed by Farzampour et al. (2015) to consider the effect of the opening. The shear strength of the bolted connection in the DB and PSS was determined using experimental tests. The following equations for the DB, PSS and PSSDB are derived based on the experimental mode of failure. The governing shear resistance $\left(\mathrm{V}_{\mathrm{g}}\right)$ of PSSDB panels are the minimum of the shear resistance values calculated based on different failure modes related to buckling, sheet distortion and connection/fastener. 


\subsection{Shear Resistance of Non-Pierced and Pierced DB Panel Considering Different Mode of Failure}

The shear resistance of the PSS panels may be governed either by the shear buckling of DB or failure at the connections between the panel and the frame. The shear resistance of non-pierced $\left(\mathrm{V}_{\mathrm{DB}}\right)$ and pierced $\left(\mathrm{V}_{\mathrm{DB}(\mathrm{p})}\right) \mathrm{DB}$ panel with presence of both vertical and horizontal fasteners considers sheet-frame connection failure and can be calculated using Eq. 4.11 and Eq. 4.12. Panels with vertical fasteners only failed due to buckling failure and the shear resistance of the DB panel is determined using Eq. 4.13 and Eq. 4.14, respectively.

$\mathrm{V}_{\mathrm{DB}}=\emptyset \mathrm{v}_{\mathrm{d}} \mathrm{J}_{\mathrm{D}} \mathrm{n}_{\mathrm{s}} \mathrm{J}_{\mathrm{us}} \mathrm{J}_{\mathrm{s}} \mathrm{J}_{\mathrm{hd}} \mathrm{L}_{\mathrm{s}}$

$\mathrm{V}_{\mathrm{DB}(\mathrm{p})}=\emptyset \mathrm{v}_{\mathrm{d}} \mathrm{J}_{\mathrm{D}} \mathrm{n}_{\mathrm{s}} \mathrm{J}_{\mathrm{us}} \mathrm{J}_{\mathrm{s}} \mathrm{J}_{\mathrm{hd}} \mathrm{L}_{\mathrm{s}}\left(1-\frac{\mathrm{d}_{\mathrm{op}}}{\mathrm{D}}\right)$

$\mathrm{V}_{\mathrm{DB}}=\emptyset \mathrm{v}_{\mathrm{pb}} \mathrm{K}_{\mathrm{D}} \mathrm{K}_{\mathrm{S}} \mathrm{K}_{\mathrm{T}} \mathrm{L}_{\mathrm{s}}$

$\mathrm{V}_{\mathrm{DB}(\mathrm{p})}=\left(\emptyset_{\mathrm{pb}} \mathrm{K}_{\mathrm{D}} \mathrm{K}_{\mathrm{S}} \mathrm{K}_{\mathrm{T}} \mathrm{L}_{\mathrm{s}}\right)\left(1-\frac{\mathrm{d}_{\mathrm{op}}}{\mathrm{D}}\right)$

The shear resistance of $\mathrm{DB}$ considering failure at the vertically $\left(\mathrm{V}_{\mathrm{f}, \mathrm{DB} \text { (vertical }}\right)$ and horizontally $\left(\mathrm{V}_{\mathrm{f}, \mathrm{DB}(\text { horizontal})}\right)$ aligned panel-frame fasteners is calculated using Eq. 4.15 and Eq. 4.16, respectively.

$\mathrm{V}_{\mathrm{f}, \mathrm{DB}(\text { vertical })}=\frac{\mathrm{F}_{\mathrm{sb}, \mathrm{DB}} \cdot \mathrm{L}}{\mathrm{p}_{\mathrm{a}}}$

$\mathrm{V}_{\mathrm{f}, \mathrm{DB}(\text { Horizontal })}=\frac{\mathrm{F}_{\mathrm{sc}, \mathrm{DB}} \cdot \mathrm{H}}{\mathrm{p}_{\mathrm{b}}}$

where the strength of bolted $\mathrm{DB}$ connection $\left(\mathrm{F}_{\mathrm{sb}, \mathrm{DB}}\right.$ or $\left.\mathrm{F}_{\mathrm{sc}, \mathrm{DB}}\right)$ was experimentally found to be $1.12 \mathrm{kN}$ per fastener.

\subsection{Shear Resistance of Non-Pierced and Pierced PSS Panel Considering Different Mode of Failure}

The shear resistance of the PSS panels may be governed either by the shear buckling of PSS or gross distortion of the profile at the end of the steel sheeting or failure at the connections (aligned vertically and/or horizontally) between the sheet and the frame.

Considering the buckling mode of failure, the shear resistance of non-pierced (VPSS) and pierced (VPS(p) $)$ PSS panel with both vertical and horizontal fasteners was determined using Eq. 4.17 and Eq. 4.18, respectively. 
$\mathrm{V}_{\mathrm{PSS}}=36 \beta \mathrm{H} \frac{\mathrm{D}_{\mathrm{x}}^{\frac{1}{4}} \mathrm{D}_{\mathrm{y}}^{\frac{3}{4}}}{\mathrm{~L}^{2}}$

$\mathrm{V}_{\mathrm{PSS}(\mathrm{p})}=\left(1-\frac{\mathrm{d}_{\mathrm{op}}}{\mathrm{D}}\right)\left[36 \beta \mathrm{H} \frac{\mathrm{D}_{\mathrm{x}}^{\frac{1}{4}} \mathrm{D}_{\mathrm{y}^{\frac{3}{4}}}}{\mathrm{~L}^{2}}\right]$

The shear resistance of non-pierced ( $\mathrm{V}_{\mathrm{PSS}}$ ) and pierced ( $\left.\mathrm{V}_{\mathrm{PSS}(\mathrm{p})}\right)$ PSS panel with vertical fasteners only failed due to gross distortion mode of failure and was calculated using Eq. 4.19 and Eq. 4.20, respectively.

$\mathrm{V}_{\mathrm{PSS}}=\frac{0.3 \mathrm{t}_{\mathrm{s}}^{1.5} \mathrm{Hf}_{\mathrm{y}}}{\mathrm{e}^{0.5}}$

$\mathrm{V}_{\mathrm{PSS}(\mathrm{p})}=\left(\frac{0.3 \mathrm{t}_{\mathrm{s}}^{1.5} \mathrm{Hf}_{\mathrm{y}}}{\mathrm{e}^{0.5}}\right)\left(1-\frac{\mathrm{d}_{\mathrm{op}}}{\mathrm{D}}\right)$

The shear resistance of PSS considering failure at the vertically $\left(\mathrm{V}_{\mathrm{f}, \mathrm{PSS} \text { (vertical) }}\right)$ and horizontally ( $\left.\mathrm{V}_{\text {f,PSS(Horizontal) }}\right)$ aligned sheet-frame fasteners was calculated using Eq. 4.21 and Eq. 4.22, respectively.

$\mathrm{V}_{\mathrm{f}, \mathrm{PSS}(\text { vertical })}=\frac{\mathrm{F}_{\mathrm{sb}, \mathrm{PSS}} \cdot \mathrm{L}}{\mathrm{p}_{\mathrm{a}}}$

$\mathrm{V}_{\mathrm{f}, \mathrm{PSS}(\text { Horizontal })}=\frac{\mathrm{F}_{\mathrm{sc}, \mathrm{PSS}} \cdot \mathrm{H}}{\mathrm{p}_{\mathrm{b}}}$

where the strength of bolted PSS connection ( $\mathrm{F}_{\mathrm{sb}, \mathrm{PSS}}$ or $\left.\mathrm{F}_{\mathrm{sc}, \mathrm{PSS}}\right)$ was experimentally found to be $5.02 \mathrm{kN}$ per fastener.

\subsection{Shear Resistance of Non-Pierced and Pierced PSSDB Panel Considering Different Mode of Failure}

Eq. 4.23 to Eq. 4.27 were used to calculate the shear resistance of the non-pierced and pierced composite PSSDB panels by conservatively summing the shear resistance of the individual elements (DB and PSS).

Considering buckling mode of failure for both PSS and DB, Eq. 4.23 and Eq. 4.24 were used to calculate the shear resistance of non-pierced ( $\left.\mathrm{VPSSDB}_{\mathrm{PS}}\right)$ and pierced ( $\left.V_{P S S D B(p)}\right)$ PSSDB panel with both vertical and horizontal fasteners, respectively.

$$
\begin{aligned}
& \mathrm{V}_{\mathrm{PSSDB}}=\left(36 \beta \mathrm{H} \frac{\mathrm{D}_{\mathrm{x}}^{\frac{1}{4}} \mathrm{D}_{\mathrm{y}}^{\frac{3}{4}}}{\mathrm{~L}^{2}}\right)+\left(\varnothing \mathrm{v}_{\mathrm{pb}} \mathrm{K}_{\mathrm{D}} \mathrm{K}_{\mathrm{S}} \mathrm{K}_{\mathrm{T}} \mathrm{L}_{\mathrm{s}}\right) \\
& \mathrm{V}_{\mathrm{PSSDB}(\mathrm{p})}=\left[\left(36 \beta \mathrm{H} \frac{\mathrm{D}_{\mathrm{x}}^{\frac{1}{4}} \mathrm{D}_{\mathrm{y}}^{\frac{3}{4}}}{\mathrm{~L}^{2}}\right)+\left(\varnothing \mathrm{v}_{\mathrm{pb}} \mathrm{K}_{\mathrm{D}} \mathrm{K}_{\mathrm{S}} \mathrm{K}_{\mathrm{T}} \mathrm{L}_{\mathrm{s}}\right)\right]\left(1-\frac{\mathrm{d}_{\mathrm{op}}}{\mathrm{D}}\right)
\end{aligned}
$$


Eq. 4.25 and Eq. 4.26 considered gross distortion mode of failure for PSS and buckling of to calculate the shear resistance of non-pierced ( $\left.\mathrm{V}_{\text {PSSDB }}\right)$ and pierced ( $\mathrm{V}_{\text {PSSDB }}$ (p) PSSDB panel with vertical fasteners, respectively.

$$
\begin{aligned}
& \mathrm{V}_{\mathrm{PSSDB}}=\left(\frac{0.3 \mathrm{t}_{\mathrm{s}}^{1.5} \mathrm{Hf}_{\mathrm{y}}}{\mathrm{e}^{0.5}}\right)+\left(\emptyset \mathrm{v}_{\mathrm{pb}} \mathrm{K}_{\mathrm{D}} \mathrm{K}_{\mathrm{S}} \mathrm{K}_{\mathrm{T}} \mathrm{L}_{\mathrm{s}}\right) \\
& \mathrm{V}_{\mathrm{PSSDB}(\mathrm{p})}=\left[\left(\frac{0.3 \mathrm{t}_{\mathrm{s}}^{1.5} \mathrm{Hf}_{\mathrm{y}}}{\mathrm{e}^{0.5}}\right)+\left(\varnothing \mathrm{v}_{\mathrm{pb}} \mathrm{K}_{\mathrm{D}} \mathrm{K}_{\mathrm{S}} \mathrm{K}_{\mathrm{T}} \mathrm{L}_{\mathrm{s}}\right)\right]\left(1-\frac{\mathrm{d}_{\mathrm{op}}}{\mathrm{D}}\right)
\end{aligned}
$$

The shear resistance of PSSDB considering failure at the vertically $\left(\mathrm{V}_{\mathrm{f}, \mathrm{PSSDB}(\mathrm{vertical})}\right)$ and horizontally $\left(\mathrm{V}_{\mathrm{f}, \mathrm{PSSDB} \text { (Horizontal) }}\right)$ aligned fasteners was calculated using Eq. 4.27 and Eq. 4.28, respectively. The strength of bolted PSSDB connection ( $\mathrm{F}_{\mathrm{sb}, \mathrm{PSSDB}}$ or $\mathrm{F}_{\mathrm{sc}, \mathrm{PSSDB}}$ ) was conservatively taken as the sum of the strength in the DB and PSS bolted connection $\left(F_{s b, P S S D B}=F_{s c, P S S D B}=F_{s b, D B}\right.$

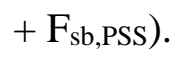

$\mathrm{V}_{\mathrm{fPSSDB}(\text { vertical })}=\frac{\mathrm{F}_{\mathrm{sb}, \mathrm{PSSDB}} \cdot \mathrm{L}}{\mathrm{p}_{\mathrm{a}}}$

$\mathrm{V}_{\mathrm{fPSSDB}(\text { Horizontal })}=\frac{\mathrm{F}_{\mathrm{Sc}, \mathrm{PSSDB}} \cdot \mathrm{H}}{\mathrm{p}_{\mathrm{b}}}$

\subsubsection{A1-B1 Series PSSDB Wall Panels}

The shear capacity of the composite PSSDB panels with and without concrete-infill can be conservatively obtained as the sum of the shear resistance of individual elements (dry board, profiled steel sheet and concrete core). The first term in the composite equation represents the shear capacity in the PSS, and the second term represents the DB shear capacity. The shear resistance for the composite panels in the B1 series uses twice the shear capacity of DB due to the addition of another board in the system. For composite panels with concrete infill, a third term representing the shear resistance of the concrete core is included. The equation reflects the PSSDB-Concrete interaction limit state. The equations for the A1 (PSS-DB) and B1 (DB-PSS-DB) series were developed based on the modes of failures observed during experimental tests.

\subsection{Shear Resistance of Non-Pierced Panels without concrete infill ( $V_{\text {A1-np }}, V_{\text {B1-np }}$ )}

The shear resistance of non-pierced PSSDB ( $\left.\mathrm{V}_{\mathrm{A1}-\mathrm{np}}\right)$ and DB-PSS-DB ( $\left.\mathrm{V}_{\mathrm{B} 1-\mathrm{np}}\right)$ panels without concrete infill was developed by considering buckling failure of both PSS and DB using Eq. 4.29 and Eq. 4.30. The shear capacity in the PSS was determined by transforming the PSS to equivalent DB using a modular ratio $\left(\frac{E_{p s s}}{E_{d b}}\right)$. 


$$
\begin{aligned}
& \mathrm{V}_{\mathrm{A} 1-\mathrm{np}}=\left[\emptyset \mathrm{v}_{\mathrm{pb}} \mathrm{K}_{\mathrm{D}} \mathrm{K}_{\mathrm{S}} \mathrm{K}_{\mathrm{T}} \mathrm{L}_{\mathrm{s}}\right]+\left[\emptyset\left(\frac{\mathrm{E}_{\mathrm{pss}}}{\mathrm{E}_{\mathrm{db}}}\right) \mathrm{v}_{\mathrm{pb}} \mathrm{K}_{\mathrm{D}} \mathrm{K}_{\mathrm{S}} \mathrm{K}_{\mathrm{T}} \mathrm{L}_{\mathrm{s}}\right] \\
& \alpha=\frac{\mathrm{a}}{\mathrm{b}}\left(\frac{\mathrm{B}_{\mathrm{a}, 90}}{\mathrm{~B}_{\mathrm{a}, 0}}\right)^{\frac{1}{4}}=\frac{900}{475}\left(\frac{24000}{70000}\right)^{\frac{1}{4}}=1.450 \\
& \eta=\frac{2 B_{v}}{\sqrt{B_{a, 0} B_{a, 90}}}=\frac{2(4600)}{\sqrt{70000 * 24000}}=0.224 \\
& \mathrm{~K}_{\mathrm{pb}}=1.7(\eta+1) \exp \left(\frac{-\propto}{0.05 \eta+0.75}\right)+(0.5 \eta+0.8) \\
& =1.7(0.224+1) \exp \left(\frac{-1.450}{0.05(0.224)+0.75}\right)+((0.5 * 0.224)+0.8)=1.222 \\
& \mathrm{~V}_{\mathrm{A} 1-\mathrm{np}}=\left[1 *\left(1.222 \frac{\pi^{2}\left(6^{2}\right)}{3000(475)}\left(670000 * 24000^{3}\right)^{\frac{1}{4}}\right) * 1 * 1 * 1 * 475\right] \\
& +\left[1 *\left(\frac{235000}{4000}\right)\left(\left(1.222 \frac{\pi^{2}\left(0.48^{2}\right)}{3000(475)}\left(70000 * 24000^{3}\right)^{\frac{1}{4}}\right) * 1 * 1 * 1 * 475\right]\right. \\
& =35300 \mathrm{~N}=35.30 \mathrm{kN} \\
& \mathrm{V}_{\mathrm{B} 1-\mathrm{np}}=2\left[\emptyset \mathrm{v}_{\mathrm{pb}} \mathrm{K}_{\mathrm{D}} \mathrm{K}_{\mathrm{S}} \mathrm{K}_{\mathrm{T}} \mathrm{L}_{\mathrm{s}}\right]+\left[\varnothing\left(\frac{\mathrm{E}_{\mathrm{pss}}}{\mathrm{E}_{\mathrm{db}}}\right) \mathrm{v}_{\mathrm{pb}} \mathrm{K}_{\mathrm{D}} \mathrm{K}_{\mathrm{S}} \mathrm{K}_{\mathrm{T}} \mathrm{L}_{\mathrm{s}}\right] \\
& =2 *\left[1 *\left(1.222 \frac{\pi^{2}\left(6^{2}\right)}{3000(475)}\left(70000 * 24000^{3}\right)^{\frac{1}{4}}\right) * 1 * 1 * 1 * 475\right] \\
& +\left[1 *\left(\frac{235000}{4000}\right) *\left(1.222 \frac{\pi^{2}\left(0.48^{2}\right)}{3000(475)}\left(70000 * 24000^{3}\right)^{\frac{1}{4}}\right) * 1 * 1 * 1 * 475\right] \\
& =39840 \mathrm{~N}=39.84 \mathrm{kN}
\end{aligned}
$$

\subsection{Shear Resistance of Non-Pierced Panels with concrete infill ( $V_{\text {A1-npc }}, V_{\text {B1-npc }}$ )}

Hossain and Wright (2004) developed a simplified equation (Eq. 4.31) to calculate the shear resistance of the profiled steel-concrete composite $\left(V_{P S S+C}\right)$ panels. It assumes full composite action and considers the cross-section of the profiled composite panel by transforming profile concrete core and steel sheet into an equivalent rectangular concrete panels.

$V_{P S S+C}=\gamma \varphi H \sqrt{f^{\prime} c}\left[t_{e q c}+n \alpha t_{s}\right]$

Where $\gamma$ is the shear resistance contribution factor that ranges between 1.19 and $1.28, \varphi$ is the factor recommended by ACI 318-83 depending on $\mathrm{H} / \mathrm{L}(\varphi=0.167), \mathrm{H}$ is the width of the panel, $\mathrm{L}$ is the length of the panel, $t_{e q c}$ is the width of the equivalent rectangular block that encloses the same area as the profiled cross-section, $\alpha$ is the ratio of developed length of a corrugation of the profiled steel sheet to its projected length and $\mathrm{n}$ is the modular ratio $\left(\frac{E_{\text {pas }}}{E_{c}}\right)$. 
The shear resistance equation (Eq. 4.32 and Eq. 4.33) of the non-pierced PSSDB $\left(\mathrm{V}_{\mathrm{A} 1-\mathrm{npc}}\right)$ ) and DB-PSS-DB $\left(\mathrm{V}_{\mathrm{B} 1-\mathrm{npc}}\right)$ panels with concrete infill are derived based on the simplified equation proposed for the profiled steel-concrete composite (Eq. 4.31) by Hossain and Wright (2004) and buckling capacity of DB (Eq. 4.9). The shear capacity in the PSS and concrete is determined by transforming it into equivalent concrete using a modular ratio $\left(\frac{E_{p s s}}{E_{c}}\right)$, where $E_{\mathrm{c}}=4700 \sqrt{\mathrm{f}_{\mathrm{c}}^{\prime}}$.

$$
\begin{aligned}
\mathrm{V}_{\mathrm{A} 1-\mathrm{npc}} & =\left[\emptyset \mathrm{v}_{\mathrm{pb}} \mathrm{K}_{\mathrm{D}} \mathrm{K}_{\mathrm{S}} \mathrm{K}_{\mathrm{T}} \mathrm{L}_{\mathrm{s}}\right]+\left[\gamma \varphi \mathrm{H}\left(\frac{\text { Epss }}{4700}\right) \alpha \mathrm{t}_{\mathrm{s}}\right]+\left[\gamma \varphi \mathrm{t}_{\mathrm{eqc}} \mathrm{H} \sqrt{\mathrm{f}^{\prime} \mathrm{c}}\right] \\
& =\left[1 *\left(1.222 \frac{\pi^{2}\left(6^{2}\right)}{3000(475)}\left(70000 * 24000^{3}\right)^{\frac{1}{4}}\right) * 1 * 1 * 1 * 475\right] \\
& +\left[1 * 0.167 * 475 *\left(\frac{235000}{4700}\right) * 1.281 * 0.48\right]+[1 * 0.167 * 30 * 475 \sqrt{22.15}] \\
& =38430 \mathrm{~N}=38.43 \mathrm{kN} \\
\mathrm{V}_{\mathrm{B} 1-\mathrm{npc}} & =2\left[\emptyset \mathrm{v}_{\mathrm{pb}} \mathrm{K}_{\mathrm{D}} \mathrm{K}_{\mathrm{S}} \mathrm{K}_{\mathrm{T}} \mathrm{L}_{\mathrm{s}}\right]+\left[\gamma \varphi \mathrm{H}\left(\frac{\mathrm{Epss}}{4700}\right) \alpha \mathrm{t}_{\mathrm{s}}\right]+\left[\gamma \varphi \mathrm{t}_{\mathrm{eqc}} \mathrm{H} \sqrt{\mathrm{f}^{\prime} \mathrm{c}}\right] \\
& =2 *\left[1 *\left(1.222 \frac{\pi^{2}\left(6^{2}\right)}{3000(475)}\left(70000 * 24000^{3}\right)^{\frac{1}{4}}\right) * 1 * 1 * 1 * 475\right] \\
& +\left[1 * 0.167 * 475 *\left(\frac{235000}{4700}\right) * 1.281 * 0.48\right]+[1 * 0.167 * 30 * 475 \sqrt{22.15}] \\
& =50800 \mathrm{~N}=50.80 \mathrm{kN}
\end{aligned}
$$

\subsection{Shear Resistance of Pierced Panels With ( $\left.V_{\text {A1-p }}, V_{\text {B1-p }}\right)$ and Without (V $\left.V_{\text {A1-pc, }}, V_{\text {B1-pc }}\right)$ Concrete Infill}

In order to take into account the effect of opening Eq. 4.34 to Eq. 4.37 is multiplied by a factor proposed by Farzampour et al. (2015) to the shear resistance of its non-pierced counterparts. For this study, the equation has assumed the board to act like a simple pierced plate thus taking into consideration the non-pierced strength of the DB panel along with the factor. Likewise, for the concrete core, similar concept has been adopted. Eq. 4.34 and Eq. 4.35 are used to determine the shear resistance of pierced PSSDB ( $\left.\mathrm{V}_{\mathrm{A1}-\mathrm{p}}\right)$ and DB-PSS-DB ( $\left.\mathrm{V}_{\mathrm{B} 1-\mathrm{p}}\right)$ panels without infill, whereas Eq. 4.36 and Eq. 4.37 are used to determine the shear resistance of pierced PSSDB (V $\mathrm{V}_{\mathrm{A1}-\mathrm{pc}}$ ) and DB-PSS-DB ( $\left.\mathrm{V}_{\mathrm{B} 1-\mathrm{pc}}\right)$ panels with infill.

$$
\begin{aligned}
\mathrm{V}_{\mathrm{A} 1-\mathrm{p}} & =\left(\mathrm{V}_{\mathrm{A} 1-\mathrm{np}}\right)\left(1-\frac{\mathrm{d}_{\mathrm{op}}}{\mathrm{D}}\right) \\
& =28240 *\left(1-\frac{316.23}{1017.66}\right)=24330 \mathrm{~N}=24.33 \mathrm{kN} \\
\mathrm{V}_{\mathrm{B} 1-\mathrm{p}} & =\mathrm{V}_{\mathrm{B} 1-\mathrm{np}}\left(1-\frac{\mathrm{d}_{\mathrm{op}}}{\mathrm{D}}\right)
\end{aligned}
$$




$$
\begin{aligned}
= & 31872 *\left(1-\frac{316.23}{1017.66}\right)=27450 \mathrm{~N}=27.45 \mathrm{kN} \\
\mathrm{V}_{\mathrm{A} 1-\mathrm{pc}} & =\left(\mathrm{V}_{\mathrm{A} 1-\mathrm{npc}}\right)\left(1-\frac{\mathrm{d}_{\mathrm{op}}}{\mathrm{D}}\right) \\
& =38430 *\left(1-\frac{316.23}{1017.66}\right)=26490 \mathrm{~N}=26.49 \mathrm{kN} \\
\mathrm{V}_{\mathrm{B} 1-\mathrm{pc}} & =\mathrm{V}_{\mathrm{B} 1-\mathrm{npc}}\left(1-\frac{\mathrm{d}_{\mathrm{op}}}{\mathrm{D}}\right) \\
& =50800 *\left(1-\frac{316.23}{1017.66}\right)=35010 \mathrm{~N}=35.01 \mathrm{kN}
\end{aligned}
$$

\subsubsection{Performance Validation of Analytical Models}

The tested shear panels are used to validate the performance of the analytical models in predicting the shear capacity of composite wall panels. Table 4.8 and 4.9 compare the theoretical and experimental load bearing capacity of the wall panels in S and A1-B1 series, respectively. The validity of the analytical models for predicting the shear load capacities of walls is analyzed in association with the observed failure modes of the system from the experimental tests.

\subsubsection{Wall Panels bounded by a rigid frame (S-series)}

This series of tests included testing each of the components in the PSSDB system individually and composite as a whole to understand the structural behavior under in-plane shear loading. Table 4.7 summarizes the shear capacity calculated using the equations derived in section 4.3.6.1 for each of the panels in the S-series (Detailed calculations are shown Appendix B).

Analytical results prove that the shear capacity of PSS and DB panel connected at all sides (vertical and horizontal) of frames displayed sheet-frame connection failure, whereas panels connected by bolts/fasteners at alternate troughs at the vertical sides only displayed grossdistortion failure of steel sheets and buckling failure of DB. Eq. 4.11 to Eq. 4.28 are used to calculate the shear resistance depending on the mode of failure of the tested panel. Eq. 4.13 (derived for panels connected to boundary frame with both vertical and horizontal fasteners) overestimated the shear resistance of the tested dry board panels (S8-DB and S11p-DB) with vertical fasteners only. Analytical equations are found to be safe in predicting the shear resistance of other panels as experimental to analytical load ratios are found to be greater than 1.0.

A modification factor $(\mu)$ is introduced as the ratio of experimental to analytical shear strength $\left(\mathrm{V}_{\exp } / \mathrm{V}_{\mathrm{g}}\right)$. The derived analytical equations can be used for determination of shear strength 
of PSSDB panels by incorporating suggested values of modification factor $(\mu)$ for practical design purposes.

Table 4.8 Comparison of analytical and experimental shear load capacities of wall panels bounded by a rigid frame (S-series)

\begin{tabular}{|c|c|c|c|c|c|c|c|c|}
\hline \multirow{3}{*}{ Shear Panel } & \multicolumn{7}{|c|}{ Shear Load Capacity (kN) } & \multirow[b]{2}{*}{$\mu$} \\
\hline & \multicolumn{6}{|c|}{ Analytical } & Exp. & \\
\hline & $V_{f v}$ & $V_{\text {fh }}$ & $\mathrm{V}_{\mathrm{PSS}}$ & $\mathrm{V}_{\mathrm{DB}}$ & $\mathrm{V}_{\text {PSSDB }}$ & $V_{g}$ & $V_{\text {exp }}$ & $\mathrm{V}_{\mathrm{exp}} / \mathrm{V}_{\mathrm{g}}$ \\
\hline S1-DB & - & - & - & $17.00 *$ & - & 17.00 & 19.01 & 1.12 \\
\hline S2-PSS & $27.40^{*}$ & 38.90 & $58.49 \dagger$ & - & - & 27.40 & 28.90 & 1.05 \\
\hline S3-DB & - & - & - & $5.13 \dagger$ & - & 5.13 & 7.82 & 1.52 \\
\hline S4-PSSDB & - & - & - & - & 12.42 & 12.42 & 24.10 & 1.94 \\
\hline S5-PSS & - & - & 7.17 & - & - & 7.17 & 8.72 & 1.22 \\
\hline S6-PSSDB & - & - & - & - & 6.44 & 6.44 & 9.02 & 1.40 \\
\hline S7-PSS & - & - & 4.01 & - & - & 4.01 & 6.32 & 1.58 \\
\hline S8-DB & - & - & - & $3.88 \dagger$ & - & 3.88 & 2.41 & 0.62 \\
\hline S9p-PSSDB & - & - & - & - & 3.66 & 3.66 & 4.81 & 1.31 \\
\hline S10p-PSS & - & - & 2.57 & - & - & 2.57 & 3.31 & 1.29 \\
\hline S11p-DB & - & - & - & $2.48 \dagger$ & - & 2.48 & 1.44 & 0.60 \\
\hline \multicolumn{9}{|c|}{$\begin{array}{l}\mathrm{V}_{\mathrm{fv}}, \mathrm{V}_{\mathrm{fh}}: \text { Shear capacity of fasteners in the vertical and horizontal direction, respectively; } \mathrm{V}_{\mathrm{PSS}}: \text { Shear capacity } \\
\text { of PSS; } \mathrm{V}_{\mathrm{DB}} \text { : Shear capacity of DB; } \mathrm{V}_{\mathrm{PSSDB}} \text { : Shear capacity of PSSDB; } \mathrm{V}_{\mathrm{g}}: \text { Governing shear capacity; } \mathrm{V}_{\mathrm{exp}} \text { : } \\
\text { Experimental shear capacity }\end{array}$} \\
\hline
\end{tabular}

\subsubsection{A1 and B1 series}

The shearing strengths from analytical equations are compared to those of the experimental and are presented in Table 4.9. Theoretical shear capacities of PSSDB wall panels in the A1 - B1-series are found to be lower than those obtained from experiments (Table 4.9). The accuracy of the proposed analytical equations to determine the ultimate shear resistance are authenticated with the results obtained experimentally. Buckling is the failure criterion and Eq. 4.29 to Eq. 4.37 are used to calculate the shear resistance of both $\mathrm{A} 1$ and $\mathrm{B} 1$-series. An adjustment factor $(\lambda)$ is introduced as the ratio of experimental to analytical shear strength $\left(\mathrm{V}_{\text {exp }} / \mathrm{V}\right)$. It can be concluded that the suggested analytical equations (Eq. 4.29 to Eq. 4.37) are safe as experimental to analytical ratio ranges between 0.99 and 1.46 . 
Table 4.9 Comparison between analytical and experimental shear load capacities of PSSDB walls (A1-B1 series)

\begin{tabular}{|c|c|c|c|c|c|c|}
\hline \multirow{3}{*}{$\begin{array}{l}\text { PSSDB } \\
\text { Shear } \\
\text { Panel }\end{array}$} & \multicolumn{5}{|c|}{ Shear load Capacity $(\mathrm{kN})$} & \multirow{3}{*}{$\begin{array}{c}\lambda \\
\mathrm{V}_{\exp } / \mathrm{V}\end{array}$} \\
\hline & \multicolumn{4}{|c|}{ Analytical } & \multirow{2}{*}{$\begin{array}{c}\text { Experimental } \\
V_{\text {exp }}\end{array}$} & \\
\hline & PSS & DB & Concrete & V & & \\
\hline A1-np & 30.76 & 4.54 & - & 35.30 (Eq. 4.29$)$ & 35 & 0.99 \\
\hline A1-npc & 12.72 & 4.54 & 21.17 & 38.43 (Eq. 4.32) & 40 & 1.04 \\
\hline A1-p & 21.19 & 3.13 & - & 24.32 (Eq. 4.34) & 30 & 1.23 \\
\hline A1-pc & 8.77 & 3.13 & 14.59 & 26.49 (Eq. 4.36) & 37 & 1.40 \\
\hline B1-np & 30.76 & 9.08 & - & 39.84 (Eq. 4.30) & 45 & 1.13 \\
\hline B1-npc & 12.72 & 9.08 & 29.00 & 50.80 (Eq. 4.33) & 55 & 1.08 \\
\hline B1-p & 21.19 & 6.26 & - & 27.45 (Eq. 4.35) & 40 & 1.46 \\
\hline B1-pc & 8.77 & 6.26 & 19.98 & 35.01 (Eq. 4.37) & 50 & 1.43 \\
\hline
\end{tabular}

\subsection{Finite Element Modeling Of PSSDB Walls under Shear Loading (A1-B1 Series)}

Finite element models simulating the behavior of PSSDB composite walls (A1-B1 series) under shear loading are developed using ABAQUS/CAE using experimental results. The effect of having a rectangular opening and concrete infill in the composite wall panels is investigated.

\subsubsection{Material Properties}

\subsubsection{Dry-board Model}

Structural wood is known for its light, stiff and strong material properties due to its unique cell structure. The stiffness and strength properties vary significantly with the direction of the material (longitudinal (L), radial (R) and tangential (T)). For the purpose of this study, an anisotropic damage model has been used as material constitutive law that takes into account the different failure modes. The non-linear behavior of the wood material is captured by Hashin damage criteria, which predicts anisotropic damage in elastic-brittle materials. It was originally used as a failure criteria for unidirectional polymeric composites, and hence using it for the application to model different laminate types and non-polymeric composites will produce an approximate result. In the elastic range, the anisotropic behavior is defined by engineering constants, that allow to input different values of elastic modulus (E) and shear modulus (G) in longitudinal (1-1), radial (2-2) and tangential (3-3) directions (Figure 4.21) (Sandhas et al., 2012). 

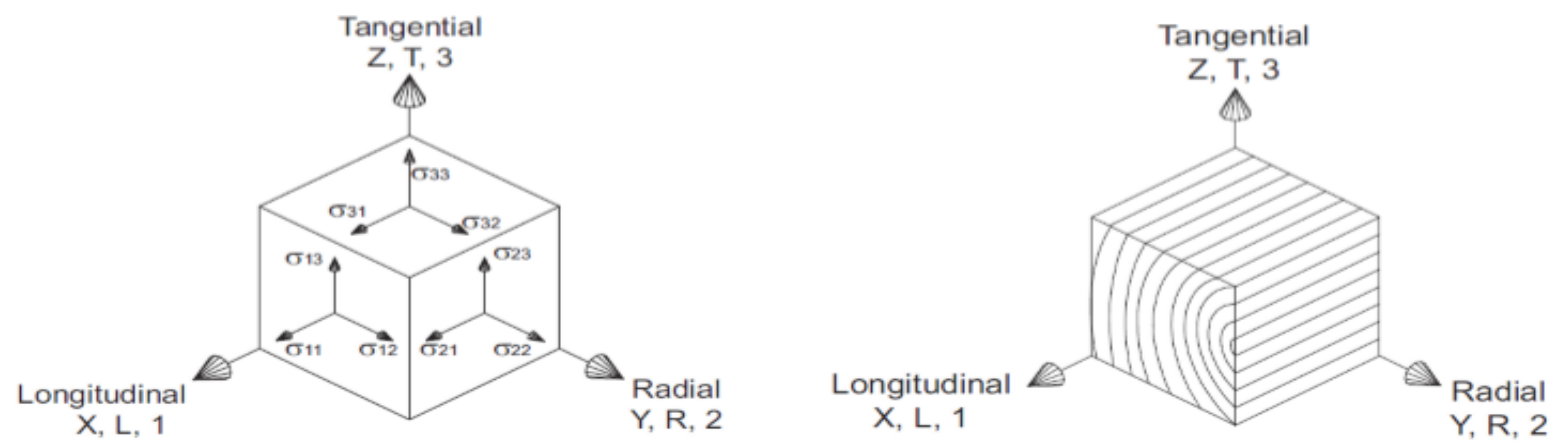

Figure 4.21 Definition of stress components and material directions (Sandhas et al., 2012)

The material model consists of nine elastic engineering constants. The elastic property $\left(\mathrm{E}_{1}\right)$ in the longitudinal direction corresponds to the direction parallel-to-grain (main grain direction), whereas $E_{2}=E_{3}$ and $G_{12}=G_{13}$ are elastic properties in the radial and tangential direction resulting in a smeared direction perpendicular-to-grain. A transverse isotropic model consisting of five elastic constants is insufficient to describe the properties of wood whereby resulting in wrong rolling shear modulus, $\mathrm{G}_{23}$. Fiber composites display similar characteristics with a matrix (perpendicular-to-grain) and main fiber direction (parallel-to-grain), where fiber rupture occurs in tension leading to brittle failure and matrix failure in compression displaying ductile mode of failure. Eight stress-based failure criteria or damage initiation functions (Eq. 4.38 to Eq. 4.40) have been defined using material strengths in tension, compression and shear, in both transverse and longitudinal directions (Sandhas et al., 2012). The tensile and compressive strength of wood was obtained from experimental tests conducted by Hossain (2007). Other parameters used in the material definition were obtained from Sandhas et al. (2012) due to lack of experimental material testing data. Table 4.10 shows typical values for the structural wood used for the purpose of this study.

Fiber Tension: $\mathrm{F}_{\mathrm{ft}}=\frac{\sigma_{\mathrm{L}}}{\mathrm{f}_{\mathrm{t}, 0}}$

Fiber Compression: $\mathrm{F}_{\mathrm{fc}}=\frac{\sigma_{\mathrm{L}}}{\mathrm{fc}, 0}$

Matrix Tension: $\mathrm{F}_{\mathrm{mt}}=\left(\frac{\sigma_{\mathrm{T}}}{\mathrm{f}_{\mathrm{t}, 90}}\right)^{2}+\left(\frac{\tau_{\mathrm{LT}}}{\mathrm{G}_{\mathrm{ft}, 0=\mathrm{fc}, 0}}\right)^{2}$

Matrix Compression: $F_{m c}=\left(\frac{\sigma_{T}}{2 G_{f t, 90=f c}, 90}\right)^{2}+\left[\left(\frac{f_{c, 90}}{2 G_{f t}, 90=f c, 90}\right)^{2}-1\right] \frac{\sigma_{T}}{f_{c, 90}}+\left(\frac{\tau_{L T}}{G_{f t}, 90=f c, 90}\right)^{2}$ 
where $f_{t, 0}$ and $f_{t, 90}$ are the tensile strength of wood along the grains and perpendicular to grains, respectively, $\mathrm{f}_{\mathrm{c}, 0}$ and $\mathrm{f}_{\mathrm{c}, 90}$ are the compressive strength of wood along the grains and perpendicular to grains, respectively, $\mathrm{G}_{\mathrm{ft}, 0=\mathrm{fc}, 0}$ and $\mathrm{G}_{\mathrm{ft}, 90=\mathrm{fc}, 90}$ denote the shear strength along the grain and perpendicular to grains, respectively and $\tau_{L T}$ is a coefficient that determines the contribution of the shear stress to the fiber tensile initiation criterion.

Table 4.10: Dry board material properties

\begin{tabular}{|c|c|c|c|c|c|c|c|c|c|c|}
\hline \multicolumn{11}{|c|}{ Engineering Constants (Elastic) } \\
\hline \multicolumn{4}{|c|}{ Young's Modulus (MPa) } & \multicolumn{4}{|c|}{ Poisson's Ratio } & \multicolumn{3}{|c|}{ Shear Modulus (MPa) } \\
\hline $\mathrm{E}_{1}$ & \multicolumn{2}{|c|}{$\mathrm{E}_{2}$} & $\mathrm{E}_{3}$ & \multicolumn{2}{|c|}{$v_{12}$} & $v_{13}$ & $v_{23}$ & G12 & G13 & G23 \\
\hline 13000 & \multicolumn{2}{|c|}{1000} & 1000 & \multicolumn{2}{|c|}{0.23} & 0.23 & 0.23 & 810 & 810 & 59 \\
\hline \multicolumn{11}{|c|}{ Plastic } \\
\hline \multicolumn{6}{|c|}{ Hashin Damage } & \multicolumn{3}{|c|}{ Damage Evolution } & \multicolumn{2}{|c|}{ Damage Stabilization } \\
\hline $\begin{array}{c}\mathrm{f}_{\mathrm{t}, 0} \\
(\mathrm{MPa})\end{array}$ & $\begin{array}{c}\mathrm{f}_{\mathrm{c}, 0} \\
(\mathrm{MPa})\end{array}$ & $\begin{array}{c}\mathrm{f}_{\mathrm{t}, 90} \\
(\mathrm{MPa})\end{array}$ & $\begin{array}{c}\mathrm{f}_{\mathrm{c}, 90} \\
(\mathrm{MPa})\end{array}$ & $\begin{array}{c}\mathrm{f}_{\mathrm{v}, 0} \\
(\mathrm{MPa})\end{array}$ & $\begin{array}{c}\mathrm{f}_{\mathrm{v}, 90} \\
(\mathrm{MPa})\end{array}$ & $\begin{array}{l}\mathrm{G}_{\mathrm{ft}, 0=\mathrm{fc}, 0} \\
(\mathrm{~N} / \mathrm{mm})\end{array}$ & \multicolumn{2}{|c|}{$\begin{array}{c}\mathrm{G}_{\mathrm{ft}, 90=\mathrm{fc}, 90} \\
(\mathrm{~N} / \mathrm{mm})\end{array}$} & \multicolumn{2}{|c|}{$\eta$} \\
\hline 41 & 45 & 1.0 & 14.2 & 6.9 & 0.5 & 100 & \multicolumn{2}{|c|}{0.71} & \multicolumn{2}{|c|}{0.0001} \\
\hline \multicolumn{11}{|c|}{$\begin{array}{l}\mathrm{f}_{\mathrm{t}, 0} \text { : Longitudinal tensile strength; } \mathrm{f}_{\mathrm{c}, 0} \text { : Longitudinal compressive strength; } \mathrm{f}_{\mathrm{t}, 90} \text { : Transverse tensile strength } ; \mathrm{f}_{\mathrm{c}, 90} \text { : } \\
\text { Transverse compressive strength; } \mathrm{f}_{\mathrm{v}, 0} \text { : Longitudinal shear strength; } \mathrm{f}_{\mathrm{v}, 90} \text { : Transverse shear strength; } \mathrm{G}_{\mathrm{ft}, 0} \text { : } \\
\text { Longitudinal tensile fracture energy; } \mathrm{G}_{\mathrm{fc}, 0} \text { : Longitudinal compressive fracture energy; } \mathrm{G}_{\mathrm{ft}, 90} \text { : Transverse tensile } \\
\text { fracture energy; } \mathrm{G}_{\mathrm{fc}, 90} \text { : Transverse compressive fracture energy; } \eta \text { : Viscosity parameter }\end{array}$} \\
\hline
\end{tabular}

\subsubsection{Steel Model}

The profiled steel sheet properties (nominal 'engineering' stress and strain) obtained from tensile coupon tests were converted to true (Cauchy) stress and logarithmic strain and inputted in ABAQUS. The conversion and the relationship between the stresses is shown in Section 3.3.2.2 (Chapter 3) and the same steel material properties were used.

\subsubsection{Concrete Model}

The CDP model and compressive stress-strain curve proposed by Popovics (1973) was incorporated to simulate the concrete behavior in the concrete infilled PSSDB panel. Two failure mechanisms resulting from tensile cracking and compressive crushing of concrete is considered in this comprehensive plasticity-based concrete model. The concepts of isotropic damaged elasticity along with isotropic tensile and compressive plasticity are used to represent the inelastic behavior of concrete (Dassault Systèmes Simulia Corp. 2008). The definition of the parameters was 
determined as discussed in Section 3.3.2.3 (Chapter 3). The concrete compressive strength and tensile strength were obtained from experimental tests. Other CDP parameters were obtained from Sadjadi (2009) due to lack of information.

\subsubsection{Description of the Developed FE Model}

In order to investigate the structural behavior of the PSSDB wall panels under shear loading, simplified finite element models were simulated using the different modules present. A set of nonpierced and pierced composite PSSDB panels were modeled using single sheathed/DB and double sheathed/DB PSSDB composite walls connected via discrete fasteners. The load bearing wall panel were further investigated using concrete infill.

\subsubsection{Parts, Meshing and Element Assignment}

Three dimensional PSSDB composite walls were created using four main components, namely profiled steel sheet, dry-boards, concrete in-fill and fasteners. The profiled steel sheet and the concrete core model adopted shell element using linear quadrilateral shell element (S4R) and linear hexahedral elements (C3D8R), respectively as shown in Figure 4.22 and Figure 4.23. Unlike in chapter 3.3, the boards were modeled as continuum shell elements using quadrilateral continuum shell elements (SC8R) (Figure 4.24) because Hashin damage model can only be applied on continuum shell elements. Material and section properties were assigned to the elements accordingly. Meshing technique and the type of element were specified in the mesh module. Reduced integration and hourglass control elements were used for this study which consisted of only one integration point located at the element's centroid.

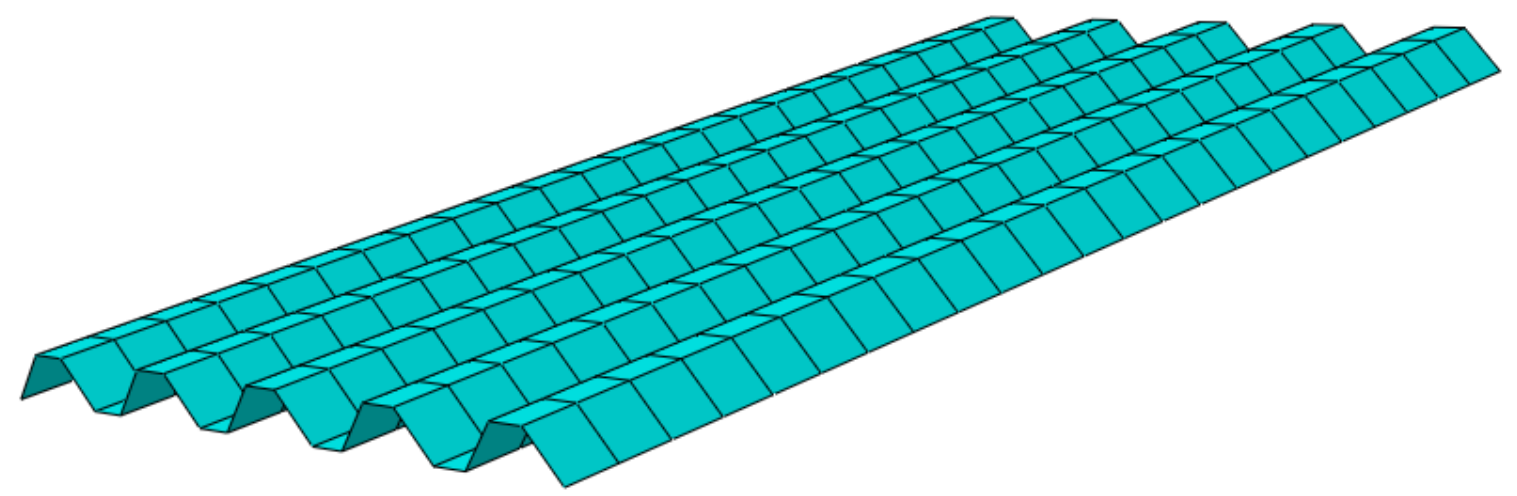

Figure 4.22 Profiled steel sheet - linear quadrilateral shell element (S4R) 


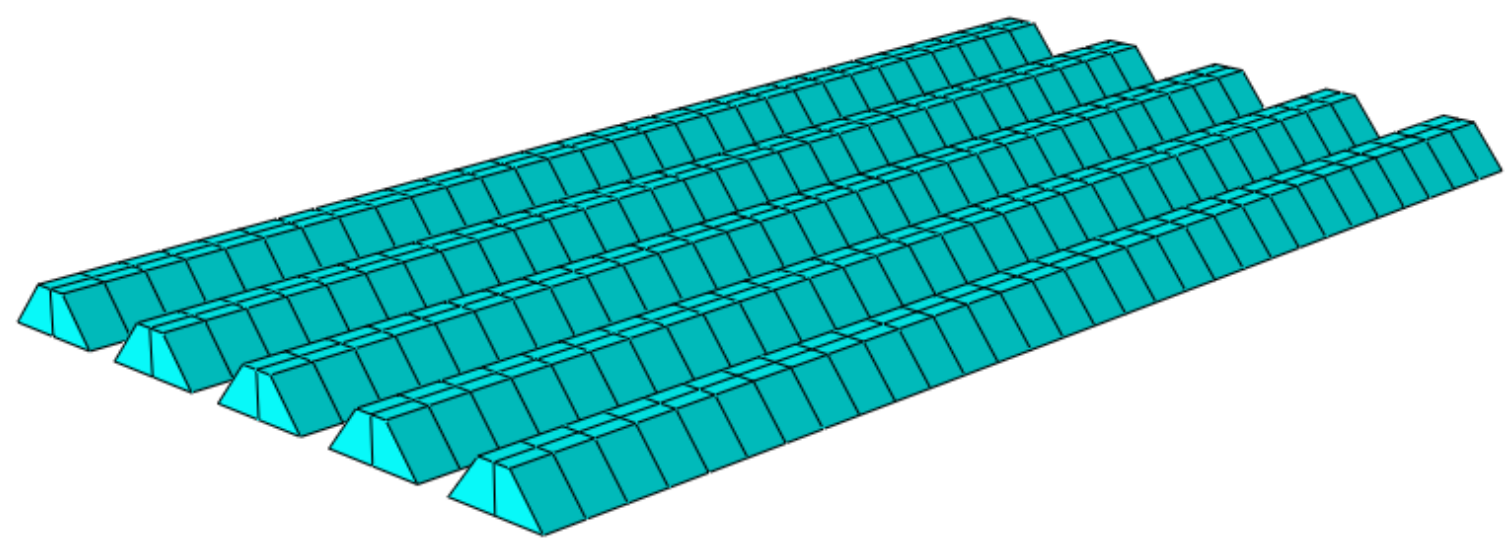

Figure 4.23 Profiled concrete core - linear hexahedral solid element (C3D8R)

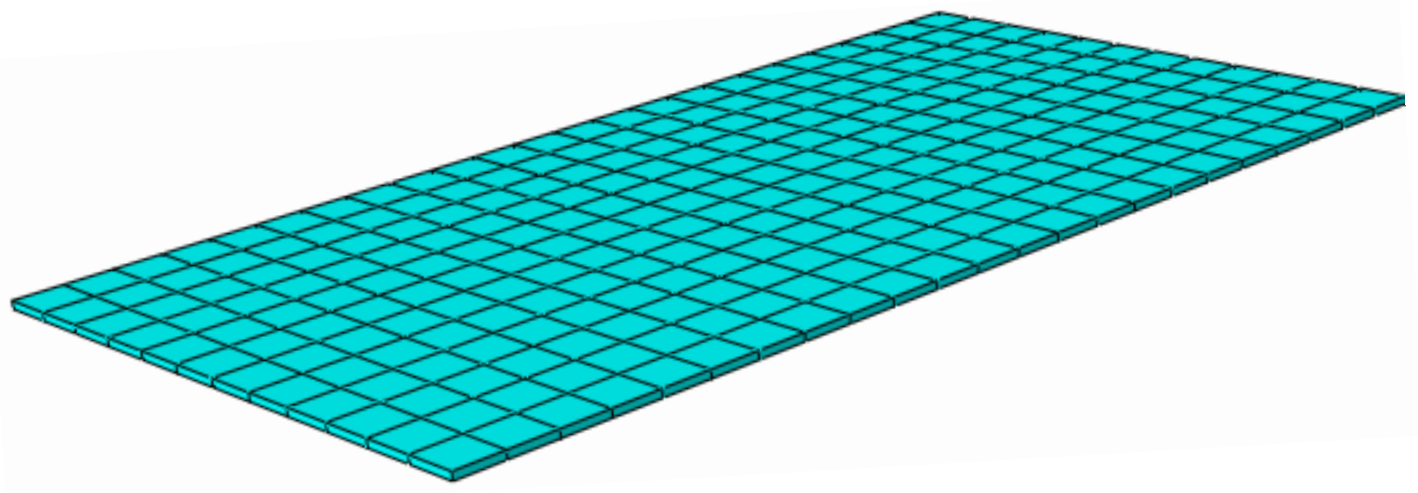

Figure 4.24 Dry board - quadrilateral continuum shell element (SC8R)

\subsubsection{Assembly of Parts, Step and Contact/Interactions}

In the assembly module, all part instances were assembled and placed geometrically together. Using of bolt and nut connection to connect the elements together made the model more sophisticated for analysis hence, discrete fasteners were used instead. The attachment toolset allows users to create attachment points and lines between selected faces where discrete fasteners can be defined. Figure 4.25 shows the assembly of discrete fasteners in the non-pierced and pierced PSS-DB (A1np and A1p) and DB-PSS-DB (B1np and B1p) composite panels. 

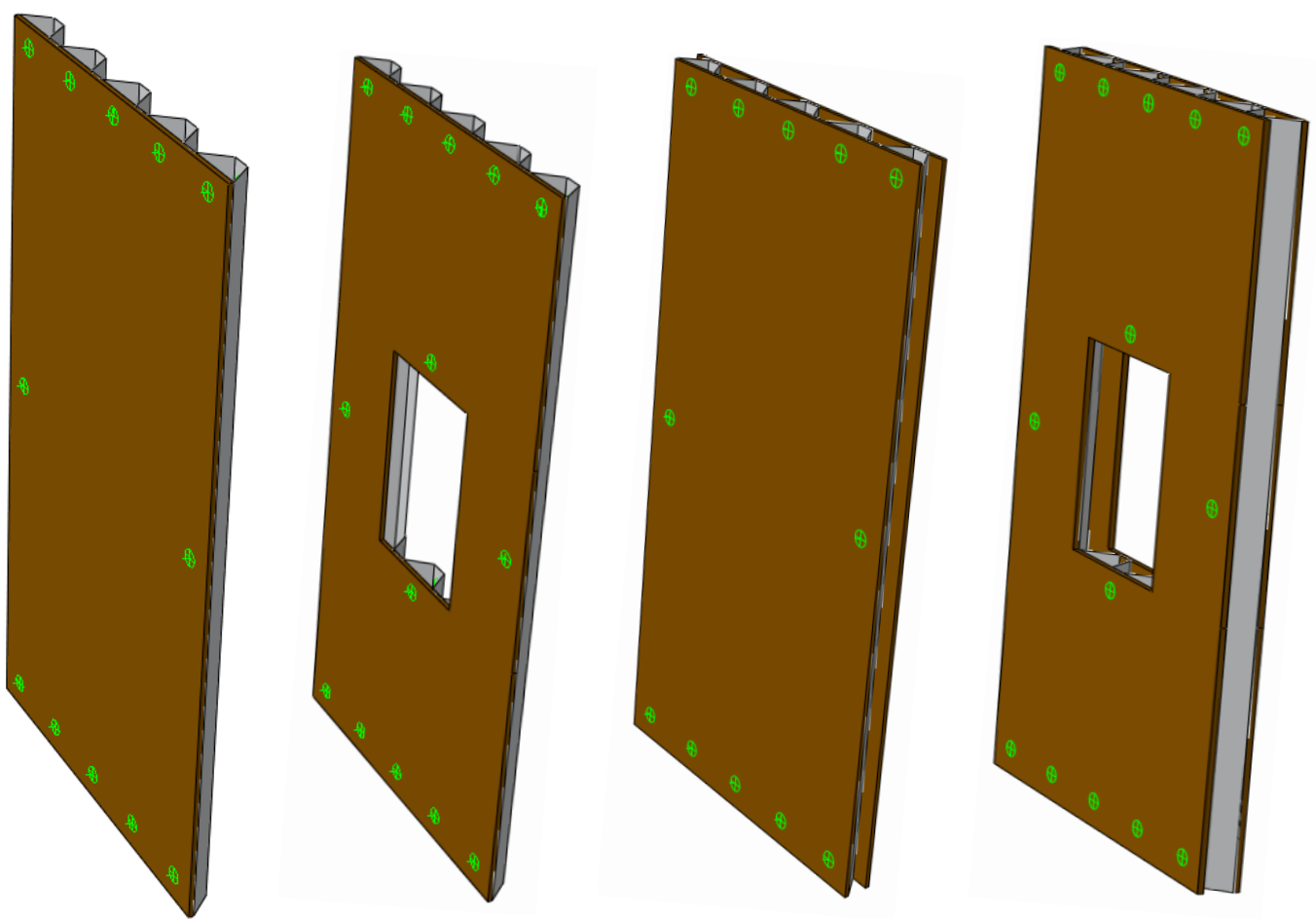

Figure 4.25 Non-pierced and pierced PSS-DB (A1-np and A1-p) and DB-PSS-DB (B1-np and B1-p) composite panels

The step module allows to create a sequence of one or more steps to perform static or dynamic analysis. The steps used for this study were Initial and Static General with the Nlgeom setting in ABAQUS/Standard to carry out the non-linear analysis of the walls. Defining the interaction between the elements is very crucial during the numerical simulation of the models. Steel-DB wood interaction and steel-DB wood-concrete interaction were defined for the elements in the step module. The interaction between the surfaces of the elements was defined using "contact interaction" and "interaction properties". The surfaces in contact were identified in the assembly module and paired using "surface-to-surface" contact interaction. The potential contact surfaces were assigned an interaction property. Tangential contact behavior and normal contact behavior were specified to secure the interaction between steel and concrete. Furthermore, the friction formulation was selected to be "frictionless" for the tangential behavior in the PSSDB panels with concrete infill. Default options for Pressure-Overclosure (Hard contact) and "Constraint enforcement method" was selected for the normal contact behavior. However, the friction formulation "penalty" was selected to establish interaction between the dry board-steel and dry board-concrete interfaces with a friction coefficient of 0.3 and 0.62 , respectively. The static friction 
for wood/DB and other materials were obtained from the Engineered Materials Handbook (ASM International Handbook Committee, 1987)). Therefore, the connections between the elements contribute to the composite action of the PSSDB wall panels.

\subsubsection{Boundary Condition and Displacement Control Analysis}

Displacement control analysis was used to determine the load-bearing capacity of the composite walls. An incremental displacement is applied via the amplitude toolset to obtain an ultimate load as reaction forces acting on the structure. The amplitude toolset in ABAQUS helps input the rate at which the load/displacement is applied with time. Loading of the composite wall was obtained by allocating a prescribed displacement at the reference point while defining a uniform distribution in the boundary condition. The reference point was positioned at the top of the panel. The reference point was constrained in the $\mathrm{x}$-direction using kinematic coupling, as shown in Figure 4.26. All three displacement degree of freedoms for the solid and continuum shell element $(\mathrm{U} 1=\mathrm{U} 2=\mathrm{U} 3=0)$ were restrained at the bottom of the tested composite panels, whereas for the profiled steel sheet element both translational as well as rotational degrees of freedom were restrained $(\mathrm{U} 1=\mathrm{U} 2=\mathrm{U} 3=\mathrm{UR} 1=\mathrm{UR} 2=\mathrm{UR} 3=0)$.
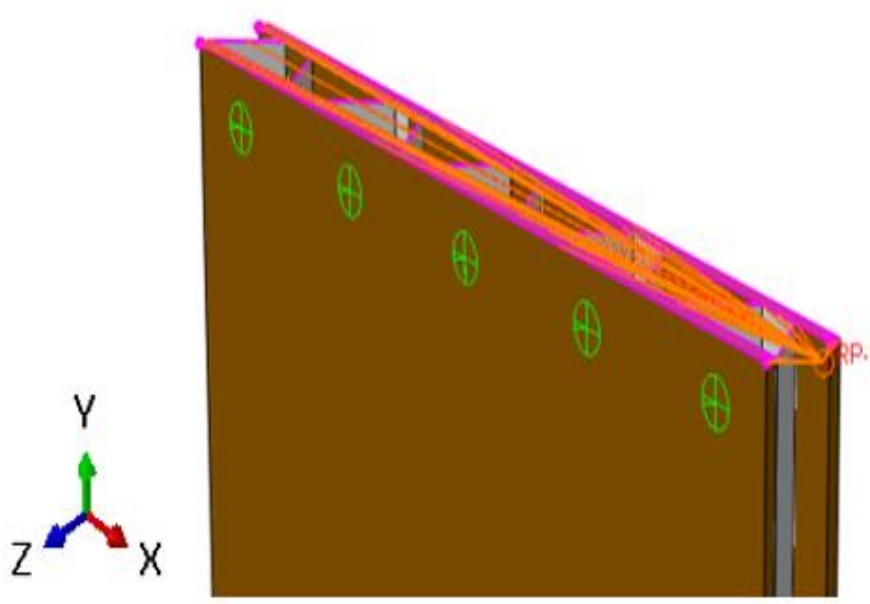

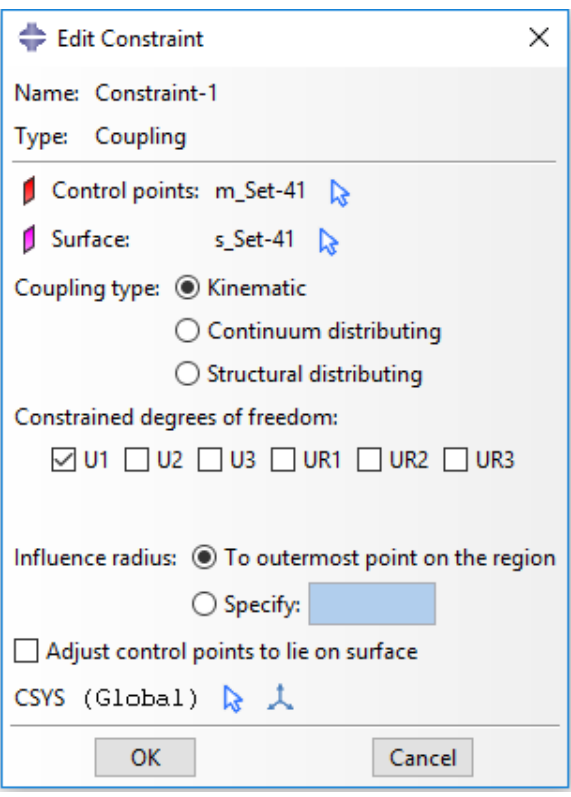

Figure 4.26 Location of reference point and constraining X-direction using kinematic coupling 


\subsubsection{FEA Results}

The FEA results presented herein are based on the shear load-deformation response, failure modes (deformed shape) and stress contour plots of the non-pierced and pierced single (PSS-DB) and double DB-sheathed (DB-PSS-DB) composite wall panels.

\subsubsection{Shear Load-Deformation Response of A1 and B1 Panels}

Figure 4.27 shows the shear load-deformation responses and Figure 4.28 shows the deformed shapes of the non-pierced single and double DB-sheathed PSSDB panels where visible failure pattern was noticed. DB-PSS-DB (B1-np) composite panel was found to sustain $27 \%$ more load than the PSS-DB (A1-np) composite panels.

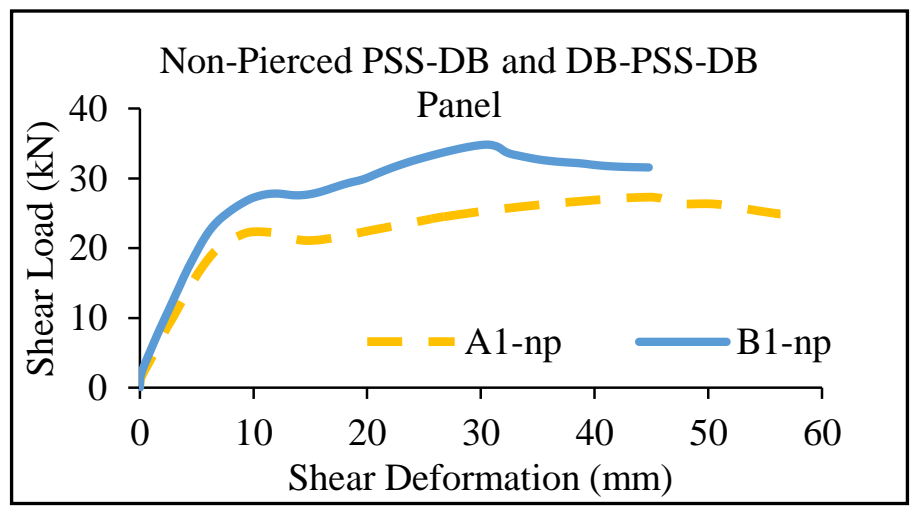

Figure 4.27 Load-deformation response of non-pierced PSS-DB (A1-np) and DB-PSS-DB (B1np) composite panels

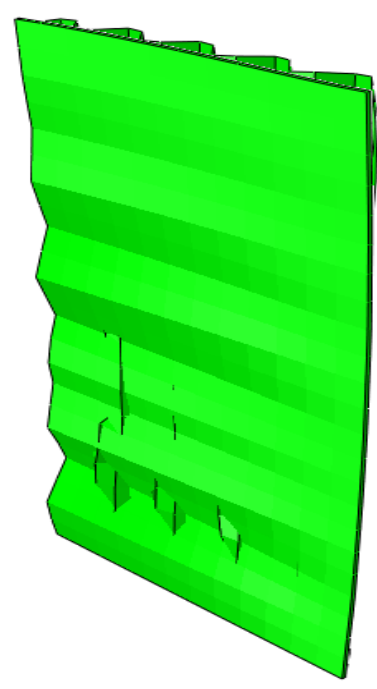

(a)

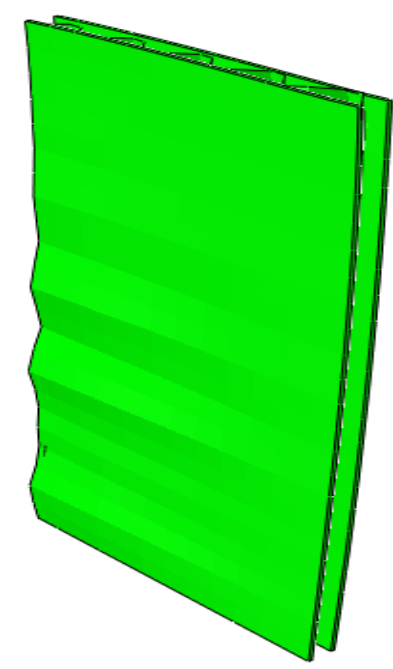

(b)

Figure 4.28 Deformed shape of the non-pierced pierced (a) A1-np and (b) B1-np PSSDB panels 
Shear load-deformation responses for the pierced PSS-DB (A1-p) and DB-PSS-DB (B1-p) composite wall panels are presented in Figure 4.29. Pierced DB-PSS-DB composite panel exhibited 31\% higher shear load bearing capacity than the PSS-DB panel. Buckling failure of the steel sheet and the dry board are quite evident in Figure 4.30 displaying the deformed shapes of the composite panels.

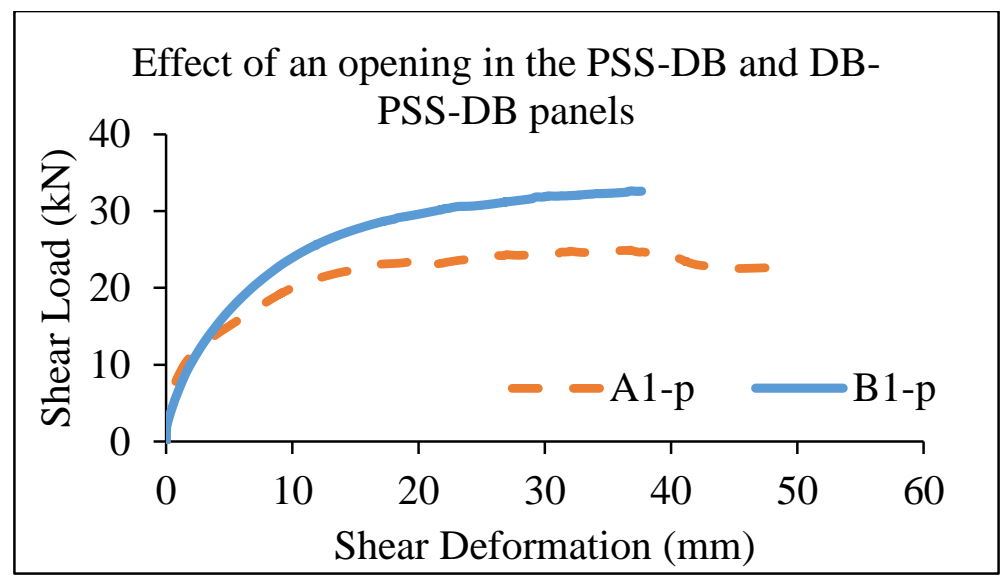

Figure 4.29 Load-deformation response of pierced PSS-DB (A1-p) and DB-PSS-DB (B1-p) composite panels

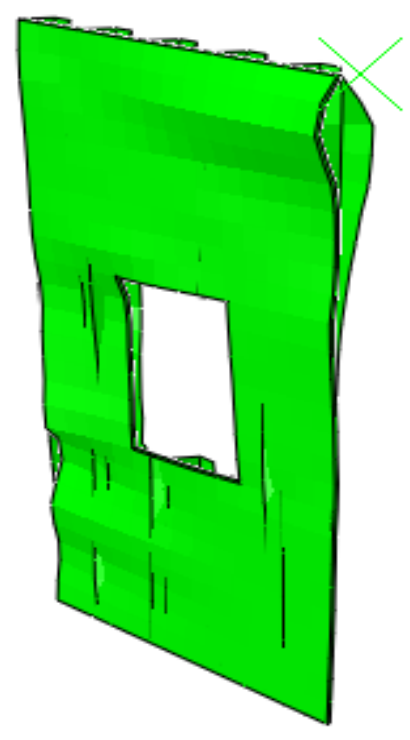

(a)

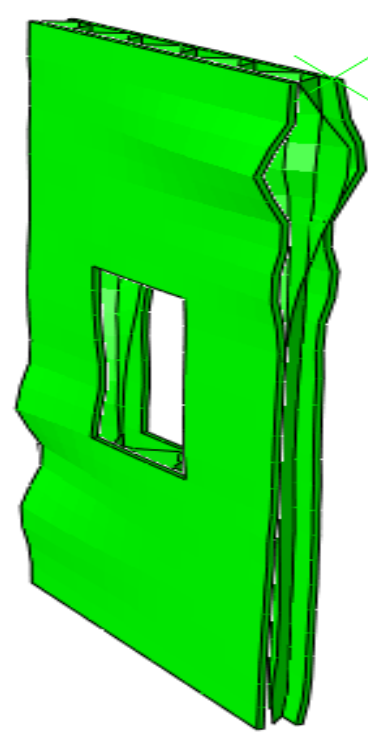

(b)

Figure 4.30 Deformed shape of the pierced (a) PSSDB (A1-p) and (b) DB-PSS-DB (B1-p) composite panels 
Figure 4.31 (a) shows the comparison of double DB-sheathed PSSDB panels with and without concrete infill. The presence of concrete infill in the voids of the PSS-troughs enhanced the shear load capacity by $22 \%$. The deformed shape in Figure 4.31 (b) shows cracking of concrete and buckling of board.

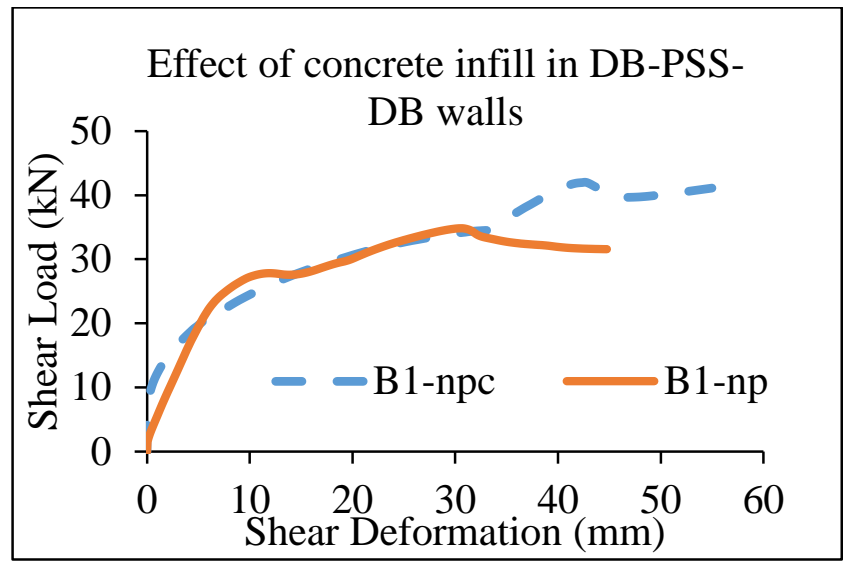

(a)

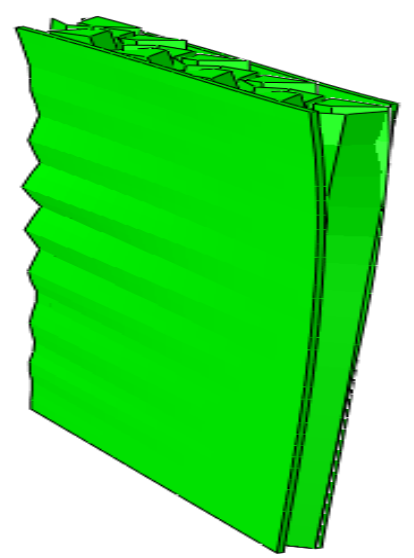

(b)

Figure 4.31(a) Load-deformation response comparing B1 panels with and without concrete infill

(b) deformed shape of the non-pierced DB-PSS-DB composite panels with concrete infill

\subsubsection{Stress-Contours of A1 and B1 panels}

The von-Mises stress and maximum/minimum in-plane principal stress distribution in the PSS as well as in the DB are displayed. The rainbow colored contour plots were used to observe the stress concentration in the composite panels. Higher stressed regions are denoted in red while the low stressed regions are presented in blue. The dry board displays see through stress contour plots on one of its element face as it is defined as continuum shell elements. The rainbow colored band are therefore presented in stripes throughout the length of the board.

The variation of shear stress in PSS and DB is shown in Figure 4.32 and Figure 4.33. Based on the Von-Mises yield criterion, the maximum theoretical shear stress capacity of the profiled steel sheet is $F_{y} / \sqrt{3}$ (Sabouri-Ghomi et al. 2005). Hence shear yield stress of the PSS is 345.32MPa when the yield strength $\left(\mathrm{F}_{\mathrm{y}}\right)$ is $598.12 \mathrm{MPa}$. It can be seen that the shear stress exceeds the shear yield stress thus leading to yielding failure of PSS. The maximum shear stress capacity for the $\mathrm{DB}$ is $8.19 \mathrm{MPa}$ calculated based on the tensile strength of $14.2 \mathrm{MPa}$. The von-Mises stress was higher in the area where the load was applied and at the bottom of the panel as observed during the experimental tests. 

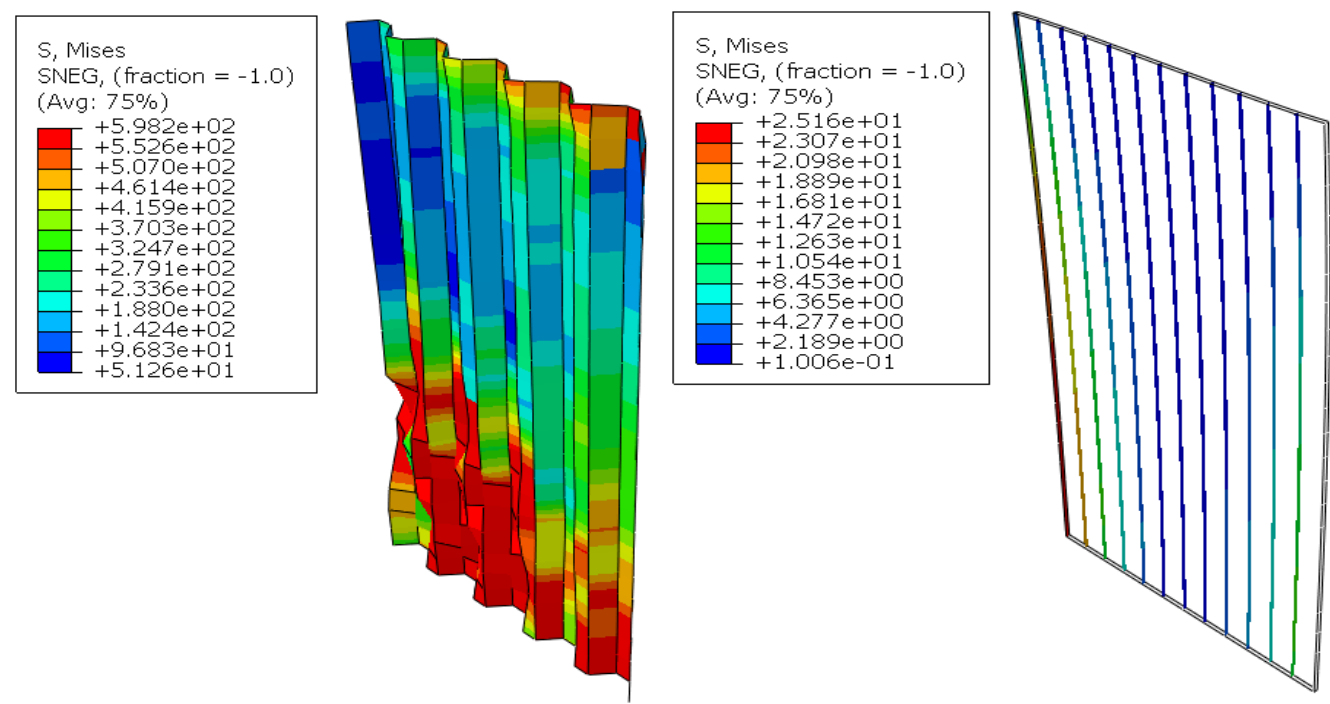

Figure 4.32 The Von-Mises stress (MPa) distribution in the non-pierced PSS-DB (A1-np) composite panel at the peak load
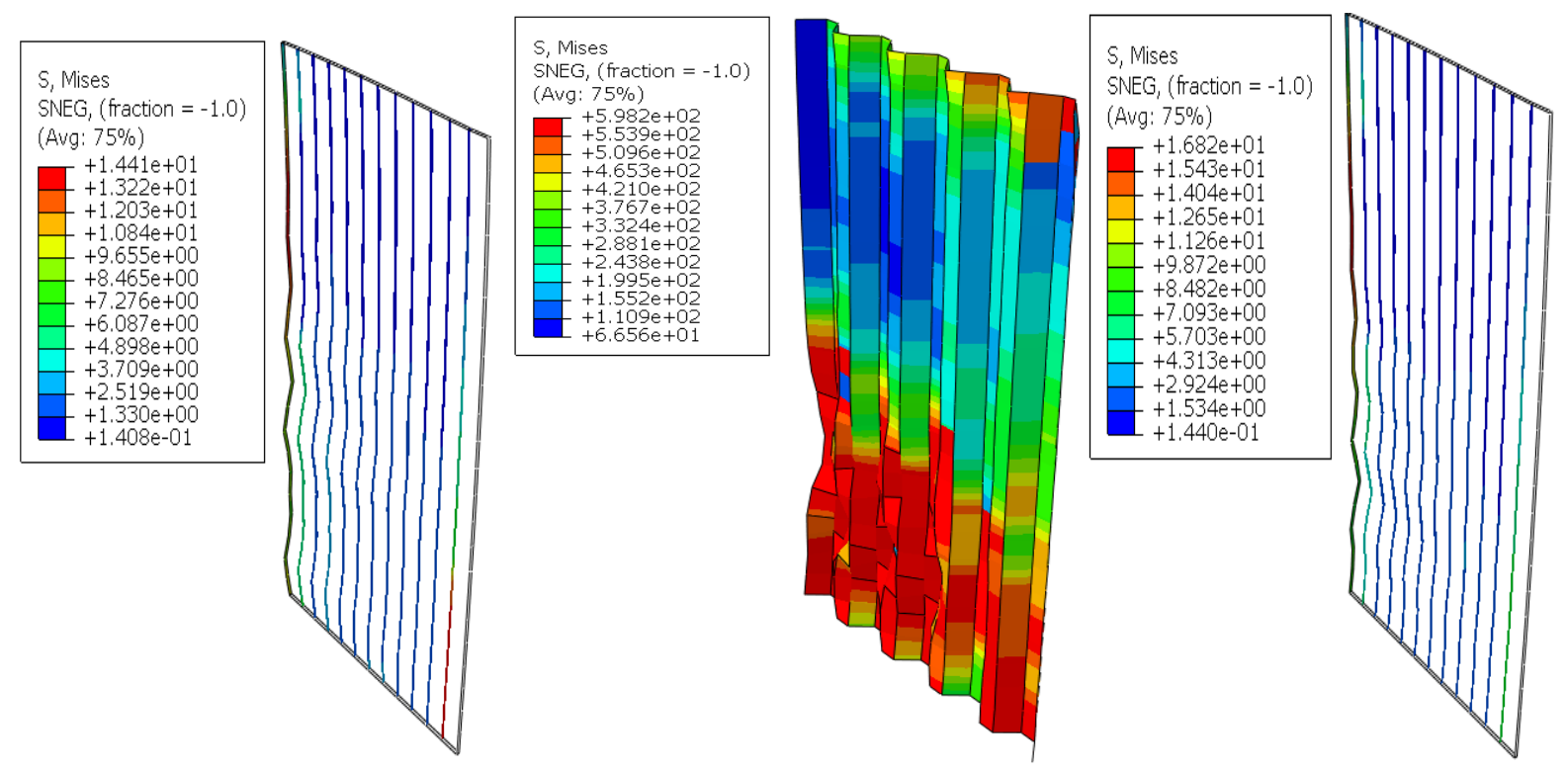

Figure 4.33 The Von-Mises stress (MPa) distribution in the DB-PSS-DB (B1-np) panel at the peak load

The values of the maximum/minimum principal stresses of each components in the PSSDB and DB-PSS-DB panel are presented in Figure 4.34, Figure 4.35, Figure 4.36 and Figure 4.37, respectively. The failure mode of the FE model wall was due to buckling of the steel sheets after the yielding of steel. Prior to failure of the panel, the principal stress and shear stress values reached 
the failure stress according to Von-Mises yield criterion. The steel plate buckled when the principal compression and tension stresses were developed in thin web steel plate under shear loading.
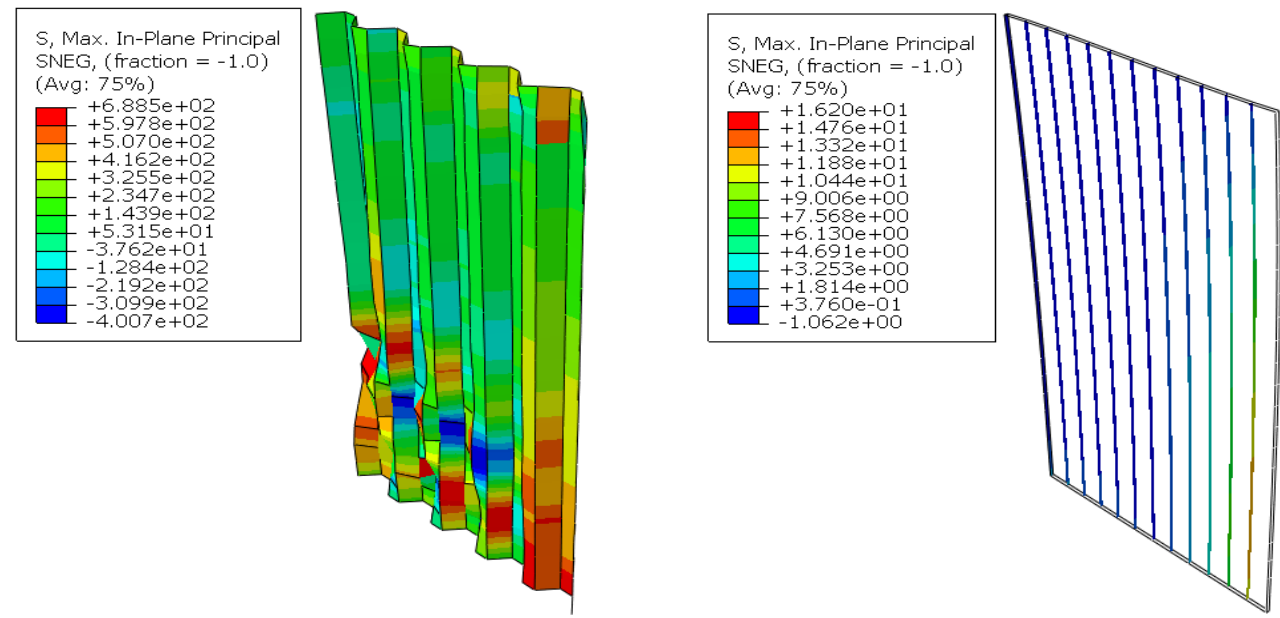

Figure 4.34 Maximum in-plane principal stress (MPa) in the non-pierced PSS-DB (A1-np) panel at the peak load
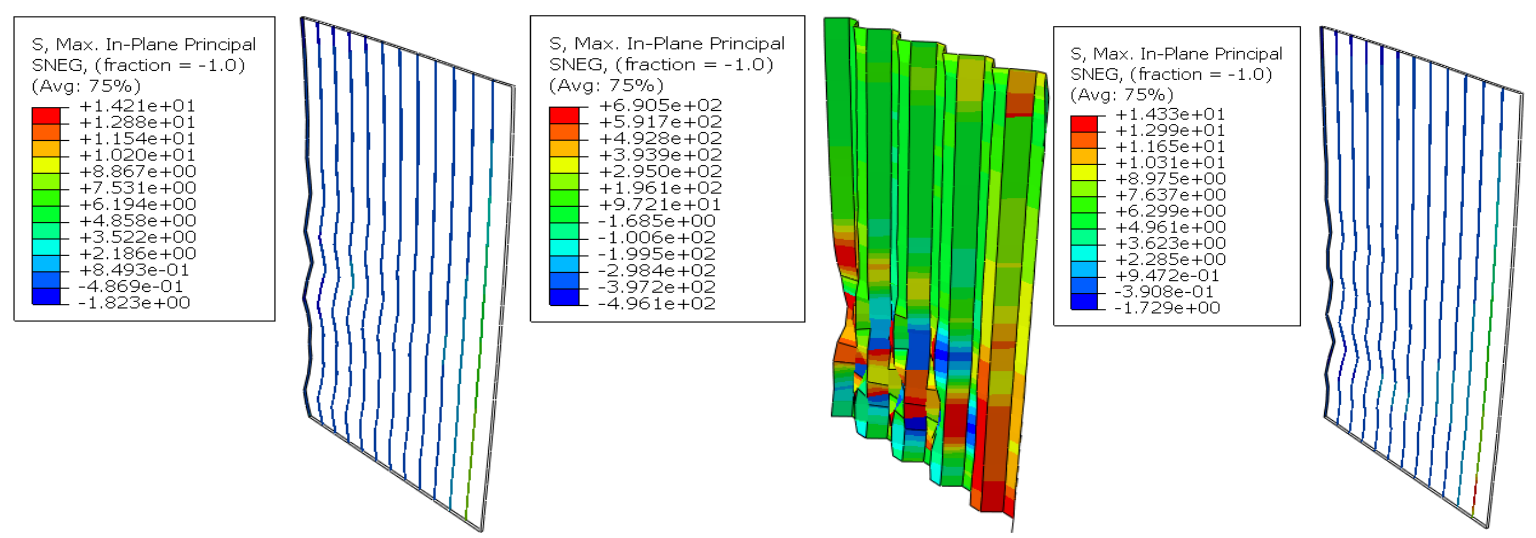

Figure 4.35 Maximum in-plane principal stress (MPa) in the DB-PSS-DB (B1-np) panel at the peak load 

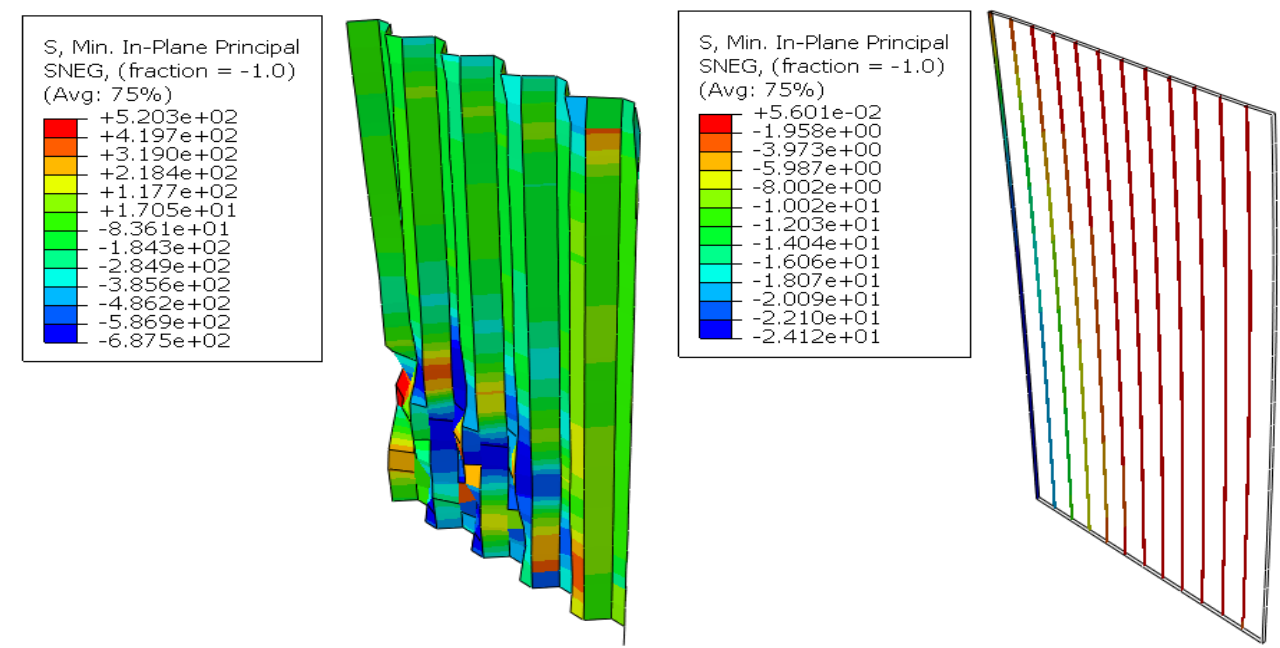

Figure 4.36 Minimum in-plane principal stress (MPa) in the non-pierced PSS-DB (A1-np) panel at the peak load
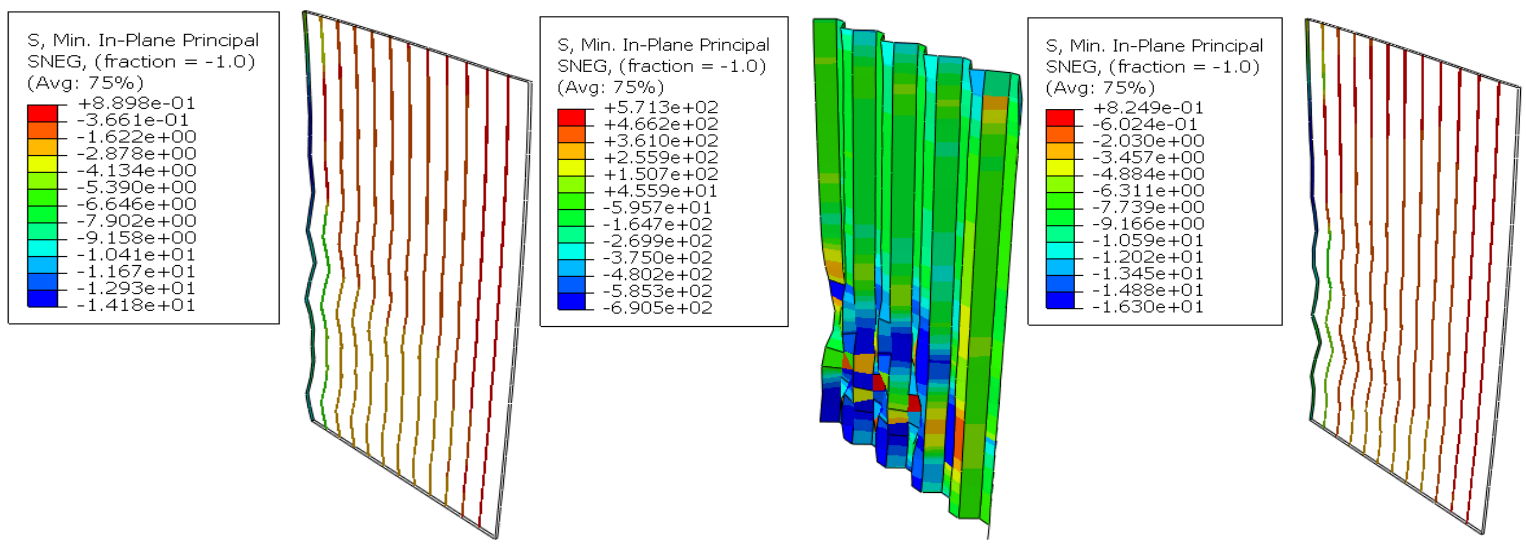

Figure 4.37 Minimum in-plane principal stress (MPa) in the DB-PSS-DB (B1-np) panel at the peak load

Figure 4.38 and Figure 4.39 show the von-Mises stress distribution where the shear stress in both the PSS and DB exceeded the shear yield stress thus leading to yielding failure. The variation of shear stress along the PSS and DB display that the amount of Von-Mises stresses were higher in the area where the load was applied and around the corners of the opening as observed during the experimental tests. 

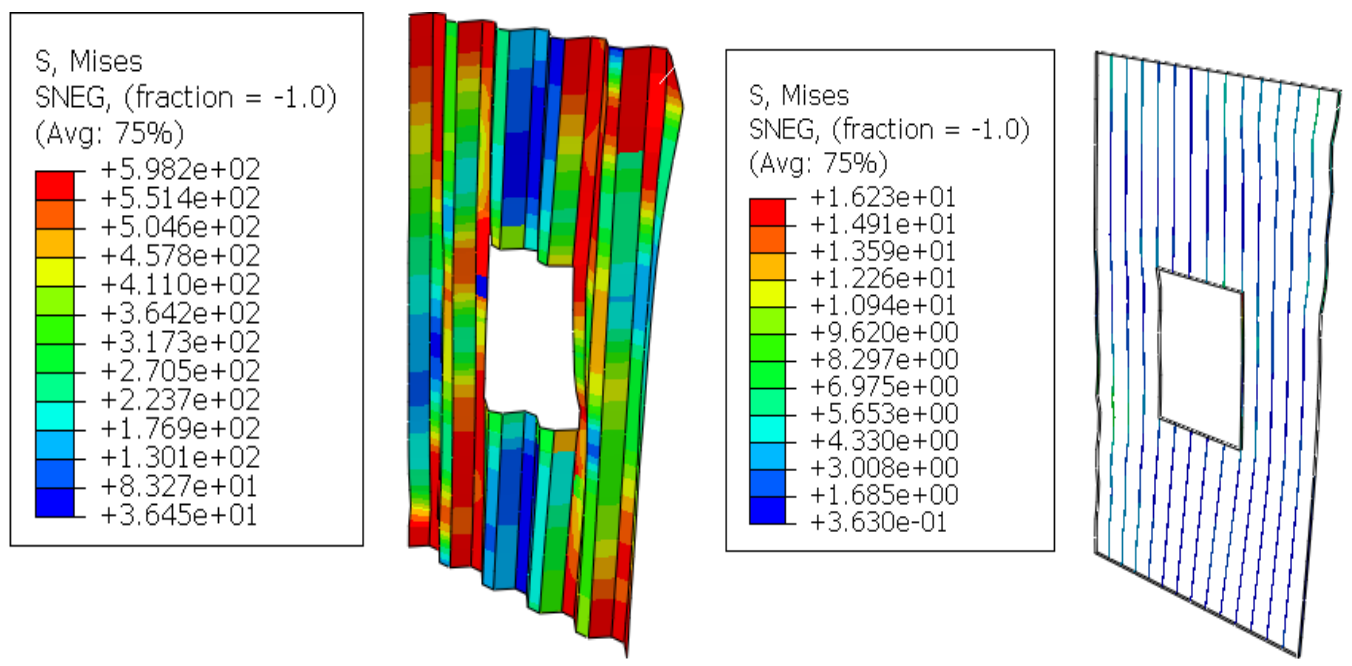

Figure 4.38 Von-Mises stress (MPa) distribution in the pierced PSS-DB (A1-p) composite panel at the peak load
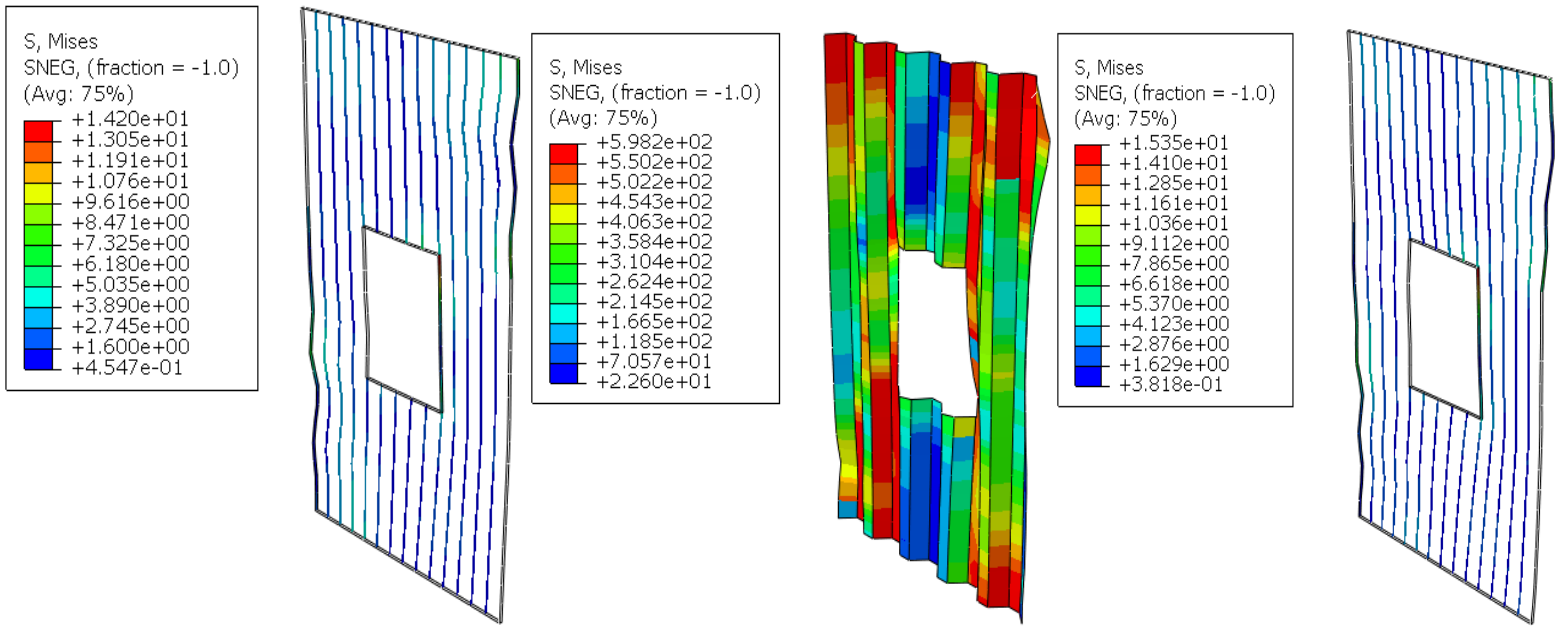

Figure 4.39 The Von-Mises stress (MPa) distribution in the pierced DB-PSS-DB (B1-p) composite panel at the peak load

The values of the maximum/minimum principal stresses of each pierced components are presented in Figure 4.40 and Figure 4.41 as well as in Figure 4.42 and Figure 4.43, respectively. Prior to failure of the panel, the principal stress and shear stress values reached the failure stress according to von-Mises yield criterion. The panels failed due to buckling of both PSS and DB. The maximum shear stress is higher than the yield shear stress in each of the components. 

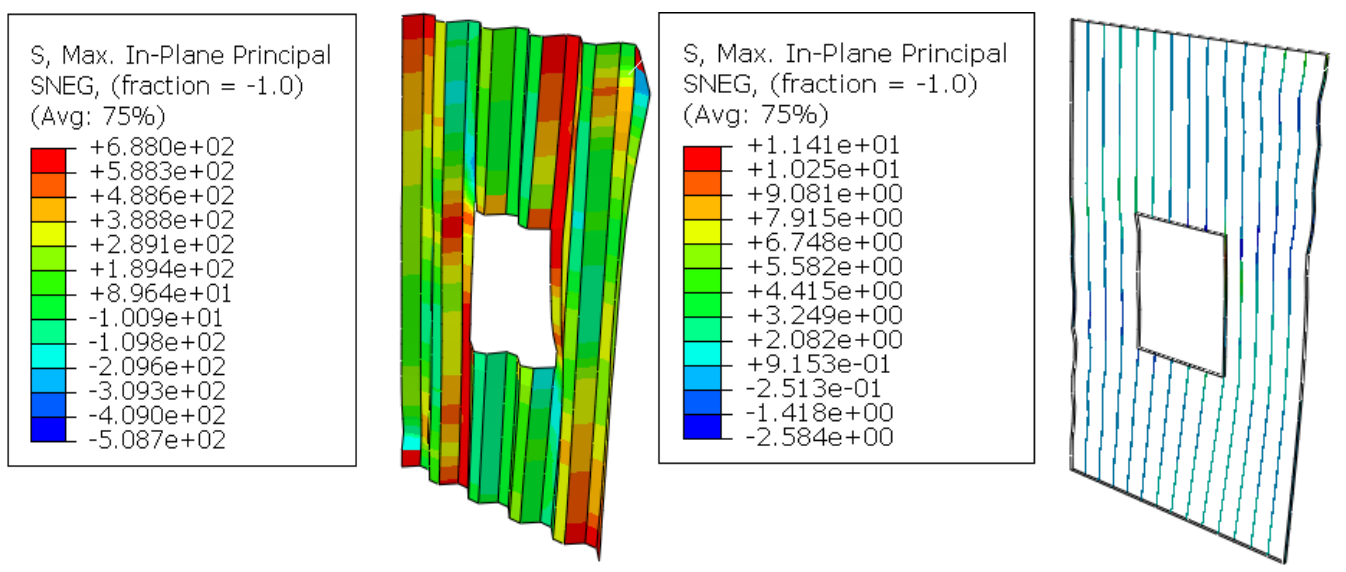

Figure 4.40 Maximum in-plane principal stress (MPa) in the pierced PSS-DB (A1-p) composite panel at the peak load
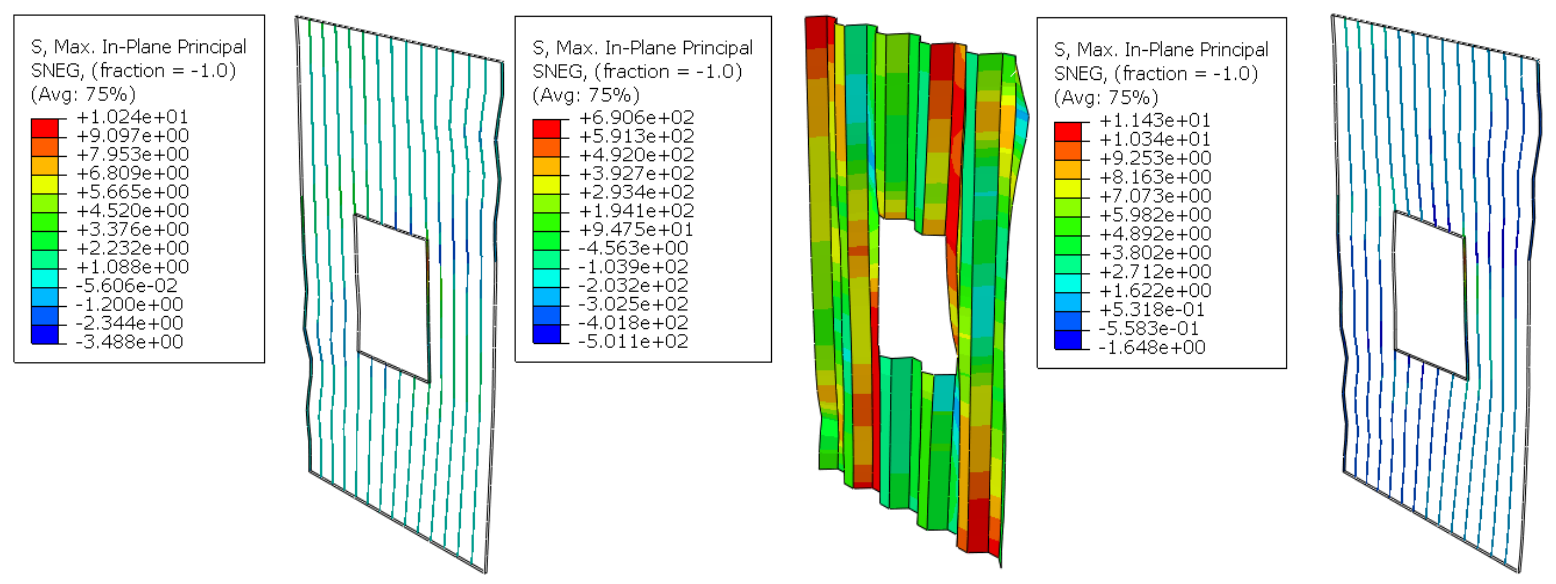

Figure 4.41 Maximum In-Plane Principal stress (MPa) in the pierced DB-PSS-DB (B1-p) composite panel at the peak load
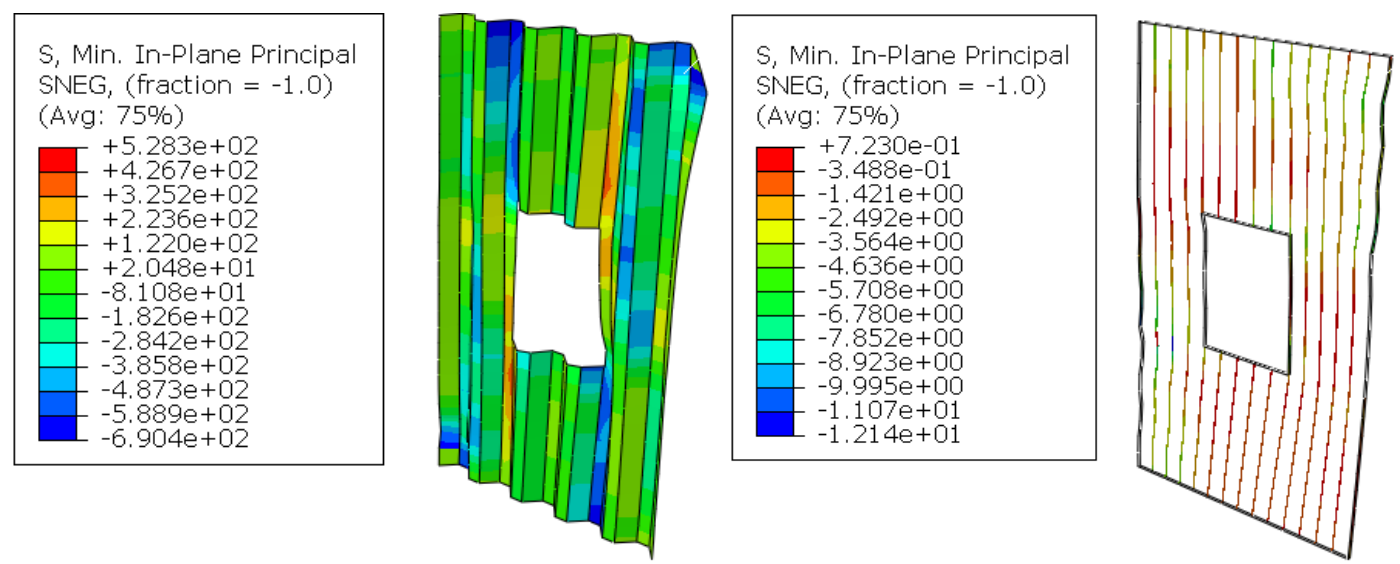

Figure 4.42 Minimum In-Plane Principal stress (MPa) in the pierced PSS-DB (A1-p) composite panel at the peak load 

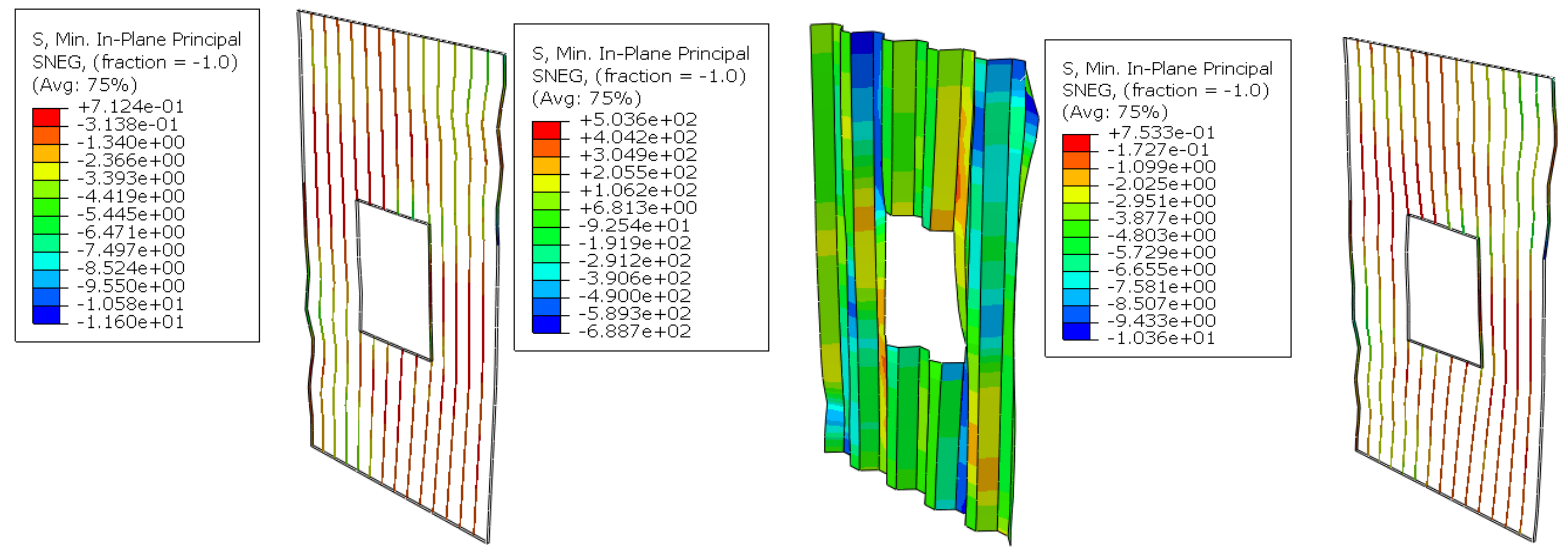

Figure 4.43 Minimum in-plane principal stress (MPa) in the pierced DB-PSS-DB (B1-p) composite panel at the peak load

The von-Mises stress distribution shown in Figure 4.44 (a) indicates high stress areas at the top of the panel where the load was applied. The values of the maximum/minimum principal stresses for the composite panels are presented in Figure 4.44 (b) and (c). Prior to failure of the panel, the principal stress and shear stress values reached the failure stress according to von-Mises yield criterion. The maximum developed shear stress (690MPa) is higher than the yield shear stress (345.32MPa).

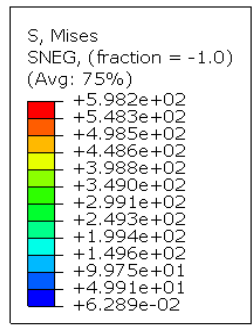

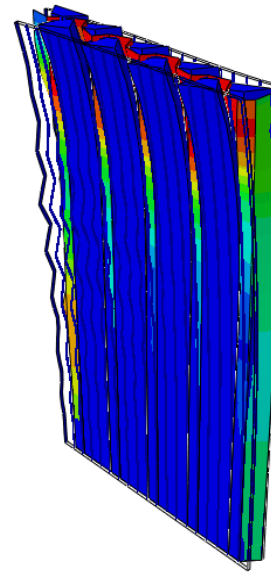

(a)

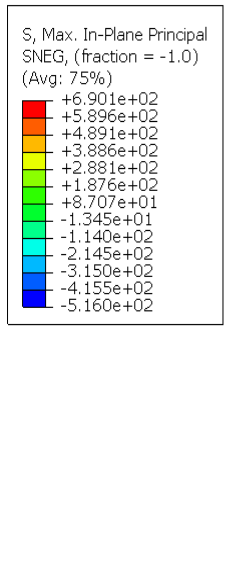

(b)

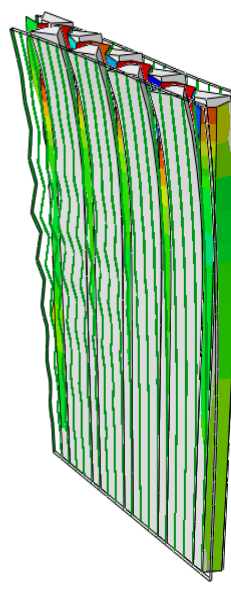

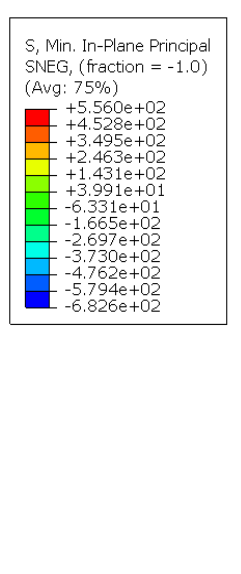

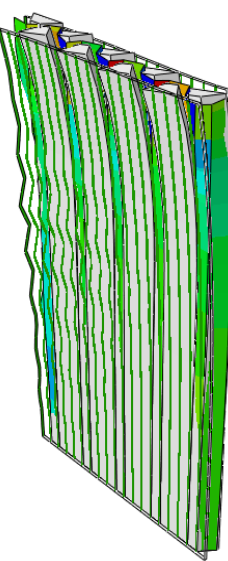

(c)

Figure 4.44 The (a) Von-Mises stress (MPa) distribution (b) maximum and (c) minimum inplane principal stress (MPa) of B1-npc composite panel with concrete infill at the peak load

\subsubsection{Comparison of FEA and Experimental Results}

The finite element shear load-deformation responses are compared with those obtained from experiments in Figure 4.45 and the results are summarized in Table 4.10. As seen in Figure 4.45, 
the load-deformation response produced by FEA showed somewhat similar response as the experimental; however, the stiffness of the FEA model was slightly higher than the experimental due to the complexity in modeling such composite panels. Hence, only the peak load and its corresponding deformation were compared for analysis. The ultimate shear load capacity of the composite walls based on the FEM was lower than those obtained from experiments. Considering the limitations in modeling, the difference in the results showed satisfactory simulation of the produced finite element models of the composite walls subjected to shear. The experimental over the FEA shear load capacity and displacement ratios vary from 1.20 to 1.30 and from 0.84 to 1.19 , respectively. Moreover, the simulated stresses, failure mode and buckling patterns in the PSSDB walls were comparable with the experimentally obtained results as discussed in previous sections.
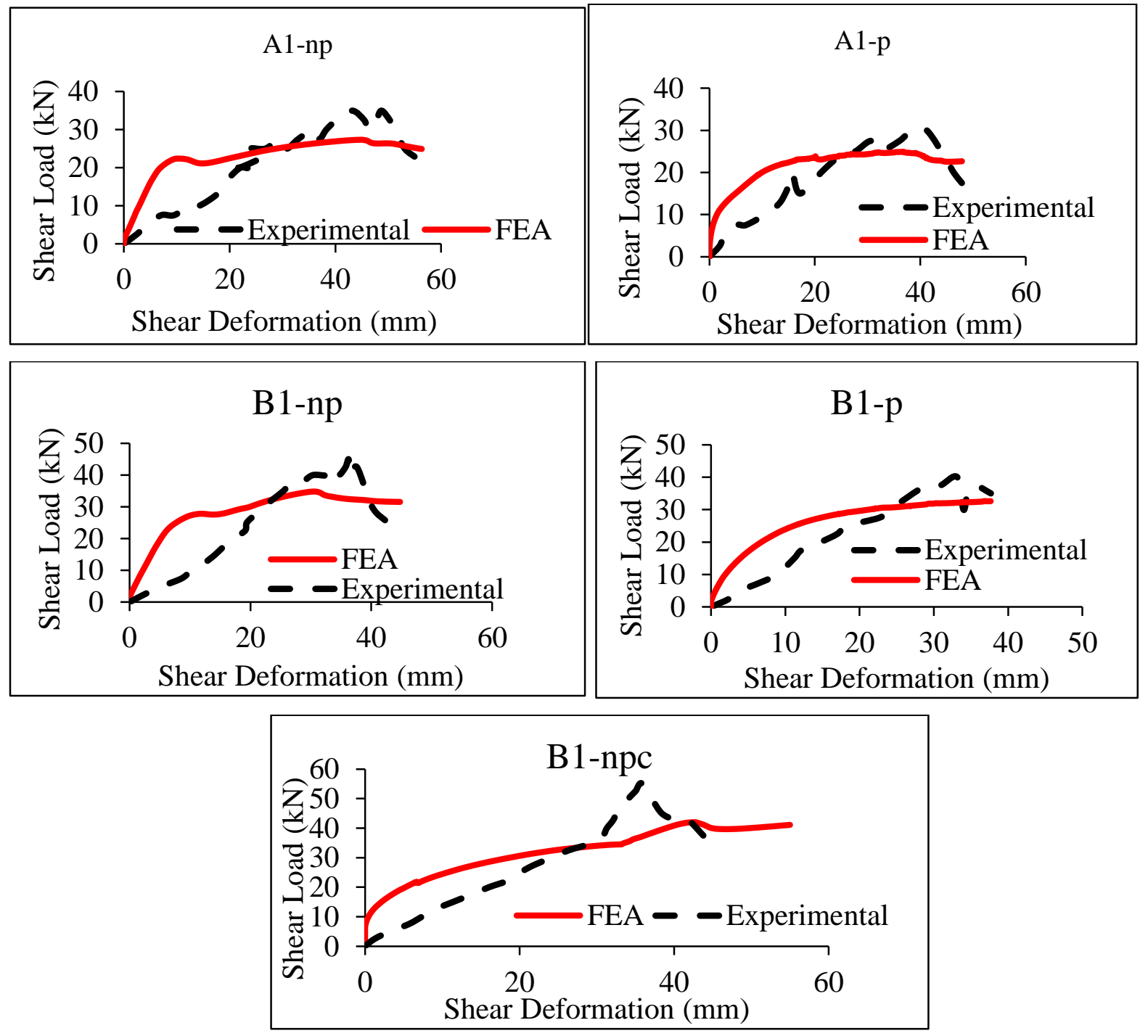

Figure 4.45 Comparison of experimental vs. FEA load-deformation response 
Table 4.11: Comparison of experimental vs. FEA

\begin{tabular}{|c|c|c|c|c|c|c|}
\hline \multirow{2}{*}{$\begin{array}{c}\text { PSSDB } \\
\text { Panels }\end{array}$} & \multicolumn{2}{|c|}{\begin{tabular}{c} 
Experimental Results \\
\cline { 2 - 7 }$(\mathrm{kN})$
\end{tabular}} & $\begin{array}{c}\text { Peak Load } \\
(\mathrm{mm})\end{array}$ & $\begin{array}{c}\text { Disp. } \\
(\mathrm{kN})\end{array}$ & $\begin{array}{c}\text { Peak Load } \\
(\mathrm{mm})\end{array}$ & $\begin{array}{c}\text { Disp. } \\
\text { Experimental/FEA }\end{array}$ \\
\hline A1-np & 35 & 43.12 & 27.32 & 44.17 & 1.28 & 0.98 \\
\hline A1-p & 30 & 38.45 & 24.94 & 36.71 & 1.20 & 1.05 \\
\hline B1-np & 45 & 36.25 & 34.8 & 30.53 & 1.30 & 1.19 \\
\hline B1-p & 40 & 33.14 & 32.63 & 36.88 & 1.23 & 0.90 \\
\hline B1-npc & 55 & 35.96 & 42.0 & 42.56 & 1.30 & 0.84 \\
\hline
\end{tabular}

\subsubsection{FEA Findings}

Finite element models were developed to predict the shear behavior of the PSSDB composite wall panels in terms of load-deformation response, failure modes and stress characteristics with quicker computation time and reasonable accuracy. The developed models were able to investigate the effect of non-pierced and pierced double and PSS-DB composite panels with and without concrete infill on the load bearing capacity of the wall. The analysis of results indicated that DB-PSS-DB wall panels had higher shear capacity than their PSS-DB counterparts as observed in tests. However, pierced PSSDB composite walls panels whether PSS-DB or DB-PSS-DB exhibited lower load capacity compared to their non-pierced counterparts (similar to experiments) and failed due to overall buckling.

As mentioned in Chapter 3 (section 3.3), an alternate option that exhibited similar behavior as wood (as recommended in previous research studies) was used to define the material properties of DB. Despite the limitations, the developed FE models were found to be capable of simulating the structural behavior of the PSSDB composite shear panels.

FEA results show good agreement with those obtained from experimental tests. Therefore, the developed models can be utilized to conduct parametric studies and obtain reasonably accurate results for preliminary design consideration of such PSSDB walls. 


\section{CHAPTER 5: CONCLUSIONS AND RECOMMENDATION}

\subsection{Conclusion}

This study was conducted to examine the axial and shear behavior of the innovative profiled steel sheet dry board (PSSDB) composite wall (non-pierced and pierced) with and without concrete infill having varying geometric properties. This research consisted of experimental, analytical and finite element (FE) investigations to predict the shear and axial strength capacity of the composite wall panels. The load bearing capacity of the walls were assessed based on the shear/axial strength, stiffness, load-deformation response, interaction among the profiled steel sheet (PSS), dry board (DB) and concrete ( PSS-DB-Concrete) and possible failure modes. The experimental results were analyzed and used to validate the developed finite element and analytical models in predicting the shear and axial strength capacities.

The following conclusions were drawn from this research based on the experimental, analytical and FE analyses of the composite walling system and presented herein:

PSSDB composite wall panel under axial loading

- The decrease in longitudinal screw spacing or increase in the number of rows of fasteners (from 3 to 5) significantly increased the axial load bearing capacity of the wall by $48 \%$. The screwed connections play a vital role in increasing or decreasing the strength in non-infilled panels rather than filled panels.

- Increase in the height-to-width $(\mathrm{h} / \mathrm{w})$ ratio of the wall decreased the ultimate load carrying capacity of the PSSDB composite panels. When the $\mathrm{h} / \mathrm{w}$ ratio increased from 1.5 to 3.5 , the ultimate load decreased by $14 \%$.

- The presence of concrete infill significantly improved the ultimate axial load by $30 \%$ compared to the non-infilled panels

- Perforated panels have less potential to sustain load than non-perforated composite PSSDB panels. It decreased the axial load capacity by $68 \%$

- The validation of the theoretical models for the axial load capacity depends on the modes of failure that is dependent on $\mathrm{h} / \mathrm{w}$ ratio. Developed analytical models are able to reasonably predict the axial load capacity of PSSDB wall panels.

- The developed finite element models displayed similar structural response and failure modes as observed during the experiments. The ratio of experimental to FEA predicted axial for PSSDB panels ranged between 1.02 and 1.18 which shows reasonable agreement though FEA was not able to fully simulate the experimental 
axial load-deformation responses. However, FEA was able to simulate the effect of holes, steel-DB-concrete fastener spacing, effect of concrete in-fill and height to width ratio of the walls on axial load capacity and failure modes.

- Parametric study exhibited an increase in axial load capacity of PSSDB wall/panels with an increase in PSS thickness, DB thickness, steel yield strength and compressive strength of concrete. Hence, combination of the right material/geometric properties of the individual components is crucial to enhance the axial strength of the PSSDB walls.

Panels bounded by pin ended rigid frame under shear loading

- The PSSDB panels are able sustain higher shear strength than the summation of the individual contributions from the dry-board and profiled steel sheet. Non-pierced PSSDB composite panels (S series) developed 46\% higher ultimate shear load than summation of its components (PSS and DB).

- Non-pierced PSSDB panels exhibited 88\% increase in the shear load capacity compared to their pierced counterparts. The shear load capacity of non-pierced PSS

panels was $90 \%$ higher than their pierced counterpart. The presence of a perforations significantly reduces the shear load capacity

- Dry board panels with only vertical fasteners carried $41 \%$ lower shear load compared to that with both vertical and horizontal fasteners. Similarly PSS panels with only vertical fasteners carried $70 \%$ lower shear load compared to that with both vertical and horizontal fasteners. So, number of fasteners and orientation has profound influence on shear capacity.

- PSS panels fixed at all ends displayed sheet-frame connection failure, whereas panels fixed at the vertical ends only displayed gross-distortion failure where fasteners were connected at alternate troughs. Wall panels fastened on both horizontal as well as vertical ends displayed greater load-bearing capacity than the panels fastened on the vertical ends of the panels.

- The derived analytical equations can be used for determination of shear strength of PSSDB panels by incorporating suggested values of modification factor $(\mu)$ for practical design purposes.

Cantilever PSSDB panels (without boundary frame) under shear loading 
- In cantilever wall, DB-PSS-DB wall panels display $29 \%$ higher shear capacity than PSS-DB panels. However, pierced PSSDB composite panels whether PSS-DB or DB-PSS-DB decreased the ultimate load and failed due to overall buckling.

- DB-PSS-DB wall panels with concrete infill whether non-pierced (about 38\%) or pierced (about 35\%) displayed greater load bearing capacity than PSS-DB panels.

- The accuracy of the proposed analytical equations to determine the ultimate shear resistance of the PSSDB panels were authenticated with the results obtained experimentally. The suggested analytical equations are safe to use for practical purposes by incorporating an adjustment factor $(\lambda)$ that ranges between 0.99 and 1.46 .

- The developed finite element models displayed similar structural response and failure modes of $\mathrm{A} 1$ and $\mathrm{B} 1$ series as observed during the experiments. The experimental over the FEA predicted shear load capacity ratio for the PSSDB panels showed reasonable agreement that varied from 1.20 to 1.30 despite its (FEA) inability to fully simulate the experimental shear load-deformation responses. However, FEA was able to simulate the effect of holes, effect of an additional DB into the PSSDB system, and effect of concrete in-fill on shear load capacity and failure modes.

The current research proves that the PSSDB system has the potential to be used as a sustainable and efficient alternative to traditional forms of construction.

\subsection{Recommendations for future research}

The following recommendations are suggested for future research to widen the perspective of this type of walling system:

- Experimental and computational investigations on the fire resistance of PSSDB composite walls can be exploited to be implemented in the construction industry

- Various types of concrete infill with efficient insulating properties can be investigated to develop a sustainable walling system

- Parametric studies under shear loading using the FE model could provide better understanding of the behavior of PSSDB composite shear wall 
- Investigate the effect of connector on the behavior of the proposed shear model to further understand the interaction between the dry board and profiled steel sheet

- Investigate the influence of varying height and width of the panel under shear loading and develop design guidelines for the PSSDB walling system

- Conduct finite element analysis on the test panels bounded by pin ended rigid frame under shear loading 


\section{APPENDICES}

\section{Appendix A: Detailed Theoretical Axial Load Capacity Calculations}

\section{A.1 Axial Load Capacities of Double Skinned PSSDB Panels With and Without Concrete} Infill

$$
\begin{aligned}
& \mathrm{A} 1, \mathrm{~A} 2, \mathrm{~A} 3, \mathrm{~A} 4, \mathrm{~A} 5 \\
& \begin{aligned}
\mathrm{P}_{\mathrm{u}} & =\left(\mathrm{A}_{\mathrm{s}}+\mathrm{nA} \mathrm{A}_{\mathrm{b}}\right) \mathrm{k} \sigma_{\mathrm{y}} \\
& =\left(([(7 * 25)+(6 * 39.05)] * 0.48)+\left(\frac{4000}{235000} * 6 * 325\right)\right) * 1 * 598.17 \\
& =40156 \mathrm{~N}=40.15 \mathrm{kN}
\end{aligned}
\end{aligned}
$$

A6, A7, A8, A9

$$
\begin{aligned}
\mathrm{P}_{\mathrm{uc}}= & {\left[\mathrm{A}_{\mathrm{s}}+\left(\frac{\mathrm{E}_{\mathrm{db}}}{\mathrm{E}_{\mathrm{pss}}} \mathrm{A}_{\mathrm{db}}\right)+\left(\frac{\mathrm{E}_{\mathrm{cc}}}{\mathrm{E}_{\mathrm{pss}}} \mathrm{A}_{\mathrm{cc}}\right)\right] \mathrm{k} \sigma_{\mathrm{y}} } \\
= & {\left[([(5 * 25)+(6 * 39.05)+(17.5 * 2)] * 0.48)+\left(\frac{4000}{235000}(6 * 310)\right)+\left(\frac{22000}{235000}(7380)\right)\right] } \\
& * 1 * 598.17=130500 \mathrm{~N}=130.50 \mathrm{kN}
\end{aligned}
$$

A10

$$
\begin{aligned}
\mathrm{P}_{\mathrm{u}} & =\left(\mathrm{A}_{\mathrm{s}}+\mathrm{nA} \mathrm{A}_{\mathrm{b}}\right) \mathrm{k} \sigma_{\mathrm{y}} \\
& =\left(([(5 * 25)+(6 * 39.05)+(17.5 * 2)] * 0.48)+\left(\frac{4000}{235000} * 6 * 310\right)\right) * 1 * 598.17 \\
& =63150 \mathrm{~N}=63.15 \mathrm{kN}
\end{aligned}
$$


A.2 Axial buckling load Capacities of double skinned PSSDB panels with and without concrete infill

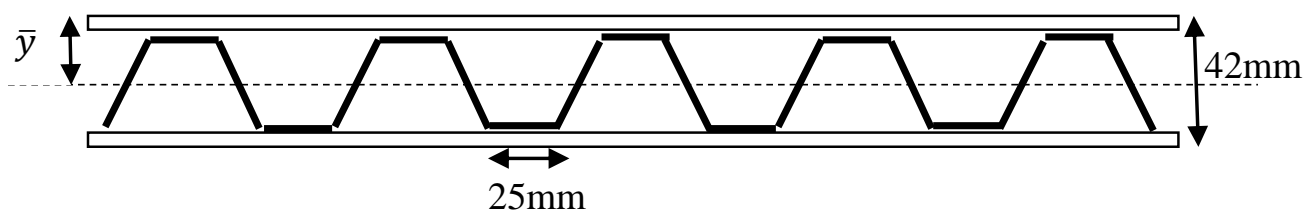

$\mathrm{A} 1, \mathrm{~A} 3, \mathrm{~A} 5$

$A * d=(4 * 25 * 0.48 * 0.24)+(3 * 25 * 0.48 * 29.76)+(6 * 25 * 0.48 * 15 * 6)=2162.88 \mathrm{~mm}^{3}$

$\overline{\mathrm{y}}=\frac{\mathrm{Ad}}{\sum \mathrm{A}}=\frac{2162.88}{156}=13.86 \mathrm{~mm}$

$\mathrm{I}_{\mathrm{x}}=\mathrm{I}+\mathrm{A} d^{2}=4\left[\frac{1}{12}\left(25 * 0.48^{3}\right)+\left(25 * 0.48 *(0.24-13.86)^{2}\right)\right]+3\left[\frac{1}{12}\left(25 * 0.48^{3}\right)+(25 *\right.$

$\left.\left.0.48 *(29.76-13.86)^{2}\right)\right]+6\left[\frac{1}{12}\left(25 * 0.48^{3}\right)+\left(25 * 0.48 *(15-13.86)^{2}\right)\right]=18101.93 \mathrm{~mm}^{4}$

$I_{c}=I_{x}+2 b T\left(\frac{E_{D B}}{E_{P S S}}\right)\left(\frac{T}{12}+\left(\bar{y}-\frac{T}{2}\right)^{2}\right)$

$=18101.93+\left(2 * 325 *\left(\frac{4000}{235000}\right) *\left(\frac{6}{12}+\left(13.86-\frac{6}{2}\right)^{2}\right)=19410.69 \mathrm{~mm}^{4}\right.$

$\mathrm{P}_{\mathrm{cr}}=\frac{\pi^{2} \mathrm{E}_{\mathrm{S}} \mathrm{I}_{\mathrm{c}}}{(\mathrm{KH})^{2}}=\frac{\pi^{2} * 235000 * 19410.69}{(1 * 890)^{2}}=56.81 \mathrm{kN}$

$\mathrm{A} 2$ and $\mathrm{A} 4$

$A * d=(4 * 25 * 0.48 * 0.24)+(3 * 25 * 0.48 * 29.76)+(6 * 25 * 0.48 * 15 * 6)=2162.88 \mathrm{~mm}^{3}$

$\overline{\mathrm{y}}=\frac{\mathrm{Ad}}{\sum \mathrm{A}}=\frac{2162.88}{156}=13.86 \mathrm{~mm}$

$\mathrm{I}_{\mathrm{x}}=\mathrm{I}+\mathrm{A} d^{2}=4\left[\frac{1}{12}\left(25 * 0.48^{3}\right)+\left(25 * 0.48 *(0.24-13.86)^{2}\right)\right]+3\left[\frac{1}{12}\left(25 * 0.48^{3}\right)+(25 * 0.48 *\right.$

$\left.\left.(29.76-13.86)^{2}\right)\right]+6\left[\frac{1}{12}\left(25 * 0.48^{3}\right)+\left(25 * 0.48 *(15-13.86)^{2}\right)\right]=18101.93 \mathrm{~mm}^{4}$

$\mathrm{I}_{\mathrm{c}}=\mathrm{I}_{\mathrm{x}}+2 \mathrm{bT}\left(\frac{\mathrm{E}_{\mathrm{DB}}}{\mathrm{E}_{\mathrm{PSS}}}\right)\left(\frac{\mathrm{T}}{12}+\left(\overline{\mathrm{y}}-\frac{\mathrm{T}}{2}\right)^{2}\right)$

$=18101.93+\left(2 * 325 *\left(\frac{4000}{235000}\right) *\left(\frac{6}{12}+\left(13.86-\frac{6}{2}\right)^{2}\right)=19410.69 \mathrm{~mm}^{4}\right.$

$\mathrm{P}_{\mathrm{cr}}=\frac{\pi^{2} \mathrm{E}_{\mathrm{s}} \mathrm{I}_{\mathrm{c}}}{(\mathrm{KH})^{2}}=\frac{\pi^{2} * 235000 * 19410.69}{(1 * 1200)^{2}}=31.25 \mathrm{kN}$ 
A6, A8, A10

$A * d=(2 * 17.5 * 0.48 * 0.24)+1071.36+1080+(2 * 25 * 0.48 * 0.24)=2161.152 \mathrm{~mm}^{3}$

$\overline{\mathrm{y}}=\frac{\mathrm{Ad}}{\sum \mathrm{A}}=\frac{2161.152}{148.8}=14.52 \mathrm{~mm}$

$\mathrm{I}_{\mathrm{x}}=\mathrm{I}+\mathrm{A} d^{2}=2 *\left[\frac{1}{12}\left(17.5 * 0.48^{3}\right)+\left(17.5 * 0.48 *(14.52-0.24)^{2}\right]+3 *\left[\frac{1}{12}\left(25 * 0.48^{3}\right)+(25 *\right.\right.$

$\left.0.48 *(29.76-14.52)^{2}\right]+6 *\left[\frac{1}{12}\left(25 * 0.48^{3}\right)+\left(25 * 0.48 *(15-14.52)^{2}\right]+2 *\left[\frac{1}{12}(25 *\right.\right.$

$\left.0.48^{3}\right)+\left(25 * 0.48 *(14.52-0.24)^{2}\right]=16700.58 \mathrm{~mm}^{4}$

$\mathrm{I}_{\mathrm{c}}=\mathrm{I}_{\mathrm{x}}+2 \mathrm{bT}\left(\frac{\mathrm{E}_{\mathrm{DB}}}{\mathrm{E}_{\mathrm{PSS}}}\right)\left(\frac{\mathrm{T}}{12}+\left(\overline{\mathrm{y}}-\frac{\mathrm{T}}{2}\right)^{2}\right)$

$=16700.58+\left(2 * 310 * 6 *\left(\frac{4000}{235000}\right) *\left(\frac{6}{12}+\left(14.52-\frac{6}{2}\right)^{2}\right)=25124.80 \mathrm{~mm}^{4}\right.$

$\mathrm{P}_{\mathrm{cr}}=\frac{\pi^{2} \mathrm{E}_{\mathrm{S}} \mathrm{I}_{\mathrm{c}}}{(\mathrm{KH})^{2}}=\frac{\pi^{2} * 235000 * 25124.80}{(1 * 900)^{2}}=71.90 \mathrm{kN}$

A7

$\mathrm{A} * \mathrm{~d}=(2 * 17.5 * 0.48 * 0.24)+1071.36+1080+(2 * 25 * 0.48 * 0.24)=2161.152 \mathrm{~mm}^{3}$

$\overline{\mathrm{y}}=\frac{\mathrm{Ad}}{\sum \mathrm{A}}=\frac{2161.152}{148.8}=14.52 \mathrm{~mm}$

$\mathrm{I}_{\mathrm{x}}=\mathrm{I}+\mathrm{A} d^{2}=2 *\left[\frac{1}{12}\left(17.5 * 0.48^{3}\right)+\left(17.5 * 0.48 *(14.52-0.24)^{2}\right]+3 *\left[\frac{1}{12}\left(25 * 0.48^{3}\right)+(25 *\right.\right.$

$\left.0.48 *(29.76-14.52)^{2}\right]+6 *\left[\frac{1}{12}\left(25 * 0.48^{3}\right)+\left(25 * 0.48 *(15-14.52)^{2}\right]+2 *\left[\frac{1}{12}(25 *\right.\right.$

$\left.0.48^{3}\right)+\left(25 * 0.48 *(14.52-0.24)^{2}\right]=16700.58 \mathrm{~mm}^{4}$

$\mathrm{I}_{\mathrm{c}}=\mathrm{I}_{\mathrm{x}}+2 \mathrm{bT}\left(\frac{\mathrm{E}_{\mathrm{DB}}}{\mathrm{E}_{\mathrm{PSS}}}\right)\left(\frac{\mathrm{T}}{12}+\left(\overline{\mathrm{y}}-\frac{\mathrm{T}}{2}\right)^{2}\right)$

$=16700.58+\left(2 * 310 * 6 *\left(\frac{4000}{235000}\right) *\left(\frac{6}{12}+\left(14.52-\frac{6}{2}\right)^{2}\right)=25124.80 \mathrm{~mm}^{4}\right.$

$\mathrm{P}_{\mathrm{cr}}=\frac{\pi^{2} \mathrm{E}_{\mathrm{S}} \mathrm{I}_{\mathrm{c}}}{(\mathrm{KH})^{2}}=\frac{\pi^{2} * 235000 * 25124.80}{(1 * 1200)^{2}}=40.47 \mathrm{kN}$

A9

$A * d=(2 * 17.5 * 0.48 * 0.24)+1071.36+1080+(2 * 25 * 0.48 * 0.24)=2161.152 \mathrm{~mm}^{3}$ 


$$
\begin{aligned}
& \overline{\mathrm{y}}=\frac{\mathrm{Ad}}{\sum \mathrm{A}}=\frac{2161.152}{148.8}=14.52 \mathrm{~mm} \\
& \mathrm{I}_{\mathrm{x}}=\mathrm{I}+\mathrm{A} d^{2}=2 *\left[\frac{1}{12}\left(17.5 * 0.48^{3}\right)+\left(17.5 * 0.48 *(14.52-0.24)^{2}\right]+3 *\left[\frac{1}{12}\left(25 * 0.48^{3}\right)+(25 *\right.\right. \\
& \left.0.48 *(29.76-14.52)^{2}\right]+6 *\left[\frac{1}{12}\left(25 * 0.48^{3}\right)+\left(25 * 0.48 *(15-14.52)^{2}\right]+2 *\left[\frac{1}{12}(25 *\right.\right. \\
& \left.0.48^{3}\right)+\left(25 * 0.48 *(14.52-0.24)^{2}\right]=16700.58 \mathrm{~mm}^{4} \\
& \mathrm{I}_{\mathrm{c}}=\mathrm{I}_{\mathrm{x}}+2 \mathrm{bT}\left(\frac{\mathrm{E}_{\mathrm{DB}}}{\mathrm{E}_{\mathrm{PSS}}}\right)\left(\frac{\mathrm{T}}{12}+\left(\overline{\mathrm{y}}-\frac{\mathrm{T}}{2}\right)^{2}\right) \\
& \quad=16700.58+\left(2 * 310 * 6 *\left(\frac{4000}{235000}\right) *\left(\frac{6}{12}+\left(14.52-\frac{6}{2}\right)^{2}\right)=25124.80 \mathrm{~mm}^{4}\right. \\
& \mathrm{P}_{\mathrm{cr}}=\frac{\pi^{2} \mathrm{E}_{\mathrm{S}} \mathrm{I}_{\mathrm{c}}}{(\mathrm{KH})^{2}}=\frac{\pi^{2} * 235000 * 25124.80}{(1 * 500)^{2}}=67.85 \mathrm{kN}
\end{aligned}
$$




\section{Appendix B: Detailed Theoretical Shear Resistance Calculations}

\section{B.1 Shear Resistance of Non-Pierced Panels}

S1-DB

Sheathing-DB to frame connection failure

$\mathrm{V}_{\mathrm{DB}}=\left[\varnothing \frac{\mathrm{N}_{\mathrm{u}}}{\mathrm{s}} \mathrm{J}_{\mathrm{D}} \mathrm{n}_{\mathrm{s}} \mathrm{J}_{\mathrm{us}} \mathrm{J}_{\mathrm{s}} \mathrm{J}_{\mathrm{hd}} \mathrm{L}_{\mathrm{s}}\right]$

$$
=\left[1.0 * \frac{1000}{100} 1 * 2 * 1 * 1 * 1 * 850\right]=17000 \mathrm{~N}=17.00 \mathrm{kN}
$$

S2-PSS

Buckling mode of failure

$$
\begin{aligned}
& \mathrm{D}_{\mathrm{x}}=\frac{\mathrm{E}_{\mathrm{s}} \mathrm{t}_{\mathrm{s}}^{3}}{12\left(1-\mathrm{v}^{2}\right)} \frac{(\mathrm{a}+\mathrm{b})}{(\mathrm{a}+\mathrm{c})}=\frac{235000 * 0.48^{3}}{12\left(1-0.3^{2}\right)} \frac{(25+25)}{(25+39.05)}=1857.85 \mathrm{~N} / \mathrm{mm} \\
& \mathrm{D}_{\mathrm{y}}=\frac{\mathrm{E}_{\mathrm{s}} \mathrm{t}_{\mathrm{s}}^{3}\left[\left(\mathrm{~d} / \mathrm{t}_{\mathrm{s}}\right)^{2}+1\right]}{6 \frac{(\mathrm{a}+\mathrm{b})}{(\mathrm{a}+\mathrm{c})}}=\frac{235000 * 0.48^{3}\left[(30 / 0.48)^{2}+1\right]}{6 \frac{(25+25)}{(25+39.05)}}=19297471.23 \mathrm{~N} / \mathrm{mm} \\
& \mathrm{V}_{\mathrm{PSS}}=36 \beta \mathrm{H} \frac{\mathrm{D}_{\mathrm{x}}^{\frac{1}{4}} \mathrm{D}_{\mathrm{y}}}{\mathrm{L}^{2}} \\
& \quad=36 * 1 * 850 \frac{\left(1857.85^{\frac{3}{4}}\right)\left(19297471.23^{\frac{3}{4}}\right)}{1000^{2}}=58492.42 \mathrm{~N}=58.49 \mathrm{kN}
\end{aligned}
$$

Failure at fasteners

$\mathrm{V}_{\mathrm{f}, \mathrm{PSS}(\text { vertical })}=\frac{\mathrm{F}_{\mathrm{sb}, \mathrm{PSS} \cdot \mathrm{L}}}{\mathrm{p}_{\mathrm{a}}}=\frac{5020 * 850}{155}=27529.03 \mathrm{~N}=27.53 \mathrm{kN}$

$\mathrm{V}_{\mathrm{f}, \mathrm{PSS}(\text { Horizontal })}=\frac{\mathrm{F}_{\mathrm{sc}, \mathrm{PSS}} \cdot \mathrm{H}}{\mathrm{p}_{\mathrm{b}}}=\frac{5020 * 1000}{128.75}=38990.29 \mathrm{~N}=38.99 \mathrm{kN}$

S3-DB

Buckling of $D B$

$\mathrm{V}_{\mathrm{DB}}=\varnothing \mathrm{v}_{\mathrm{pb}} \mathrm{K}_{\mathrm{D}} \mathrm{K}_{\mathrm{S}} \mathrm{K}_{\mathrm{T}} \mathrm{L}_{\mathrm{s}}$

$\alpha=\frac{a}{b}\left(\frac{B_{a, 90}}{B_{a}, 0}\right)^{\frac{1}{4}}=\frac{1000}{850}\left(\frac{28000}{70000}\right)^{\frac{1}{4}}=0.936$

$\eta=\frac{2 B_{v}}{\sqrt{B_{a, 0} B_{a, 90}}}=\frac{2(5500)}{\sqrt{70000 * 28000}}=0.248$ 


$$
\begin{aligned}
\mathrm{K}_{\mathrm{pb}} & =1.7(\eta+1) \exp \left(\frac{-\propto}{0.05 \eta+0.75}\right)+(0.5 \eta+0.8) \\
& =1.7(0.248+1) \exp \left(\frac{-0.936}{0.05(0.248)+0.75}\right)+((0.5 * 0.248)+0.8)=1.546
\end{aligned}
$$

$\mathrm{v}_{\mathrm{pb}}=\mathrm{K}_{\mathrm{pb}} \frac{\pi^{2} \mathrm{t}^{2}}{3000 \mathrm{~b}}\left(\mathrm{~B}_{\mathrm{a}, 0} \mathrm{~B}_{\mathrm{a}, 90}^{3}\right)^{\frac{1}{4}}=1.546\left(\frac{\pi^{2} 6^{2}}{3000 * 850}\right)\left(70000 * 28000^{3}\right)^{\frac{1}{4}}=7.588$

$\mathrm{V}_{\mathrm{DB}}=\emptyset \mathrm{v}_{\mathrm{pb}} \mathrm{K}_{\mathrm{D}} \mathrm{K}_{\mathrm{S}} \mathrm{K}_{\mathrm{T}} \mathrm{L}_{\mathrm{s}}=1.0 * 7.588 * 1 * 1 * 1 * 850=5129.84 \mathrm{~N}=5.13 \mathrm{kN}$

\section{S4-PSSDB}

Gross distortion failure of PSS and buckling of DB

$$
\begin{aligned}
\mathrm{V}_{\mathrm{PSSDB}} & =\left(\frac{0.3 \mathrm{t}_{\mathrm{S}}^{1.5} \mathrm{Hf}_{\mathrm{y}}}{\mathrm{e}^{0.5}}\right)+\left(\varnothing \mathrm{v}_{\mathrm{pb}} \mathrm{K}_{\mathrm{D}} \mathrm{K}_{\mathrm{S}} \mathrm{K}_{\mathrm{T}} \mathrm{L}_{\mathrm{s}}\right) \\
= & {\left[\frac{0.3 * 0.48^{1.5} * 1000 * 598.17}{100^{0.5}}\right]+[0.8 * 7.588 * 1 * 1 * 1 * 850]=12417.52 \mathrm{~N}=12.42 \mathrm{kN} }
\end{aligned}
$$

S5-PSS

Gross distortion failure of PSS

$$
\begin{aligned}
\mathrm{V}_{\text {PSS }} & =\frac{0.3 \mathrm{t}_{\mathrm{s}}^{1.5} \mathrm{Hf}_{\mathrm{y}}}{\mathrm{e}^{0.5}} \\
& =\frac{0.3 * 0.48^{1.5} * 1000 * 598.17}{100^{0.5}}=7170 \mathrm{~N}=7.17 \mathrm{kN}
\end{aligned}
$$

\section{S6-PSSDB}

Gross distortion of PSS and buckling of $D B$

$$
\begin{aligned}
\mathrm{V}_{\text {PSSDB }} & =\left(\frac{0.3 \mathrm{t}_{\mathrm{s}}^{1.5} \mathrm{Hf}_{\mathrm{y}}}{\mathrm{e}^{0.5}}\right)+\left(\varnothing \mathrm{v}_{\mathrm{pb}} \mathrm{K}_{\mathrm{D}} \mathrm{K}_{\mathrm{S}} \mathrm{K}_{\mathrm{T}} \mathrm{L}_{\mathrm{s}}\right) \\
& =\frac{0.3 * 0.48^{1.5} * 475 * 598.17}{100^{0.5}}+(1.0 * 7.588 * 1 * 1 * 1 * 475)=6440.10 \mathrm{~N} \\
& =6.44 \mathrm{kN}
\end{aligned}
$$

Failure at the fasteners

$\mathrm{V}_{\mathrm{fPSSDB}(\text { vertical })}=\frac{\mathrm{F}_{\mathrm{sb}, \mathrm{PSSDB}} \cdot \mathrm{L}}{\mathrm{p}_{\mathrm{a}}}=\frac{(5020+1120) * 1000}{450}=13644.44 \mathrm{kN}=13.64 \mathrm{kN}$ 
S7-PSS

Gross distortion failure of PSS

$$
\begin{aligned}
\mathrm{V}_{\text {PSS }} & =\frac{0.3 \mathrm{t}_{\mathrm{s}}^{1.5} \mathrm{Hf}_{\mathrm{y}}}{\mathrm{e}^{0.5}} \\
& =\frac{0.3 * 0.48^{1.5} * 475 * 598.17}{100^{0.5}}=4010 \mathrm{~N}=4.01 \mathrm{kN}
\end{aligned}
$$

S8-DB

Buckling failure of $D B$

$\mathrm{V}_{\mathrm{DB}}=\emptyset \mathrm{v}_{\mathrm{pb}} \mathrm{K}_{\mathrm{D}} \mathrm{K}_{\mathrm{S}} \mathrm{K}_{\mathrm{T}} \mathrm{L}_{\mathrm{s}}$

$\alpha=\frac{\mathrm{a}}{\mathrm{b}}\left(\frac{\mathrm{B}_{\mathrm{a}, 90}}{\mathrm{~B}_{\mathrm{a}, 0}}\right)^{\frac{1}{4}}=\frac{1000}{475}\left(\frac{24000}{55000}\right)^{\frac{1}{4}}=1.674$

$\eta=\frac{2 B_{v}}{\sqrt{B_{a, 0} B_{a, 90}}}=\frac{2(3400)}{\sqrt{55000 * 24000}}=0.187$

$\mathrm{K}_{\mathrm{pb}}=1.7(\eta+1) \exp \left(\frac{-\propto}{0.05 \eta+0.75}\right)+(0.5 \eta+0.8)$

$$
=1.7(0.248+1) \exp \left(\frac{-0.936}{0.05(0.248)+0.75}\right)+((0.5 * 0.248)+0.8)=1.106
$$

$\mathrm{v}_{\mathrm{pb}}=\mathrm{K}_{\mathrm{pb}} \frac{\pi^{2} \mathrm{t}^{2}}{3000 \mathrm{~b}}\left(\mathrm{~B}_{\mathrm{a}, 0} \mathrm{~B}_{\mathrm{a}, 90}^{3}\right)^{\frac{1}{4}}=1.160\left(\frac{\pi^{2} 6^{2}}{3000 * 475}\right)\left(70000 * 28000^{3}\right)^{\frac{1}{4}}=8.142$

$\mathrm{V}_{\mathrm{DB}}=\emptyset \mathrm{v}_{\mathrm{pb}} \mathrm{K}_{\mathrm{D}} \mathrm{K}_{\mathrm{S}} \mathrm{K}_{\mathrm{T}} \mathrm{L}_{\mathrm{s}}=1.0 * 8.142 * 1 * 1 * 1 * 475=3880 \mathrm{~N}=3.88 \mathrm{kN}$

\section{B.2 Shear resistance of pierced panels}

\section{S9p-PSSDB}

Gross distortion of PSS and buckling of $D B$

$\mathrm{V}_{\mathrm{PSSDB}(\mathrm{p})}=\mathrm{V}_{\mathrm{PSSDB}}\left(1-\frac{\mathrm{d}_{\mathrm{op}}}{\mathrm{D}}\right)=5.72 *\left(1-\frac{316.23}{879.99}\right)=3.66 \mathrm{kN}$

S10p-PSS

Gross distortion failure of PSS

$\mathrm{V}_{\mathrm{PSS}(\mathrm{p})}=\mathrm{V}_{\mathrm{PSS}}\left(1-\frac{\mathrm{d}_{\mathrm{op}}}{\mathrm{D}}\right)=4.01 *\left(1-\frac{316.23}{879.99}\right)=2.57 \mathrm{kN}$

S11p-DB 
Buckling failure of $D B$

$$
\mathrm{V}_{\mathrm{DB}(\mathrm{p})}=\mathrm{V}_{\mathrm{DB}}\left(1-\frac{\mathrm{d}_{\mathrm{op}}}{\mathrm{D}}\right)=3.88 *\left(1-\frac{316.23}{879.99}\right)=2.85 \mathrm{kN}
$$




\section{REFERENCES}

- Ahmed, E., \& Ahmad, B. G. (2011). Performance of Profiled Steel Sheet Dry Board System under Flexural Bending and Vibration. Journal of Civil Engineering, Science and Technology, 2(1), 42-48.

- Ahmed, E., Badaruzzaman, W. H., \& Rashid, A. K. (1996). Composite Partial Interaction Of Profiled Steel Sheeting/Dryboard Floor Subject To Transverse Loading. CIB W89 Bejing International Conference (pp. 21-24). Beijing: Construction Modernisation and Education.

- Ahmed, E., Badaruzzaman, W. H., \& Rashid, K. (1996). A Simplified Elastic Composite Floor Section Analysis with Incomplete Interaction. Journal of Engineering, 8, 67-78.

- Ahmed. E (1999). Behaviour of Profiled Steel Sheet Dry Board Folded Plate Structure. $\mathrm{PhD}$ thesis, Bangi: Universiti Kebangsaan Malaysia.

- Ahmed, E., Badaruzzaman, W. W., \& Wright, H. (2000). Experimental and Finite Element Study of Profiled Steel Sheet Dry Board Folded Plate Structures. Thin-Walled Structures, $38(2), 125-143$.

- Ahmed, E., Badaruzzaman, W. W., \& Wright, H. D. (2002). Two-way bending behavior of profiled steel sheet dry board composite panel system. Thin-Walled Structures, 40(11), 971-990.

- Ahmed, E. and Wan Badaruzzaman, W.H. (2003). Finite element prediction of the behavior of profiled steel sheet dry board folded plate structures - An improved model. International Journal of Engineering, Transaction B: Applications, 16(1), 21-32.

- Ahmed, E. and Wan Badaruzzaman, W.H. (2005). Finite element prediction on the applicability of profiled steel sheet dry board structural composite system as a disaster relief shelter. Journal of Construction and Building Materials, 19(4), 285-295.

- Akhand, A.M. (2001). Nonlinear finite element modeling and partial plastic analysis of composite profiled steel sheeting dry board continuous floor. $\mathrm{PhD}$ dissertation, Bangi: Universiti Kebangsaan Malaysia. 
- Al-Shaikhli, M. S., Badaruzzaman, W. H., Baharom, S., \& Hilo, S. J. (2017). Theoretical and finite element analysis of the two-way PSSDB floor system. Journal of Constructional Steel Research, 135, 49-55.

- Awang, H., \& Badaruzzaman, W. H. (2011). Development of profiled steel sheeting dry board roof panel system in school classroom modules. Journal of Civil Engineering and Construction Technology, 2(4), 72-81.

- Awang, H., \& Badaruzzaman, W. W. (2010). Structural Performance and Application of a Reversed Profiled Steel Sheeting Dry Board Roof Panel System. Asian Journal of Civil Engineering (Building and Housing), 11(3), 371-384.

- Benayoune, A.G. (1998). Behavior of Profiled Steel Sheeting dry Board Panel as Wall Units. MSc Thesis, Universiti Kebangsaan Malaysia.

- Benayoune, A.G., Wan Badaruzzaman, W.H. (2000). Limit state behaviour of profiled steel sheeting/dry board wall panel, Proceeding of APSEC, 2000 (pp. 39-46).

- ASM International Handbook Committee. (1987). Engineered Materials Handbook. Ohio: ASM International.

- Badaruzzaman, W. H., Ahmed, E., \& Rashid, A. K. (1996). Behaviour of Profiled Steel Sheet Dry Board System. CIB W89 Beijing International Conference. Beijing: International Council for Building Research Studies and Documentation (CIB).

- Badaruzzaman, W. H., Shodiq, H. M., \& Eng, J. (2006). Performance Improvement of Profiled Steel Sheet Dry Board Floor System by Concrete Infill. 10th East Asia Pacific Conference on Structural Engineering and Construction, EASEC 2010 (pp. 381-386). Construction and Professional Practices-Proceedings.

- Badaruzzaman, W. H., Shodiq, H. M., \& Hamid, A. A. (2004). Performance of Infilled Profiled Steel Sheet Dry Board (PSSDB) Load Bearing Wall. IJE Transactions B: Applications, 17(4), 343-348.

- Badaruzzaman, W., Zain, M. F., Shodiq, H. M., Akhand, A. K., \& Sahari, J. (2003). Fire resistance performance of profiled steel sheet dry board (PSSDB) flooring panel system. Building and Environment, 38(7), 907-912. 
- Badaruzzaman, W. W., Zain, M., Akhand, A., \& Ahmed, E. (2003). Dry boards as load bearing element in the profiled steel sheet dry board floor panel system-structural performance and applications. Construction and Building Materials, 17(4), 289-297.

- Bedair, O. (2003). Analytical Effective Width Equations for Limit State Design of Thin Plates Under Non-Homegenous In-Plane Loading. Architecture Applied Mechanics, 79(10), 1173-1189.

- Benayoune, A., \& Wan Badaruzzaman, W. (2000). Limit State Behaviour of Profiled Steel Sheeting/ Dry Board Wall Panel. Proceedings of the 4th Asia-Pacific Structural Engineering \& Construction Conference (ASPEC). Malaysia.

- Bouchaïr, A., \& Vergne, A. (1995). An Application of the Tsai Criterion as a Plastic Flow Law for Timber Bolted Joint Modelling. Wood Science and Technology, 30, 3-19.

- CSA Committee. (2014). Engineering design in wood O86-14. Mississauga: CSA Group.

- Dassault Systèmes Simulia Corp. (2008), “ABAQUS/CAE Documentation, Version 6.83," Providence, RI, USA (www.simulia.com).

- Dias, A., Van de Kuilen, J., Cruz, H., \& Lopes, S. (2010). Numerical Modelling of the Load-Deformation Behaviour of Doweled Sodtwood and Hardwood Joints. Wood and Fiber Science, 42(4), 480-489.

- Easley, J. (1975). Buckling Formulas for Corrugated Metal Shear Diaphragms. Journal of Structural Division, ASCE, 101(7), 1403-1417.

- Easley, J., \& McFarland, D. (1969). Buckling of Light-Gage Corrugated Metal Shear Diaphragms. Journal of Structural Division, ASCE, 95(7), 1497-1516.

- Easterling, W. S. \& Porter, M. (1994a). Steel-deck Reinforced Concrete Diaphragms I. Journal of Structural Division, ASCE, 120(2), 560-576.

- Easterling, W. S. \& Porter, M. (1994b). Steel-deck Reinforced Concrete Diaphragms II. Journal of Structural Division, ASCE, 120(2), 577-596. 
- Farzampour, A., Laman, J. A., \& Mofid, M. (2015). Behaviour Prediction of Corrugated Steel Plate Shear Walls with Openings. Journal of Constructional Steel Research, 14(1), 258-268.

- Fastening House Inc. (2017). Retrieved on November 12, 2017, from https://www.fasteninghouse.com: https://www.fasteninghouse.com/product/fastenersthreaded-products/

- Hamzah, S. H., \& Badaruzzaman, W. H. (2009). Structural Evaluation of PSSDB Wall Panel with Square Opening and Vared Screw Spacing. Journal of Engineering Science and Technology, 4(1), 32-46.

- H.D. Wright, \& H.R. Evans (1987). A folded plate method of analysis for profiled steel sheeting in composite floor construction, Thin-Walled Structures, 5(1), 21-37.

- Holmberg, S., Persson, K., \& Petersson, H. (1999). Nonlinear mechanical behaviour and analysis of wood and fibre materials. Computers and Structures, 72(4), 459-480.

- Hossain, K. M. A., \& Wright, H. (1998a). Shear Interaction between Sheeting and Concrete in Profiled Composite Construction. Proceedings of the Australasian Structural Engineering Conference, 1, pp. 181-188. Auckland.

- Hossain, K. M. A., \& Wright, H. (1998b). Performance of Profiled Concrete Shear Panels. Journal of Structural Engineering, ASCE, 124(4), 368-381.

- Hossain, K. M. A., \& Wright, H. D. (2004). Experimental and Theoretical Behaviour of Composite Walling under In-Plane Shear. Journal of Constructional Steel Research, 60(1), 59-83.

- Hossain, K. M. A., Mol, L., Jahan, A. \& Anwar, M. S. (2015). Experimental testing of PSSDB panels under various loadings, Technical report no. PNG-2015, Department of Civil Engineering, Ryerson University, Toronto, 37p.

- Hossain, K. M. A., \& Shakeel, S. (2012), Design Aspects of PSSDB Panels under Axial Loading - Experimental and Theoretical Approach, Technical report: -TR1-2012, Department of Civil Engineering, Ryerson University, Toronto, 35p. 
- Hossain, K. M. A., Rafiei, S. L., Behdinan, K., \& Anwar, M. S. (2016). Finite element modeling of impact shear resistance of double skin composite wall. Thin-Walled Structures, 107, 101-118.

- Ismail, S., Abdullah, R., \& Ahmad, Z. (2017). Finite Element Modeling and Analysis of Sandwich Dry Floor Slab. International Journal of Civil \& Environmental Engineering, $17(1), 21-26$.

- Ivanov, I. V., Sadowski, T., Filipiak, M., \& Kneć, M. (2008). Experimental and numerical investigation of plywood progressive failure in CT tests. Budownictwo i Architektura, 2, 79-94.

- Jaffar, M. I., Badaruzzaman, W. H., \& Baharom, S. (2016). Experimental Tests on Bending Behaviour of Profiled Steel Sheet Dry Board Composite Floor with Geopolymer Concrete Infill. Latin American Journal of Solids and Structures, 13(2), 272-295.

- Khorsandnia, N., Valipour, H. R., \& Crews, K. (2013). Nonlinear finite element analysis of timber beams and joints using the layered approach and hypoelastic constitutive law. Engineering Structures, 46, 606-614.

- Kulak, G. (2005). High Strength Bolting for Canadian Engineers (First ed.). Toronto: Canadian Institute of Steel Construction.

- Lubliner, J. (1990). Plasticity Theory. New York: Macmillan Publishing Company.

- Luo, R., \& Edland, B. (1996). Shear Capacity of Plate Girders with Trapezoidally Corrugated Webs. Thin-Walled Structures, 26(1), 19-44.

- Majid, M. A., \& Badaruzzaman, W. H. (2013). Structural Performance of Profiled Steel Sheet Dry Board Wall Panel System. International Journal of Construction Technology and Management, 1(1), 28-32.

- Mayor, H., \& Larsson, M. (2016). Innovative timber floor Development of a timber sandwich structure. Masters Thesis, Gothenburg: Chalmers University Of Technology.

- Mengesha, W.J. (1992). Composite Profiled Steel Sheet/Dryboard Panels. MSc thesis, Glasgow: University of Strathclyde. 
- Mirianon, F., Fortino, S., \& Toratti, T. (2008). A method to model wood by using ABAQUS finite element software. Espoo: VTT Technical Research Centre.

- Shokory, S. M., \& Wan Badaruzzaman, W. H. (2000). Theoretical Study on the Behaviour of Profiled Steel Sheet Dry Boards Wall. UKM Civil Engineering Proceedings (pp. 107116). Bangi: UKM.

- Nagar, S. (2017). Lysaght. Retrieved on February 26, 2017, from http://tatabluescopesteel.com: http://tatabluescopesteel.com/cms/Media/file/Spandek.pdf

- Nilsen, T. S. (2015). Numerical modelling of Wood Microstructure. Trondheim: Norwegian University of Science and Technology.

- Ohene, A. A. (2014). Modelling the Fire Performance of Hybrid Steel-Timber Connections. Ottawa: Carleton University.

- Plywood. (2017). Retrieved on November 12, 2017, from http://www2.wisd.net: http://www2.wisd.net/it/PLYWOOD.htm

- Popovics, S. (1973). A numerical approach to the complete stress-strain curve of concrete. Cement and Concrete Research, 3(5), 583-599.

- Portioli, F., Marmo, R., Ceraldi, C., \& Landolfo, R. (2010). Numerical Modeling Of Connections with Timber Pegs. World Conference on Timber Engineering. 3, pp. 18811886. Trentino: Trees and Timber Institute, National Research Council.

- Rafiei, S. (2011). Behaviour of double skin profiled composite shear wall system under inplane monotonic, cyclic and impact loadings. $\mathrm{PhD}$ dissertation, Toronto: Ryerson University.

- Rafiei, S., Hossain, K. M., Lachemi, M., Behdinan, K., \& Anwar, M. S. (2013). Finite element modeling of double skin profiled composite shear wall system under in-plane loadings. Engineering Structures, 56, 46-57.

- Rhodes, J. (2003). Some observation on the post buckling behavior of thin plates and thin walled members. Journal of Thin-Walled Structures, 41(2), 207-226. 
- Roberts, T., \& Sabouri-Ghomi, S. (1992). Hysteretic Characteristics of Unstiffened Perforated Steel Plate Shear Panels. Thin Walled Structures, 14(2), 139-151.

- Sandhaas, C., \& Kuilen, J. W. (2013). Material Model for Wood. HERON, 58(2/3), 171192.

- Sandhaas, C., Kuilen, J.-W. v., \& Blass, H. J. (2012). Constitutive Model for wood based on Continuum Damage Mechanics. World Conference on Timber Engineering (pp. 159167). Auckland: New Zealand Timber Design Society.

- Seraji, M., Badaruzzaman, W. H., \& Osman, S. A. (2014). Non-linear Analysis of Membrane Action Effect in Profiled Steel Sheeting Dry Board Flooring System. International Journal of Steel Structures, 14(2), 305-314.

- Shanmugam, N., Thevendran, V., \& Liew, J. R. (1998). Thin-Walled Structures: Research and Development. Oxford: Elsevier Science Ltd.

- $\quad$ RCSC Committee. (2004). Specification for Structural Joints Using ASTM A325 or A490 Bolts . Chicago: Research Council on Structural Connections.

- Sabouri-Ghomi, S., Ventura, C., \& Kharrazi, M. (2005). Shear Analysis and Design of Ductile Steel Plate Walls. Journal of Structural Engineering, 131(6), 878-889.

- Sadjadi, R. (2009), "Response of Reinforced Concrete Rectangular Liquid Containing Structures under Cyclic Loading," Doctor of Philosophy thesis, Toronto: Ryerson University.

- Shakeel, S. (2012). Axial Load Behavior of Profiled Steel Sheet Dry Board (PSSDB) Walling System. Tech. Report, Toronto: Ryerson University.

- Vafa, M., Badaruzzaman, W. H., \& Osman, S. A. (2013, September 23-24). Cover width effect of Profiled Steel Sheet Dry Board (PSSDB) Panel on Strength-to-Weight Ratio. International Conference on Civil and Architecture Engineering (ICCAE'2013) (pp. 7073). Phuket: IPCBEE.

- Yip, W. K. (1998). Generic Form of Stress-Strain Equations for Concrete. Cement and Concrete Research, 28(1), 33-39. 
- Wright, H. D., \& Hossain, K. M. (1997). In-Plane Shear Behaviour of Profiled Steel Sheeting. Thin-Walled Structures, 29(1-4), 79-100.

- Wright, H.D., Evans, H.R. and Burt, C.A. (1989). Profiled steel sheet/ dry boarding composite floors. The Structural Engineer, 67(7), 114-129.

- Wan Badaruzzaman, W. H., Shodiq, H. M., \& Khalim, A. R. (2002, July 22-25). The Effect of Concrete infill and Topping to the Structural Behavior of Profiled Steel Sheet Dry Board (PSSDB) Flooring System. Proceeding of the World Engineering Congress and Exhibition (pp. 245-247). Kuchong: WEC.

- Curry, W. T., \& Hearmon, R. F. (1974). The Strength Properties of Timber . Lancaster: Medical \& Technical Publishing Co. Ltd St. Leonard's House.

- Wright, H.D. (1988). Design of Floor Decks Utilizing Profiled Steel Sheeting and Through Deck Welded Studs. PhD dissertation, University College Cardiff, University of Wales, UK.

- Wright, H.D. and Evans, H.R. (1986). Profiled steel sheeting for the replacement of timber flooring in building renovation. United Kingdom: SERC Grant GR/D/76875.

- Wan Badaruzzaman, W. H., Wan Mohtar, W. H., Hamzah, N., Khalim, A. R., \& Hamzah, S. H. (2003). Indicative Behaviour of Profiled Steel Sheeting Dry Board Wall System Stiffened With Steel Plates. Proceedings of the 3rd International Conference on Advances in Strategic Technologies (pp. 1097-1102). Kuala Lampur: ICAST 2003.

- Xu, B., Taazount, M., Bouchaïr, A., \& Racher, P. (2009). Numerical 3D Finite Element Modelling and Experimental Tests for Dowel-type Timber Joints. Construction and Building Materials, 23(9), 3043-3052. 


\section{GLOSSARY}

PSSDB Profiled Steel Sheet Dry Board

PSS Profiled Steel Sheet

DB Dry Board

FEA Finite Element Analysis

LVDTs Linear voltage displacement transducers 